\title{
Valuation and construction issues in real estate indices
}

Citation for published version (APA):

Hordijk, A. (2005). Valuation and construction issues in real estate indices. [Doctoral Thesis, Maastricht University]. Europe Real Estate Publisher. https://doi.org/10.26481/dis.20050622ah

Document status and date:

Published: 01/01/2005

DOI:

10.26481/dis.20050622ah

Document Version:

Publisher's PDF, also known as Version of record

\section{Please check the document version of this publication:}

- A submitted manuscript is the version of the article upon submission and before peer-review. There can be important differences between the submitted version and the official published version of record.

People interested in the research are advised to contact the author for the final version of the publication, or visit the DOI to the publisher's website.

- The final author version and the galley proof are versions of the publication after peer review.

- The final published version features the final layout of the paper including the volume, issue and page numbers.

Link to publication

\footnotetext{
General rights rights.

- You may freely distribute the URL identifying the publication in the public portal. please follow below link for the End User Agreement:

www.umlib.nl/taverne-license

Take down policy

If you believe that this document breaches copyright please contact us at:

repository@maastrichtuniversity.nl

providing details and we will investigate your claim.
}

Copyright and moral rights for the publications made accessible in the public portal are retained by the authors and/or other copyright owners and it is a condition of accessing publications that users recognise and abide by the legal requirements associated with these

- Users may download and print one copy of any publication from the public portal for the purpose of private study or research.

- You may not further distribute the material or use it for any profit-making activity or commercial gain

If the publication is distributed under the terms of Article $25 \mathrm{fa}$ of the Dutch Copyright Act, indicated by the "Taverne" license above, 


\section{Valuation and Construction Issues in Real Estate Indices}

Scientific studies dealing with direct real estate are relarively rare, particularly with respeer to its return. The objective of this thesis by Aart Hordilk - in daily life Director of the ROZ/IPD Real Estate Index - is to raise corporate investors and other investors awareness of the renurn of direct real estate as an investment earegory, and to give them a realistic indication of what they can expect from investments in direct real estate.

\section{Chapters}

\section{Introduction}

2. Long-run return senies: 25 years of commercial real estate in the Netherlands

3. Development of historic time series of office rents in the Netherlands

4. Valuation model uniformity and consistency in real estate indices

5. Valuation accuracy in real estate indices

6. European market dimensions: an inventory of the potential investment matket in. 11 Europen countries

7. Conclinsions and further research

\section{Some main conclusions}

- Valuation accuracy is much better than most people think

- Consistency in valuations should and can be inproved

- Institutional investors and appraisers arclives are essential in the development of reliable 25 -year real estate returns

- Stimulating results from the relation between real estate stock and GDP in 11 European countries

- Two to three year lag in 25 -year office marker rent response on the change in supply and demand ratio 


\section{Valuation and Construction Issues in Real Estate Indices}

Aart HordiJk 
Copyright (C)

Europe Real Estate Publishers B.V.

All rights reserved

ISBN 9077997016 


\section{Valuation and \\ Construction Issues \\ in Real Estate Indices}

PROEFSCHRIFT

ter verkrijging van de graad wan doctor

aan de Universiteit Maastricht

op gezag van de Rector Magnificus

Prof. mr. G.P.M.F. Mols

volgens het besluit van het

College van Decanen

in het openbaar te verdedigen

op woensdag 22 juni 2005 om 16.00 uur

door

Aart Hordijk 


\section{Promotor:}

Prof. dr. P.M.A. Eichhollt

\section{Beoordelingscommissie:}

Prof dr C.G. Koedijk (Universiteit van Maastricht, voorzitter)

Prof dr R. Bauer (Universiteit van Maastriche)

Prof dr P. van Gool (Universiteit wan Amsterdam)

Prof D. Geliner Ph. D (Massachusetts Institute of Technology)

\section{TROOSTWIJK}

This publication has been made possible thanks to the support of the Troostwijk Education and Research Foundation (STROW). 
Dedicated to all those who were not given the time to achieve their goals in life 


\section{ACKNOWLEDGEMENTS}

Many students who have finalised their Masters degree at University every now and then think about writing a dissertation. So did I. Already back in 1994 I considered writing a dissertation, not really knowing what I was talking about. In 2000 , when I was appointed a senior lecturer in real estate valuation at the University of Amsterdam. for one day a week, this changed. The Arcalauris Troostwijk group of companies, who sponsored this chair, saw the need for teaching real estate valuation at university level, which was almost non-existent in the Netherlands. It was an appointment for 5 years and the arrangement was that I should also write a dissertation during this time. So a deadline was set. It is good that you only partially realize what kind of task you have accepted, writing a dissertation on top of your normal work. Several things made it happen: the fact that I could combine some of the research work with my normal work for the ROZ-IPD Netherlands Property Index, cooperation with other people in writing papers, serting deadlines by presenting drafts of the papers at international real estate conferences, support by many people and last but not least a lot of discipline. It sometimes means that at work and at home You will not always mentally be there'. I very much appreciated everybody's acceptance of that situation.

When digging into the material that already exists on the different subjects you want to cover, you admire the efforts of previous and existing generations of researchers and practitioners and you realize the tiny contribution to the debate you hope to achieve. It was a pleasure for me to work with the different co-authors of the chapters and I very much appreciated their contributions.

Thanking those who supported and inspired me on my journey by name is dangerous because you might easily forger somebody. Therefore, many rhanks to all of you who contributed directly or indirecty to this book, maybe in some cases even without knowing it. However, three people I want to mention in particulat. First of all my promorer Piet Eichholtz, whose enthusiasm, criticisms and creativeness stimulated me to get on with the job. Secondly David Gelner, whose previous research was very useful for my research and whose comments on my findings were grearly appreciated. And thirdly Marsha van Buitenen, who helped me with the time-consuming editing work. Also, I would like to mention my co-authors Carl Ivar Ahlquist, Harry de Kroon, Wouter van de Ridder, Sander van Riel, Cees Schekkerman and Marcel Theebe, I enjoyed the cooperation very much and their contriburions were most helpful. Last but not least I want to thank my family, who contributed directly (the laborious data entry work) or indirectly by accepting a smaller contriburion to our private affairs. Without that support it would have been much more difficult to write this dissertation.

\section{Aart Hordijk}

WWW.roz.nl 


\section{CONTENTS}

Acknowledgements

\section{Chapter 1}

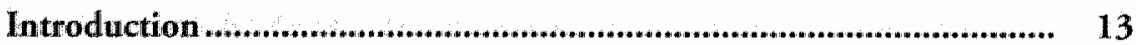

1.1 Background ROZ-IPD Netherlands Property Index ........................ 1.4

1.2 Outline ..................................................................................... 15

\section{Chapter 2}

Long-run return series: 25 years of commercial real estate in the Netherlands ............................................................................. 19

2.1 Introduction ........................................................................ 19

2.2 Literature ............................................................................. 20

2.3 Methodology ...................................................................... 21

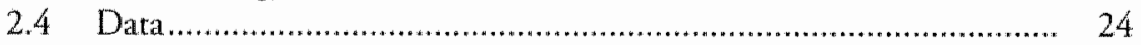

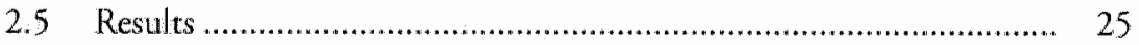

2.6 Reliability check: checks and balances ............................................ 28

2.6.1 Office market ............................................................................ 28

2.6.2 Retail market................................................................... 30

2.6.3 Market for residential real estate.................................................... 31

2.7 Summary and conclusions............................................................. 32

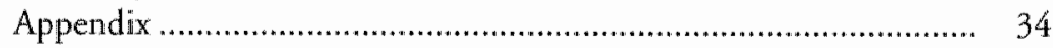

\section{Chapter 3}

Development of historic time series of office rents in the Netherlands ................................................................................... 47

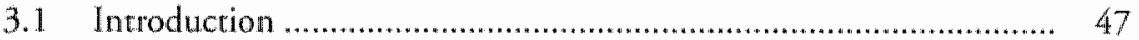

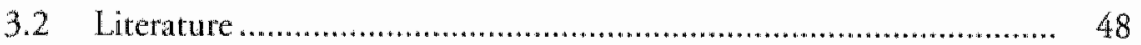

3.3 Methodology ........................................................................ 49

3.4 Data............................................................................... 49

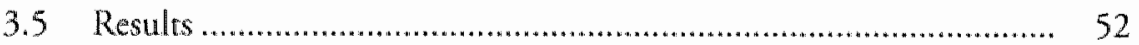

3.6 Dutch office rents time series in an international perspective............ 53

3.7 Office markets' relation to the economy: rents, returns and cyclical patterns................................................. 55

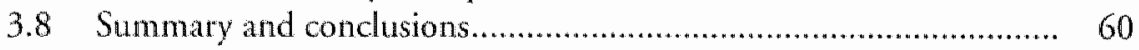

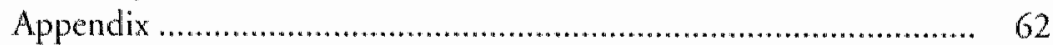




\section{Chapter 4}

Valuation model uniformity and consistency in real estate indices........ 65

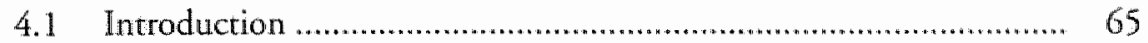

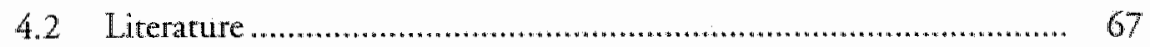

4.3 Methodology ……................................................................. 72

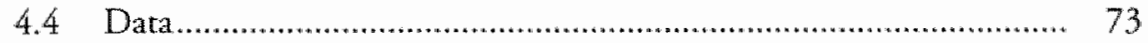

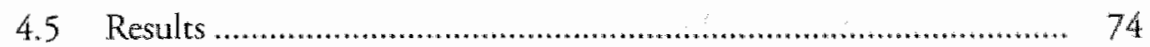

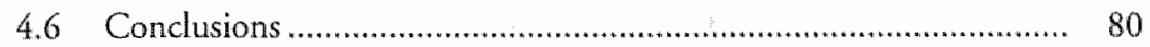

4.7 Recommendations to improve the $\mathrm{ROZ}$ Valuation guidelines .......... 81 Appendix ................................................................................ 82

\section{Chapter 5}

Valuation accuracy in real estate indices.................................................. 91

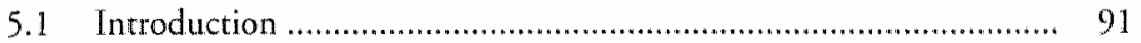

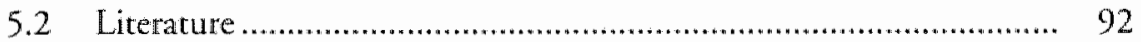

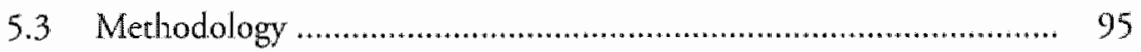

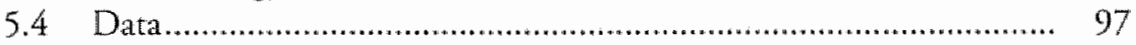

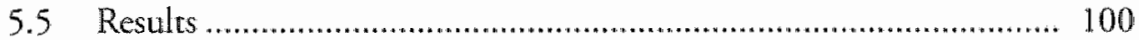

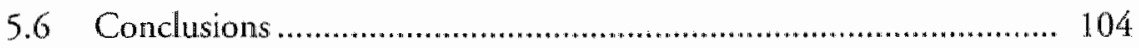

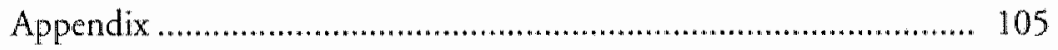

\section{Chapter 6}

European market dimensions: an inventory

of the potential investment market in 11 European countries............... 111

6.1 Introduction .................................................................. 111

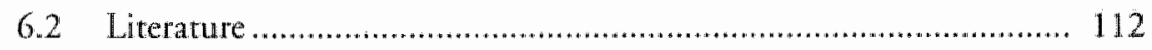

6.3 Methodology …..................................................................... 114

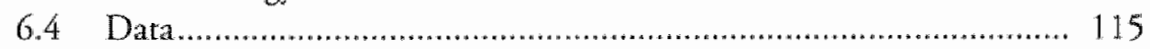

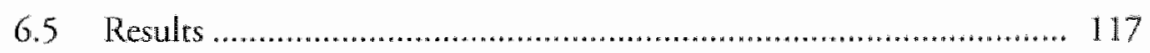

6.6 Summary and conclusions........................................................ 121

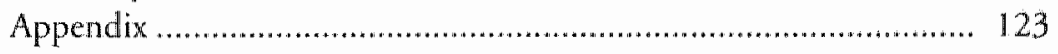

\section{Chapter 7}

Conclusions and Further Research ........................................................ 135

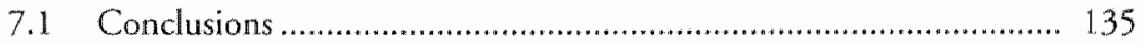

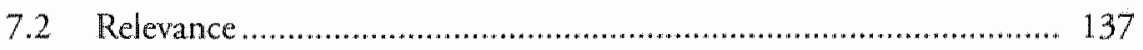

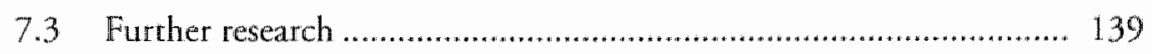

References .......................................................................... 141

Nederlandse samenvatring........................................................... 153

Curriculum Vitae .................................................................... 158 


\section{CHAPTER 1}

\section{Introduction}

I

n the Western world, most of us pay premiums to save money for the time when we reach retirement age. In principle there are two methods; the first is the "pay as you go" method, whereby premiums paid by employees are immediately used to pay the already retired employees. The second method is a capitalized pension scheme, whereby each employee builds up his own savings deposit to meet the liabilities after retirement, based on the statistical average length of life. In the larter case there will be much more money, in premiums, to be invested by pension funds and insurance companies. European countries with capitalized pension schemes are: the UK, the Netherlands and to a certain extent, some Scandinavian countrics. When investing these premiums, pension funds and insurance companies try to make sure that the assets plus the related revenues will be sufficient to match the liabilities. The majority of these assets are stocks and bonds. These assets have the advantage that they will be traded almost every day in some quanticy and that very long performance time series are available, which can be used to predict future performance of these assets. Continuous asset liability management studies calculate the expected revenues as well as the future liabilities to find out what coverage of the liabilities exists. Allocation decisions will be based on the outcome.

Real estate as an asset class turns out to be attracrive over time because ir appears to be a good diversifier. Therefore pension funds and insurance companies want to invest in real estate, although the allocation to real estate is generally less than $10 \%$ of their rotal investments. This is due to the fact that investing in real estate involves several uncertainties. First, the performance time series for real estate are much shorter than for stocks and bonds. As a result, less analyses and less certainty can be provided to accommodate asset liability studies. Secondly, real estate is a heterogeneous product, which waries in size and capital value. This can creare liquidiry problems when an 
individual property. Therefore, consistent and accurate valuations are of the utmost importance. Due to previous index expeniences in the Netherlands at the end of the 1980 s and the beginning of the 1990s, Dutch institutional investors still felt that for the benefit of an unambiguous index, Valuation Guidelines had to be developed and prescribed in order to arrive at more consistent and accurate valuations. Since the start of the ROZ-IPD index (1994), considerable effort has been put into the guidelines and standardisation of valuations, while however avoiding infuencing the independence of the appraisers. These valuation guidelines became mandatory for every appraiser producing valuations for the ROZ-IPD property index. To maintain the valuation guidelines is a continuous process; as described in Chapter 4.

Other important issues have been the development of hiscoric return data and historic office rents, as described in Chapters 2 and 3. These figures are important inpur variables for asser liability managers at pension funds and insurance companies. The figures are used to give the managers a feeling of greater security and reliable data on long term real estate investments on which they can base their allocation decisions.

\subsection{Outline}

In the Netherlands, asset liability managers have been looking for data and statistical information to measure the performance of real estate over a longer period. Unlike the UK and the USA, where this data is abundantly available, continental Europe still suffers from a lack of data on real estate investments. This dissertation provides data on European market dimensions, 25 year return series for Durch investment-grade real estate and 25 year office market rents in the Netherlands. Another important element in performance measurement is the use of appraisal-based real estate indices. Buildings are not traded regularly, therefore valuations are a necessity in order to estimate value growth. On the other hand, valuations are only an estimate of market value, with a large acceptable latitude which increases the risk. Valuations are the Achilles hee of appraisal-based indices. Therefore valuation accuracy and consistency in the Netherlands is addressed as well.

Chaprer 2 looks at the long-run retum series for the Netherlands. The vast majority of studies on the performance of real estate or the role of real estate in a mixed-asser portfolio are based on USA or UK return indices. For investors on the European continent, these conclusions can be utilised, but must then be made representarive of their home markets, since no return series will be long enough to perform such studies. To fill this gap in data availability, 25-year historic series for Dutch offices, retail and residential real estate were constructed. Repeated-measures regression results provided indices exhibiting fairly to very similar patterns, as visual comparisons with major economic indicators rewealed. Individual time series are available for offices, retail and residentials. As expected, a strong correlation has been found between office returns and economic cycles, although with some lagging.

Next, Chapter 3 describes the development of historic time series for office rents. The ROZ-IPD Netherlands Property Index has been established in the Netherlands since 1.995, measuring the renurn of institutionally-held direct real estate. Nine years of real 
estate indices is still a relatively short period of cime on which to carry out analysis, especially as most of the nine years saw exceptional economic growth. Therefore the development of a 25-year historic office market rents time series is analysed and put into an international context.

Chapter 4 continues with a discussion of the valuation model uniformity and consistency in real estate indices. This chapter has two objectives: the first is to shed light on the uniformity of, and consistency within, the valuation models for the ROZ-IPD Netherlands Property Index. The second objective is to analyse diversity/divergence and uniformity of the assumptions on several important input variables which have been retrieved from the valuations of retails, offices and residentials from 1994 to 2002. Around 150 original valuation reports from the ROZ-IPD Index participants were checked for compliance with the valuation regulations and for model uniformity and consistency over the Discount Cash Flow (DCF) term in years, the inflation scenario, the discounting method and the residual value calculation. The diversity $/$ divergence and uniformity of the input variables were also checked for each of the index sub-segments. They were checked for the following: does the standard deviarion decrease over time and what is the quantitative difference between the inpur variables assumed by an internal and an external appraiser, and between external appraisers? The largest differences between the internal and external appraisers are found in the assumptions on the exit gross yield. The standard deviations of internal valuations are smaller than the standard deviations of external valuations. Especially in residential waluations, the differences in value between internal and external appraisers, and between external appraisers among themselves, are large.

Chapter 5 concentrates on another valuation issue: valuation accuracy in real estate indices. This chapter investigates the difference between the actual selling price and the previous valuation, using a unique dataset from the ROZ-IPD Netherlands Property Index's databank. The dataset covers 1,943 sale transactions between 1995 and 2002 . The survey focuses on commercial property alone, because residentials in the Nerherlands are mostly rraded on a partial sale basis (on falling vacant, units will be sold to private individuals). As far as the appraisal error is concerned, this chapter contributes to the debate by splitting the appraisal error into a systematic component (lagging, based on transactions from the past and the appraisal process as well as the rime-span between the date of appraisal and the date of sale) and a residual random errot. The results have been placed in an international context by comparisons with similar research in the USA and the UK.

Chapter 6 describes a survey of the European market dimensions and an inventory of the potential investment market in 11 European countries. The purpose of this survey is to creare more reliable estimates of the total size of the potential investment real estate market in Western Europe. To compile an accurate estimate of the value of investment property in each national market, the survey divides the investment markets into two groups: France, Germany, Sweden, the Netherlands and the UK, in which reliable estimates could be retrieved. Denmark, Ireland, Finland, Norway, 
Portugal and Spain, in which some dara was available. The results of the survey are a first step towards stimulating more research on this issue.

Chapter 7 concludes the dissertation. The main conclusions are summarised and suggestions for further research are listed. Especially as so many new areas of research in the Nerherlands are introduced in this dissertation, the main conclusion is that there are still many more areas to investigate or to expand the research as described in this dissertation. 


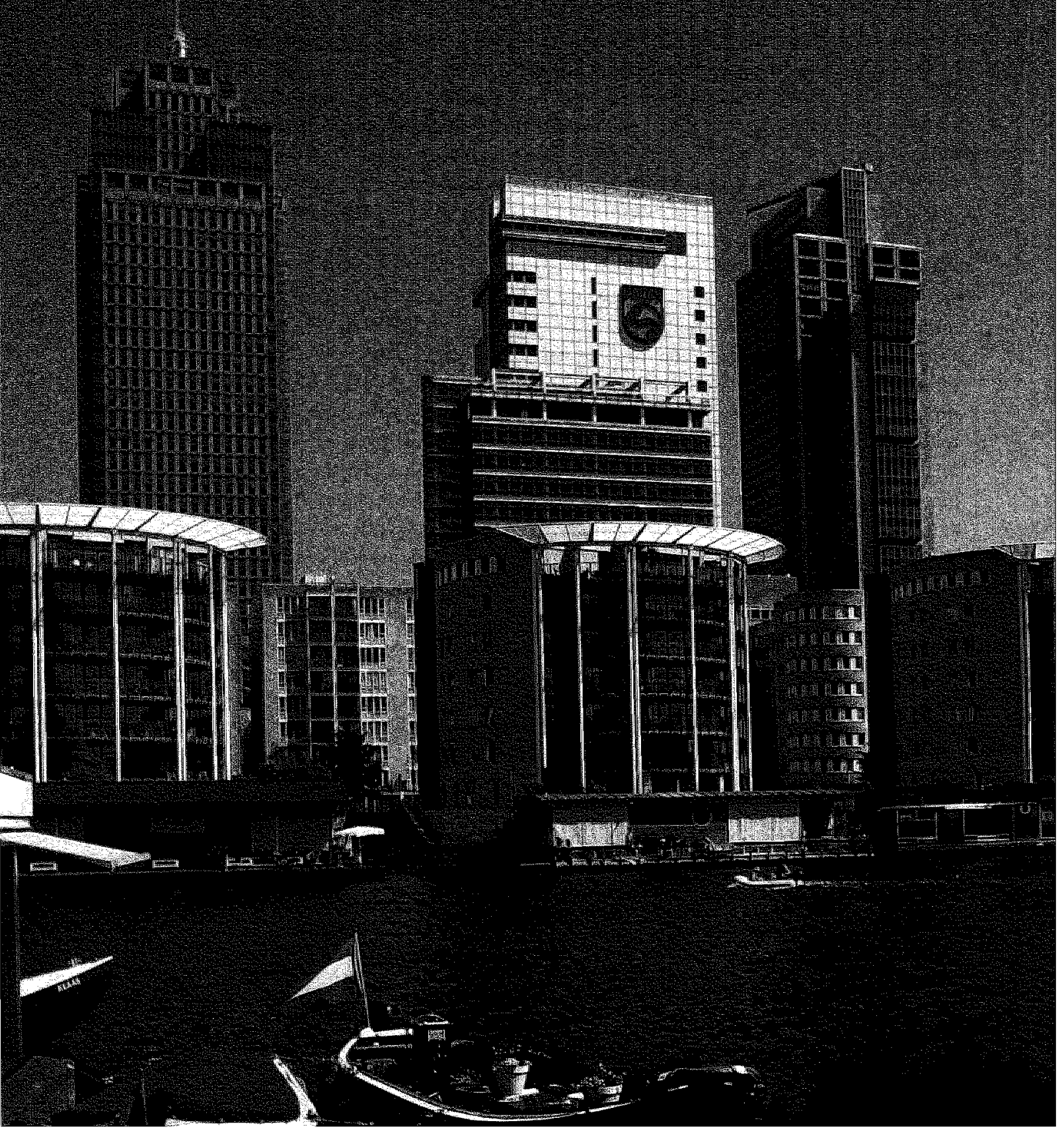




\section{CHAPTER 2}

\section{Long-run return series: 25 years of commercial real estate in the Netherlands ${ }^{1}$}

\subsection{Introduction}

7 Thus far, Anglo-Saxon countries have held a monopoly on long-run return indices for commercial properties. Since the American NCREIF and the British IPD prowide the longest time series, performance and mixed-asset portfolio studies concerning commercial real estate are primarily based on these two sources. But do their conclusions also apply to real estate on the European continent? Since most total return series for the European continent only cover a few years of history, there is just one way to find out, apart from wating a fow more decades: the present indices can be extended with historical information.

Outside the UK, the USA, Australia and Ireland, the performance measurement of commercial real estate is still in its infancy. Return series of the British IPD and the American NCREIF boast 32 and 25 years of history respectively; the Australian PCA and the Irish IPD follow with 18 and 19 years. On the European continent, JPD only recently started benchmark indices in several countries. IPD constructed national indices in the Netherlands in 1995, followed by Germany (1996), Sweden (1997), France (1998), and Denmark and Norway (both in 2000). In 1993, BD2i, a real estate index company in France, supported by the major insurance companies and currently affiliated to the IPD, reconstructed French return indices using historical 
demands sufficienty long and broadly based indices for all major real estate sectors; in an asset-liability context, series of 25 to 30 years are desired.

Therefore, Dutch indices for retums on offices, retail, and residential real estate were constructed dating back to 1977 . This chapter presents the construction process for these long-run total return indices, and discusses its results. The results so far will hopefully encourage researchers in other countries to emulate initiatives like this and to meet the urgent need for historic real estate data.

Following a review of index construction literature applied to commercial real estate and a descriprion of the methodology and data used, the outcome of the index estimation will be presented, as well as a discussion of the plausibility of the resulting indices. A summary and conclusions will end this chapter.

\subsection{Literature}

Index construction comprises a large part of real estate literature, although only a small part of it concerns indices for commercial properties. The hererogeneity and low frequency of transaction data and the inaccuracy of appraisals are likely to impede accurate return measurements. The impact of the distorions may be mitigated by techniques like hedonic regression and repeat-sales regression, or combinations of both, and de-smoorhing.

Hedonic regression addresses the heterogeneity problem directly, since it is able to distinguish between value due to cross-sectional differences in samples and value caused by a temporal effect, such as changes in the property market. Following its introduction by Court (1939) to measure car price changes, and the theoretical foundation provided by Tinbergen (1959) and Rosen (1974), this technique has been applied frequently, but especially to single-family house prices. The few applications to commercial real estate focus mainly on rents (Wheaton and Torto, 1994, and Bollinger et al, 1998), though some address prices (Munneke and Slade, 2000).

Repeat-sales indices are even less frequently applied to commercial real estate prices, presumably due to the low frequency of transactions, which makes it difficult to construct pairs of repeated transactions. Repeat-sales regression constructs a real estate price index by weighting of price changes between two succeeding observations for the same property. Introduced by Bailey, Muth and Nourse (1963), it was later improved by Case and Shiller (1987 and 1989). Alongside the many studies focusing on prices of owner-occupied housing, only a few studies applied the technique to commercial property prices, such as Gatzlaff and Geltner (1998).

More recenty, Geltner (1996) and Geltner and Goetzmann (2000) extended the repeatsales regression method by including cash flows from activities other than selling the property to create total return indices. This repeated-neasures regression still focused on the matched-pair principle, but used actual cash flows instead of percentage value changes. However, these authors used appraised values instead of property prices, since their repeated-measures regression aimed primarily at elimination of the understatement 
of volatility and of the lagging of appraisal-based returns. This index construction study extended the smoothing literature of studies describing technigues to de-smooth and de-lag existing return indices, such as Gelmer (1993) and Fisher and Geltner (2000). As will be shown later, the dataset consists both of transaction prices, appraised values and cash flows, thereby making the Geltner-Goetzmann repeated-measures regression well suited to the construction of the total return indices.

Following construction of the indices in this chapter, a plausibility study is performed to evaluate their reliability. One way to realize this is using the abundant real estate cycle literature in a reverse way. Instead of assessing and explaining real estate cycles by fundamental indicators, findings of earlier studies can be used to judge the reliability of the cycles reflected by the indices constructed in this chapter.

Using the length of cycles in real estate indices is not a trustworthy check, since real estate cycle lengths can wary widely. An IPD-study (Royal Institution of Chartered Surveyors, RICS, 1997), based on three-quarters of a century, reported an average British cycle length of 8 years, but with variations ranging from 4 to 12 years. Moreover, Kaiser (1997) complicated this issue by arguing that there are many types of real estate cycles, some of them even covering several decades.

More of a handle can be found in studies focusing on indicators driving real estate returns. For example, Liang and McIntosh (1998) explored the relationship between office returns and employment growth, while D'Arcy et al (1997) showed the importance of the more general. GDP growth indicator for office markets. Retail investment returns over time can be partly explained by changes in retail sales (Tsolacos and McGough, 1995). However, literature exploring macro-economic indicators as driwers behind the investor-owned housing market is scarce, since differences in apartment values or rents are usually explained by property-specific features or neighbourhood characteristics. Therefore, alchough not based on academic findings, a comparison between the owner-occupied market and the general economy might be helpful for looking at developments in investor housing returns.

These relationships between economic developments and the real estate markets can be used to create expectations regarding the movements of Durch real estate returns in history, and thereby to check the trustworthiness of the regression outcomes: do the Dutch historic real estate return series track the developments of the driving indicators?

\subsection{Methodology}

As mentioned, the repeated-measures methodology, as described by Geltner and Goctzmann (2000), was applied to develop total return series for separate real estate sectors. It is based on discounted cash flows with non-linear periodic returns, as reflected by equation (1).

$$
V_{0}=\sum_{s=1}^{T} \frac{N O I_{s}+P S_{s}-C I_{s}}{\prod_{s=1}^{i}(1+r)^{s}}+\frac{V_{T}}{\prod_{s=1}^{r}\left(1+r_{i}\right)^{s}}
$$


In (1), the purchase price $\left(V_{0}\right)$ is the discounted walue of future net income cash flows $(\mathrm{NOI})$, returns from partial sales (PS), capital improvements $(\mathrm{Cl})$, and the sales price $\left(\mathrm{V}_{\mathrm{T}}\right)$ ). The total return ( $r$ ) in the denominators is allowed to vary per period, and can be estimated by means of linear regression, since the equation is linear in the inverse of the compounded return level (Geltner and Goetzmann, 2000). The regression equation for this will be:

$$
V_{i}=\sum_{i=1}^{T} \beta_{i} D_{t, i}+\varepsilon_{i}
$$

(2)

with

$V_{i}=\left\{\begin{array}{l}V_{f} \text { if the first value of a matched pair relates to the base period of the index } \\ 0 \text { otherwise }\end{array}\right.$

and

$D_{i, i}= \begin{cases}-V_{f} & \text { if the first value does not relate to index base period and } t=f \\ N O I_{t, i}+P S_{t, i}-C I_{t, i} & \text { if } t \text { does not relate to index base period and } t \neq f \\ N O I_{t, i}+P S_{t, i}-C I_{t, i}+V_{s} & \text { if } t=s \\ 0 & \text { otherwise }\end{cases}$

In $(2), V_{f}$ and $V_{s}$ denote values of the same property at two succeeding value observations, sales or appraisals, the first and second observation of a matched pair. $D_{t, i}$ equals the sum of all positive and negative cash flows to the property owner in years after the index base period. It is negative for the first price or appraisall of a marched pair, since this can be regarded as a new investment, with the second value and all other intermediate cash flows as reward. "The estimated $\beta$ 's reflect the inverse of the product terms in the denominators of equation (1). Therefore, periodic total returns can be calculated as in (3). The $\beta$ for the base period, $\beta$, is set to 1 .

$f_{s}=\frac{\hat{\beta}_{i-1}}{\hat{\beta}_{i}}-1$

A capital growth index can be estimated by the same procedure, but with the omission of the NOI of the cash flow terms. The capital components of the cash flow, consisting of the capital improvements and the partial sales, should remain. Separate indices are estimated for offices, retail and residential, while an all-property return index is calculated as a weighed average based on observations.

Goetzmann (1992) and Shiller (1991) refer to two corrections that might be applied to the ordinary least squares (OLS) regression in (2). First, regression errors $\varepsilon_{\mathrm{i}}$ reflect borh random appraisal error, in the case of appraised values, and property-specific return components causing individual property returns to deviate from the population average. As a result., OLS estimates will be biased downward, leading to upward-biased estimated periodic returns. Instrumental variables estimation solves this problem (Shiller, 1991). Second, lack of a sufficient number of observations could introduce excessive regression noise. 
A ridge escimator as suggestod by Gostzmann (1992) corrects for this. However, to satisfy the explicit desire of the Dutch institutional investment industry for transparent retum indices, neither of these rwo corrections have been applied at this stage to the index series.

In an ideal situation, one would only use transaction prices and avoid appraisals due to the inherent problems. Nevertheless, data availability does not allow for this. Therefore, academic ideals are combined with feasibility, by using both transaction prices and appraisals. Although this might introduce a new form of smoothing or lagging, it seems to be the only way to construct historic return series for the Netherlands.

Many transaction prices are matched with appraisalls of 1994 or later. Since the period 1994-2001 corresponds to an upward phase in the Dutch real estate market, and appraisals tend to be somewhat below transaction prices in such periods, this might induce underestimation of the appreciation component. However, it might also cancel out the potential overestimation due to random appraisal error and property-specific return components, as mentioned above.

Besides transaction prices and appraisals, cash flows resulting from net operating income and capital expenditures are required to compute total recurn indices. However, documented rents from before 1994 in many cases appeared to be difficult to match with corresponding property values, as did capital expenditures. Therefore, cash flows from net income and capital improvements are reconstructed using certain assumptions. Due to the scarcity of historic real estate data, it is again a trade-off between academic idealism and practical feasibility.

For the construction of total return indices, separate indices are calculated for capital growth and rental income. The income return for offices is assumed to be equal to the prevailing net yields for prime locations over cime, and is added to the capital return series to construct the total return series for offices. Since yields of other sectors are uniknown for such a long period, a different approach is used for retail and residential real estate, as described by Hordijk and Voorhorst (1999). Average rental cash flows are calculated for the period 1994-2001, and indexed to inflation. Values of properties for which historical rents could be assumed by this approach are reconstructed by means of the separately estimated capital growth series. Combined, the assumed income cash flows and the assumed values produce income return figures. The assumption of indexing rents to inflation is not unrealistic, since Dutch rent contracts usually specify Consumer Price Index (CPI) increases, but it ignores the impact of vacancy on income. As a result, actual net income will be somewhat more volatile than the reconstructed cash flows.

Dara on historical capital expenditure is also only sparsely available. Therefore, cash Hows for capital improvements are reconstructed. The average of the capital improvements of 1994-2001 is calculared as a percentage of average capital values. For each matched pair of property values, this percentage is applied to the average of the first and the second observation, thereby assuming that the resulting capital improvement cash flow does not change during the holding period of the property. For tetail properties, this means an annual capital improvement of $0.42 \%$, and for offices and residential real estate respecrively, 0.71 and $0.29 \%$. 


\subsection{Data}

The aim of this study is to construct annual indices for appreciation returns and total returns, sufficiently long for application in asser liability management studies. The earliest attempts to construct such indices with data from real estate brokers failed, due to insufficient observations (Goslings and Hordijk, 1996). A pilot study (Hordijk and Van Riel, 2001a) was more successful, when historic data from the participants in the ROZ-IPD Netherlands Property Index yielded an all-property return index dating back to 1982. This chapter is an improvement on this pilot, by extending the time period to 1976-2001, and by construction of indices for the separate segments offices, retail, and residential real estate.

Transaction prices, external valuations and cash flow amounts are obtained from archives from institutional investors, valuation firms, mortgage banks, transaction archives from a Dutch seal estate journal and private sources. Although a lot of data should be available in theory, in practice many historical archives have been lost, due to relocation, new computer systems and mergers and acquisitions. Besides, the Durch real estate market only started to become a substantial investor market at the beginning of the 1980s. Finally, external valuations were not very common until 1994, when the ROZ-IPD Netherlands Property Index started its real estate benchmark.

For the period after 1994, valuations are known for every included propercy on an annual basis. For preceding years, purchase prices and external valuations are available on an occasional basis, as are intermediate capital expenditures on improvements. Internal valuations were rejecred, due to their potentially less reliable nature. The repeat measure regression technique is based on two or more observations of capital value movement of each of the assembled properties included in this survey. Figure 2.1 illustrates the resulting number of accepted value observations prior to 1994, as used as the first observation of a matched pair. For the residential sector, sufficient observations are known for all years. This number is lower for offices, especially in the early years; however, it exceeds 25 in every year except one. Rerail suffers the most from sparse data, with five years containing less than 25 observations. Exact numbers are given in Table 3.A.3 in the appendix.

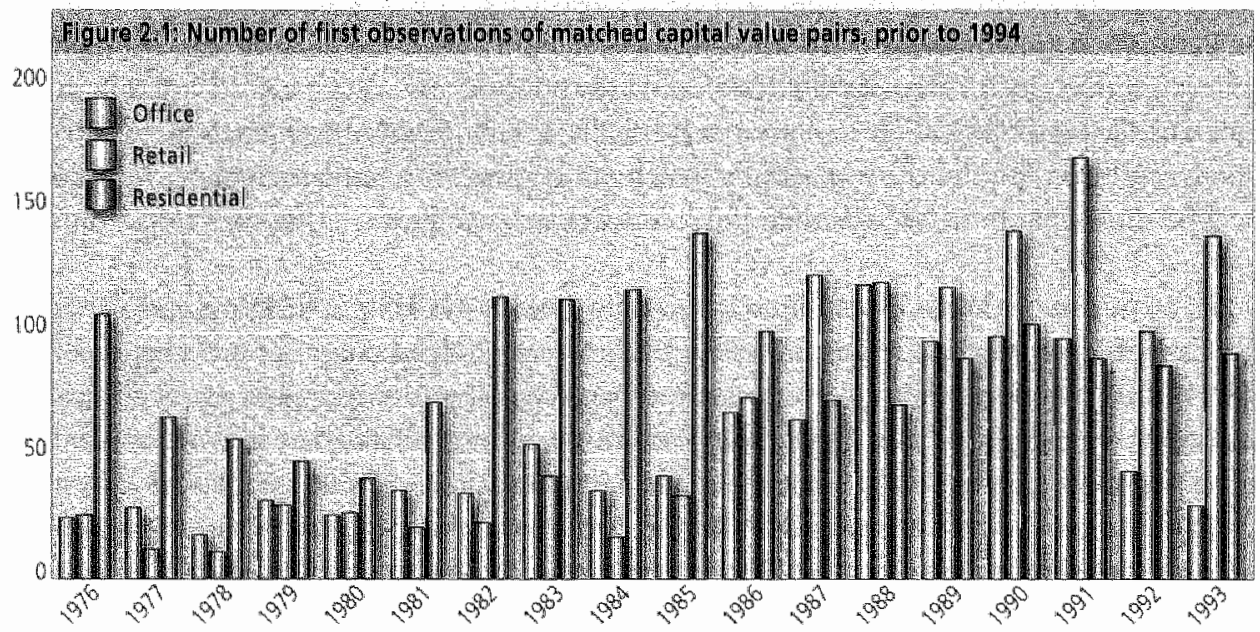


When screening the historical dara, awkward observations were excluded, and records were verified for correct currency conversions, since the Netherlands changed from the Dutch Guilder to the Euro as the currency for the financial markers in 1999 (in 2001, the Euro was established as the national currency). Development projects were not included. For residential real estate, properties with partial sales were exduded due to difficulties in determining the resulting capital consequences. During the sample period, Dutch Valuation Guidelines changed with respect to this aspect.

In the 1980 s, the Dutch government subsidized institutional inwestors in residential real estate. However, those subsidies were not passed on to individual properties, but appeared directly on the income statement of institutional investors. As a result, there is no attributable impact of subsidies on returns of individual properties.

For a visual inspection of the plausibility of results, the estimated return series and other real estate return series (NCREIF and IPD) are compared to data on economic growth (Eurostat), retail sales volume (OECD Main Economic Indicators), returns of other brokers (Jones Lang LaSalle), and national house price series (the Dutch Association of Brokers NVM, the Dutch Department of Housing, Urban Planning and the Enviromment VROM, and OFHEO).

\subsection{Results}

Due to the required transparency, index construction improvements like weighted repeat sales, usage of instrumental variables and ridge estimators have not been used so far. Table 2.1 shows the statistics of the ordinary least squares regression for the office, retail and residential sectors. The best fit is found for housing, while the lowest $\mathrm{R}^{2}$ concerns offices. No statistics are shown for the all-property index, since this is a calculared weighed result.

\begin{tabular}{|c|c|c|c|}
\hline & office & Aotat & Residential \\
\hline $\mathrm{R}^{2}$ & 0.11 & 0.24 & 0.37 \\
\hline Adjusted $\mathrm{R}^{2}$ & 0.11 & 0.23 & 0.37 \\
\hline standard error regression & 0.18 & 0.10 & 0.09 \\
\hline F-statistic & 25.0 & 80.2 & 446.2 \\
\hline Significance $f$ & 0.0 & 00 & 0.0 \\
\hline Observations & 5,075 & 6,459 & 18,804 \\
\hline
\end{tabular}

The results are shown graphically in Figures $2.2 \mathrm{a}$ through to $2.2 \mathrm{e}$. The historic part of the indices is more volatile than for 1994 and onwards. As mentioned before, the benchmark started in that year, based on appraisal-based returns on hundreds to thousands of properties. Returns for the years 1977-2001 are based on regression calculations, reffect a lower number of observations, and partially represent transaction prices, all factors that could explain the larger volatility. Estimates for the early retail years in particullar may suffer from an insufficient number of observations. The exact return estimates and the annual numbers of first obserwations of a matched pair are shown in the appendix, as are t-values for capiral index estimations. 


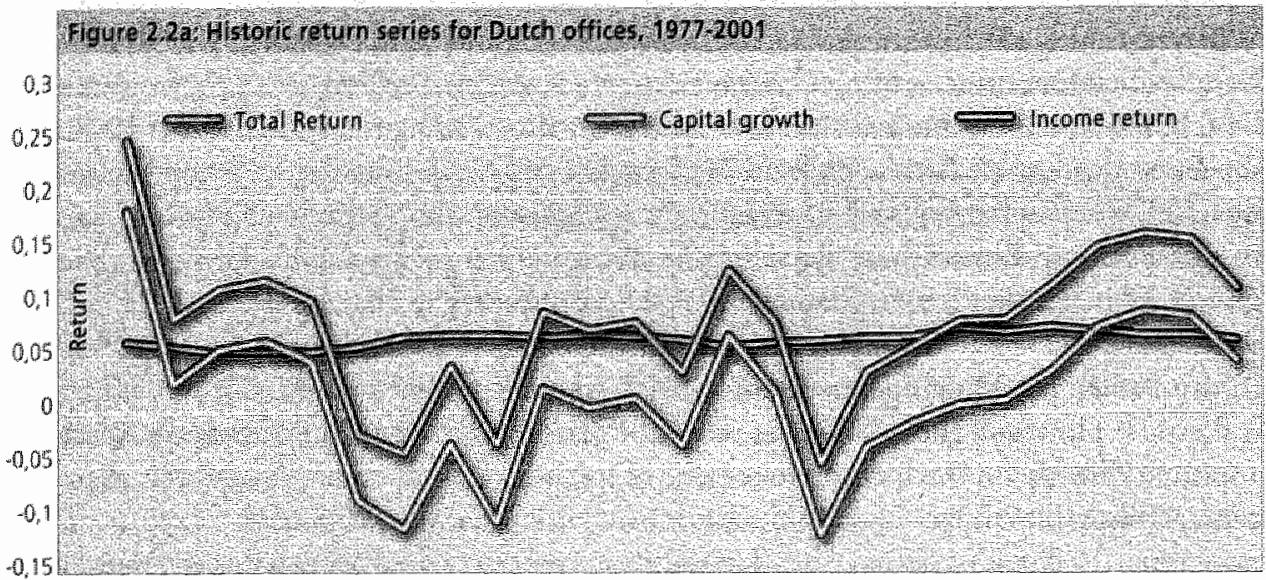

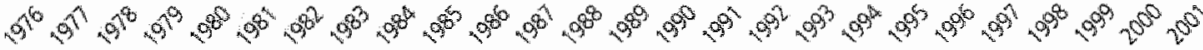
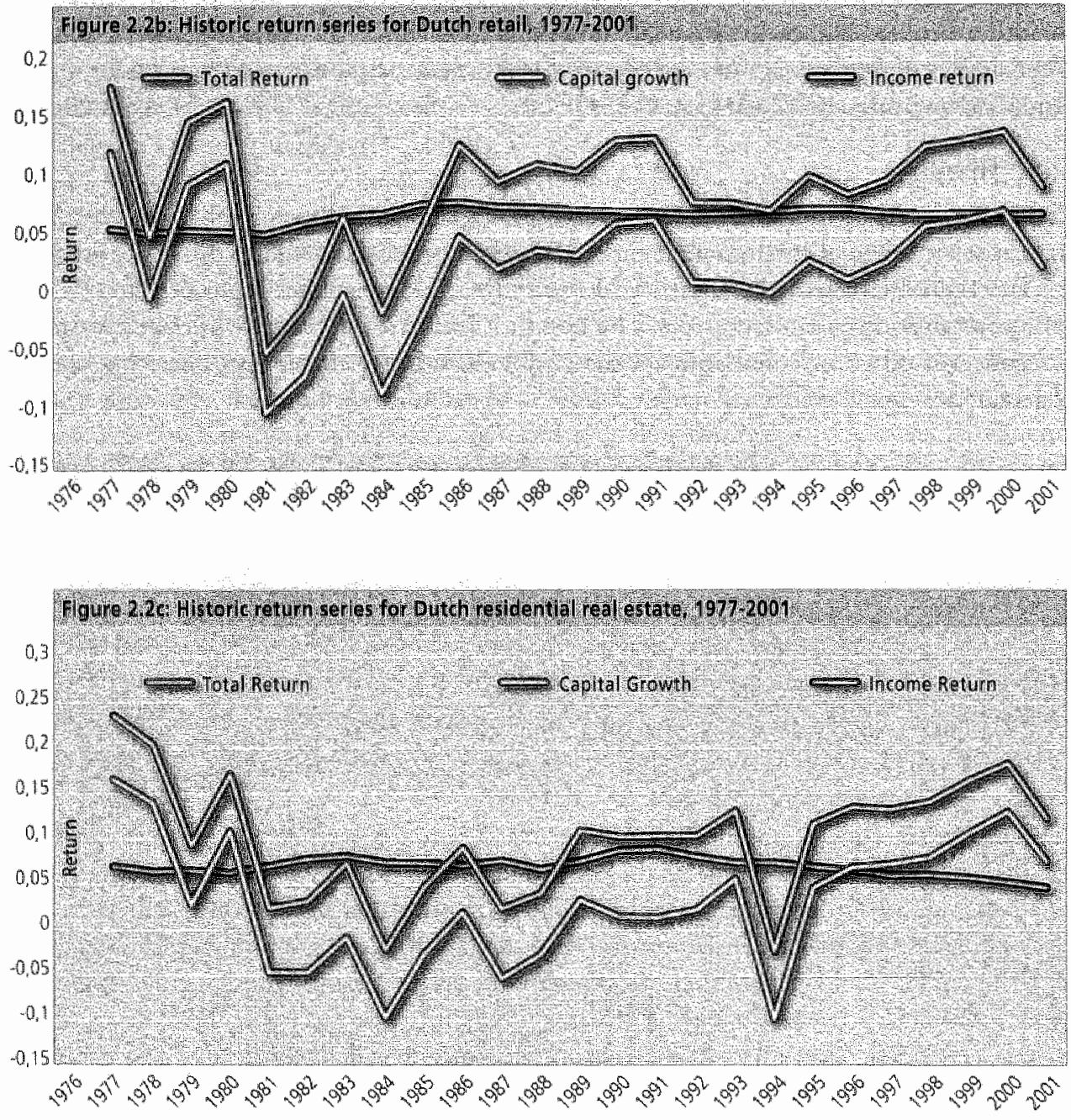


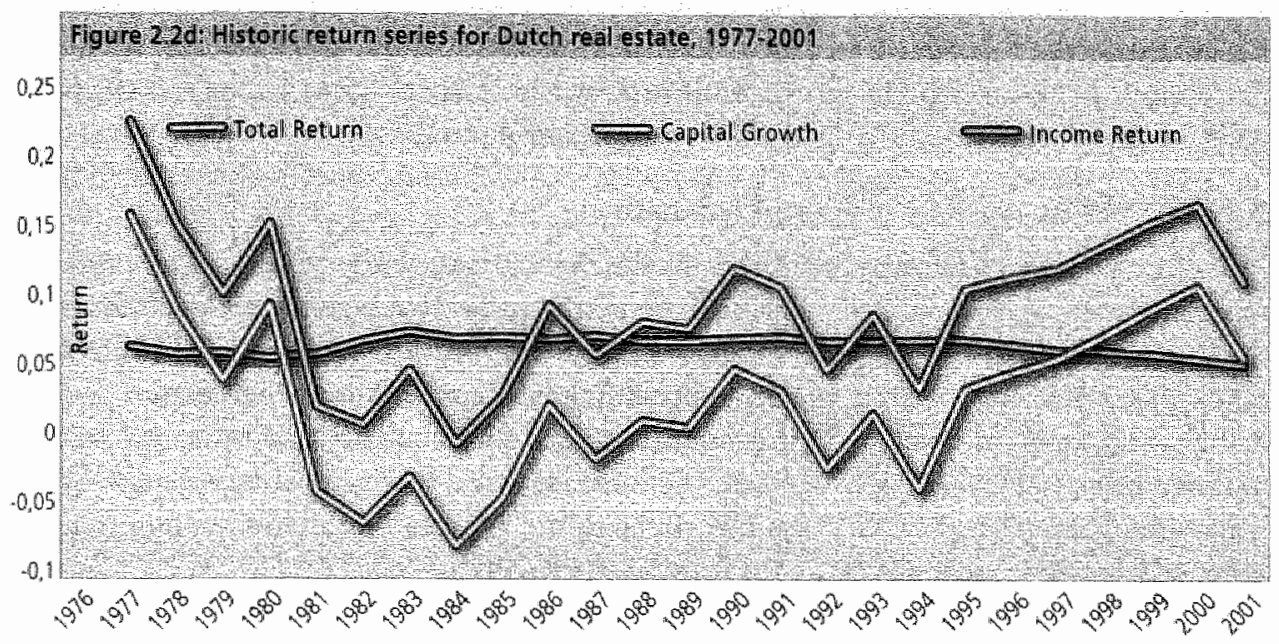

The $\mathbb{R}^{2}$ 's are low compared to Geltner et al (2000) reflecting the heterogeneity and low frequency of the data. Nevertheless, the average returns and stanclard deviations of these series, as shown in Table 2.2, are in line with the return and risk generally reported for real estate. Total annual returns between $8 \%$ and $10 \%$ are quite common for real estate. The standard deviations are somewhat larger than those of appraisal-based indices, but are in line with studies (Gatzlaff and Geltner 1998) based on transaction data, and studies (Clayton, Geltner and Hamilton, 2001) correcting for smoothing and lagging. Perhaps the potentially present regression noise outweighs the smoothing by partial usage of appraisals. Also the relarive positions of the sectors are in line with those found in other countries, with offices mean-variance inefficient compared to retail, and with housing yielding the highest return.

\begin{tabular}{|c|c|c|c|c|}
\hline & $\sqrt{3}$ & Total return & Capital growth & hecome return \\
\hline \multirow[t]{3}{*}{ office } & Average & $8.3 \%$ & $1.6 \%$ & $6.8 \%$ \\
\hline & Standard deviation & $6.9 \%$ & $7.0 \%$ & $0.7 \%$ \\
\hline & Autocorrelation & 0.43 & 0.43 & 0.81 \\
\hline \multirow{3}{*}{ Retail } & Average & $92 \%$ & $2.5 \%$ & $6.7 \%$ \\
\hline & Standard deviation & $55 \%$ & $5.5 \%$ & $08 \%$ \\
\hline & Autocorrelation & 0.23 & 0.24 & 0.91 \\
\hline \multirow[t]{3}{*}{ Residential } & Average & $102 \%$ & $3.2 \%$ & $70 \%$ \\
\hline & Standard deviation & $66 \%$ & $7.1 \%$ & $10 \%$ \\
\hline & Alutocorrelation & 0.39 & 0.45 & 0.82 \\
\hline \multirow[t]{3}{*}{ All property } & Average & $9.7 \%$ & $2.9 \%$ & $68 \%$ \\
\hline & Standard deviation & $5,6 \%$ & $5.9 \%$ & $0.6 \%$ \\
\hline & Autocorrelation & 0.56 & 0.61 & 0.81 \\
\hline
\end{tabular}


Partly due to the relacively low regression performance statistics, an evaluation of the plausibility of the estimated return indices would be helpful here. Therefore, paragraph 6 discusses the developments of these series in more detail.

\subsection{Reliability check checks and balances}

In contrast to the absolute return levels of the historic series, the periodicity in estimated returns can be validated ex-post. To verify the cycles represented by these return series, a comparison between the series and economic indicators known to drive real estate markets is made. First of all, comparisons between economic indicators and real estare returns are made for other countries with suffictently long time series at a national level. If the similarity berween the indicators and foreign real estate markets is reasonably large in the USA, the UK, Ireland and France, one might assume that these relationships are likely to hold for the Netherlands as well.

\subsubsection{Office market}

Usually, the office market is seen as the real estate segment with the most pronounced cycle. With both office employment growth and economic growth suggested by the literature, neither indicator was the dominant driving factor for all countries studied. Therefore, real GDP growth is used as reference for office sector developments.

Figure 2.3 1 ilustrates the correlation between office returns and economic growth for the UK. The economic recoveries of the late 80 's and mid 90 's and preceding recessions are clearly visuble in the return series. These patterns also hold for the USA, Ireland and France, as far as these series are known. Exceptions to this are the huge USA returns around 1980 in conjunction with an economic decline, and a continuing French office market downturn during a recovering economy in the 1990s. Nevertheless, the intemational comparisons hold up well enough to use Dutch economic growth as an indicator for the newly constructed historic office return series.

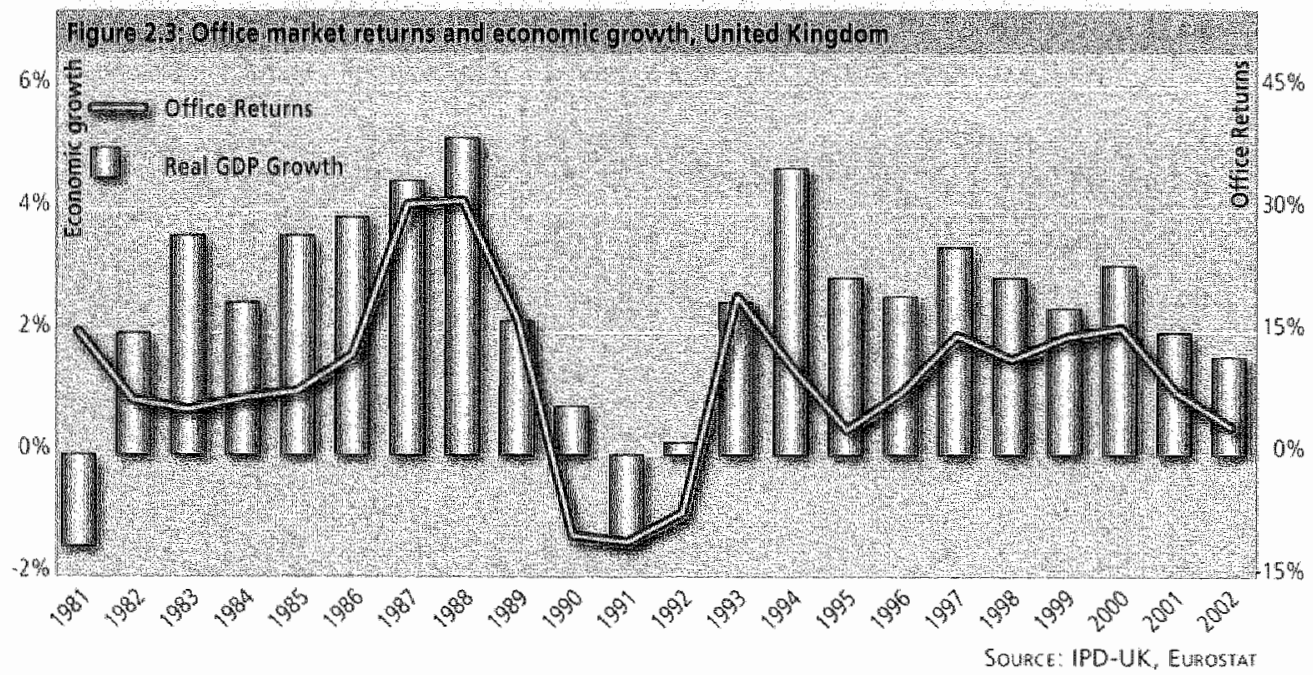


Figure 2.4 illustrates this comparison for the Nethenlands. Since the return series is likely to contain some regression noise, and because of the somet mes relatively small number of observations, part of the volatility shown might be erroneous. Therefore, the chart also shows a dotted line, representing a weighted average return over time: This average weights the preceding and next observation at 25 percent each, and the observation for the relevant year at 50 percent, until the start of the original benchmark in 1994. This is an intuitive correction for not using the ridge estimator (Geltner et al, 2000) to reduce excess volatility. The ridge estimator is a subjective adjustment, which corrects for deviations from market developments. Also a major Dutch asset liability consultancy firm advised against using the ridge estimator because it would reduce transparency.

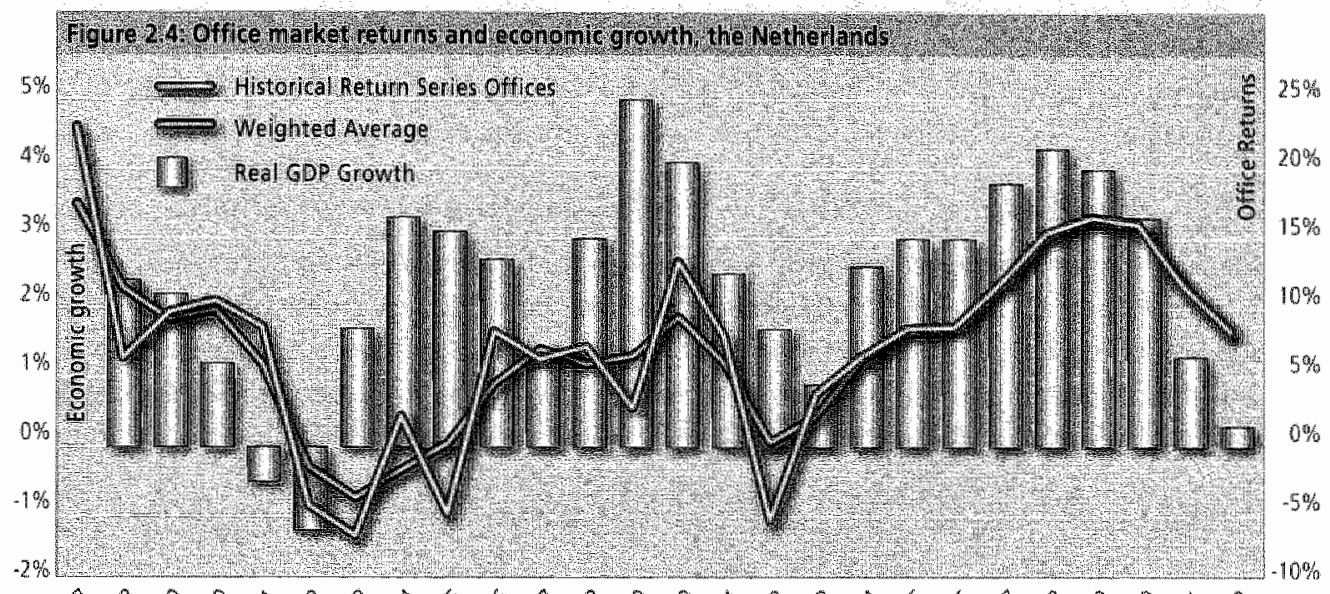

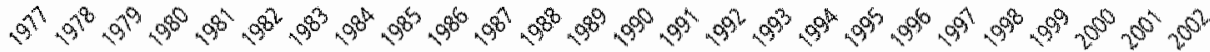

SOURE: ROZ-IPD, EUROSTAT

The long-run development of the Dutch office series and of economic growth look very simillar in the chart. The local minimums of the office return series around 1983 and 1992 are close to the troughs in economic growth in 1982 and 1993 . From 2000 , both the general economy and the office market switched to a declining phase. Therefore the cycles in the economy and the office return series look very similar, as was expected from the international comparison. This visual inspection makes the long-run development of the historic office return series look quite reliable.

This conclusion is confirmed by the development of the ratio of net absorption to the sum of vacant, constructed and sublet space. This is shown in Figure 2.5. As a third check, alongside economic growth and the demand/supply ratio, this chart also shows stock-weighted Durch office market returns from ciry returns provided by Jones Lang LaSalle. All three visual tests confirm that the development in the historic office series looks reliable. However, it remains difficult to elucidate the difference between actual market changes and regression noise. If more data becomes available, this might reduce the noise and thereby the index volatility to some degree. 


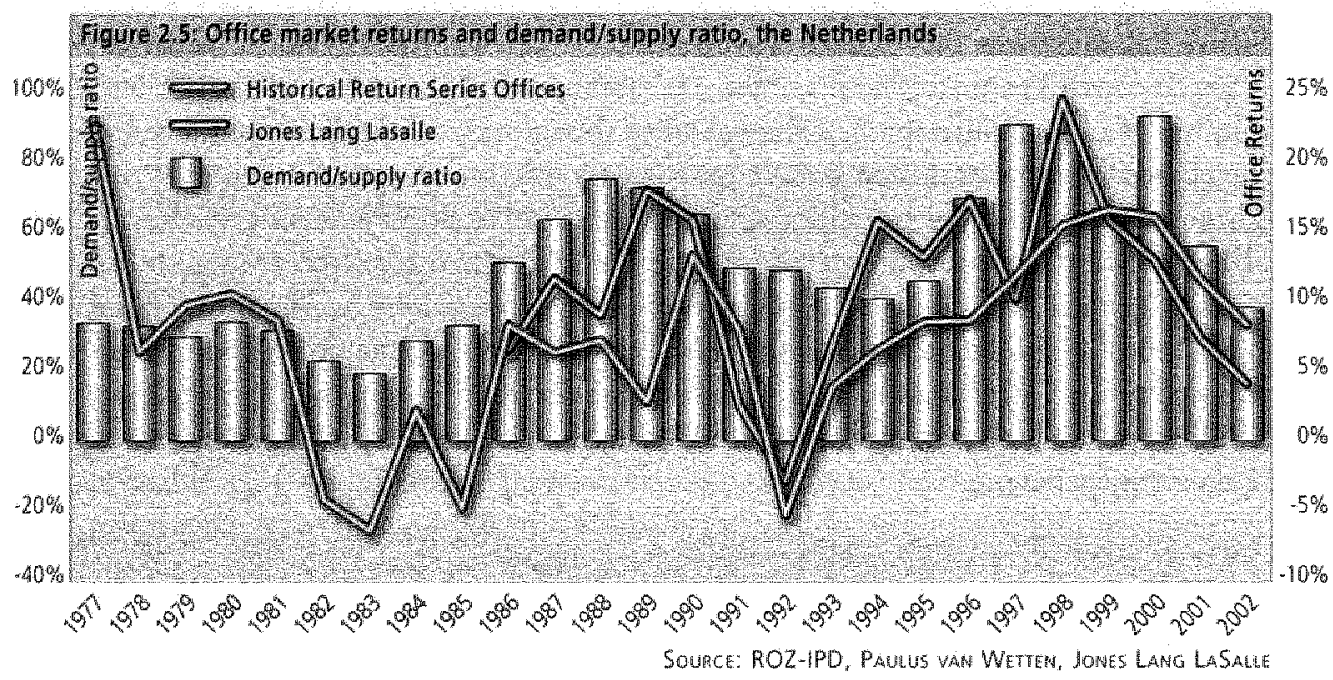

\subsubsection{Retail market}

Developments in consumer spending are important for demand for retail space. Figure 2.6 shows the relationship for Ireland; the same correlation also holds for the UK and the USA. The relationship is less pronounced than the link between economic growth and the office market, but appears to be sufficiently strong to be used as reference for the Dutch historic retall series.

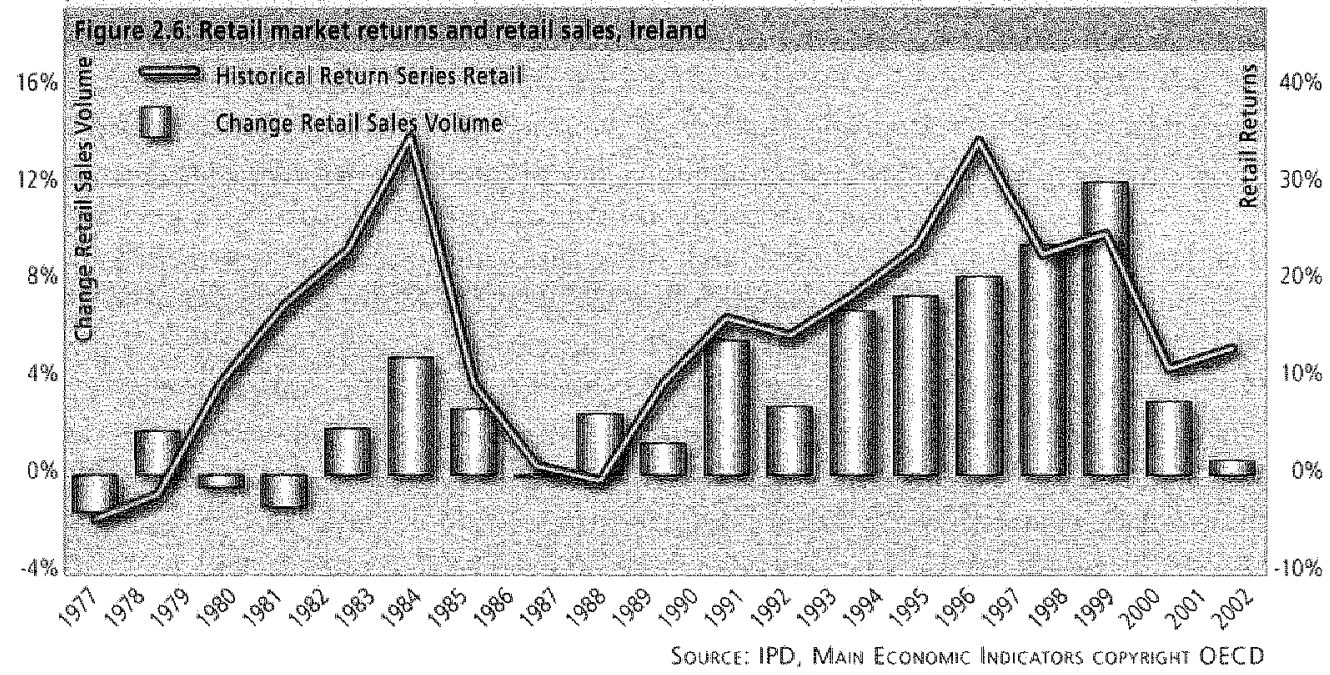

Figure 2.7 illustrates retail sales growth and retail returns for the Netherlands. The similarity to changes in retail sales volume is clearly visible during the economic recoveries in the mid 1980s and late 1990s. Relatively few observations are available during the early years. Although Dutch office returns dropped significantly during the economic slowdown around 1993, the historic retail return series only shows a moderate dedine for that year. This is different from the situation in other countries, where recail returns did fall in the early 1990s. On the other hand, Dutch retail sales did not drop as much at that rime as during the previous period of decline. 


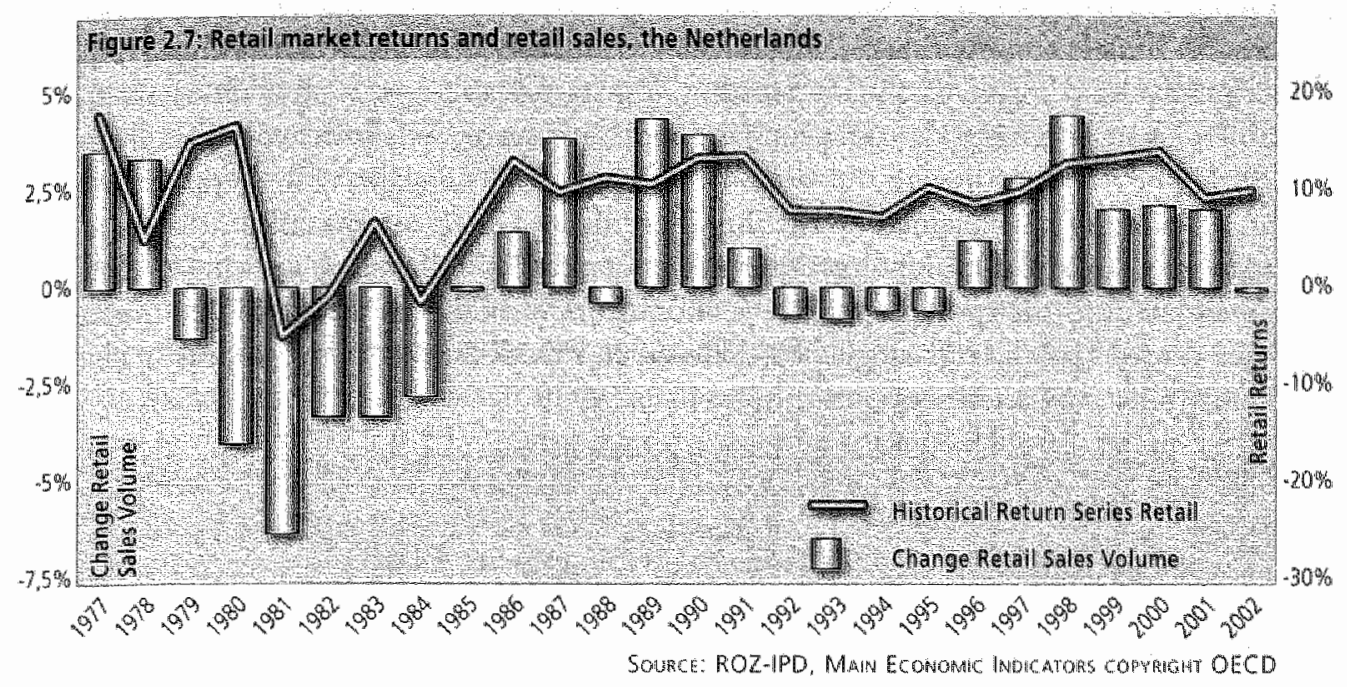

\subsubsection{Market for residential real estate}

For the housing market, it is more difficult to declare one macro-economic variable to be an important indicator. Sometimes house prices over time are explained by a mixture of variables like average disposable household income or mortgage rates, but the focus is often on the market for owner-occupancy. Is this market similar to the market for rental housing owned by investors? Moreover, the IMF recently (2003) showed that a period of declining house prices on average appears every 20 years. With a rerurn series of 25 years, it is not certain that peaks and troughs will be clearly visible.

Therefore, it is complicated to repear the comparison performed for offices and retail now for residential real estate. Figure 2.8 shows that price changes both for American rental apartments and American owner-occupied housing shared a declining rrend until 1991, and continued on an upward slanting trend after that. However, value changes for investor housing are based on appraisals, while owner-occupied house price changes are calculated using transaction prices. If the first five years are disregarded, some similarity with the economy can be seen as well, over the long run.

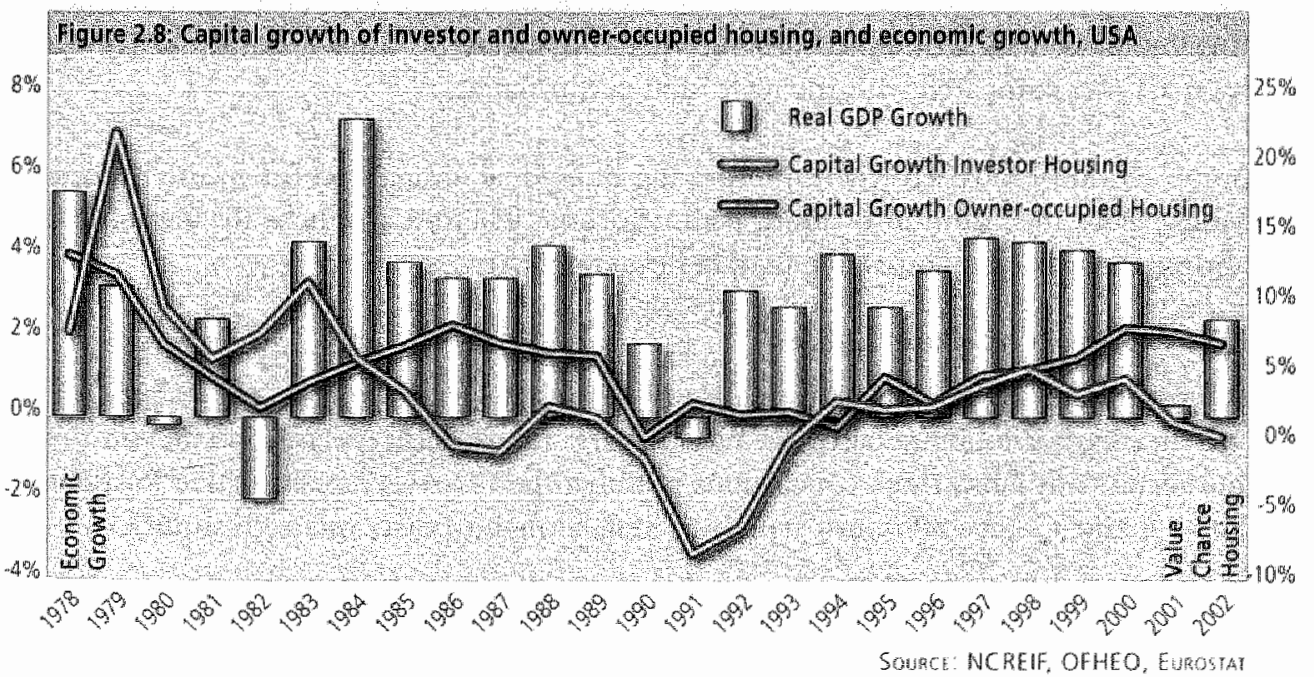


For the Dutch housing market, illustrated by Figure 2.9 , the same condusions hold, although the rising trend for inwestor housing started a few years after the recovery of the owner-occupied housing marker, and both segments showed declines from 2001. The relationship with the economy is less clear. The unexpectedly sharp decline in 1994 might be explained by the nitiation of the Dutch benclimark in that year, assuming participants might have started conservatively in the index, creating a larger potential for future appreciation. No economic or political event occurred that might have caused such a large single drop. However, this decline does not appear in the Dutch office and retail series.

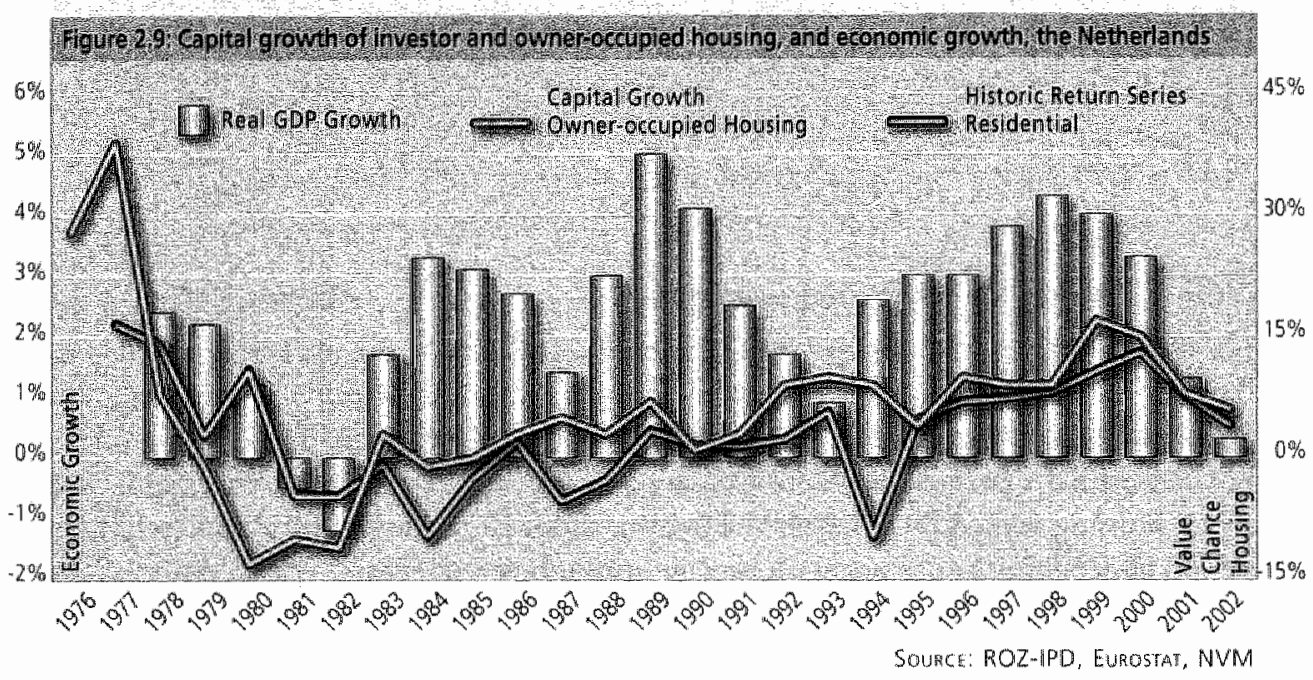

Summarizing these findings from the graphical inspections, although potentially still suffering from some regression noise, the historic ROZ-IPD office series provides a satisfactory pattern of recoveries and contractions. The historic retail index reflects a rather acceptable cycle, but might suffer to some degree from an insufficient number of obserwations in the early years. Comparisons for the investor housing market are the most difficult, but some similarity with the owner-occupied housing market can be observed, which makes the cycle represented by the historic housing index not unacceptable. It is striking to observe that the degree of visual plausibility is in a reverse order compared with the regression performance.

Some caution is advised when interpreting individual annual returns in the historic series. Only the addition of more data can show whether and how the sometimes abrupt changes represent acrual marker developments.

\subsection{Summary and condusions}

Almost all studies on the performance of real estate or the role of real estate in a mixed-asset portfolio are based on Anglo-Saxon return indices. For investors on the European continent, these conclusions have had be taken as representative for their home markets, since no return series was long enough to carry out such studies. 
As a first attempt to fill this gap in data availability, three 25 -year series for offices, retail and residential real estate have been constructed. Repeated-measures regression calculations provided indices exhibiting fair to very acceptable patterns, as graphical comparisons with major economic indicators revealed.

To be more specific, peaks and troughs in economic growth can be seen in the office returns as well, although not very strong. The correlation between economic growth and office returns berween 1978 and 2002 is 0.35 (Theebe, 2003). In retail, peaks and troughs in retail sales also occur in the retail returns; the correlation between the rwo from 1977 till 2002 is 0.55 . A more extensive test of the results than referred to in this chapter has been carried out from different viewpoints and is described in PropercyNL Research Quarterly 2003-2. Comments have been given by a major ALM advisory firm. They conclude that over 25 years direct real estate has had a higher return than shares with a much lower standard deviation (see appendix). Additionally, the real estate investment director of a Durch medium sized pension fund looked at the results and came to the conclusion that correlations between real estate and real estate sectors show that real estate turns out to be a good diversifier over time (see also appendix). Another commentary came from the director of a major investment management firm looking at the allocation consequences of the results. Based upon the office results, he concluded that timing was essential for office returns - much more than for residential and retail investments. These comments have been very stimularing for this research because it means that the results have been taken wery seriously.

Annual returns should still be treated with some caution, since regression noise might: still exist for years with a low number of observations. However, the results so far will hopefully encourage Dutch investors to contribute their archives as well, to enhance the reliability of the series. Researchers in other countries are encouraged to emulate initiatives like this, to meet the urgent need for historic real estate data. 


\section{APPENDIX}

\section{BRIEF METHODOLOGICAL EXPLANATION OF THE UNSMOOTHING TECHNIQUE BEING USED}

We have artached four spreadsheets which include the smoothed long term series for TR, IR and $C G(1)$ and unsmoothed $(2,3,4)$ capital growth series. $A$ description of the historic time series' realisation can be found in our paper presented at the ERES conference Helsinki 2003.

As explained in the attached article discussing the technical marters of the unsmoothing practice (Stewerson) we concentrated on unsmoothing of the capital growth series. Unsmoothing is based on a confidence factor (in the Stevenson paper = alpba; in Dutch = vertrowwensfactor). This factor is a proxy for the degree of smoothing in the capital growth series and can be calculated by subtracting the autocorrelation of the capital growth from one.

In each unsmoothing spreadsheet wel included four series:

1 The smoothed version; based on a confidence factor $=1$

2. Unsmoothed version, based on autocorrelation from 1994 till 2001

3. Unsmoothed version, based on autocorrelation from 1977 till 2001

4. Unsmoothed version, based on a confidence factor $=0.5$

The second series are methodologically the most sensible series, but when the unsmoothed office serie is considered, one should be aware of the fact that the produced returns from 1994 till 2001 don't reflect the actual market movements. Although this is methodologically the most sensible way of unsmoothing time series, one should notice that autocorrelation based on eight rerurn figures only, provides just little hold. To put these results in perspective we have unsmoothed the time series with a confidence factor based on autocorrelation over the total capital growth series and conservative estimate on the basis of American licerature.

According to David Gelcner (MTT), the developer of the Repeated Measures Regression/unsmoothing practice, we should detain the fourth version of the unsmoothed $\mathrm{CG}$ series (confidence factor $=0.5$ ) because the other versions would be an overestimation of the true market volatility. 


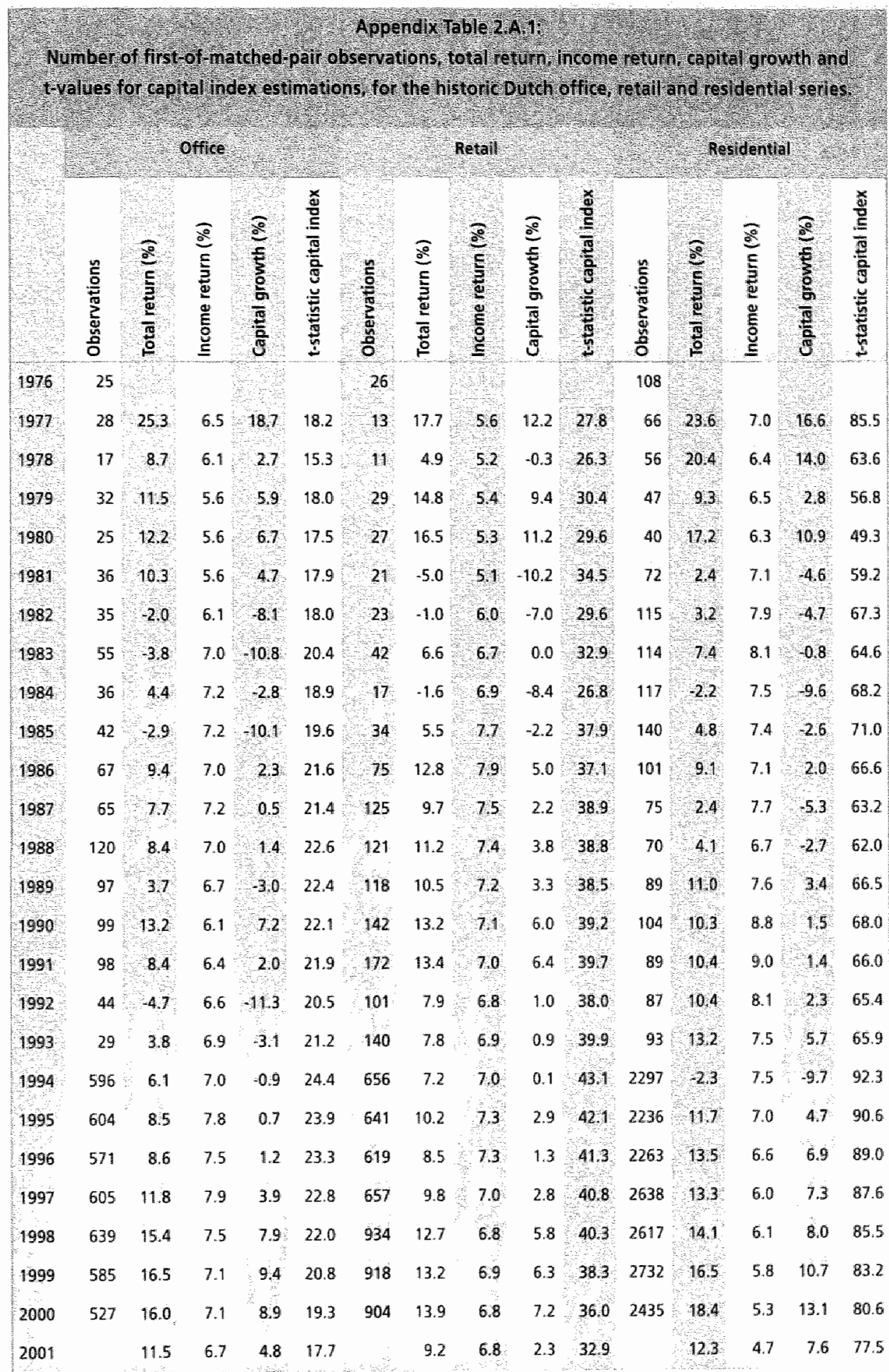




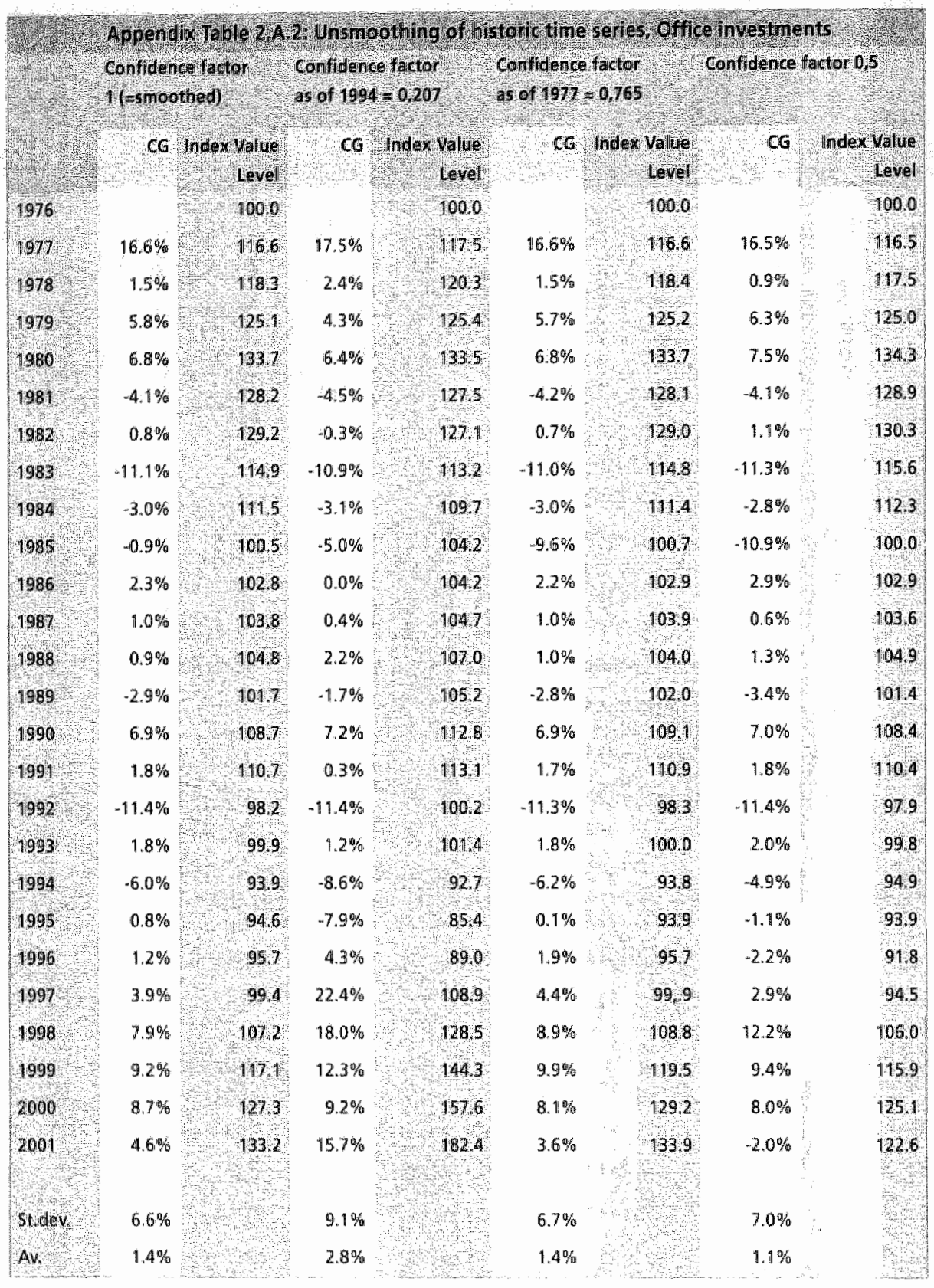



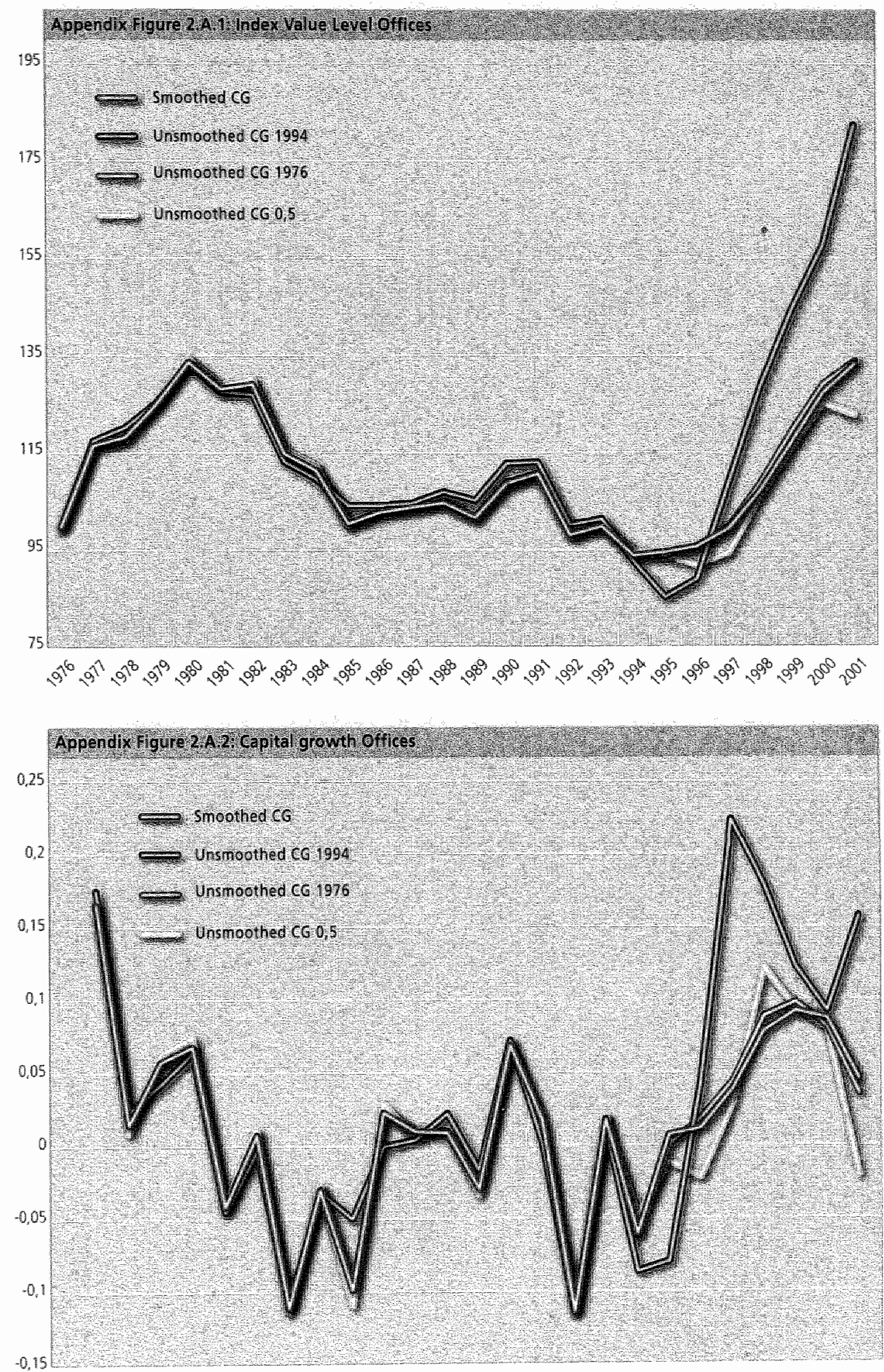

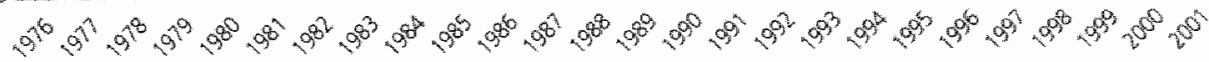




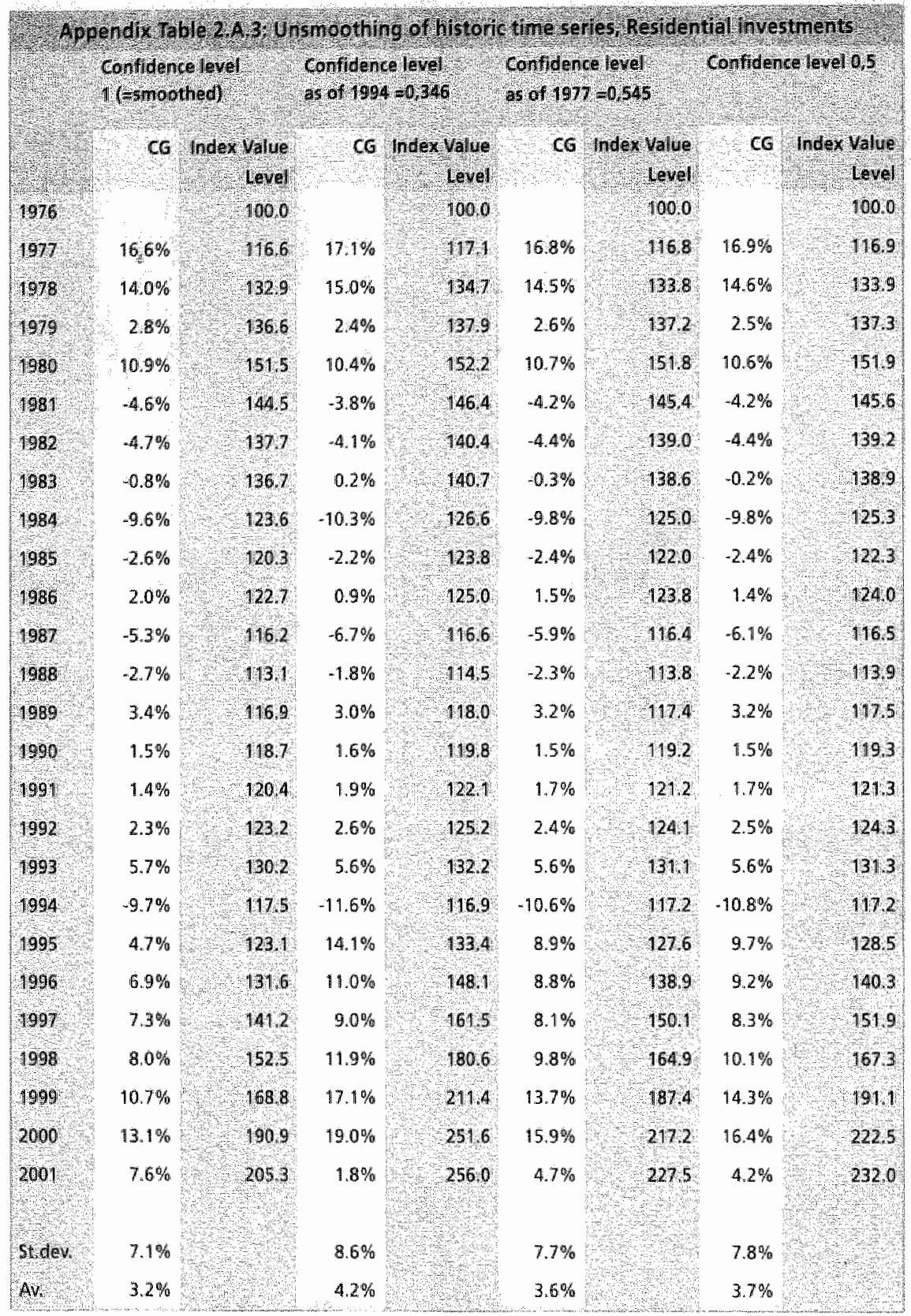




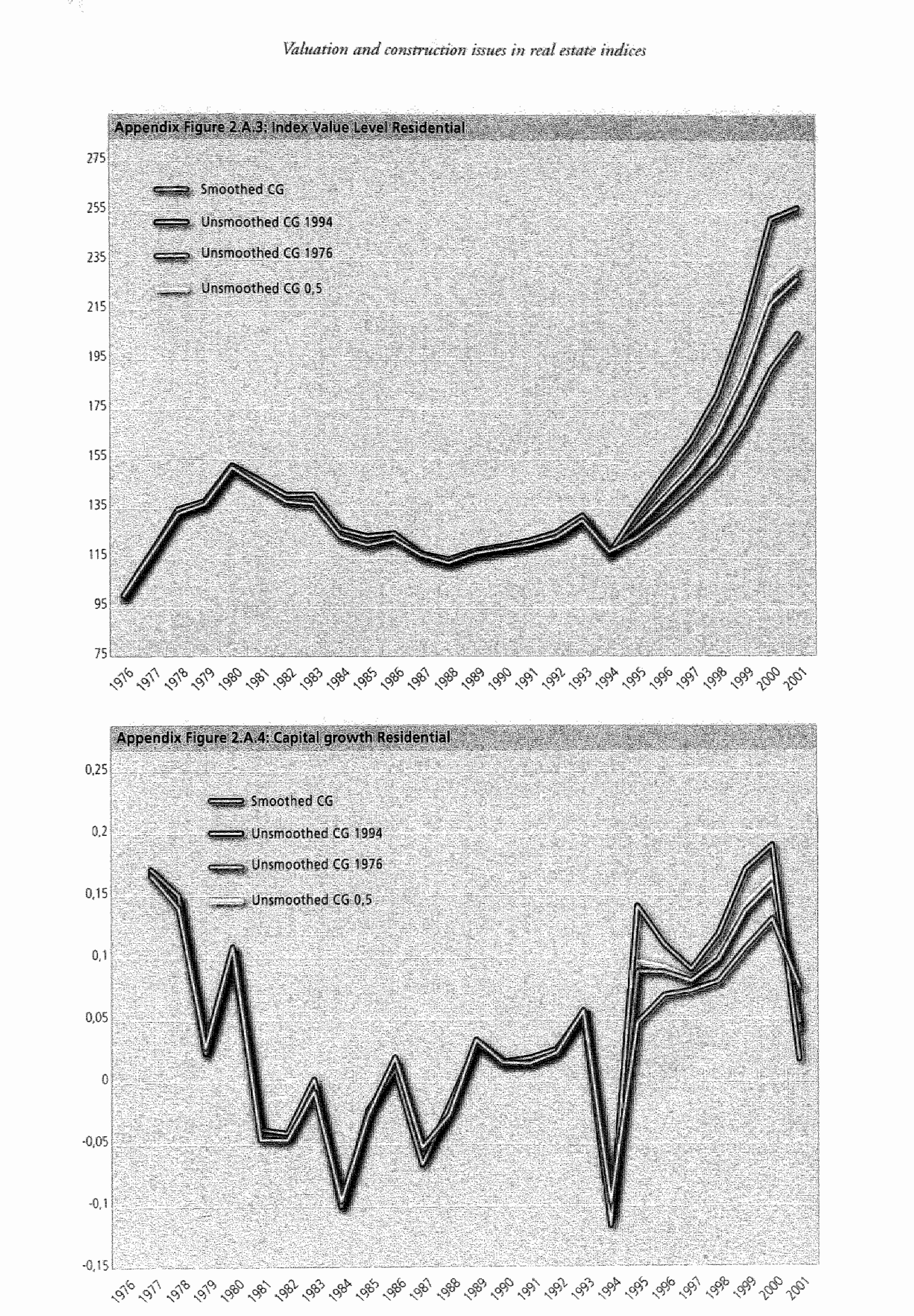




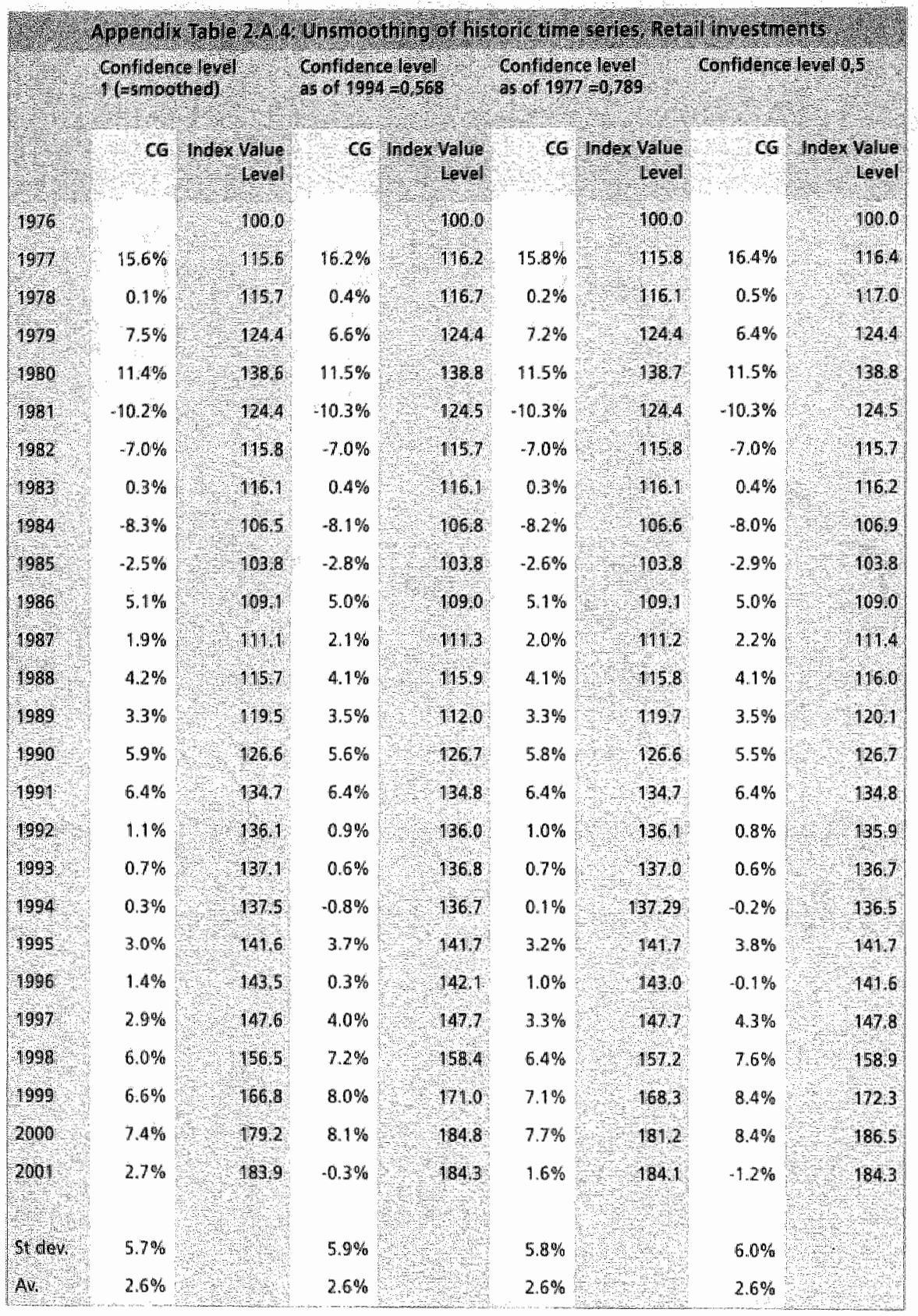




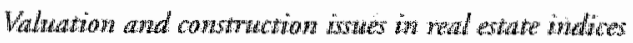

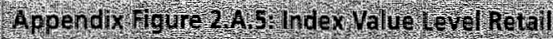

195

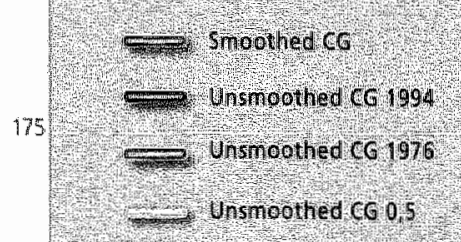

155

135

115

,

95

75

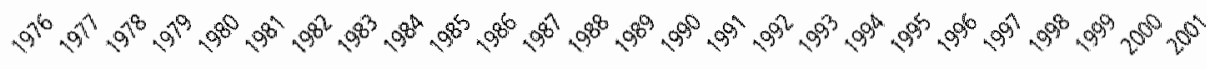

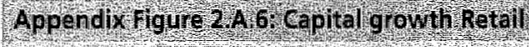

0.25

0,2

smoothed co

Whinopthed CG 1994

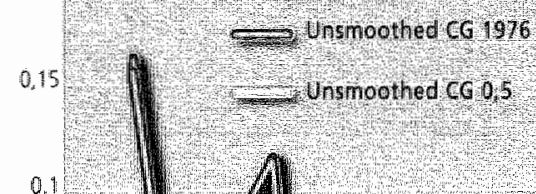

$a_{3} 9$

0,05

0

0,05

0.1

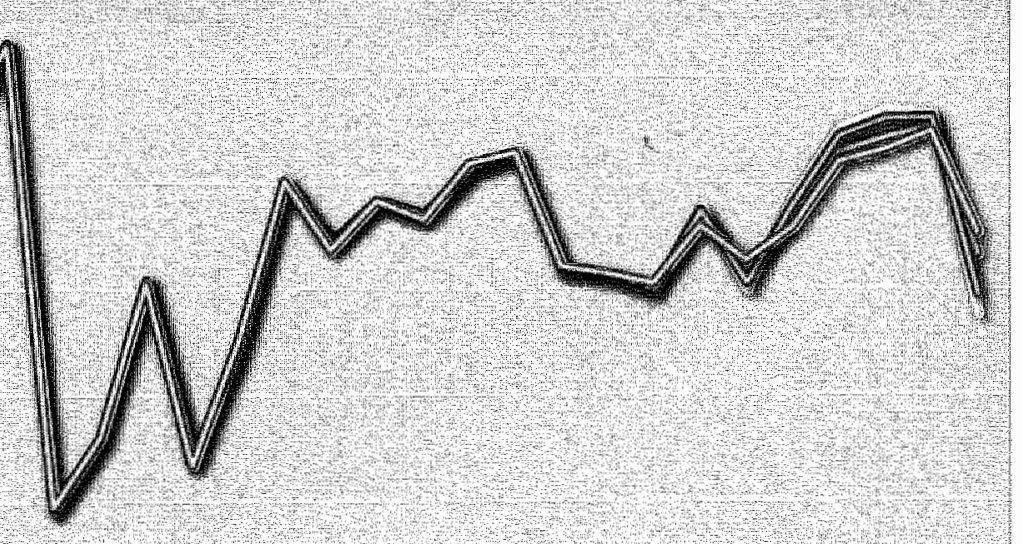

$+0,15$

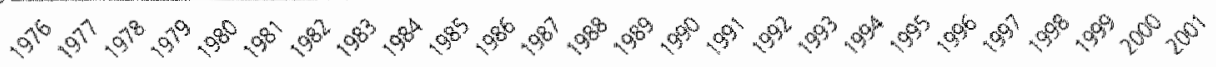

41 


\begin{tabular}{|c|c|c|c|c|c|c|}
\hline$\%$ & $\begin{array}{l}\text { Copital growth } \\
\text { Unsmoothed } \\
\text { alpha } 0,5\end{array}$ & smoothed & Income return & 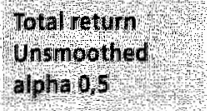 & $\begin{array}{l}\text { Smod thed } \\
\text { alpha } 1\end{array}$ & \\
\hline 1977 & $175 \%$ & $17 \%$ & $67 \%$ & $24.2 \%$ & & $24.5 \%$ \\
\hline 1978 & $98 \%$ & $9.6 \%$ & $62 \%$ & $16.0 \%$ & & $15.8 \%$ \\
\hline 1979 & $13 \%$ & $23 \%$ & $6.20 \%$ & $75 \%$ & & $8.5 \%$ \\
\hline 1980 & 899 & $83 \%$ & $5.8 \%$ & $148 \%$ & & $14.2 \%$ \\
\hline 1981 & $-6.00 \%$ & $5.9 \%$ & $6.1 \%$ & $01 \%$ & & $0.2 \%$ \\
\hline 1082 & $-19 \%$ & $1.9 \%$ & $7.1 \%$ & $51 \%$ & & $51 \%$ \\
\hline 1983 & $31 \%$ & $3.9 \%$ & $7.7 \%$ & $46 \%$ & & $3.8 \%$ \\
\hline 1984 & $-7.5 \%$ & $6,8 \%$ & $7.3 \%$ & $03 \%$ & & $0.5 \%$ \\
\hline 1985 & $-4.8 \%$ & $53 \%$ & $7.4 \%$ & $26 \%$ & & $2.1 \%$ \\
\hline 1986 & $-0.5 \%$ & $00 \%$ & $7.2 \%$ & $6,7 \%$ & & $7.2 \%$ \\
\hline 1987 & $-2.4 \%$ & $31 \%$ & $7.5 \%$ & $151 \%$ & & $4.4 \%$ \\
\hline 1988 & $0.3 \%$ & 11106 & $7.1 \%$ & $74 \%$ & & $8.2 \%$ \\
\hline 1989 & $2.1 \%$ & $0.9 \%$ & $7.1 \%$ & $928 \%$ & & $8.0 \%$ \\
\hline 1990 & $5.2 \%$ & $55 \%$ & $7.3 \%$ & $12,4 \%$ & & $12.7 \%$ \\
\hline 1991 & $1.5 \%$ & $1,6 \%$ & $7.4 \%$ & $90 \%$ & & $9.0 \%$ \\
\hline 1992 & $0.4 \%$ & $0.5 \%$ & $7.1 \%$ & $1,5 \%$ & & $3.6 \%$ \\
\hline 1993 & $1.1 \%$ & $11 \%$ & $7.1 \%$ & $82 \%$ & & $8.2 \%$ \\
\hline 1994 & $-6.0 \%$ & $50 \%$ & $7.2 \%$ & $12 \%$ & & $2.2 \%$ \\
\hline 1995 & $6.0 \%$ & $3,3 \%$ & $7.2 \%$ & $132 \%$ & & $10.5 \%$ \\
\hline 1906 & $4.8 \%$ & $45 \%$ & $6.9 \%$ & $117 \%$ & & $11.4 \%$ \\
\hline 1997 & $5.9 \%$ & $55 \%$ & $6.5 \%$ & $12.4 \%$ & & $12.0 \%$ \\
\hline 1999 & $9.3 \%$ & $74 \%$ & $6.4 \%$ & $157 \%$ & & $13.8 \%$ \\
\hline 1999 & $12.0 \%$ & $94 \%$ & $6.2 \%$ & $18.3 \%$ & & $15.7 \%$ \\
\hline 2000 & $13.4 \%$ & $112 \%$ & $5.9 \%$ & $19.3 \%$ & & $17.0 \%$ \\
\hline 2001 & $2,3 \%$ & $59 \%$ & $5.5 \%$ & $78 \%$ & & $11.4 \%$ \\
\hline
\end{tabular}




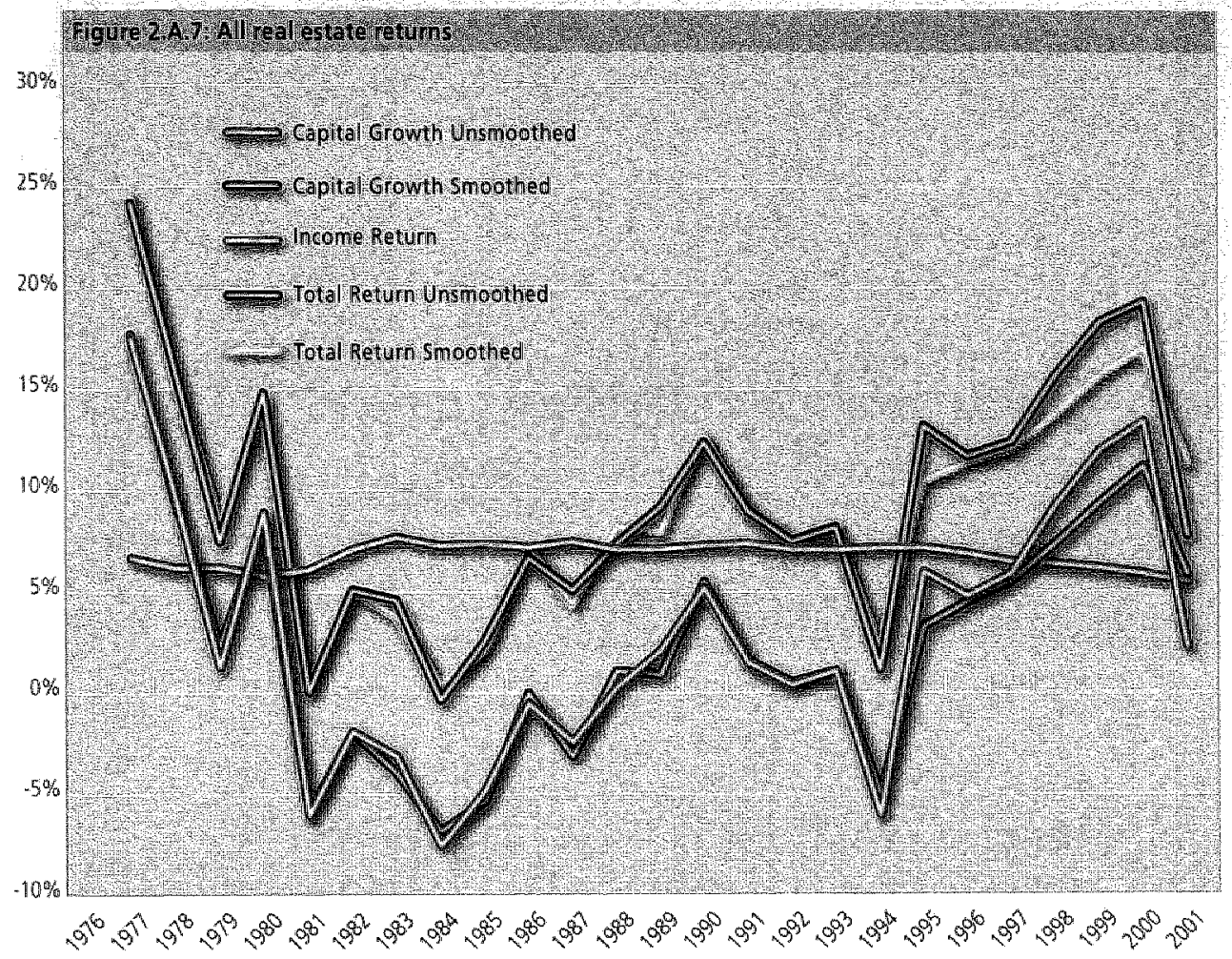




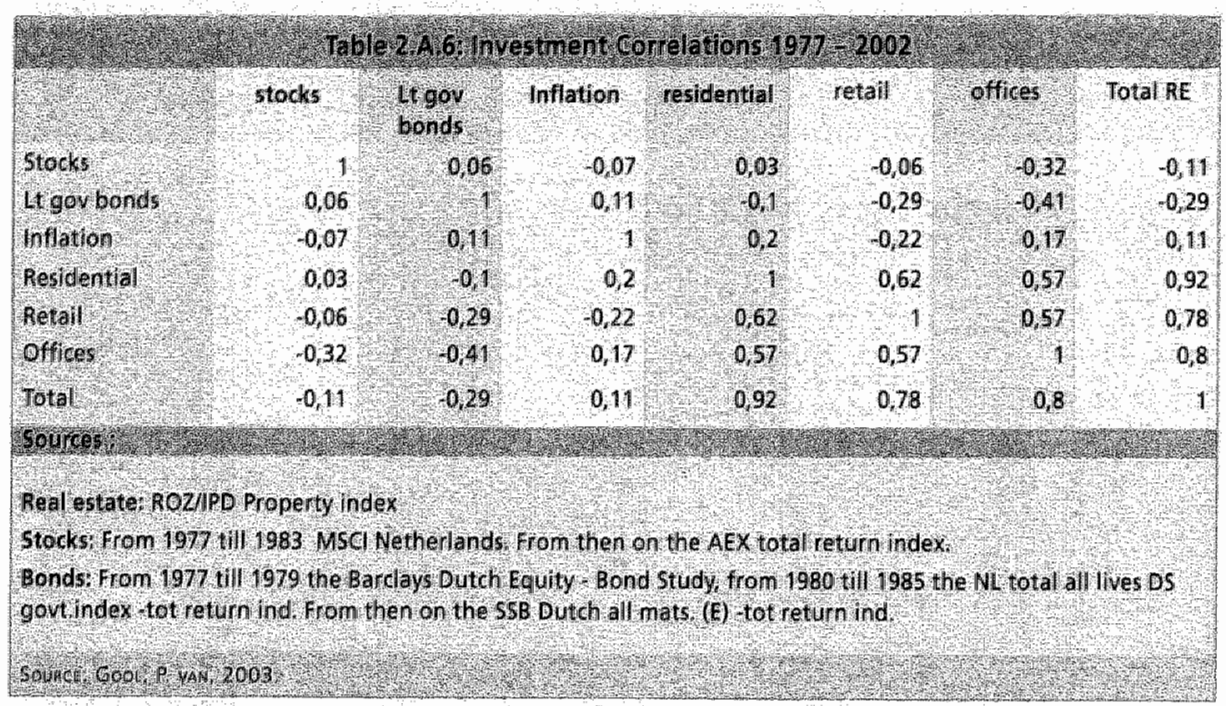




\section{Walwation and constrwation assues in weal estate nalios}

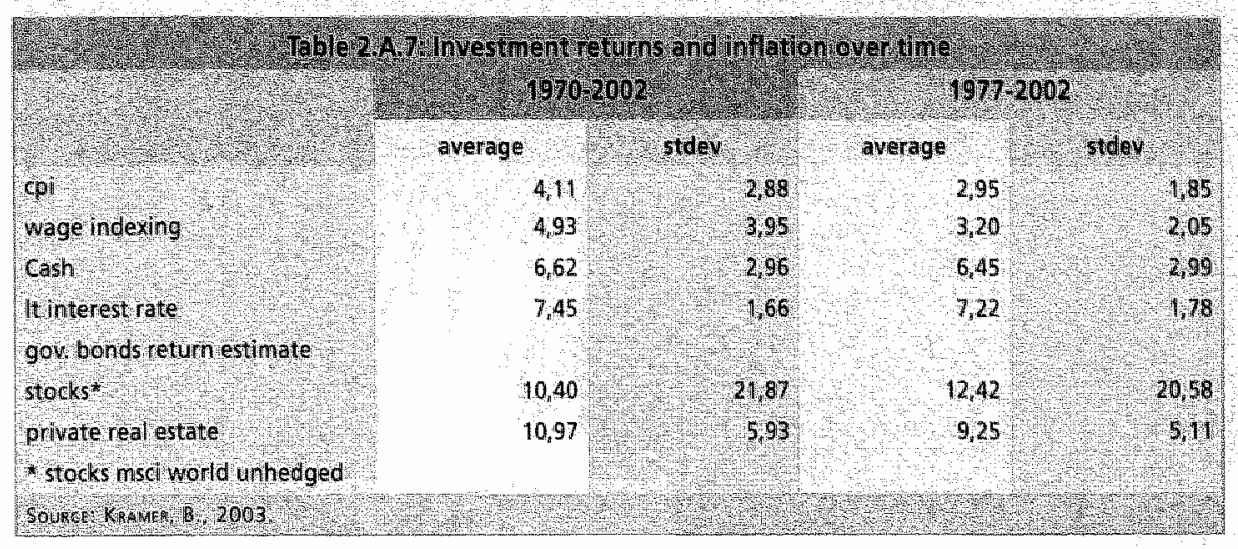




\section{CHAPTER 3}

\section{Development of historic time series of office rents in the Netherlands'}

\subsection{Introduction}

$\mathrm{E}$

I ver since Real Estate became an asset class for institurional investors, there has been a demand for statistically relevant long rime series, not only with regard to the returns but also with regard to rental levels. This chapter describes the movement of office rental levels in the Netherlands between 1977 and 2003. For institurional investors, such time series are of the utmost importance as one of the parameters for forecasting furure office rental levels. This is the first time that a scientific survey has been carried out in the Netherlands on the development of oflce rental levels over time, based on an extensive databank. The survey begins with the review of previous literature. The common element in most of the literature is the supply and demand cycle for offices. Cyclical patterns and their infuences on construction and take-up levels are analysed. Furthermore, the drivers behind those cyclical patterns have been reviewed. In the data section, information from VGM (VastGoedMarkt) on the period berween 1977 and 1989 has been used. VGM publishes all transactions they are aware of, on a monthly basis. All the data was available only in written format, and more than 4,000 office rent transactions had to be digitalised. From 1989 through to 2002, the DTZ databank was used. The results are discussed thereafter, showing the differences between the cities of Amsterdam, Rotterdam, The Hague and Utrecht and the results are also placed in the perspective of the development of inflation over the same period.

Due to the well known specific characteristics of real estate in the past, such as lack of transparency, infrequent reporting of transactions and hidden factors like incentives, it has been and will be difficult to create and analyse longer time series for office rents,

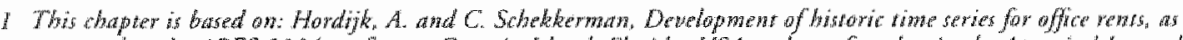

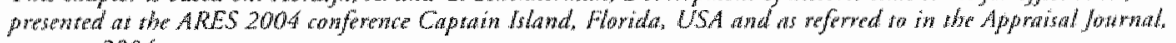
awwm 2004. 
especially with regard to effective rents. To establish the right level of qualitative and quantitative information, it is therefore not only important to collect the data but also to pay attention to the story behind the figures and marker circumstances in the past. Some evidence has been recovered, especially in the section on incentives.

The created time series for office rental levels was examined and pur into an international perspective by comparing the results with similar research in the USA and the UK, not only for the countries as a whole, but also for Amsterdam, London City and Manhattan New York.

Office rental levels are assumed to have a close connection with the economy, as the demand for offices is assumed to be closely connected to economic growth, especially in economies which are service industry oriented. An analysis of this relationship is included in this chapter.

\subsection{Literature}

The cyclical pattern in the supply and demand of offices has fascinated the professionals and the researchers in the industry. Within the scope of this chapter it would be impossible to discuss all the articles which have been published. Only a representative selection of articles is discussed here, to give a cross-section of the different views on cyclical patterns.

Extensive research was conducted by IPD (1994), together with the university of Aberdeen, on behalf of the RICS in the UK. They came to the following conclusions: the UK property industry shows a recurrent cycle, which cannor be described definitively by statistical techniques. Secondly, the property cycle is the compounded result of cyclical influences from the wider economy and lastly, the critical linkages between property and economic cycles can be captured in simple models which are intuitively plausible and statistically sound.

Hakfoort (1994) looked at the relationship between macro-economic facrors such as GDP and employment in the office sector, and the vacancy rate in offices in the Netherlands, berween 1974 and 1992, but did not find a direct relationship. He also addresses the difference between contract rents and effective rents. Concessions such as rent-free periods and tenant improvements may well be cyclical; omitting them effecrively means smoothing of the series. Wheaton and Torto (1992) and a number of papers by Fisher and Webb also show that this is very relevant in the office markets they researched.

Mcgough and Tsolacos (1995) concentrated on the conventional factors (employment, rents etc) of business cycles and they compare the property aggregate time series with Auctuations in aggregate business output. They demonstrate the pro-cyclicality of the demand side variables such as GDP, manufacturing and business output in the office and the industrial sector. As far as rents are concerned, the outcome is puzzling: they appear pro-cyclical and they are coincident with the office cycle. 
More recently, Pugh and Dehesh (2001) have distinguished between endogenous and exogenous real estate cycles. Endogenous cycles occur because of the long lead time between commissioning a project and completing the building work. Exogenous cycles are caused by the external transmission mechanisms which link the macroeconomy and real estate. They studied periods of asset inflation and the magnitude of this. They conclude that the Scandinavian countries, the UK and Japan were all faced with serious magnitudes of asset inflation of land value between 1995 and 1989.

Béchade (2002) compared the office market cycles in Paris, London, Munich and Frankfurt and found different patterns: in Paris and London the office market slowed down or stabilized in 2001, while Frankfurt and Munich were faced with overbuilding and oversupply. His conclusion was that one could benefit from riding the cycle in different countries.

The general conclusion is that all researchers identify cyclical movements in real estate as well as in the economy but they vary in assessing the consequences and the relationship berween the rwo. Almost all researchers avoid forecasting cyclical movements based on historic cyclical patterns.

\subsection{Methodology}

Data was collected and non value weighted average market rents were calculated. The choice between weighted or non weighted average office rents is debatable. Non value weighted calculations will overstate the rental income since larger premises will be renred out at lower rental levels than smaller ones. On the other hand, value weighted calculations have the disadvantage that one very large transaction could distort the average rental value excessively, especially when only a small number of observarions is available.

As well as average market rents for the office market as a whole, average market rents for the main cities of Amsterdam, Rotrerdam, The Hague and Utrechr were calculated. Statistical tests were complicated due to the very few observations at the beginning. Therefore, it was decided to calculate standard deviations for the period between 1977 and 1989 for the Netherlands as a whole. For the main cities, standard deviations from 1985 through 1989 were calculated. Standard deviarions for the period from 1990 through 2002 have not been calculated because only the average non value weighted rental levels are available due to DTZ's confidentiality rules.

The rime series for office rents are also put into perspective by inserting the CPI over the same period. The average market rent is than also compared to the direct and indirect office returns over the same period, as calculated by the ROZ/IPD property index.

\subsection{Data}

The main source of the historic data is VastGoedMarkt (VGM) and in particular, former editor-in-chief Dirk Rompelman. He started the VGM magazine in 1973 and collected commercial real estate transaction data from then onward. The number of observations at the beginning were very small for two reasons. First, he had to built his network to obrain the rransaction data from original sources. At that time, the market 
was very opaque and the major players were reluctant to provide information about individual transactions when they did not know what was going to happen with that information. Therefore obtaining their support was essential.

Secondly, commercial real estate as an asset class for institutional investors was more or less non-existent at the end of the 1970s and beginning of the 1980s. If pension funds and insurance companies invested in real estate at that time, they invested mostly in residential real estate, stimulated by government grants, adjusting the gross returns to $1 \%$-point above the return on government bonds. Due to the very small number of observations when VGM was launched in 1973, 1977 has been taken as the starting year for this survey. This is consistent with the previous study on 25 year returns on real estate in the Netherlands described in chapter 2, which also starts in 1977.

During the 1970 s and 1980 s, VGM was virtually the only source with regard to transaction information, because the large firms like JLL, CBRE, C\&WH\&B, DTZ and most local brokerage firms did not show much interest in the systematic assembly of transaction clata. Real estate market research was in its infancy in the Netherlands, and was carried our mainly in a descriptive form rather than in a quantitative form. Appreciation of systematic data compilation emerged at the end of the 1980 s when, due to market circumstances, the number of observations increased significantly and also software for creating darabanks became much easier to use than previously. From that time onwards, most brokerage firms started databanks for assembling market/ transaction data and produced more solid market reports, based on this data. Table 3.1 shows the increase in the number of observations between 1977 and 1989. The total number of observations between 1977 and 1989 is 3,529, but from the mid$1980 \mathrm{~s}$, the numbers became statistically significant, with over 30 observations per city per year, and gradually increased.

\begin{tabular}{|c|c|c|c|c|c|c|}
\hline Wrats & Amsterdam & The Hague & Rotterdain & utreecht & Other cities & Iotal \\
\hline 1977 & 28 & 10 & 17 & 1 & 27 & 83 \\
\hline 1978 & 29 & 11 & 25 & 3 & 27 & 95 \\
\hline 1979 & 19 & 12 & 18 & 3 & 32 & 84 \\
\hline 1980 & 29 & 25 & 24 & 7 & 63 & 148 \\
\hline 1981 & 21 & 12 & 23 & 10 & 84 & 150 \\
\hline 1982 & 19 & 18 & 27 & 6 & 62 & 132 \\
\hline 1983 & 22 & 27 & 21 & 12 & 65 & 147 \\
\hline 1984 & 33: & 37 & 30 & 16 & 74 & 190 \\
\hline 1985 & 34 & 33 & 44 & 31 & 125 & 267 \\
\hline 1986 & 85 & 42 & 45 & 57 & 174 & 403 \\
\hline 1987 & 93 & 50 & 69 & 57 & 235 & 504 \\
\hline 1988 & 95 & 53 & 66 & 62 & 343 & 619 \\
\hline 1989 & 137 & 36 & 93 & 52 & 389 & 707 \\
\hline Total & 644 & 366 & 502 & 317 & 1700 & 3529 \\
\hline
\end{tabular}


The VGM information from 1977 to 1989 was assembled and combined with databank information from DTZ. The databank from the DTZ Research Department was used because it is estimated to have a market coverage of around $40 \%$ of office transactions in the Netherlands. Another reason for using the DTZ data is that it provides country-wide coverage, while the other firms concentrated mainlly on the four larger ciries, or had done so in the past.

The next step was the calculation of the average rent price. The transactions show a variety of size in square meters. It was decided not to create a value weighted average for two reasons. First, DTZ calculates the average rent per square meter on a non value weighred basis. Therefore, to make the connection berween the two time series possible it is necessary to apply the same logic. The second reason is that in the previous chapter on historical returns, the returns were also calculated on a non value weighted basis. The effect of using non value weighted transactions will in most cases be that the time series will reflect much more volatility than the value weighted ones.

The standard deviation of the observed office rent transactions was calculared, resulting in Table 3.2 and Figure 3.1. The standard deviation can only be calculated reliably if sufficient observations are available. Figure 3.1 shows the standard deviation for the four large Dutch cities from 1984, due to the lack of sufficient data in earlier years. The data for the other ciries was sufficient to perform reliable calculations from 1977.

\begin{tabular}{|c|c|c|c|c|c|}
\hline (4) & Amsterdam & The Hague & Rotterdam & utredst & Other cities \\
\hline 1977 & $15.7 \%$ & $129 \%$ & $15.1 \%$ & & $16.7 \%$ \\
\hline 1978 & $28.5 \%$ & $131 \%$ & $13.7 \%$ & $36.9 \%$ & $16.1 \%$ \\
\hline 1979 & $31.2 \%$ & $15.5 \%$ & $13.6 \%$ & $23 \%$ & $22.5 \%$ \\
\hline 1980 & $19.7 \%$ & $205 \%$ & $13.8 \%$ & $179 \%$ & $17.0 \%$ \\
\hline 1981 & $19.6 \%$ & $274 \%$ & $13.3 \%$ & 19,90 & $19.5 \%$ \\
\hline 1982 & $24.4 \%$ & $267 \%$ & $24.8 \%$ & $173 \%$ & $17.1 \%$ \\
\hline 1983 & $17.6 \%$ & $248 \%$ & $16.0 \%$ & $22,7 \%$ & $20.6 \%$ \\
\hline 1984 & $20.6 \%$ & $2710 \%$ & $21.7 \%$ & $35,3 \%$ & $22.7 \%$ \\
\hline 1985 & $17.2 \%$ & $22,3 \%$ & $20.3 \%$ & $24.6 \%$ & $21.2 \%$ \\
\hline 1986 & $18.5 \%$ & $262 \%$ & $22.4 \%$ & $157 \%$ & $21.7 \%$ \\
\hline 1987 & $18.3 \%$ & $280 \%$ & $18.8 \%$ & 2270 & $21.7 \%$ \\
\hline 1988 & $25.8 \%$ & $2111 \%$ & $23.2 \%$ & $22.6 \%$ & $19.1 \%$ \\
\hline 1989 & $25.5 \%$ & $21,9 \%$ & $18.0 \%$ & $16.6 \%$ & $19.9 \%$ \\
\hline
\end{tabular}

The standard deviations in Figure 3.1 on average show a variation of between $15 \%$ and $30 \%$. Standard deviations which are that high reflect volatile office market rent over 1977 and 1989. This is partially due to the fact that at the beginning of the time series, the commercial real estate market was almost non-existent. 


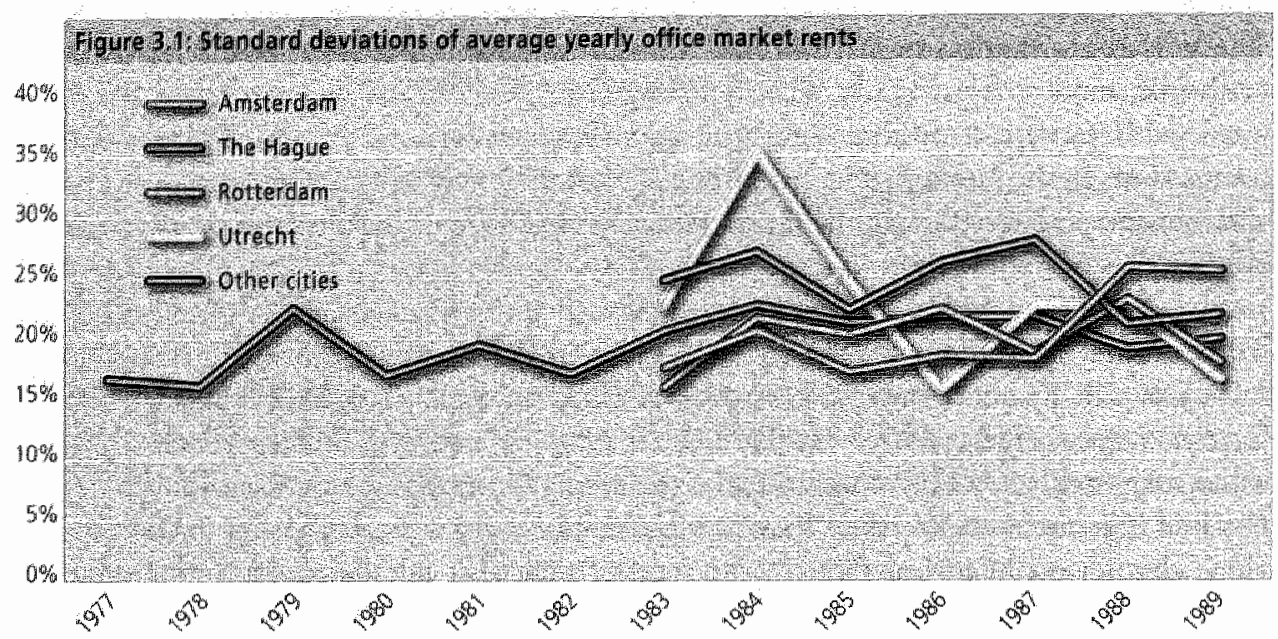

\subsection{Results}

Differences in office rental values over time were expected between the main cities and other areas in the Netherlands, and berween the four main cities. Therefore calculations of office market rental growth in Amsterdam, The Hague, Rotterdam, Utrecht and other cities were made. The results are shown in Table 3.3.

Presented here are the average office rental levels for the four main cities of Amsterdam, The Hague, Rotterdam and Utrecht and for the other cities in the Nerherlands as a whole. One would expect the time series to be quite volatile at the beginning, reflecting the small numbers of observations in the early years. However, this is not the case. An explanation might be that in the Netherlands, office rents at the beginning were quite flat across the country. From the 'éminence grise' of the real estate industry it was found that there was not much appreciation for differences in location compared with what is experienced today. Next, the index of the inflation rate was inserted and compared wirh the rental increase over 25 years.

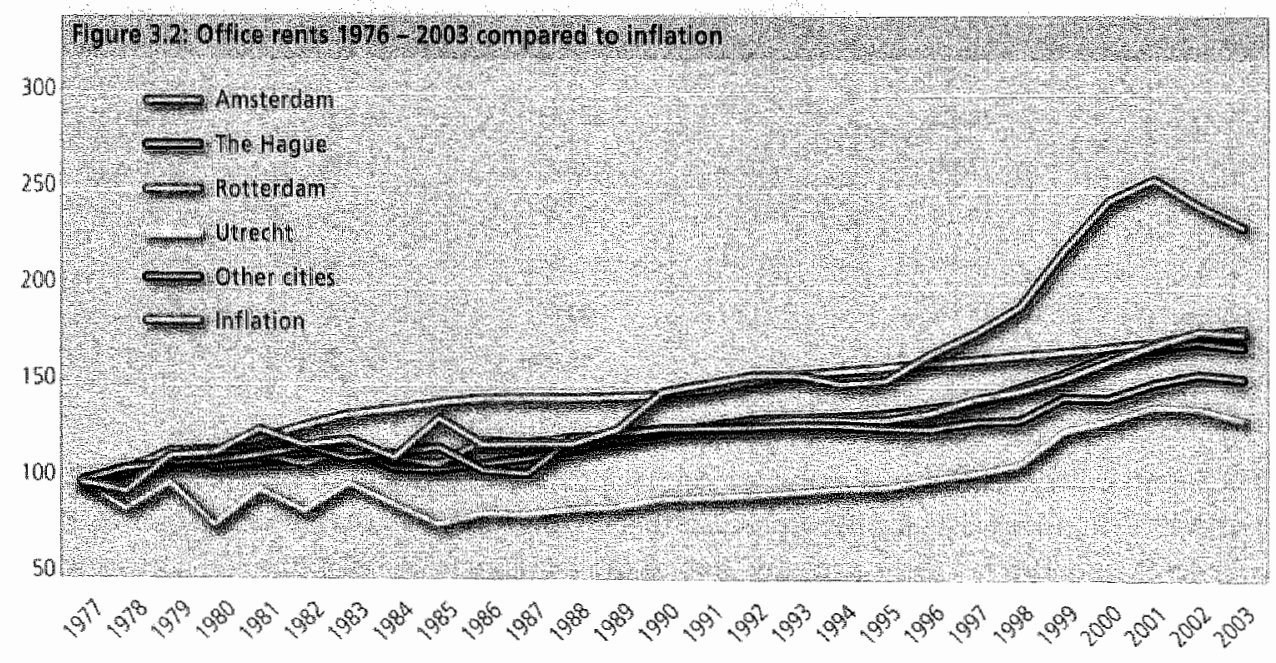


The outcome is very disapponting; only Ansterdam shows a rental ncrease which kept up with the inflation rate over 25 years, while the orther cities do not In the case of Urrecht, which performed the worst, there is an explanation for this. In the mid1970 s, the centre of Utrecht in the neighbourhood of the railway station was completely demolished and reconstructed. This created a new area with modern offices at a higher rent, just at the moment that the time series starts. Therefore the increase ower time in Utrecht is low.

Another time series was created, starting in 1986 for two reasons first, the number of observations became statistically significant from that year. Secondly, following very high inflation rates in the 1970 s, the inflation rate dropped significantly in the mid1980s. The results of this analysis are shown in Figure 3.3.

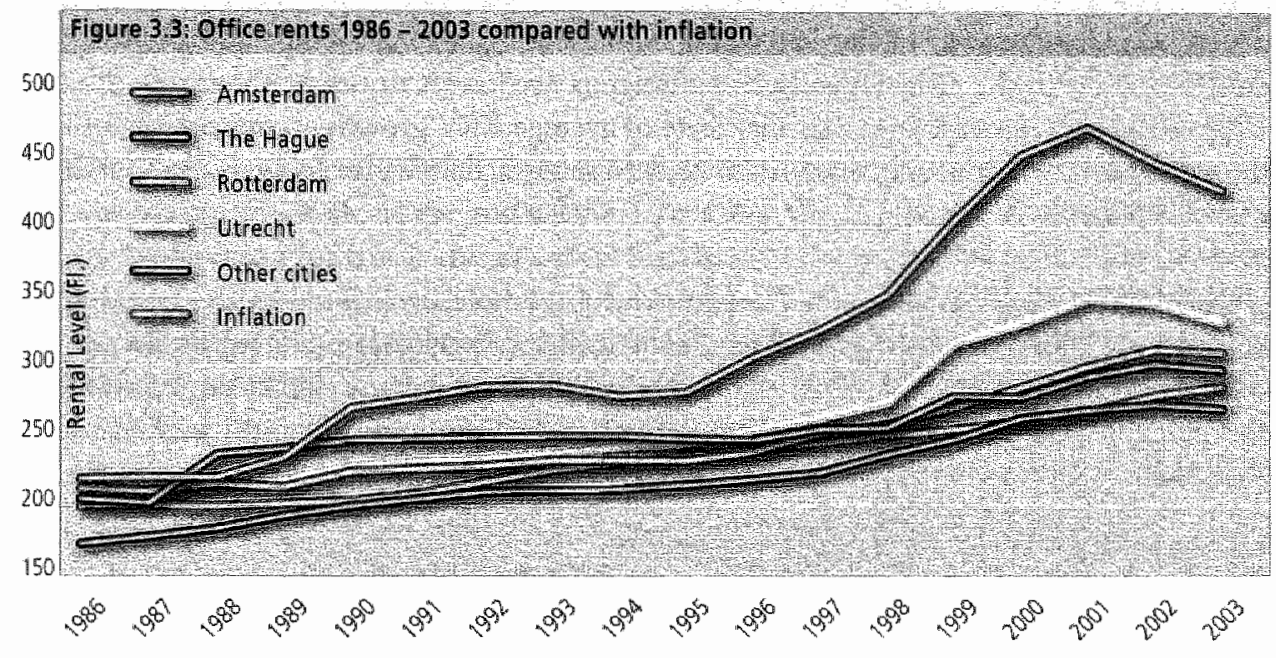

The pattern is different now, because the volatility in the early years at the beginning of the time series has disappeared. The conclusion is also that as the inflation rate is much more benign, all office rents in Rotrerdam, The Hague, Utrecht and wie country as a whole now just keep up with the inflation rate as well.

\subsection{Dutch office rents time series in an international perspective}

Unfortunately, longer time series in other countries are scarce. Only the UK and the USA have developed time series over a similar period of time. For the UK, IPD data was used, which is available from the beginning of the 1990s. For the USA, the Torto Wheaton Research rime series was used. Torto Wheaton Research had already developed time series at the end of the $1980 \mathrm{~s}$, which were published in the AREUEA Journals. To keep it simple, the rental growth figures of the country as a whole are shown for each country, as well as those for each of the main office areas of Amsterdam, London City and Manhattan, New York. The average Estimated Rental Value (ERV) growth and the standard deviation of each of the series were calculated, as shown in Table 3.3. 


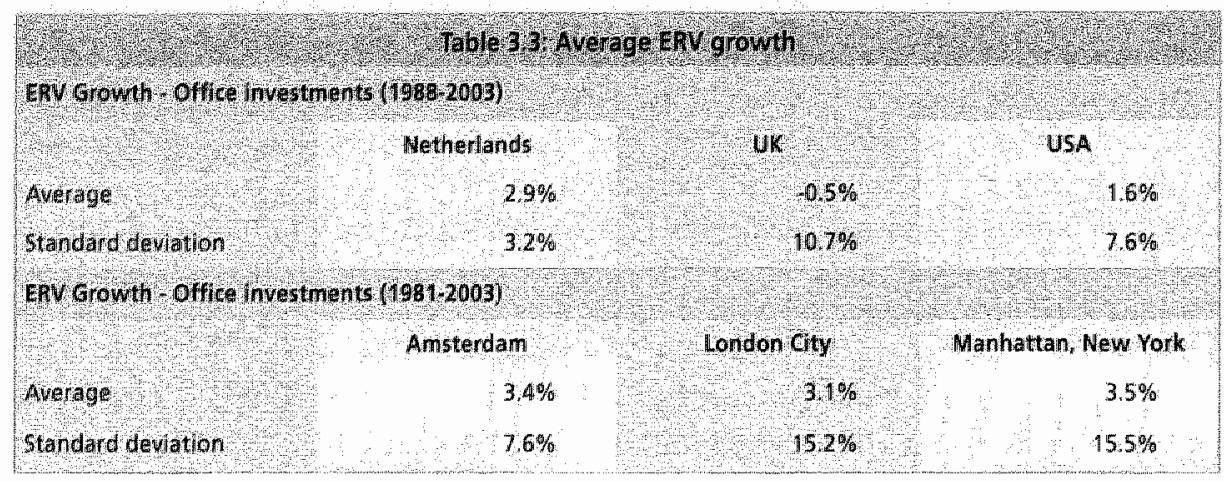

As one would expect, the awerage of the countries as a whole as well as the standard deviation is much lower in the 1988-2003 time series than the average and the standard deviation in the cities. Also both parameters are lowest in the Netherlands. The 1981-2003 time series shows a similar level of average ERV growth ar around 3\% but the standard deviations in Amsterdam and Manhattan ere twice as high compared with the country as a whole.

Unfortunately, the time series for the countries as a whole are limited by the fact that only from 1988 were all Metropolitan Statistical Areas (MSAs) included in the allcountry figures for the USA. Therefore the results are shown from 1988 both for the countries as a whole and for the cities of Amsterdam, London Ciry and Manhattan, New York.
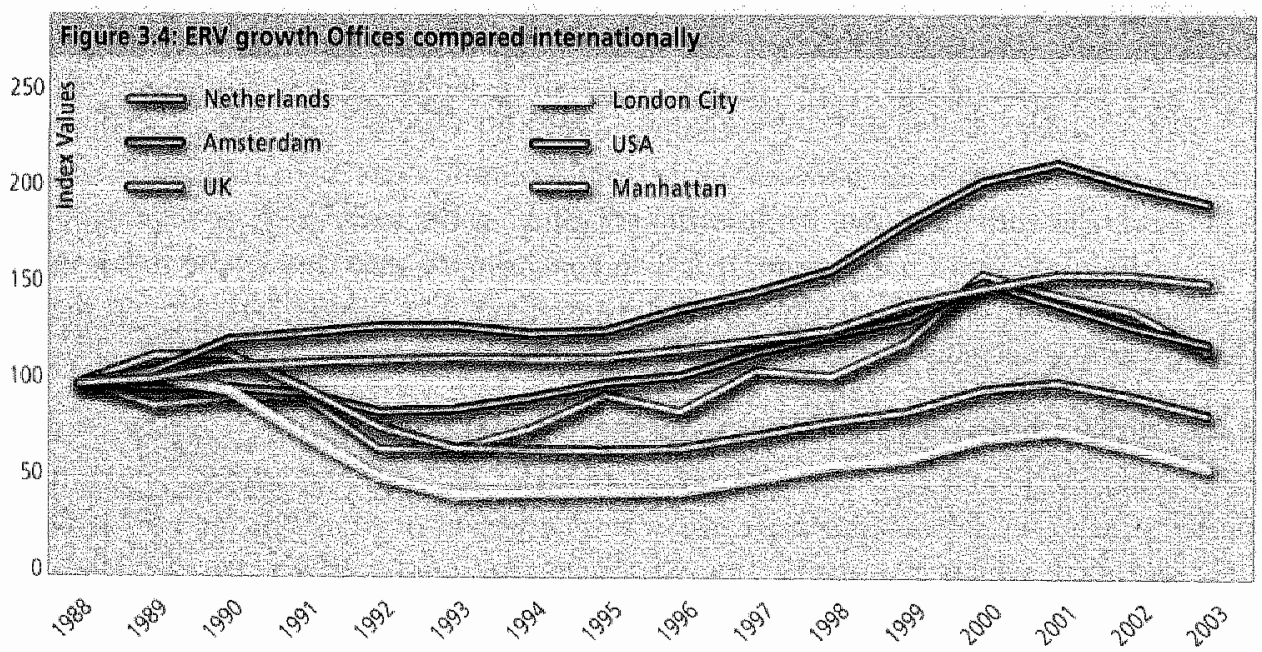

Ir is interesting to see the trends of the $\mathbb{E R V}$ in each of the countries. The Dutch office market shows a steeper increase than the USA, while the UK shows a decrease. The trends become even more striking if one looks at the office locations in Amsterdam, London City and Manhattan. Fortunately there are longer time series for these cities, from 1981 onwards. 


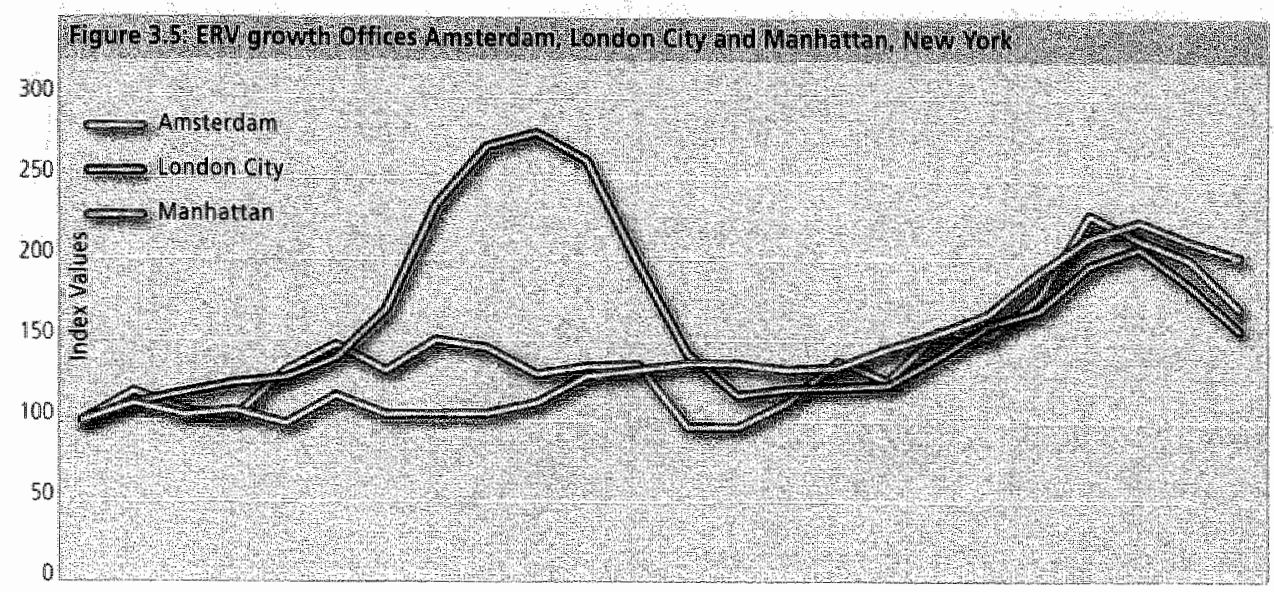

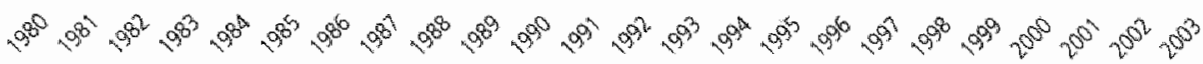

London City in particular shows a wild pattern at the end of the $1980 \mathrm{~s}$ which is not repeated in the cycle at the end of the 1990 s and the beginning of the 21 st century. An explanation for this is the so-called Big Bang in the mid-1980s when the financial markets in London were liberalised, which meant that foreign banks were allowed to participate in stock market trading in London. This boosted office rents, because there was hardly any space available at that time due to development restrictions in London City. The Docklands (Canary Wharf) were being developed at the time, atrracting major financial institutions from the City. London Ciry then decided to relax its development restrictions and development in the City boomed. As is widely known, Canary Wharf ran into difficulties because the financial institutions which had showed an interest in moving to the Docklands decided almost overnight to stay in the Ciry. Within a couple of years, London as a whole had an oversupply which had never been seen before, with disastrous effects on office rents: rents dropped from GBP $70 / \mathrm{sq}$. ft. at the peak to GBP 26/sq. ft. plus incentives just a few years later This effect is shown in Figure 3.5. The cycle at the end of the nineties is far less volatile; major players in the London office market still seem to remember what happened in: the $1980 \mathrm{~s}$.

\subsection{Office markets' relation to the economy: rents, returns and cyclical patterns}

As stated in the previous chapter on the 25 year office return time series, the office market is seen as the real estate segment with the most pronounced cycle, since office employment growth and economic growth are assumed to be closely linked (Figure 3.6). This conclusion is confirmed by the development of the ratio of gross absorption to the sum of vacant, constructed and sublet space (demand/supply ratio). As a third check, alongside economic growth and the demand/supply rario, this chart also shows stock-weighted Dutch office market returns from city returns prowided by Jones Lang LaSalle. 


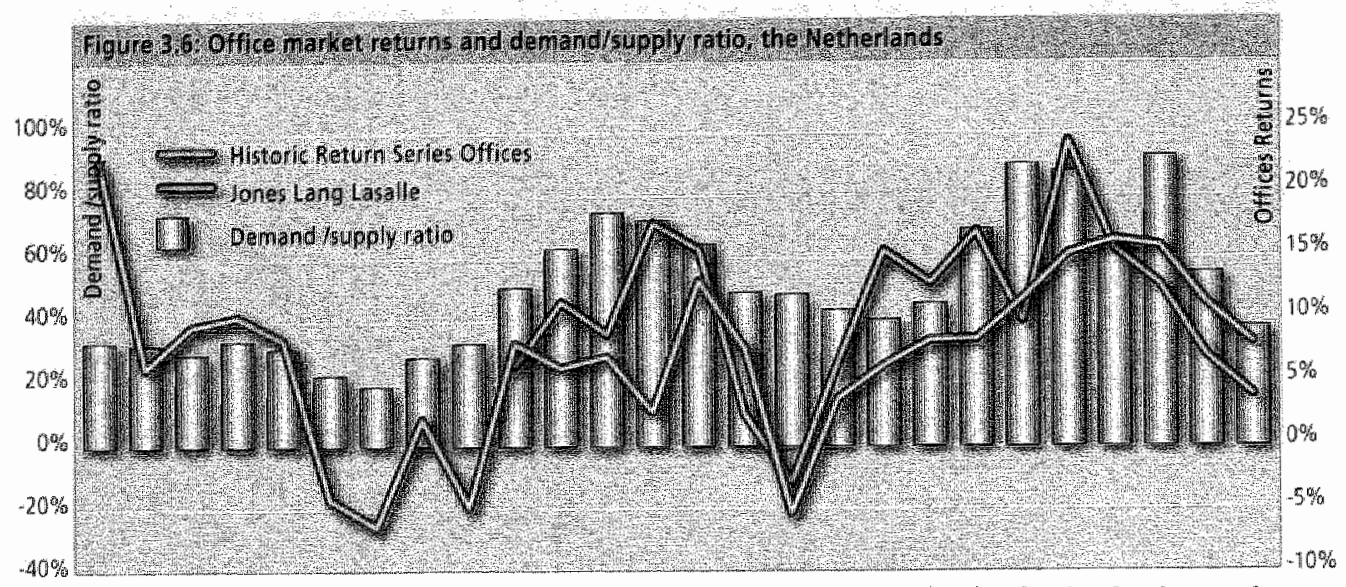

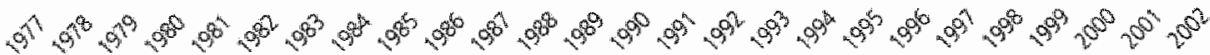

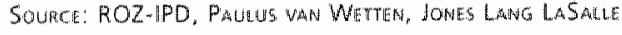

All three graphical tests confirm that the trend in the historic office series looks reliable and is cyclical. Is this also the case with office rental values? To analyse this, the office rental value graphs for the Netherlands were inserted.

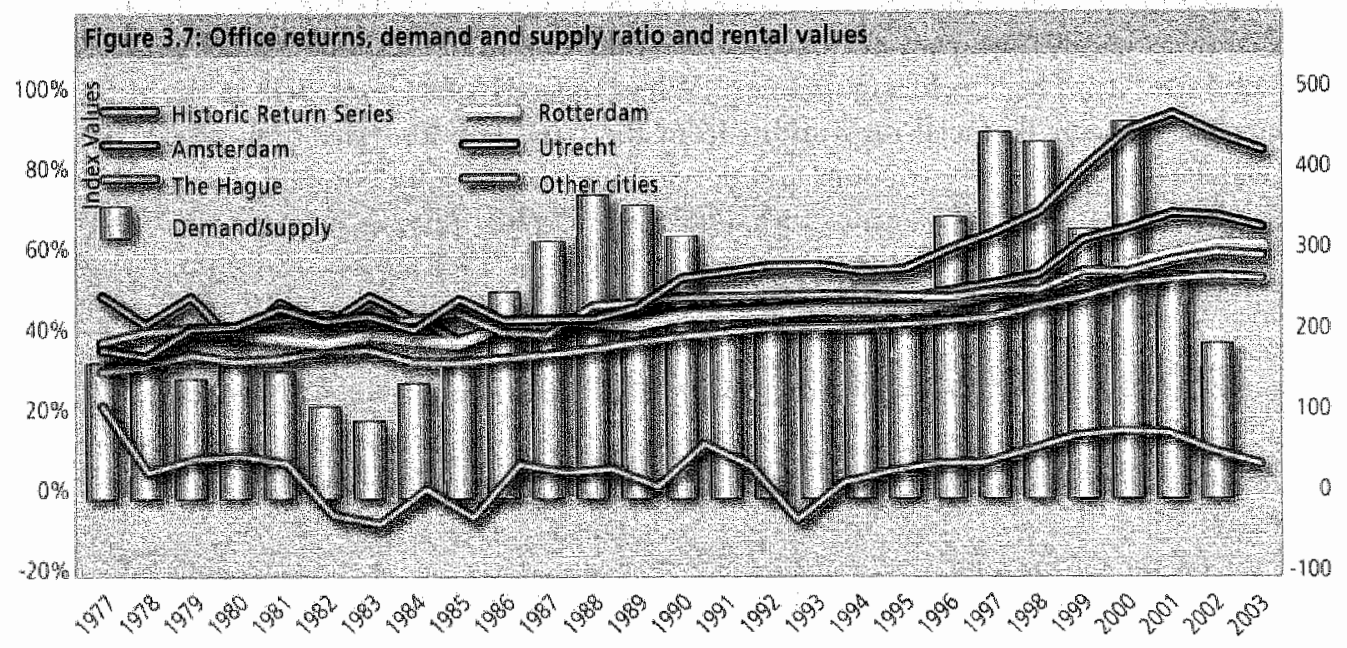

The results are astonishing; office rental values don't seem to respond to the supply and demand rarios too well. A first explanation could be that both time series, the office returns and the office rental values, suffer in the beginning from small samples. As one can see, volatility in the office rental values increases somewhar in later years when there were larger samples. A second explanation might stem from the limited knowledge at that time about office cycles and the like, leading to overestimating of future rental values. 
A thard explanation might be found in the negative effects of the high inflation tates at the end of the 1970 s. That could easily have led to a common feeling that construction costs would always keep in step with inflation, which they have not always done. VastGoedMarkt (March 1994) analyses show that between 1992 and 1994 , construction costs went down while inflation was still going up, leading to a net difference in construction costs over that period of more than $15 \%$.

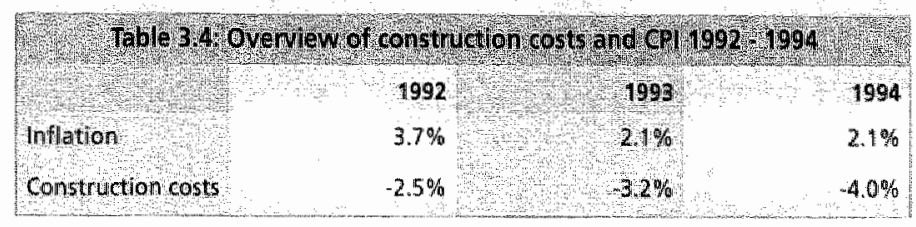

SOURCE: VastGordMaRk. March 1994

Examining the results from another angle, it looks like if the pattern of the historic office rents is similar to the demand and supply ratio, but smoothed and lagged. Smoothed because the peeks and troughs are smaller than in the demand/supply ratio's. Lagged, because the troughs and peaks seem to occur two to three years later: than the demand and supply ratio's. To prove that we have calculated the correlations between the demand and supply ratio and the historic office rents in Amsterdam, Rotterdam, the Hague, Utrecht and other cities. In order to get a clear picture of the lagging effect, correlations have been calculated without lag and with 1,2,3 and 4 years lag. The results are shown in table 3.5 and figure 3.8 .

\begin{tabular}{|c|c|c|c|c|c|}
\hline lag in years & 0 & 1 & 2 & 3 & 4 \\
\hline Returnsenles offices & 0,46 & 0,60 & 0,50 & 0,38 & 0,22 \\
\hline Offices Amsterdam & 0.50 & 0,69 & 0,78 & 0,78 & 0,69 \\
\hline Offices the trague & 0.46 & 0,70 & 0.84 & 0,82 & 0,78 \\
\hline Doffices Botterdam & 0.53 & 0,70 & 0,80 & 0,75 & 0,68 \\
\hline offes utrecht & 0,33 & 0,58 & 0,71 & 072 & 0,61 \\
\hline Offlices owher cities $M$ L & 0.53 & 0,71 & 0,82 & 0,80 & 0,72 \\
\hline
\end{tabular}




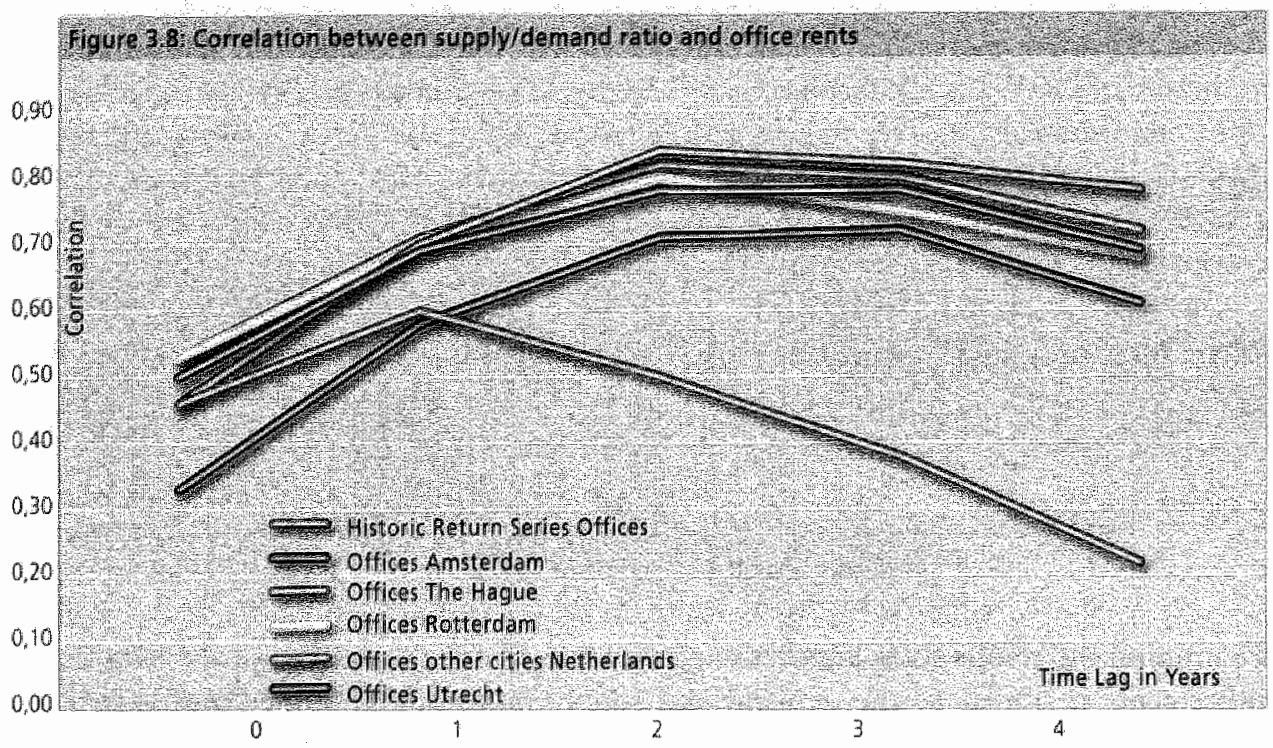

The correlations between the demand and supply ratio and historic office rents with a lag of 2 and 3 years are the highest in almost all of the office rent series. The correlation between the demand and supply ratio and the historic office returns is not very high and is the highest with one year lag.

As far as the smoothing is concerned, an explanation might be found in effective rents (market rent net of incentives). The effects of incentives in a depressed office market might be quite marked. What impact do incentives have on the transaction prices and is it possible to trace the effects accurately? This issue needs an explanation. As in other countries, when the office market in the Netherlands becomes depressed, incentives will be given to attract tenants. The incentives are mostly two fold: a rent-free period and inwestment by the landlord in voids like partition walls, carpets, kitchen etc. The rent-free period is more atractive for the owner than an effective lower rent, since the rental increase, which in the Netherlands is based on the CPI, will be calculated over the higher contract tent, which means more cash flow during the term of the contract. The problem is that most landlords are reluctant to supply information about the incentives which have been given in a specific transaction, which means that data will only become available via information from brokers about the average level of the incentives at a particular point in time. VGM has made corrections for incentives during the period in which oflice markets were depressed, as in the late $1970 \mathrm{~s}$ and the beginning of the 1980 s.

The first time incentives were used in the Nerherlands was at the beginning of the 1980 s. A major project developer lured tenants away from their existing offices to brand-new offices at far lower rents than their contract rents, offering to pay the tenant improvements and even to take over part of the financial obligations of their existing rental contracts. In percentage terms, this could be as high as around $30 \%$. The second time incentives came up were at the beginning of the 1990 s. Incentives at that time were $15 \%$ to $20 \%$ and this percentage lasted even up to 1996 . The third 
time incentives were used was in 2002 , and their use has increased since then. Ar the moment, estimates of incentives can be as high as $20 \%$ of the market rent as published and sometimes even more Due to the lack of hard evidence, it was decided nor to include those observations in the chapter, but there are strong feelings that this subject should be further investigated.

As described by Brown (1995), regarding the UK, incentives there may occur in different forms. The incentives can be divided into rental and capital incentives. "The most common rental incentives are rent-free periods and rent subsidies in addition to normal fitting-out periods, stepped rents and rent capping, break clauses and lease concessions (for example, capping service charges). As far as the capital incentives are concerned, the most common ones are fitting-out costs paid by the landlord, cash payments and take-back of existing premises. As well as this, Jeffries (1994) also mentioned the payment of relocation costs and put options on additional space. One must be aware that in the UK, cyclical patterns occur regularly: particularly since the end of World War II, the office market has experienced some four periods of boom and slump. At that time, 25 year leases with upwards-only rent reviews were the most common form of leases in the UK. These contracts were to the advantage of the owners and most of the value of the property was relared to the length of the lease. As a result of the upwards-only rent reviews at market level every 5 years, the owners would be prepared to concede all kinds of incentives to maintain the market rental level. Rent-free periods of more than 2 years have been common, when possible however, in combination with step-up rents to the target rent level by the end of year 5 in order to secure the rental income at a high level, just before the (upwards only) rent review to market rent. What will the effect of all the incentives be on the effective rent? Brown (1995) came up with an example showing that effective rent could be some $40 \%$ lower than the marker rent. Davidson et al (1993) found that a difference of $30 \%$ was quite common. However, one must bear in mind that as described earlier, the London office market experienced a very uncommon situation berween 1986 and 1991, when office market rents went up steeply and subsequently plunged steeply as a result of the so-called "Big Bang" when the stock market was opened up to financial traders from outside the UK. Depending on the length of the contract fat that wime, 25 year leases with break options after 10 years were introduced) the effect of the incentives could be smoothed. In the case of the Netherlands, it has been difficult to find reliable information on the incentives which are given to tenants under depressed circumstances. Some general remarks: first of all, one should realize that incentives have a different impact on empry new buildings compared to empty older buildings. Secondly, the market evidence of incentives will also have an impact on renewal of existing contracts. The cypical lease length for offices in the Netherlands is 5 years plus 5 option years (the option for the renant of extending his contract under the same conditions). The effect of the extension or renewal problem in a cyclical environment is illustrated in Figure 3.9. 


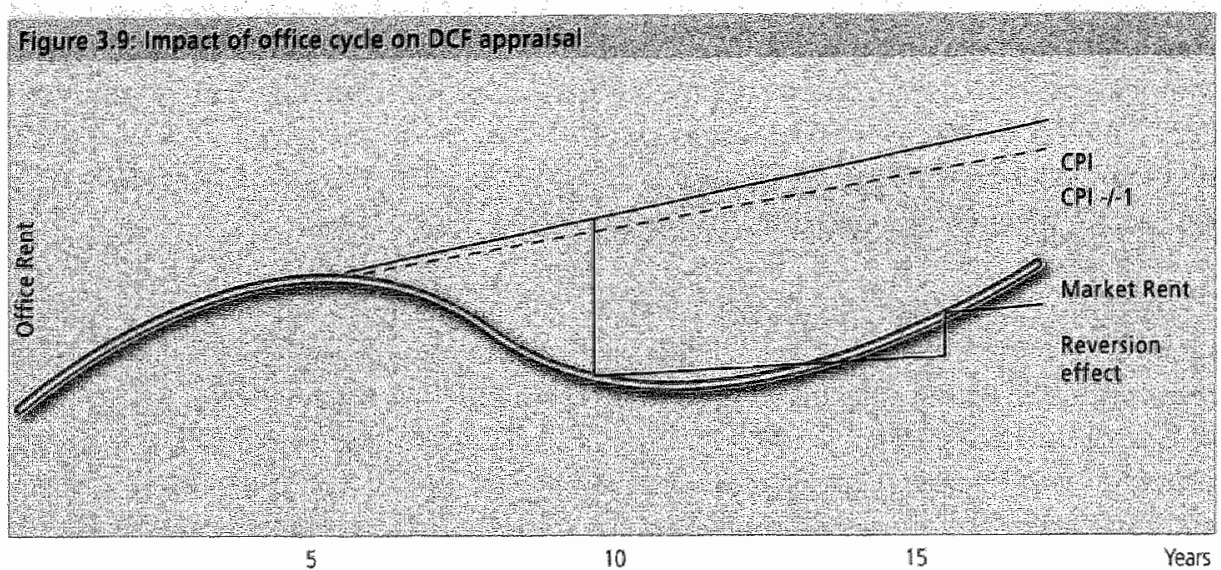

The figure shows four different types of office market rent assumptions. The CPI line depicts the approach by the valuers, assuming that the market rental value at a certain point in time will increase in line with the CPI, regardless of the stage in the office cycle. When there are signs of a depressed market, the valuers will react by reducing the rental value increase minus $1 \%$-point from the $\mathrm{CPI}$. The cyclical partern of the market rent graph is reflected in the assumed cyclical pattern and the last line reflects the reversion effect, assuming 5 year rental contracts, adjusted to marker every 5 years. As everyone can understand, the effects of using the different market rental value growth assumptions will have a big impact on the net rental income from the properry. When a contract started at the highest point in the cycle, the market rent will probably be much lower after 5 years than the contract rent raised in line with the CPI. Therefore, the tenant will start to negotiate a rent reduction with the landlord. Probably not to a figure as low as the market rent at that moment, because the landlord will realise that to move to another location might cost a lot of money for the tenant, but a substantial reduction will be very likely. Over the next 5 years, the renewed contract will increase with the CPI and depending on the length of the cycle, the owner might increase the rent after 5 years as shown. One might expect that implementation of this effect could have a huge impact on the valuation, sometimes reducing the internal rate of return by more than $3 \%$-points (Hordijk et al, 2004).

\subsection{Summary and conclusions}

This chapter describes the creation of the historic time series for office rents in the Netherlands. The time series were composed of historic information between 1977 and 1989, which was assembled in a unique databank consisting of around 3,500 office transactions over that period. This darabank was than combined with the aggregate data from the DTZ office transaction databank from 1.989 through to 2003. Results for Amsterdam, Rotterdam, The Hague and Utrecht as well as the average of the total of the orther cities were separated and in another graph, compared with the intlation rate. Several conclusions can be drawn. First, the pattern for Amsterdam is different from the other cities, much more volatille and going up to very high levels at the end of the 1990s. Due to a very small number of observations in the 1970 s, some graphs (Urrecht) show much more volatility than larer on when the numbers 
became statistically significant. Compared with the inflation rate, estimated rental value (ERV) growth between 1977 and 2002 was lower than the inflation rate with the exception of ERV growth in Amsterdam. It is a well known fact that the inflation rate in the 1970 s was much higher than from the late 1980 s onwards. Therefore the patterns from 1986 through 2002 were examined. In this period, ERV growth in all the major cities was able to keep up with inflation and only the average ERV growth of the other cities could not do so.

The results were then put in an international context with similar time series from the USA and the UK. From 1988 (the USA figures for the country as a whole don't go back furcher in time) ERV growth has been significantly higher in the Netherlands than in the UK and the USA. The same is true if Amsterdam is compared with London and New York: the ERV growth in Amsterdam is much higher than in the other two cities. Furthermore, the difference between the three cities as such is higher than if the countries as a whole are compared. When only Amsterdam, New York and London are compared from 1981 onwards (London City has data from that date), a completely different picture emerges due to the "Big Bang" in London described earlier.

The Dutch office cycle was also reviewed, comparing it with demand and supply ratio's between 1977 and 2002. The conclusion was that the office rental value time series reflected the economic cycle well although with a 2 to 3 year lag and smoothed. It is believed that most of the smoothing is caused by the fact that incentives like rent-free periods and tenant improvements in a downturn market are not sufficiently reflected in the market rent. At the end of the analysis, the office cycle was compared wirh the demand and supply ratio and the conclusion was that the marker rental value didn't adequately reflect the changes in demand and supply during the cycle. 


\section{APPENDIX}

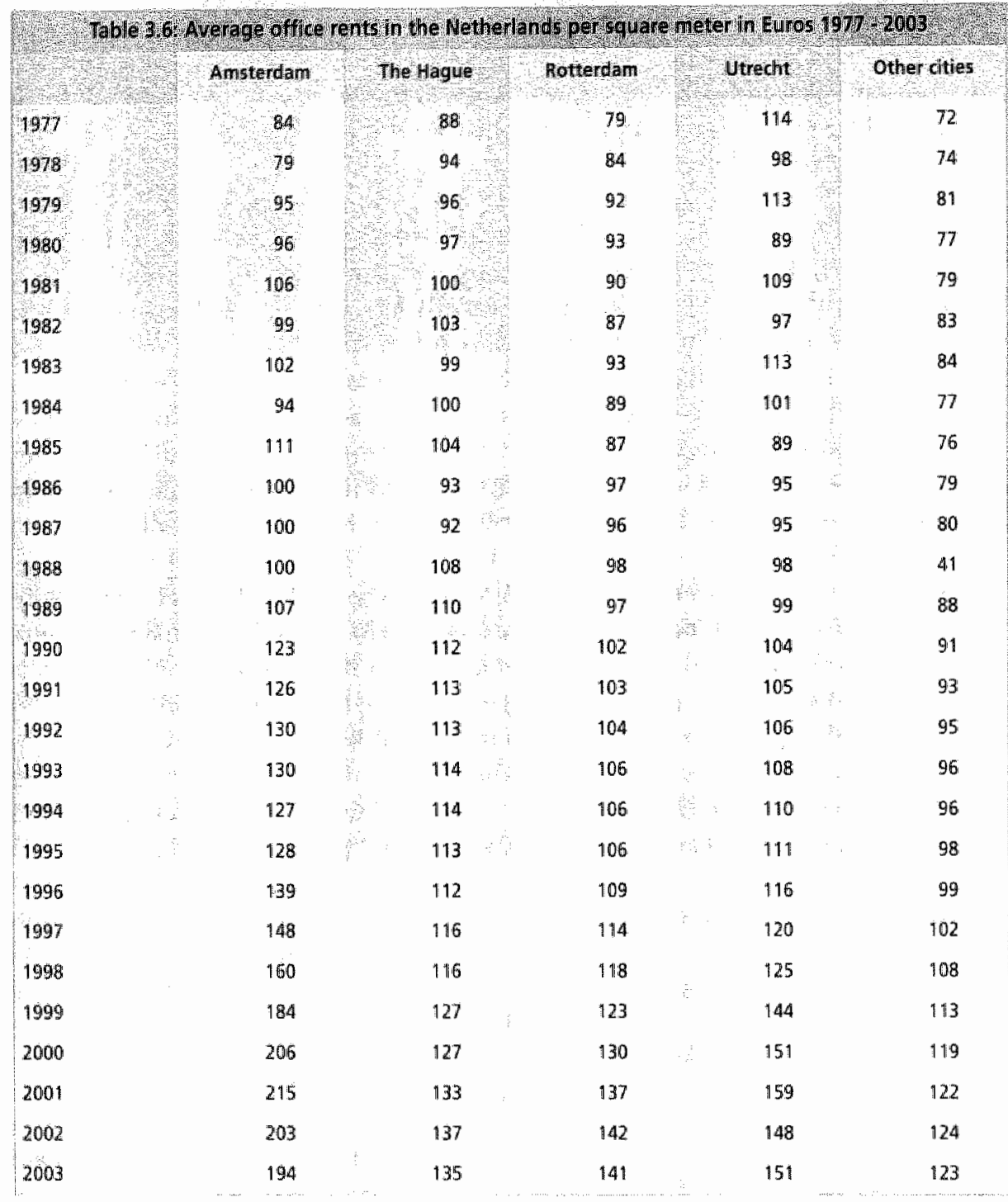




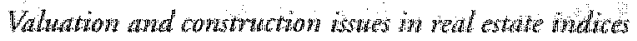




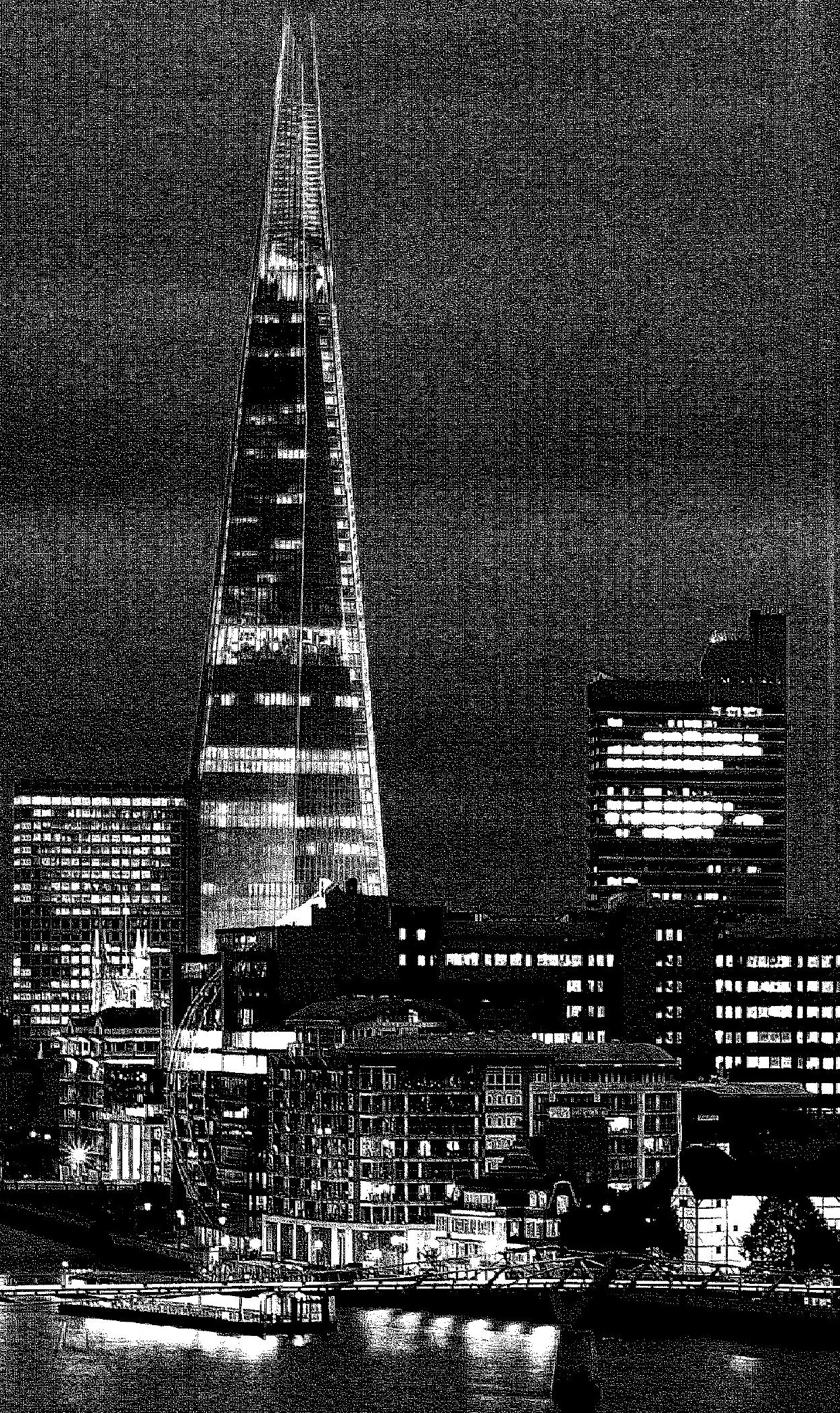




\section{CHAPTER 4}

\section{Valuation model uniformity and consistency in real estate indices'}

\subsection{Introduction}

The value of assets such as shares and bods are based on daily transactions, which would also be the ideal for a market index such as the ROZ-IPD Netherlands Property Index. However, as direct real estate is not traded frequently and publicly, and also because the income from an individual property is nor available in public domains, the capital growth of the properties which form the universe of the ROZ/IPD index need to be estimated through valuations. It is very important that these valuations are based on uniform and consistent valuation models, because the data is used for measuring, analysing and explaining the differences between the portfolios of the participants of the ROZ-IPD Index and the benchmark; asset allocation; setting performance targets and rewards; research and organisational development. The consequences of inconsistent and non-uniform data could seriously limit the usefulness and quality of the index, as stated above, especially at portfolio and property level - even if at ROZ-IPD Index level, the differences would probably balance out (Gelmer, 1998). Another problem is the potential loss of trust in the index by its participants. Finally, it would diminish the transparency of the market.

The growing use of performance-related information creates a need for data with high accuracy, consistency and integrity. In addition, the growing need for detailed property-level information and the further development of indices and performance measurements make the valuations crucial. The call from institurional investors participaring in the ROZ-IPD Netherlands. Property Index for the use of valuation checks

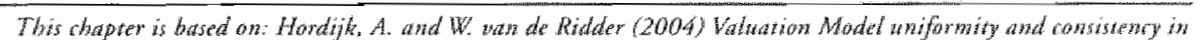

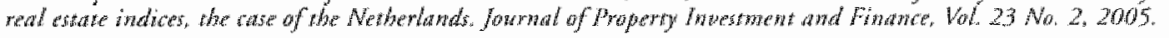


has become lowder over time. Therefore it was decided to have each participant's valuation data checked, as well as the valuation models. This type of information is normally private and confidential, therefore it is exceptional that this unique information could be used in this survey. Analyses of valuation accuracy are more common, but very seldom is an opportuniry provided by valuers as well as institutional investors to study their methods and results in order to improve future valuations in a qualitative and quantitative way.

The key question in the surwey as described in this chapter is: 'Do the valuers for the ROZ $-I P D$ Index comply with valuation regularions, is there consistency and uniformity between the valuation models and how much variation or uniformity is there in the assumptions for certain input variables for the period 1994-2002 at segment level; between the internal and external valuers, and berween the external valuers?'

The survey is divided into a qualitative part and a quantitative section. The qualitative section firstly deals with compliance with valuation regulations, and then focuses on the uniformity and consistency in the valuation models with respect to specific elements of the Discounted Cash Flow (DCF) model, such as the discounting method, the valuation period, the calculation of the residual value and several elements of the part-selling DCF model. It also looks at the consistency of a number of variables such as inflation and the risk-free rate. Where possible, the impact of a certain method or applied variable (as stated abowe) on a value is also calculated using a dummy DCF model (see appendix 4.A.2). The valuation regulations which are set by the ROZ-IPD are used as the basis on which the valuations are judged (for the ROZ Valuation Guidelines, see the appendix).

The quantitative section demonstrates the variation and uniformity in the assumptions with respect to the net yield, the discount rate, the exit gross yield, and the investment capital value percentage for tesidentials, as well as the tenancy turnover rate for the asset categories retail, offices and residentials. This verifies whether the standard deviations of the assumptions for these input wariables have diminished over the period 1994-2002 at segment level, and whether there is much variation in the averages and standard deviations in the internal versus external comparison and the comparison of extermal valuers among one another.

The chapter is structured as follows: The literature review in the following paragraph looks at earlier similar research, and also at papers which address the different ellements of the DCF model that are discussed in this chapter. Paragraph 4.3 and 4.4 outline the research merhod and data. The qualitative and the quantitative results are presented in paragraph 4.6. Finally, the conclusions and recommendations for the ROZ-IPD Index are given in paragraph 4.7. 


\subsection{Literature}

\section{QUALTTATIVE LITERATURE}

Many recent papers have focused on valuation accuracy or valluation variance. Valuation model consistency and uniformity has however not been studied as much, even though it is perhaps one of the most important subjects in real estate valuation.

Newell (1997) invesrigated the perception of the quality of valuation reports of Australian properties among external users and compared it to similar earlier research from 1989 to see whether the active improvement policy of the Australian Institute of Valuers and Land Economists (AIVLE) had helped to improve the quality of the appraisals. The number of organizations that believed that valuations were very important for investment decisions rose from $55 \%$ to $65 \%$. Eighry percent of those questioned thought there were significant differences in the quality and reliability of the reports and their firms. Weaknesses of the reports were described as: inadequate market analysis; too few details and insufficient discussion of analyrical aspects; limited assumptions and use of reference transactions, and a lack of understanding of complex situations and market positions of a property. Finally, the respondents were concerned about the justification for the assumptions in the DCF model, the reliance of the valuers on computer analysis and the strong dependence of the quality of the report on the instructions to and discussions with the valuer prior to the valuation.

Both Hutchinson (1996) and Gallimore (2002) conducted research into the components of valuation accuracy and came to the conclusion that there is a lack of consistency in the applied calculation methods, and that improvements in the consistency of the applied valuation models and some input variables are necessary.

Written recommendations (2002) for the ROZ-IPD Index from the main valuation firms carrying out valuations for institutional investors stated that the valuers use multiple duration periods in the DCF model and that the valuers have different opinions about the exit yield. They recommend that the regulations on these subjects should be revised, for example with a DCF term of ten years, and that the exit yield should be more precisely defined: thus, "the exit yield ar the end of year ten should be excluding purchaser's costs". Most of the suggestions have been taken up by the ROZ/IPD index in order to improve the valuation regulations.

Smit (2002) carried out research on the uniformity of the valuation models of the seven largest valuation companies in the Netherlands which value properties for the ROZ-IPD Index. He had two non-existent buildings valued, supplying the valuers with all necessary input data such as rent, discount rate, exit yield, costs, rental growth, inflation etc. He came to the conclusion that identical input of data does not lead to identical output in the valuarion models. Aside from this, he found many differences in approach between the valuers: some models were unable to work with a Hexible inflation scenario; the residual value was calculated in many different ways, with some using the cash flow in the last year and some that of the following year, while opinions also differed on whether to use the residual value including or excluding purchaser's 
costs. The term of the DCF model ranged from 10 years ( 5 cases), to 15 ( 1 case) and 20 years (1 case). Finally, in the determination of the residual value in the part-selling DCF model for residentials; several different methods were applied to calculate the number of exploited units to be included in the cash flow. It was recommended that only one term should be used for the DCF model and that the method for discounting and the calculation of the residual value should be standardised. As the capitalization method had smaller deviations among the valuers than the DCF method, Smit recommended that in future the Index waluations should only be carried our using the capitalization method. This conclusion has not been adopted by the ROZ/IPD index, as it was felt that both methods - DCF as well as income capitalisation - have their contribution to make to arriving at the market value.

Boyd (2002) states that in the 1960s, 1970s and 1980s a lot of attention was devoted to the application of the DCF approach in real estate research, but even in the 1990s, much remained unclear about this and there was in some cases insufficient understanding of the DCF approach. During the last few years however, there has been more emphasis on the DCF models, due to increased pressure from asser managers who have to quantify the risk level of the real estate assets in their portfolio. Boyd focuses on the cash flow process of the DCF method and the most important input variables, applying a sensitivity analysis. According to Boyd, several research findings have shown that the DCF models applied by valuers are far from consistent. The conclusion is that there is much inconsistency, especially in the time components and in the residual value calculation. The time components in a DCF model are the time intervals between the cash flows, the position of the cash flows within the time interval and the duration of the study. If one does not apply a yearly interval, the yearly discount rate should be converted into an effective rate, orherwise the difference between yearly and monthly intervals might be as high as $4 \%$ in value. The difference in value between cash flow in advance or in arrears is $9.1 \%$ with yearly cash flows, depending on the discount rate. Aside from this, Boyd concludes that a valuation based on yearly cash flows in arrears results in an inaccurate and low value. In terms of the residual value, there are many different approaches relating to what cash flow should be taken (the last year, or the previous one), the calculation of the exit yield and where in the rime interval the sale occurs. Finally, Boyd mentions that it is unfortunate that the International Valuation Standards of 2001 are not more specific on the above-mentioned points. This could have led valuers to use a uniform approach, whereas the lack of clear definitions and calculation methods at present leads to very different and inconsistent market values.

\section{QUANTITATIVE LITERATURE}

The inpur variables discussed in this chapter are very important in property valuarions, development, decisions and analysis. However, comparative research on assumptions about these variables from valuation-based data such as the ROZ-IPD Index or for example NCREIF is rather scarce. Previous research has primarily focused on valuation accuracy, valuation versus sale price and on the explanation of the variance in and deciding factors of the input variables. The different views from the previous literature will be discussed according to subject. 
Sivitanides and Sivitanidou (1996) conducted research in which they compared the net yield of a sample of offices from a number of cities in the years 1.991 and 1995. The average net yield in 1995 was $8.8 \%$ with a standard deviation of $0.5 \%$, compared to $8.8 \%$ and $0.9 \%$ respectively in 1991 . The difference between the highest and lowest value was $2.8 \%$ in $1995(7.1 \%-9.9 \%)$ and $4.6 \%$ in $1991(6.9 \%-11.5 \%)$. They concluded that the variations were not enormous, but big enough to cause substantial differences in the valuations.

Hordijk and van Riel (2001) compared the standard deviations of the assumed office net yields as well as the discount rate for 1995 and 2000, to see if there had been a decrease. They did this research expecting the quality of the valuations to have improved over this period due to higher transparency, increased frequency of valuations, and more established valuarion practices in instirutions in general, which should result in decreasing standard deviations and thus increased uniformity. While they found a decrease in the standard deviation of the discount rate in the office and retail segments, this was not the case for the net yield. The already very low yield, which had dropped even further, may have resulted in more insecurity and therefore a higher standard deviation. The fact that retails include both stand-alone units as well as large shopping centres, both with their own yield characteristics, might also have influenced this result.

Gunnelin, Hendershott etc. (2002) tried to explain the net yield, discount rate and exit yield of 600 office properties in Stockholm, Malmö and Gothenburg in the Swedish IPD Index. The net yield ranged from $1.4 \%$ to $16 \%$, the discount rate from $6 \%$ to $12 \%$ and the exit yield from $4.3 \%$ to $10 \%$. The exit yield was largely explained by the discount rate, and the net yield was strongly correlated with the discount rate. They concluded that the valuation process is less mechanical then they thought since they found the above-mentioned variance in the input variables, which are nonetheless to a large extent explained in the research.

Lundström (1999) also found a high correlation between the discount rate and the exit yield in the CBD office market of Stockholm. This was as expected, as many waluers assume an automatic relationship between these two input variables. However, he hopes to start a discussion with his findings of exit yields ranging from $5.8 \%$ $7 \%$ in the city centre of Stockholm with the same discount rate. This discussion will highlight the effect of market positions, contract structures, technical status etc. on performance and risk. The ultimate goal is to arrive at more accurate estimates which are more in line with the market price.

Research on differences berween the assumed input variables of internal (from the investor's organisation) and external (independent) valuers is even more scarce. Key and Franson (1999) conducted research on the Swedish IPD Index, in which they looked whether there were significant differences in the assumptions on, for instance, the exit gross yield. They calculated the unweighted average, the standard deviation and the difference between the assumptions made by internal and external valuers. After this, they applied a t-test to check the possibility that this difference is not significantly different from zero (if $P<0,1$ ). They concluded that in thirteen out of fourteen segments, the 
average from external valluations was higher than the average from internal waluations: on average, $0.87 \%$ higher. However, in only six segments was this difference significant, with four segments having a large geographical spread. The differences on the residential valuations were the largest, for Gothenburg and Malmö, the external gross exit yield was $0.76 \%$ and $1.06 \%$ higher respectively, with higher external standard deviations. They conducted the same research with the data of 1999 and once again, the internal valuers assumed lower gross exit yields: on average, $0.6 \%$ lower, with the biggest differences again in the residential yields. The differences in the office and retail data, however, had diminished Hordijk (1998) conducted this type of research on assumed net yields and discount rates from the ROZ-IPD databank for the years 1994-1997 with an aggregation level comparable to this research. As with the results from Key and Franson (1999), the residential data showed the highest differences, while ner yields for the top locations in the major city centres showed little variance. It is remarkable that the changes per year often move in different directions, for example with an internal net yield increase and an external yield decrease in 1995 and 1997.

Graff and Young (1998) investigated 700 simultaneous internal and external valuations and concluded that the internal valuers are tempted to value more conservatively with regard to specific difficulties in valuing properties: properties with a higher risk factor, such as those with one tenant whose contract is ending where there is uncertainty about the renewal of the contract.

\section{Discounting, Residual value and duration of the DCF MOdel}

By analysing what is written on elements of the DCF model discussed in this chapter, suggestions are given on how to deal with these problems. First of all the discount rate.

The discount rate is the rate which discounts the cash flow from the furure to a certain present date, usually the valuation date. The valuer should take into account the time interval between the cash flows and whether these cash fows occur at the beginning of the period or at the end. Along with Boyd (2002), Scarrett (1996) and Keeris (2000) also briefly discuss this specific problem. It is important that the valuer checks the contractual agreements and makes sure that the discounting is in line with these. The conclusion is that there has been little research on this topic and there are no generally accepted regulations or theories either. The ROZ-IPD advises simulating the discount rate by taking the risk-free rate on government bonds, plus the following risk adjustments: asset class risk - the basic risk for the property asset class; property category risk - the risk relating to a retail, office or residential property; and property-specific risk - risks specifically due to the property for example the competitive position and market developments in the immediate surroundings.

The residual value is the expected sale price at the end of the term. It is separate from the sum of the present values of the cash flows, the other component of the total value in the DCF model. The most accepted method for arriving at the residual value is the income capitalization method. There are several difficulties with calculating the residual value. 


\section{THE CALCULATION OF THE EXIT YIELD}

Research has shown that the ner or gross yield should be the basis for the exit yield as they have a functional relationship which has a clear link with the development of furure cash flow. Sivitanides and Sivitanidou (1996) and Van Gool et al (2001) also claim that the net or gross yield is often used to calculate the exit yield. The exit yield does not necessarily have to be higher than the gross or net yield: changes in vacancy, market developments and the quality/diversity of the tenant mix can cause it to be lower.

Rust (2004) wrote a paper on the exit value / yield of commercial real estare (offices) in DCF valuations, in relation to the initial yield. His assumptions are that land will increase in walue over time and the buildings should be written off in 50 years. He distinguishes between deterioration / obsolesce of location, economic and technical. Theoretically he found that the gross exit yield should be $0.45 \%$ higher than the gross initial yield. He also assumes that the other component for determining the exit value, namely the market rent, should grow by $0.5 \%$-point less per year than the inflation rate and he also allows for an adjustment of the locational factor varying between $-1 \%$ for less favourable locations and $+0.5 \%$ for superior locarions. The total effect on the exir yield is kept under review.

\section{GROSS OR NET CASH FLOW AND THE YEAR TEN OR ELEVEN CASH FLOW?}

Pagliari (1991), Keeris (2000) and Lusht (2001) all state that valuers should use the $11^{\text {th }}$ year cash flow as this is the first year of exploitation for the buyer. Boyd (2002) also believes the $11^{\text {th }}$ year cash flow should be applied. Van Gool et al (2001) finally warn that the $10^{\mathrm{th}}$ or $11^{\mathrm{th}}$ year cash flow might be lower because of postponed large maintenance costs or extra (postponed) tenant fitting-out costs.

\section{REsidual VALUE WITH OR WITHOUT PURCHASERS' COSTS?}

According to Wiley (1993), Keeris (2000), Lusht (2001) and Van Gool et al (2001) the valuer should deduct the purchasers' costs before discounting. This because otherwise one includes the costs, while these should be subject to tax payment.

In several papers (Keeris, 2000 and Boyd, 2002) a period of ten years is seen as the most appropriate. This might be so, because extended periods up to for instance 15 years will most likely result in excessively complicated predictions and will therefore only reflect artificial scenarios rather than real market developments. If the term is too short, say three to seven years, the impact of the residual value on the value is too high, which also makes the cash flow predictions inferior. 


\subsection{Methodology}

\section{QUALTATIVE METHOD}

The qualitative part of this survey tests whether the valuers comply with the valuation regulations and analyses the waluation model uniformity and consistency as well as the uniformity of mathematical inputs such as inflation and the risk free rate. The following parts of the valuation models are focussed on: valuation models; the way the different models work; the calculation of the residual value; the discounting of the cash flows; the use of the prescribed inflation scenario; the risk-free rates applied as part of the discount rate; well-founded important input variables; risk surcharges as part of the discount rate; part-selling model residentials; the different ways the value is calculated the assumed tenancy turnover rate; assumed value increase of the unsold residential units, and the method used for the residual value calculation.

It is interesting to calculate the impact of the different approaches on the value or the sensitivity of the value based on a change of one of the input variables mentioned. This will be shown with the help of a dummy DCF model (see appendix 4.A.2). The dummy model uses the following assumptions, as retrieved from the ROZ website (2003): inflation is steady at $2.5 \%$; rent is indexed at 100 in year $\mathbb{1}$ and rises with inflation; cost percentages are $10 \%$ of gross rent for commercial real estate and $20 \%$ for residentials; cash flows are discounted halfway through the year (CF/discount rate ${ }^{\wedge}$ 0,5 , with $\mathrm{t}$ as the year of the cash How); the discount rate is $7 \%$; residual value consists of the gross cash flow year $10 /$ exit gross yield, and the exit gross yield is equal to the discount ate $+1 \%$.

To create a part-selling dummy DCF model, the above model has been changed in a few ways. "The sale price per unit is related to the rent. Rent has been set at $€ 6,000$ a year $-1-20 \%$ costs, resulting in a net rent of 64,800 . The formula used to calculate the sale price equates $€ 4,800$ to $4.3 \%$ (average direcr return over 2002 ) of $75 \%$ of the vacant value, resulting in a net rent/sale price ratio of $3.2 \%$. Apart from this, the model has variables such as a discount rate of $6 \%$, management of the unsold units at the end of the DCF period as the basis of the calculation of the end value and a basic tenant turnover race of $10 \%$, and in the first year $10 \%$ extra for the expected salle to buying tenants.

\section{QUANTITATIVE METHOD}

The quantitative part of the analysis analyses the variation and uniformity of the following inpur variables mentioned: net yield, discount rate, exit gross yield, investment capital value $\%$ and tenancy curnover rate. To check if these variables have been set more uniformly through the years, several simple statistical calculations have been performed: the unweighted average; total value of the observarions/number of observations; the standard deviation (S.D.); the coefficient of variation (absolute standard deviation/un-weighted average* $100 \%$ ), and a percentage of the observations ourside the average $+1-1^{*}$ standard deviarion ${ }^{2}$.

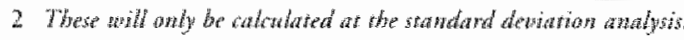


The data has been analysed in three different ways. The first part shows the standard deviation and the coefficient of variation at sub-segment level of each of the sectors: offices, retail and residential, and will analyse whether the yearly standard devation has decreased over the 1994-2002 period. The uniformity concerning the assumptions on the variables between the internal and external valuers and between the external valuers is analysed by calculating the average and the standard deviation of some of the variables. For the staristical inference, some sub-segments in the last rwo analyses have been merged. In all cases, comments are made only on years with more than 30 observations. From the retail segments, all three analyses are carried out for the sub-segments prime locations in large ciry centres, prime locations in semi-large city centres and small city centres with a value of less than $€ 3$ million per property. In this way only stand-alone retail units have probably been selected, which improves the comparability of the analysis, as shopping centres have their own specific yield characteristics. For the internal-extenal and external valuers analysis of the office data, the sub- segments ciry centres, office locations and offices in residential areas have been combined. The residential data has only been analysed for multiple family homes for the ten cities with the largest representative value of the properties. The valuers analysis, however, uses data from all cities.

\subsection{Data}

The data for the qualitarive analysis has been retrieved from participants in the ROZ. IPD Index, who provided valuation reports of external valuers, which is unique for this kind of research. In total about 150 reports were retrieved and checked for uniformity and consistency. The data for the quantitative analysis has been drawn from the ROZ-IPD databank for the years 1994 to 2002 and has been filtered for extreme and unusual numbers, which can be seen in Table 4.1: only parameters falling within the size band have been processed in the research. Observations outside this range were considered to be too far out of the acceptable range and have been filtered.

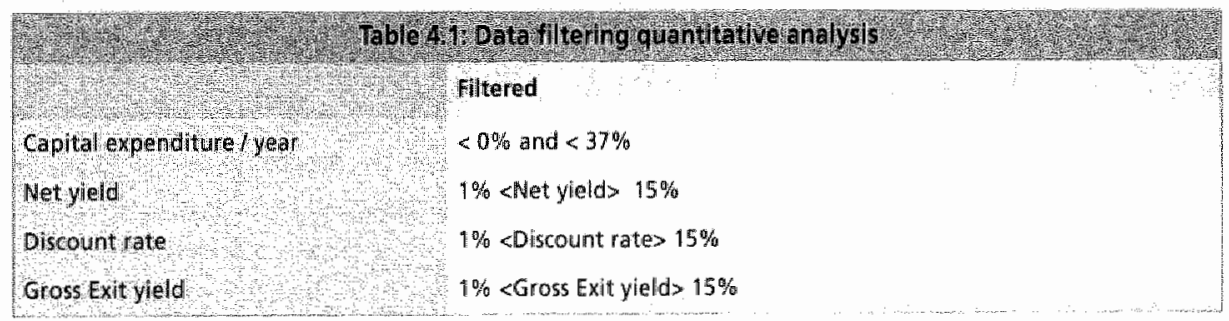

Table 4.2 shows how many valuations there are in each analysis, for all the sub-segments. The exit gross yields have about the same number of properties in every analysis, as they need to be analysed together with the discount rate. There is a difference between the number of valuations for the standard deviation analysis and the internal versus external analysis because for a number of valuations it was unclear whether it concerned internal or external valuations. As can be seen in Table 4.2, all numbers are generally seen as sufficient to allow for reliable statistical analysis. 


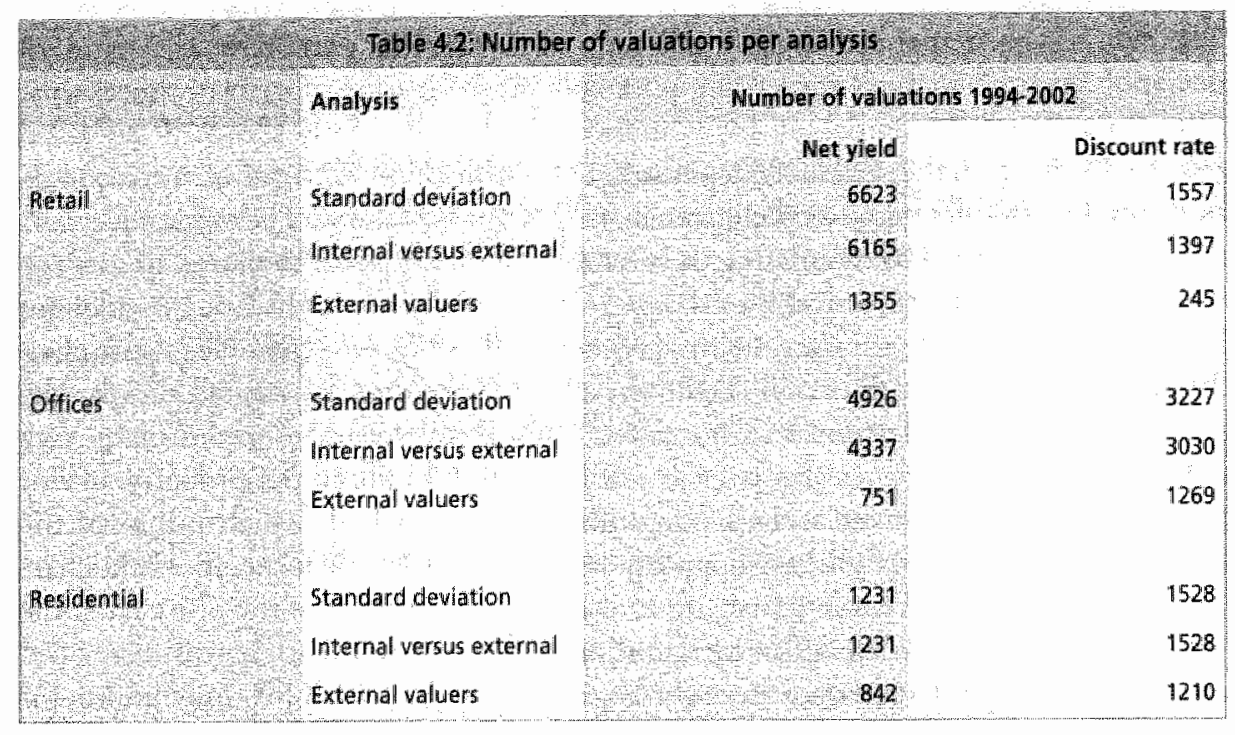

\subsection{Results}

\section{QUANTTTATIVE RESULTS}

In general, most valuers are in compliance wich most of the $\mathrm{ROZ}$ Valuation Guidelines. The most important deviations appeared in the foundations of the net yield and discounr rate, risk-free rate, minimum number of transactions as reference, and inflation rate. To begin with, the discount rate, which is built up from the risk-free rate adjusted for risk premiums, shows remarkable differences berween valuers, as shown in the "Table below (Table 4.3).

\begin{tabular}{|c|c|c|c|}
\hline Naluer & $\begin{array}{l}\text { Rikkfree rate } \\
\text { government bonds (in \%) }\end{array}$ & $\begin{array}{l}\text { Toral discount } \\
\text { ate (in } 6)\end{array}$ & Segment \\
\hline Extrelnal & 5 & 71 & Retail, larger city centres, prime locations \\
\hline External 2 & 4.3 & 8 & Retteil, medium city centres, prime lacations \\
\hline External 3 & 4.8 and 5.5 & 8 and 8.4 & Offices, CBD \\
\hline Extennal & $4.6-5.5$ & 21,81 and 82 & offices, office area \\
\hline Externals & $4.6 \cdot 5.3$ & 8.4 and $6.0,63$ & Offices, $\mathrm{CBD}$ Residentials \\
\hline Internalla & 4.6 & 79 & Retail, medium city centres, prime locations \\
\hline nowernal 2 & 5 & unknown & Retails, larger city centres, prime locations \\
\hline
\end{tabular}


There is also quite some variation in the duration of the government bonds cited, though a duration of 10 years is prescribed by the $\mathrm{ROZ}$ Valuation Guidelines. Some valuers use 2-year, others 10-year government bonds. Also, risk adjustments are being treated in different ways as shown in Table 4.4 . According to the literature, a percentage of $1 \%$ to cover the asset class risk is most common, but this is not reflected in the Table (4.4). Without explanation by the valuers, it is very difficult to understand the differences. Furthermore, the risk adjustment percentage for each of the sectors offices, retail and residential shows a remarkable spread, which is also hard to explain without talking to the valuers.

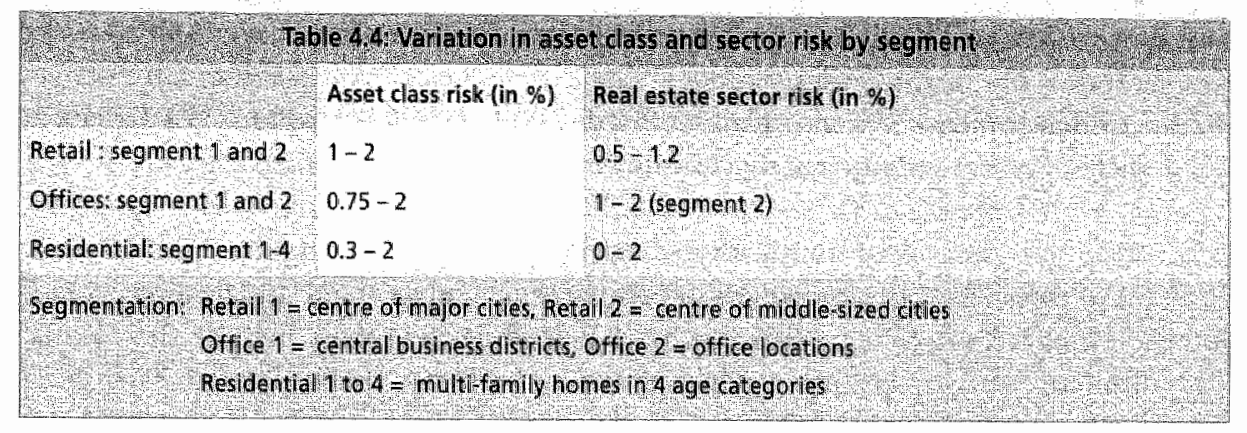

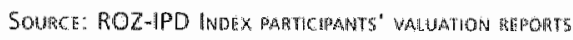

As far as comparable transactions or valuations are concerned, most valuers have a hard time finding sufficient observations or mall'ket evidence. The ROZ Valuation Guidelines require at least 3 investment transactions as well as 3 rental transactions for comparisons. It is obvious that smaller valuation firms have more difficulty in finding transacrions than larger ones. Also, valuers don'r analyse the differences between the reference transaction and the valuation they are working with, nor do they make clear what kind of adjustment they apply to make the two comparable.

Another ROZ valuation guideline has to do with the inflation rate to be used in DCF valuations. The ROZ-IPD has chosen to use the 10-year inflation estimates of Consensus Forecast. Although this regulation is very clear, a number of valuers don't use the Consensus Forecast figures for various reasons. One is that onlly $30 \%$ of the valuers are able to handle a Hexible inflation scenario in their DCF models. Furthermore, a number of valuers use other sources for some unspecified reason. A strange fact is that even within the same valuation company, the valuers use different inflation scenarios. The impact of using different inflation scenarios is significant. For instance, using an inflation rate of $2 \%$ instead of $3.5 \%$ will lead to a value difference of $1.0 \%$ in the dummy DCF model. In general, if the inflation rate changes from $2 \%$ to $2.2 \%$ or from $3 \%$ to $3.3 \%$, the impact on the value will be $1.3 \%$ and $2 \%$ respectively.

Many differences thave been found in the applied valuation models on the parts of the DCF model already mentioned. The duration period varies from 10 to 15,20 and even 25 years, with a 10 -year period applied most frequently, followed by 15 years. 
The valuers for the ROZ-IPD Index apply different methods to discount the cash Hows. Cash flows are discounted quarterly in advance, yearly in arrears (CF/discount rate ${ }^{A} \mathrm{t}$, with to being the year) or averaged over the year (CF/discount rate $\left.{ }^{\wedge} t-0,5\right)$ and very few valuets give an insight into the yearly net present value. Sometimes all three methods are applied in reports for one participant; which will obviously lead to inconsistency. Furthermore, only a few valuation firms look at the schedule of the cash How payments. All of this makes the models less understandable and makes a check by the participant or third parties difficult. Some of the valuation companies vary the discounting depending on the contract structure; however, most valuers always discount the cash flows on a yearly basis or averaged over the year, independent of the contract structure. The difference between discounting per year or averaged ower the year is about $2 \%$ in the dummy model. The difference berween yearly cash flows in arrears or in adwance is 9\% according to Boyd (2002), while Scarrett (1996) arrived at a $2 \%$ difference between quarterly cash flows in advance or in arrears.

Most striking is the lack of uniformity when it comes to calculating the residual value. Five out of the sixteen largest valuation companies calculate the residual value excluding the purchasers' costs ( $=$ residual value $/ 1,07$ ) while the others include these costs. "The difference in the dummy model appears to be 3,5\%. To indicate the inconsistency in these calculations, Table 4.5 displays an example of the different methods applied by several external valuers for one participant in the ROZ-IPD Index. From Table 4.5 some other inconsistencies can be seen, namely the method of calculating the exit yield.

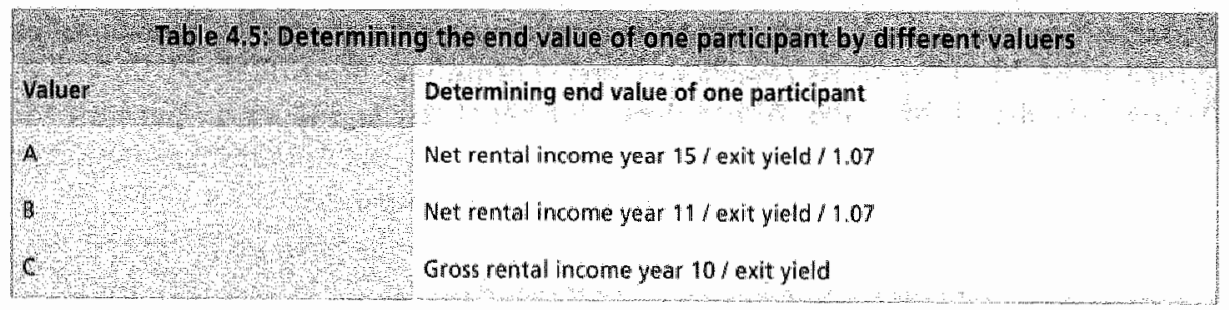

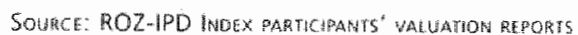

According to the literature, the exic yield should be based on gross or net yield in year one. One of the largest valutation companies calculates the exit yield by working with a constant risk adjustment for the net yield, independent of the property or the asset category. Some valuers simply add one percent to the net yield and owers adjust the discount rate up or down to arrive at the exit yield. No uniformity whatsoever. The sensitivity of the value to the exit yield is large: a ten percent rise in the exit yield results in a $5.2 \%$ lower value in the dummy model, a sensitivity of abour -0.5 . This is comparable with earlier research from Francis (1995) and Boyd (200).

In some cases, valuers apply income capitalisation and DCF for the same property. Interestingly enough, in these cases, many reports showed a very marginal difference berween the value based on the income capitalization model and the DCF model, which can be seen in Table 4.6. 


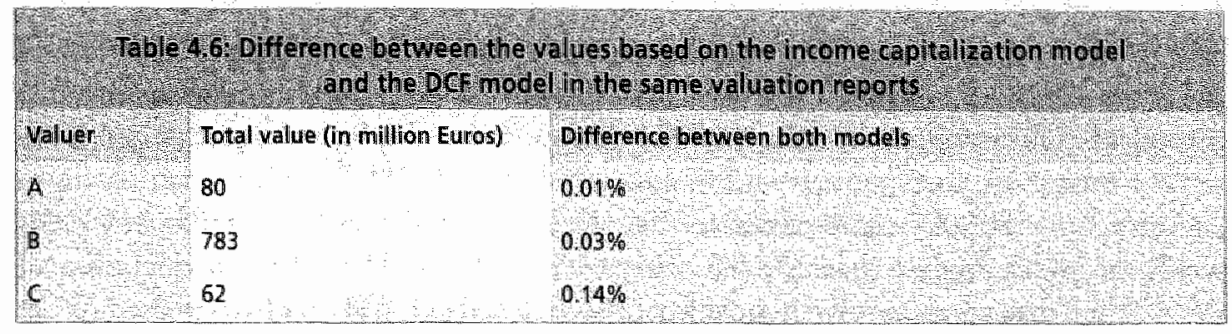

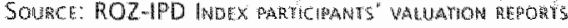

The differences appear to be so small that this cannot be a coincidence. Most probably the so-called confirmation bias is present. One of the two values might be displayed only for extra information to the investor, which means the valuer has deliberately matched the values. However, the fact that some of the best-known and largest valuation companies take the average of the two models to come to the end value makes the marching useless and misleads the participant. Some earlier researchers have declared their suspicions about the existence of the confirmation bias: Talmage (1995) and Smit (2002).

\section{QuALTTATIVE RESULTS}

It is not only the applied valuation model that reveals something about the consistency and uniformity; the models' input variables also play an important role. Rodney and Axcell (2000) phrased it as follows: "However, whatever the valuation method, it is still vital to carefully consider the most appropriate figures to inpur in the valuation model". The question then arises, whether the assumptions on the input variables in the valuations for the ROZ-IPD are more uniform and whether there are important differences between the internal and external input variables and among the valuers. This section will briefly discuss the results of retail, offices and residentials respectively for each variable. The figures in the text will show some important findings, but not all the results. From the figures 4.1 to 4.3 one can see that in general, the standard deviation in all three categories has nor decreased through the years, which means that the assumprions on the variables have not become more uniform.

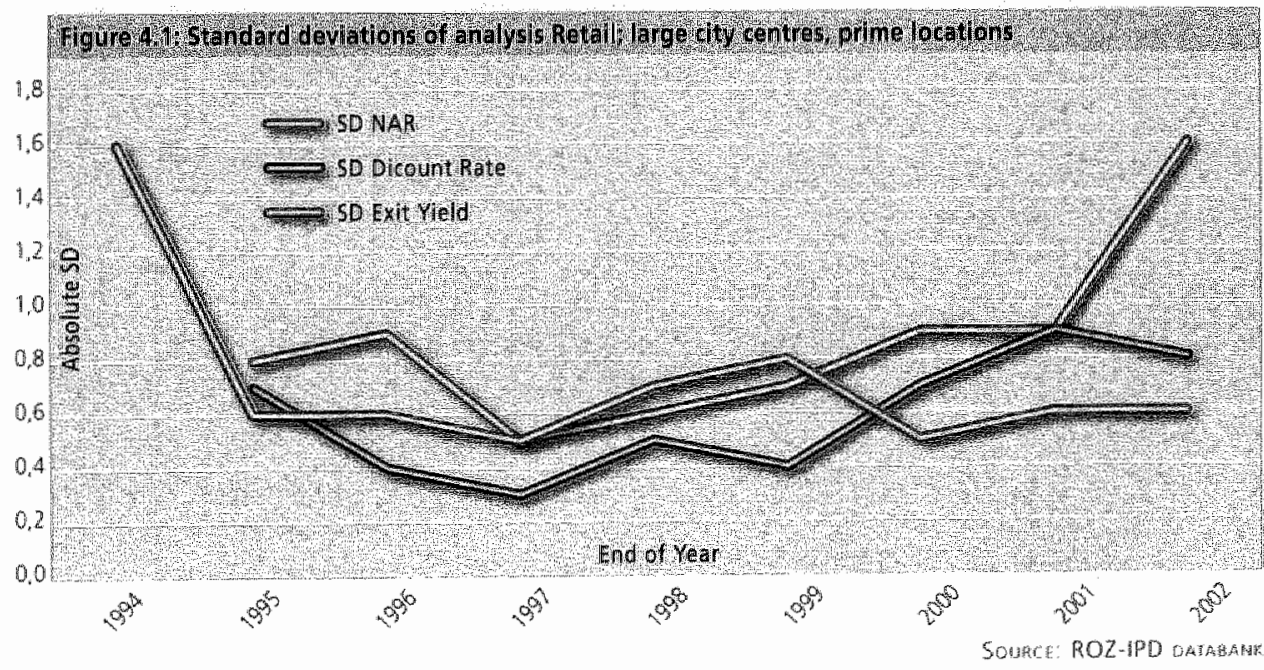


The standard deviation of the net yield does not show a decreasing trend for any of the three categories during the 1994-2002 period, in fact, there is even an increasing trend. The standard deviation of the discount rate displays a slightly increasing trend for retail and residentials and in general remains stable for offices, with a slight decrease since 2000 . It is remarkable that the standard deviarions for the exit gross yields are much higher than for the other two variables. The standard deviation of the exit yield decreases only slightly for offices; for retail and residential there is no decreasing trend. From the figures, it can also be concluded that the standard deviations are much higher for residentials than for the orher two categories.
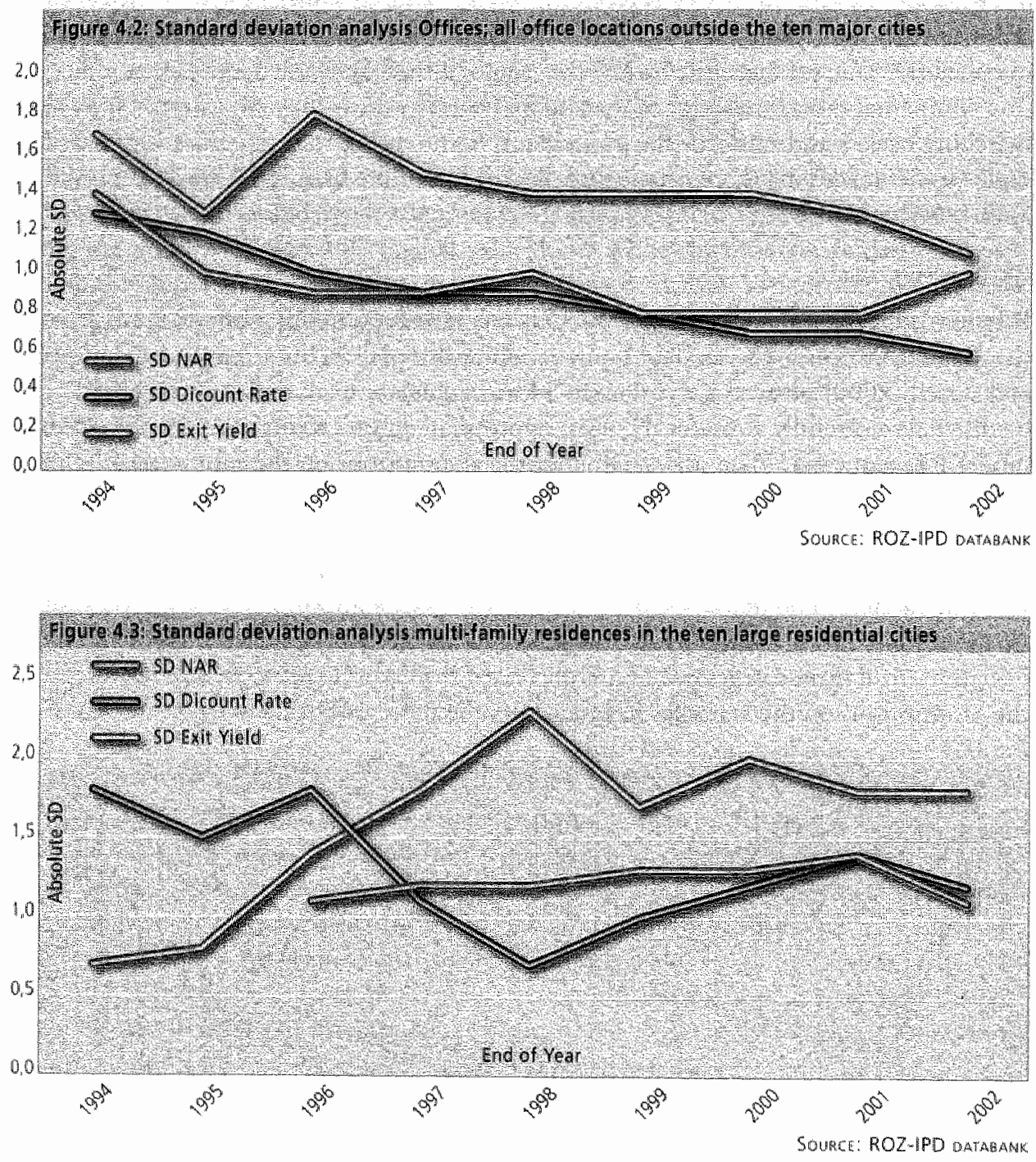
As for the differences between the internal and external valuers (see Figure 4.4 and 4.5 ), it can cautiously be said that the internal valuers seem to be a bit more careful in their assumptions and that in general they determine lower averages, also with lower standard deviations. In Figure 4.4 the results are grouped per office segment. The office segmentation in the Netherlands consists of offices in central business districts (1), offices at office locations (2), offices in residential districts (3) and offices in industrial areas (4). For the office market, there are also many opposite yearly movements concerning the exit gross yield: it rises internally, while it falls externally, and the other way around. However, it seems to be that external valuers anticipare marker movements earlier than internal ones.

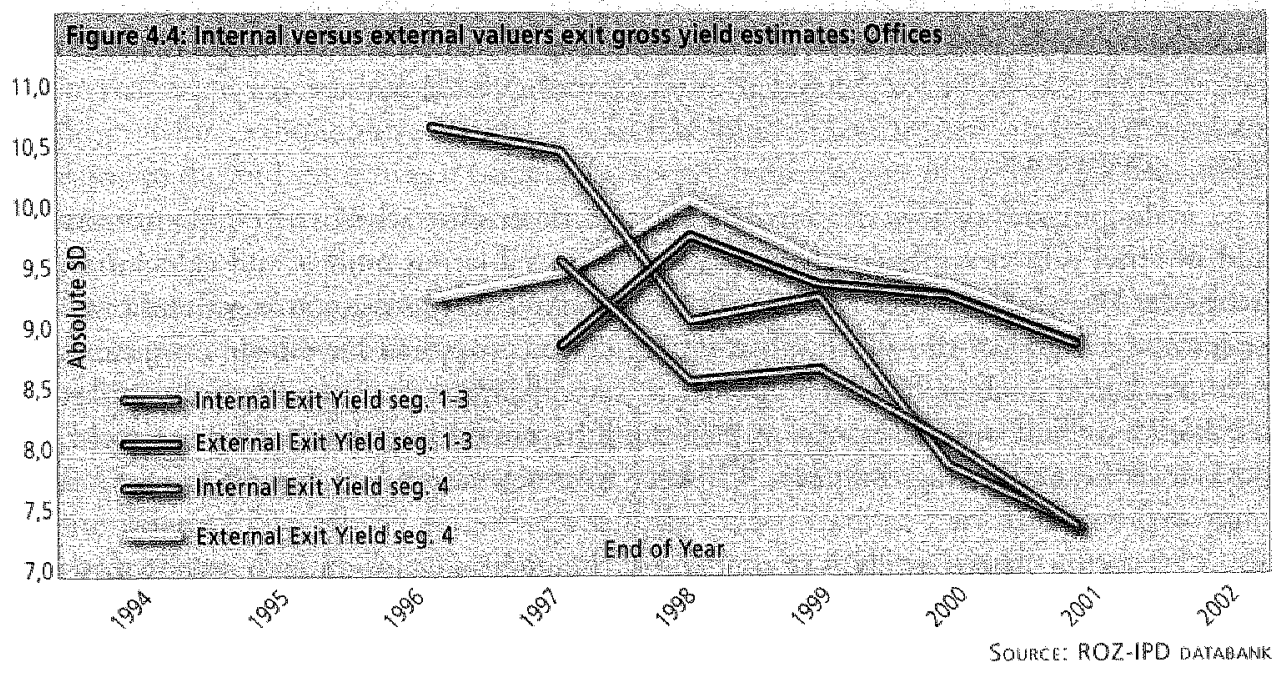

As can be seen in Figure 4.5, net yields as employed by internal and external valuers in the case of multi-family residentials show little difference. In the 'other locations' segment of offices and with the residentials in the ten largest residential cities in the first years, there are large differences, sometimes $2.4 \%$ in one year. The internal discount rates are generally higher than the external discount rates. The discount rate displays a much higher S.D. in the last few years.

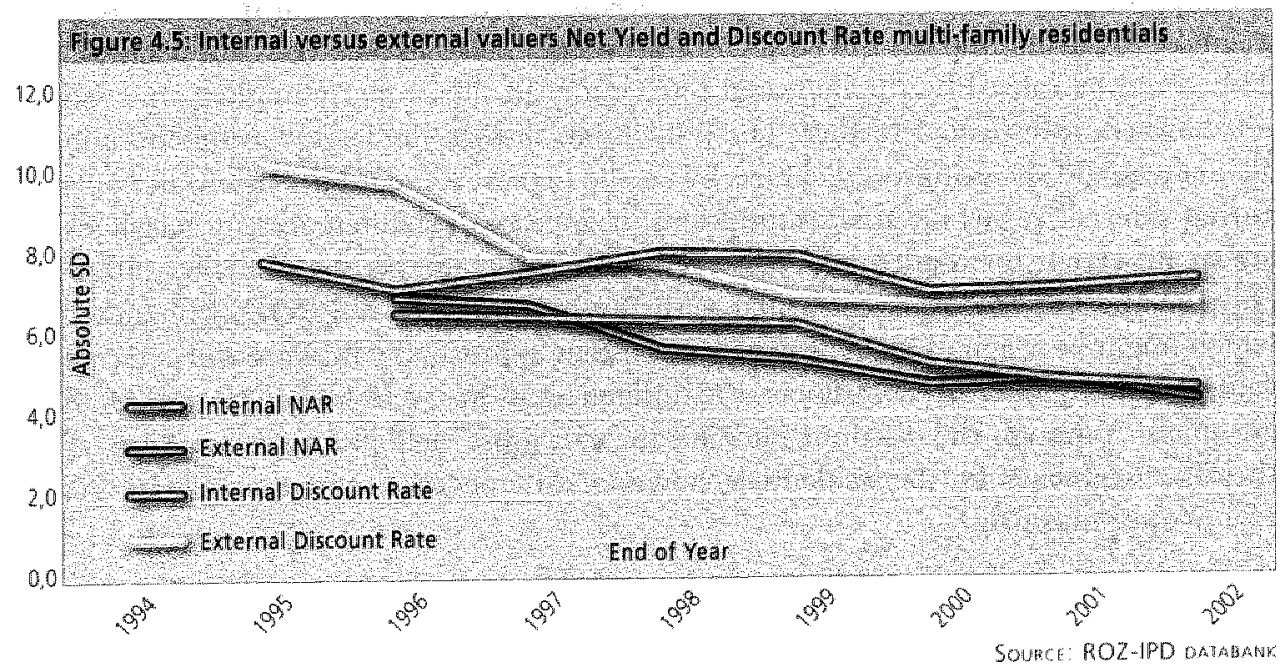


As with the standard deviation analysis, the exit gross yield displays the largest variatons in all three categories: retail, offices and residential. Ignoring the levels of the net yields, discount rates and exit gross yields by internal and external valuers, the survey also showed the following. The differences between the external valuers are rather large, especially for the residentials. The standard deviations for the net yield are $0.6 \%$ at the most for retail and offices; however, the differences for the residenrials are larger, often between 1\%-1.7\% points per year. As for the discount rate, the differences between valuers is also as high as $1.7 \%$ points for the prime locations in the large city centres. The very small standard deviations are particularly remarkable: $0.0 \%$ and $0.3 \%$ respectively, which means that for 50 properties, a certain waluer employed the same discount rate. Unlike offices, where the differences are not that high, the differences between the residential valuers are once again enormous, often more than $2 \%$ points. The same holds for the exit gross yields in the residential caregory.

\subsection{Conclusions}

The main purpose of this chapter has been to determine whether or not external and internal valuers apply consistent and uniform valuation models and calculation methods. Therefore the more qualitative elements in valuations, such as general principles and the use of the ROZ valuation regulations supplied have been examined. Also, statistical analysis has been applied to several property segments of the Index databank, to find out differences in assumptions on the input variables net yield, discount rate and exir gross yield, in order to determine whether uniformity has improved over time.

As far as the qualitative analysis is concerned, the main conclusion is that valuations should be checked by the principal for compliance with the valuation regulations much more than is the case at present. The impression is that a lot of improvement might be achieved if principals take more notice of the correct way to apply market evidence, foundation of yield and discount rate, inflation rate (especially Hexible inflation scenarios) and if there is more uniformity in timing of the cash inflow and outflow (per year in arrears, quarterly in advance etc.).

The answer to the question of whether uniformity of assumptions on the input variables has improved is "no". The standard deviation of the variables in most sub-segments of the main property categories, offices, residentials and retail, did not decrease. "This could be caused by the increased uncertainty in the property market; this was not however investigated further. The residentials display the largest differences in all analyses and the exit gross yield has by far the highest standard deviation. In comparing external versus internal assumptions, it appears that differences in net yields are small, except for residentials. However, some sub-segments show smaller differences in the last few years compared with the beginning of the ROZ-IPD Index, which might be a sign of an increasingly consistent approach by internal and external valuers. Among the external valuers, the differences in net yield for offices and retail are small. Although the discount rate and the exit gross yield are rather uniform in the office segments, for the residencials, however, differences of more than $2 \%$ in one year are not unusual. 


\subsection{Recommendations to improve the ROZ Valuation guidelines}

Looking at the different approaches in valuations, it is clear that the walluation regulations need to be adjusted. The inconsistencies are mainly in the DCF model, which is why it might become necessary to have the valuation models checked or certified by the ROZ-IPD Index. Looking at the lack of uniformity found in the valuation models, the aim should be to arrive at a uniformly applied DCF model incorporating the following elements: an insightful explanation of the assumptions concerning the input variables, a ROZ-IPD prescribed risk-free rate as part of the discount rate, a prescribed, flexible inflation scenario that is adjusted to market changes every quarter, a duration period of ten years, a clear insight into the method of discounting the cash flows. This could possibly also be prescribed by the ROZ-IPD, as a residual value based on the net cash flow of year 11/exit gross yield/1.07. To make sure the cash flow in year 11 is not manipulated, a valuer could be required to apply the average cash How of for example the years 10,11 and 12 plus a clear insight on how the valuer came to the end value: was it because he/she took the average of the income capitalization model or the DCF model or was the average of both models taken?

Furthermore, every participant should be notified of a change in valuation regullations at the same time and it should be the participant who has to make sure its valuers are familiar with the latest regulations. Also, there should be a penalty regulation for participants who fail to adhere to the regulations systematically. Finally, the ROZIPD Index should be able to do more with the assumptions and dara delivered by the valuers. The valuers could for example receive feedback on the assumptions in the total benchmark or sub-segments, as happens in the Swedish IPD Index. In this way, a more transparent valuation process is created. It is hoped that this research will stimulate the efforts of borh valuers and owners to improve on these unnecessary inconsistencies, so that the ROZ-IPD Index can continue to grow as a trustworthy investment policy instrument. 


\section{APPENDIX}

\section{A.1: VAluATION GUIDELINES ROZ, LAST UPDATED IN JUNE 2004}

\section{Introduction}

For the purpose of the ROZ-IPD Netherlands Property Index, the value of the properties to be included will have to be determined periodically. Currently, valuations can vary considerably. The determination of a value is also dependent on the purpose for which the waluation is carried out. In addition, there are differences in the level of detail of the foundation and methodology of the valluation. Due to this, the danger arises that non-comparable measurements enter into the Index. To prevent this, it is necessary to prescribe a valuation model to be used both internally as well as externally. The model prescribes rules with respect to the choice of valuation models and their justification. It is aimed at a verifiable clear financial calculation.

\section{Determination of the term "Value"}

The determined value for the purpose of the ROZ Netherlands Property Index is the "Market Rental Value": the estimated amount in case of a private sale after the vendor has put the property on the market afrer adequate preparation, whereby the buyer accepts all conditions of the current rental contracts including all privileges and duties (def, 26.4).

\section{Permitted Valuation Methods/Models}

In the context of the ROZ-IPD Netherlands Property Index, two valuation methods are permitred: the so-called "conventional method" and the "discounted cash flow method". The way in which both methods should be justified in financial terms is indicated in paragraph 6 "Guidelines".

\section{The Conventional Method, based on the Gross Initial Yield/Net Initial Yield approach}

This method is based on:

- The estimated cash flow on a market rent basis

- Deducrible entries for owners' expenses which are in conformity with the marker

- Valuation, via realisation of the net returns, of comparable transactions

Potential correction entries for, among others, initial wacancy and for the present value of the difference between actual rent and market rent, overdue maintenance, possible future renovations, etc.

The conventional method has the following advantages:

- Easy to determine

- Market-technically a good yardstick for comparison

- Easy to conmunicate

The conventional method has, among others, the following disadvantages:

- A discrepancy between the NIY in valuations, and the GIY in the case of new investments 
- The NIY becomes less reliable when there are only a few narker ransactions

- There are hidden assumptions in the NTY, esnecially the assumption that there will be an infinite rental income stream at the level established at the valuation. It allows for some freedom in correcting for, for example, a big difference berween market rent and contractual rent

\section{The Discounted Cash Flow method (DCF)}

This method is based on:

- A spreadsheet with cash flows for a term of at least ten years.

- An assumed residual value in the last year.

- The desired IRR percentage to be applied as the discount factor:

The advantages of this method are:

- Good insight into the devellopment of costs and revenues over the period

- Verifiable results because of the clarity of the method

- No "hidden" assumptions possible

The disadvantages of this method are:

- Assumptions have to be made with regard to the end value. These are sometimes too optimistic, which can largely be attributed to the relationship between the associated cap rate and the cap rate in the first year (the Gross Initial Yield in the first year is completely different from the required return)

- Assumptions have to be made with respect to the discount rate percentage (which are not always clear)

\section{Guidelines for the determination of Open Market Rental Value}

In the context of the ROZ-IPD Netherlands Property Index, two valuation models are permitted, as stated previously, the DCF method and the conventional method. In current properry practice there is a wide diversity in the application of the two methods. In the context of the ROZ-IPD Netherlands Property Index, aiming to streamline all these differences is not feasible. Nevertheless, the degree of freedom in the valuations has to be restricted somewhat and particularly the financial calculation should be as clear as possible. The ROZ Property Index Foundation has decided to set out guidelines, both for the application of the conventional and DCF method, relating to their financial justification. These guidelines follow below:

Choice of method - Only the GIY/NIY method or the DCF method are permitted for valuations. The aim should be to use the method chosen again for the next year. The DCF method is preferred when:

a Large expenses for investment, renovation or maintenance are to be expected over the next five years (more than $35 \%$ of gross annual rent).

b More than $50 \%$ of the leases will expire in the next five years. This guideline does not apply for individual shop units.

If in these cases the GIY/NTY method is applied, however, it has to be accompanied by a comprehensive explanation. 
Operating costs and revenues - Normally the valuer assesses operating costs and revenues which conform to the market, i.e. an average yearly partern of for instance maintenance expenditure. These assessments have to be well substantiated, especially concerning market rental trends and vacancy estimates. As a guideline, the valuer estimates all costs and revenues and possibly supplements these with as yer unspecified costs or revenue categories. The assessment should be based upon an average of at least five years ahead.

Net yield - The net yield is the percentage used in the valuation to calculate the gross capital value (see framework GIY/NIY - valuation). The yield used should be based on the market. The determination of the yield is typically regarded as the responsibility of the valuers. In addition, their independence would be at stake if client funds were to prescribe yields. As a guideline, a clear justification should be given for the yield. This also applies to internal valuations. The foundation of the yield when used for GIY/NIY method must dilate on:

- General property risks

- Risk connected to the property type

- Property specific risks

- The risk must be quantified as far as possible

In addition, the yield applied in the previous year should be specified. Any changes should be justified in terms of changing market conditions or changes in perspective at project level.

\section{The derivation of the IRR (required return/discount factor for the DCF method)}

- Valuers using the DCF method derive the required return on state loans plus a premium which varies according to the property type, and a property specific risk. As a guideline, a clear justification needs to be given for the derivation of the chosen IRR percentage (discount rate for the DCF method). The chosen discount rate, the rerm (minimum 10 years), as well as the rate of return which underlie the residual value calculation, should be stated explicitly.

For the ROZ-IPD to be able to conduct better comparisons of the exit gross yield, the exir gross yield must be stated when using the DCF method with a 10 year term. The gross initial yield must be based on the forecasted cash fows of the beginning of the $11^{\text {th }}$ year. The total should be a rate of return which can be substantiated as typically required by investors in that particular property type and category.

Interest rate for correction entries in the conventional method - The valuer must increase the risk free returns with a premium to be determined by the valuer. For the risk-free returns, the interest on a 10 year state loan is used.

Vacancy - In the conventional method, it is possible to include the rental value of vacancy as costs in the gross-net differential, and also as a (discounted) correction entry after the valuation. It has proven necessary to bring some uniformity into this. The guidelines for the various types of vacancy are as follows: 
a Actual vacancy is a cash flow item and as such only has informative value for the valuer in the appraisal process.

b Structural vacancy is included in the gross-net differential. This relates to vacancy arising due to market-technical circumstances. This can be due to general market condirions (structural oversupply) as well as to the property concerned (difficult to lease due to obsolescence, location, etc.).

c Friction vacancy: once-off when a major tenant leaves. In that case it will be a (discounted) correction entry after the valuarion. Continuous, for instance an office with many tenants where there is always a certain vacancy level. The gross-net differential must be included.

d Initial vacancy: this occurs on completion of a building which has not been fully pre-ler. This can be entered as a correction on the valuation up to two years after the completion, after which it becomes structural (see b.).

Comparable transactions - A minimum of three reference transactions should be included for market rents (per sqm.) as well as the yield. These reference transactions should be substantiated as comparable transactions. In case of a small market or minimal investment activity, transactions in comparable towns or past transactions (max. three years back with explanation) may be used. Reference to market reports will also be acceptable, as will references/transactions from the (fund's) own portfolio (as long as comparability of market scenario and the property to be valued are kept in mind).

Inflation - Valuers use many, often very different, sources to determine inflation, which leads to large inconsistencies (sometimes 10 to $15 \%$ value difference due to difference in inflation estimate). The percentages the ROZ Property index prescribes originate from the Consensus Forecast. The inflation percentages are updated twice a year. Percentages below are from October 2003. The prescribed percentages only apply to contact rent. For building costs and exploitation costs, other percentages must be used.

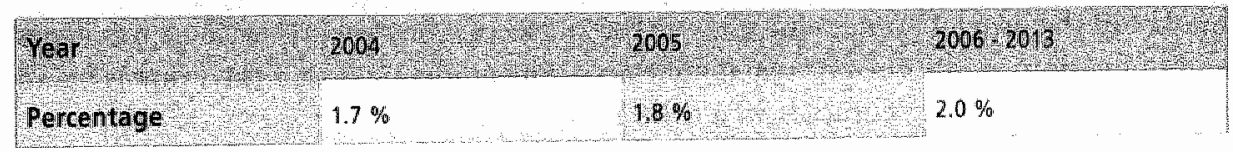

Intermediate investments - If large investments, renovations or mainteriance expenditures are expected within the next five years, these must explicitly be incorporated in the valuation.

Value determining factors - All issues which have relevance to the result of the valuation musc be noted (back maintenance, renovation/upgrading).

Definitions - Standard definitions as mentioned in the separate definition list must be used. 
Frequency of valuation - Participants in the Index must have each property in their portfolio valued, externally, at least once every three years. The variables which have been used for internal valuations musc be externally examined.

\section{Additional guidelines for retail property on which procedure 1632 a can be applicable}

It is unrealistic, when valuing a retail property (and other commercial properties ex article 7A:1624 Dutch Civil Code) to use the market rent when this market rent is not obtainable due to procedure $1632 \mathrm{a}$.

In these cases the valuer can determine a achievable rent review rental value (as consequences of Dutch law) justified by the market rent. On this basis a value will be determined. The achievable rent review rental value is a percentage of the market rent. Research (September 2002) shows that the achievable rent review rental value in $86 \%$ of the cases for retail properties up to $200 \mathrm{sqm}$. lies between 60 and $90 \%$ of the market rent.

The valuer can however further deviate, also above $100 \%$ when there is a downward market. The determination of the deviation is a matter for the expertise of the valuer. He must however justify the achievable rent review rental value used.

\section{Additional guidelines for the determination of the market value of private dwellings}

Even though there are a number of similarities with respect to the guidelines for offices and shopping centres, there also appear to be a number of obvious differences. For both, the valuation method as well as the manageable market rent value for private dwellings deviant guideline is used.

Valuation of dwellings - The point of departure with respect to the $R O Z$ valuation remains the property's open marker value. The estimated yield in case of a private sale of property when the owner, after ample preparation, has put the property on the market in the usual manner, whereby the buyer accepts the property with all privileges and obligations of the current rental contracts. The guideline is that the value is based on the sale of an entire complex to a third party.

Sale of an entire complex to a third party - This means considering the highest affordable price a party could offer, usually taking into considerarion the effects of individual sales of the dwellings. As a rule dependent on the muration level, the rate of possible property gain is determined by considering the market value development, interest and possibilities of sale to present tenants.

The cash value of this yield is subsequently used to determine the present value. These calculations usually are done by parties who generally buy private dwellings by the complex from institutional investors and subsequently sell the dwellings individually. With respect to this kind of transaction, the market is generally limited to dwelling complexes built 15 to 20 years ago. 
Recommended is calculating the sale of individual units by the present owner. "The valuer must, in case of a sale of a dwelling complex to a third party, state what percentage the sale of individual units is of the vacant value as of the date of the valuation. As reference, the vacant value can be used, as published by the NVM for 80 residential areas every quarter.

Market rent value vs. actual rent - Most valuers use, as point of departure, the actual rent and not the market rent value, arguing that the market rent value is not easily attained due to rent protection. Often the market rent value goes up faster than the periodic rent increases, which creates the situation that the tenants pay relatively less rent than would be attainable market-technically. Even though it deviates from the point of departure used in the case of commercial propercy, this approach corresponds to the actual cash flows, which is why the $\mathbb{R O Z}$ maintains it. The guideline is to use the actual rent in the valuation and not the market rent.

Sale hindering conditions - When a property cannot be sold for a period of time due to external restrictions (e.g. agreements with the municipality or social housing organisation), all cash flows in this period must be capitalised and not the value mutations due to possible sale of individual units. This is only again permitred from the moment the property is sold.

Valuing dwellings above retail - When valuing dwellings situared above single shops, no sale by the complex value to a third party should be calculated. The reventes should be included in a DCF model, while using a net return method. This adjustment does not apply to dwelling complexes situated above retail.. 
APPENDLX 4.A..2: DUMMY MODEL

\begin{tabular}{|c|c|c|}
\hline Mollo parameters & xenanto & scenario? \\
\hline Perhod (n vears) & 10 & 10 \\
\hline Oiscount rate & 7 & 7 \\
\hline Inflation & $2.5 \%$ & $25 \%$ \\
\hline Yearly rental increase $\%$ & infllation & Inflatsan \\
\hline Exit held & $70 \%$ & $80 \%$ \\
\hline Gross cash flow year 10 & 125 & 125 \\
\hline Met exat value & 1784 & 1561 \\
\hline Gross market value & 1630 & 1516 \\
\hline Difference with scenario 1 & . & $6.96 \%$ \\
\hline Difference withi scenario? & $-6.96 \%$ & \\
\hline
\end{tabular}

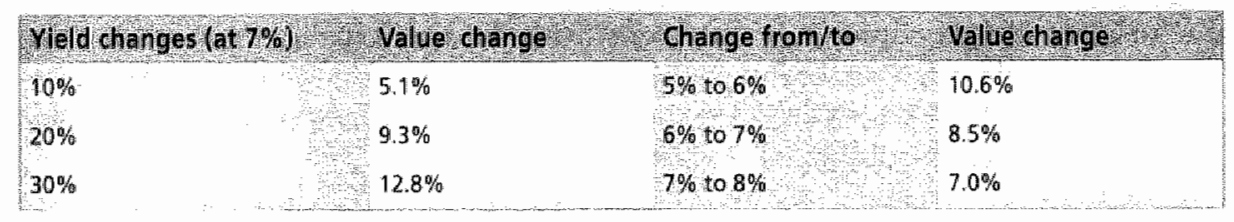

\begin{tabular}{|c|c|c|c|c|c|c|c|c|c|c|c|c|}
\hline Discounted net exlt value & & औ? & & & & & & & & 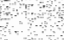 & & 1907 \\
\hline Yeat" & 1 & 2 & 3 & 4 & 5 & 6 & 7 & 8 & 9 & 10 & Total & \\
\hline Inflation & $2.5 \%$ & $25 \%$ & $2.5 \%$ & $2.5 \%$ & $2.5 \%$ & $2.5 \%$ & $2.5 \%$ & $25 \%$ & $2.5 \%$ & $25 \%$ & & \\
\hline Total gross income & 100 & 103 & 105 & 108 & 110 & 113 & 116 & 119 & 122 & 125 & 1120 & \\
\hline Discounted gross income & 97 & 9 & 89 & 85 & 81 & 78 & 75 & 72 & 69 & 66 & 803 & 803 \\
\hline Total operating costs & 10 & 10 & $\|$ & 11 & 11 & 11 & 12 & 12 & $\$ 2$ & 2 & 112 & \\
\hline biscounted operating costs & 10 & 9 & 9 & 8 & 8 & 8 & 7 & 7 & 7 & 7 & 80 & \\
\hline Gross market value & & & & & & 3 & & & & & & 16 \\
\hline
\end{tabular}

\begin{tabular}{|c|c|c|c|c|c|c|c|c|c|c|c|c|}
\hline \multicolumn{13}{|l|}{ Discounted net exit value } \\
\hline 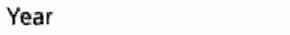 & 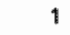 & 2 & 3 & 4 & 5 & 6 & 7 & 8 & 9 & 10 & Tottal & \\
\hline inflation & $2.5 \%$ & $25 \%$ & $2.5 \%$ & $25 \%$ & $2.5 \%$ & $2.5 \%$ & $2.5 \%$ & $2.5 \%$ & $2.5 \%$ & $2.5 \%$ & & \\
\hline Total gross income & 100 & 103 & 1015 & 108 & 110 & 113 & 196 & 119 & 122 & 125 & 1.120 & \\
\hline Discounted gross income & 97 & 93 & 89 & 85 & 81 & 78 & 75 & 72 & 69 & 66 & 803 & 803 \\
\hline Totall operating costs & 10 & 10 & $1 \%$ & 11 & 11 & 11 & 12 & 12 & 12 & 12 & 112 & \\
\hline Discounted operating costs & 10 & 9 & 9 & 8 & 8 & 8 & 7 & 7 & 7 & 7 & 80 & 80 \\
\hline Gross market value & & & & & & & & & & & & 1516 \\
\hline
\end{tabular}




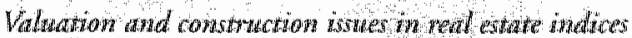




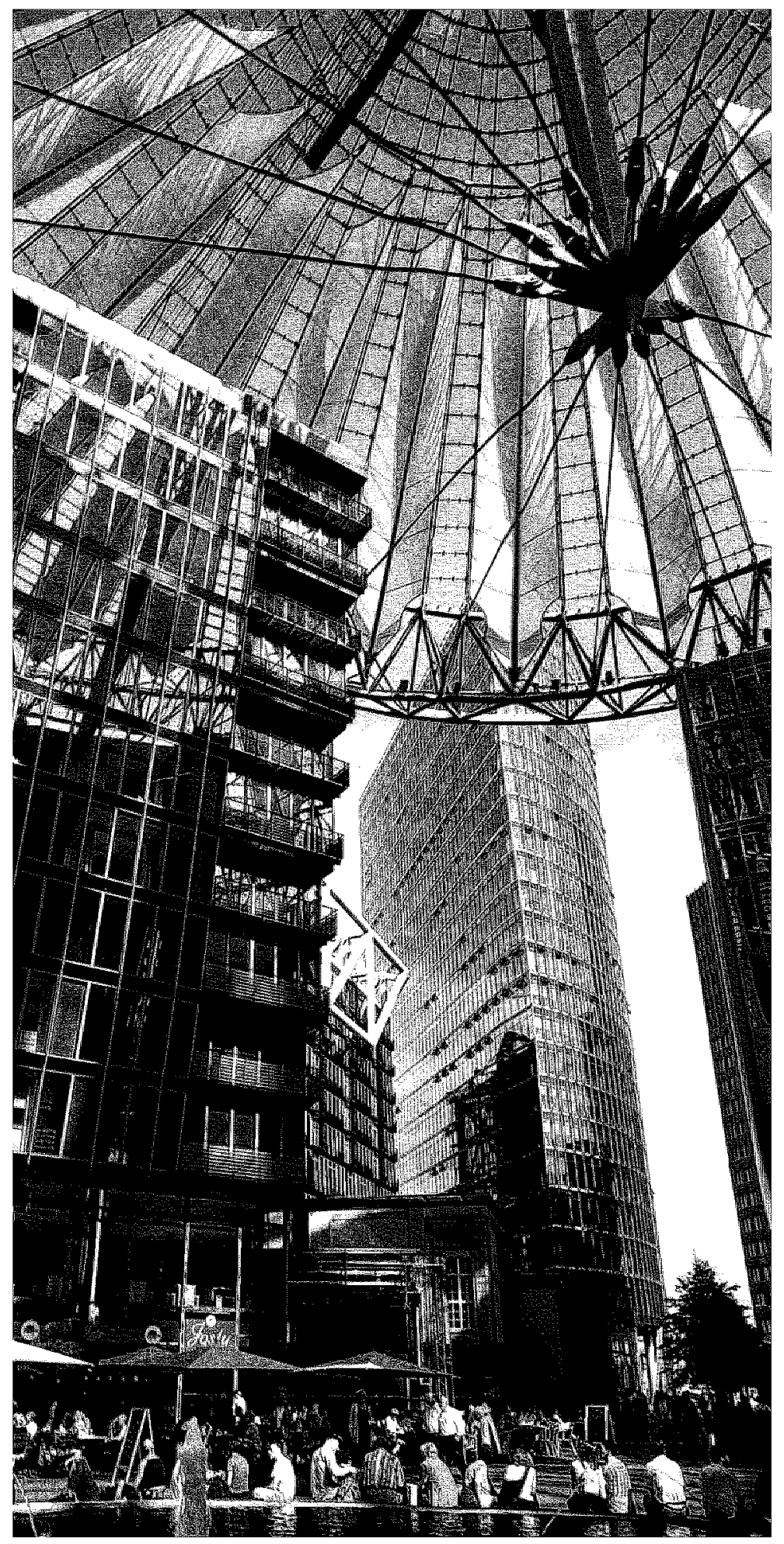




\section{CHAPTER 5}

\section{Valuation accuracy in real estate indices'}

\subsection{Introduction}

This is the first time that waluation accuracy has been studied in the Netherlands concerning commercial real estate held by instirutional investors, using the

1 unique ROZ-IPD index valuation and sales data since the start of that index in 1995. The valuation method used is the market value acconding to the International Valuation Standards version 2 (IVS 2) and the American Institute for Management and Research (AIMR) standards as described in their Global International Performance Standards (Gips). Those standards have become even more important since the introduction of the International Accounting Standards (LAS) as of $1^{\text {s1 }}$ January 2005.

In the absence of continuously traded markets, commencial property appraisals perform an essential function in the property market as a surrogate for transaction prices (Fisher et al, 1998). It is commonly understood that such appraisals fail to capture the true market volatility (smoothing effect) and tend to lag the underlying performance (Gelmer and Fisher, 2000 and Cho et al, 2003). As a result, issues such as the level and narure of appraisal uncertainty and the causes and existence of smoothing and lagging have generated substantial research literature in the USA and the UK.

The principle that freely traded assets in a competitive market provide a useful reference point for determining the value of other similar assets is widely adopted in real 
tive to the average return. However, a property index should reflect true market volatility as much as possible and valuations are the best estimate of a transaction price at a certain moment. Therefore, the aim of this chapter is to determine the accuracy of valuations, based on the latest valuation and the achieved selling price.

The main focus of this chapter will be on valuation accuracy in commercial real estate. Residential property is also a major investment category for institutional investors in the Netherlands: by the end of 2003 , almost $43 \%$ of the universe in the ROZ-IPD index consisted of residential investments. However, to study valuation accuracy in the case of residential real estate is more difficul because of the valuation method and the nature of the selling process. In the case of residential real estate, the highest value will be achieved by a potential buyer who does not plan continuous operation of the investment, but will sell residential units to private individuals when these become wacant, or to sitting tenants with or without a discount on the selling price. Looking at the ROZ-IPD databank, a variety of factors can explain the difference berween the valuation and the selling price. These can be the frequency with which wacant residential units will be sold, whether (and what kind of) discounts will be given to sitting tenants if they buy their unit and if the remaining residential units are kept in the portfolio or whether those are sold as a whole, normally via a tender. Because of this variety of factors underlying the difference berween the valuation and the selling price, and the fact that comparable figures from the IPD in the UK don't include residential investments and the NCREIF in the USA only has a small fraction in apartments, institutional residential investments are excluded from the main survey.

The ultimate test of the accuracy of an appraisal is the subsequent selling price of the property itself, assuming an 'arm's length transaction'. Particularly when the sale occurs only a short period after the appraisal, one would not expect too much difference. In using the ROZ-IPD Index as a measure of private reall estate performance over time, it is important, for teliability reasons, to derermine the confidence intervals between the appraised value and the achieved selling price.

In the following paragraph, previous literature on a number of valuation accuracy items will be discussed, resulting in a focus on the systematic and random appraisal error in valuations. In order to quantify the systemaric as well as the randon error, the methodological section describes in detail the way in which those differences might be quantified. This is followed by a comparison of the characteristics of appraisalbased real estate indices, such as the ROZ-IPD Netherlands Property Index, in the international context of the IPD index in the UK and the NCREIF index in the USA. The subsequent paragraph outlines the results, while the final paragraph discusses the main conclusions of the research, additionally endeavouring to place the differences in a different context by comparisons with similar processes in the case of shares.

\subsection{Literature}

In real estate literature, there is considerable analysis and investigation with regard to smoothing and lagging effects. Smoothing, in the context of appraisal-based property series, has been assumed to refer to an under-representation of true variance. 
Commonly observed statistical qualities of property returns indices are relatively low levells of standard deviation, non-normality in positively skewed returns and relatively high and persistent levels of serial correlation positively linked to frequency of performance measurement and underlying valuations (Baum et al, 2000).

As well as under-representing the extent of market change, it is also generally accepted that appraisal-based series fail to accurately record the timing of market movements, the so-called lagging effect. In previous price theory literature, it has been consistently found that market change in securitised property investment provides a leading indicator of market change in non-securitised markets. However, researchers have been cautious about concluding that there is a structural lead/lag relationship. It has been argued by McAllister and Tarbert (1998) that there are strong grounds for concluding that a significant proportion of any lag reflects delayed recording of market change due to the use of appraisals. In the appraisal accuracy literature, Matysiak and Wang (1995) look at the accuracy of appraisals in different market states and suggest that appraisals are higher than selling prices when the marker is falling, and wice versa. This is consistent with studies in both the USA and Australia (Webb, 1994; Newell and Kishore, 1998).

With reference to Webb (1994) it should be taken into account that the disaggregate appraisal error is not the difference between the appraised value and the subsequent transaction price of the property in question, as a result of smoothing and lagging, but rather the difference between the appraised value and the market value of that particular property. Brown and Matysiak (2000) and Parker (1999) refer to the fact that professional valluers are faced with the practical problem of preparing valuations in a market that is infrequently traded. Therefore the information used to form a valuation may be incomplete. As appraisers respond to this in different ways, it becomes clear that behavioural issues cause random errors in valuarion processes. Parker (1999) concludes that a variety of practical limitations have a serious impact on valuations and should be investigated further.

Based on an IPD dataset, Drivers Jonas (from 1988, biannually) used the total variance test to compute the difference between an individual valuation and its subsequent sale price, expressing this as a proportion of the achieved sale price. The resulting distributions clearly demonstrate a pattern and spread of valuation estimates around the target price.

Liziery and Venmore Rowland (1991) studied the probability of achieving a selling price within acceptable size bands. If a $70 \%$ probability of achieving a sale price is required, a range of $20 \%$ above or below the previous valuation should be accepted. If only a $10 \%$ difference between the valuation and the sale price is acceptable, the probability of achieving this drops to $30 \%$.

Bearing in mind the necessary distinction between errors caused by smoothing, lagging and behavioural issues, Cullen (1994) used the partitioned variance test to quantify the random error in valuations. This method takes the simple descriptive analyses 
of the total wariance test one step further by splitting the overall measured differences berween valuation and price into systemaric components, like market changes berween valuation and actual sale date and random components, which cannor be easily quantified. He concluded that valuations tend to be less accurate in rapidly changing markets, resulting in $25-30 \%$ larger differences. However, the random error is not influenced by market circumstances and is stable at around $5 \%$.

Apart from smoothing and lagging issues, Geltner et all (1994) studied the random disaggregate error which might be caused by an inability to perfectly adjust for differences between the subject property and comparable properties or by an ability to perfectly match the market's assumptions regarding expected furure rents and discount rate, etc. In essence, their procedure combines a model of appraisal error with the market model of true real estate returns. By subtracting the observable aggregate return, they were left with disaggregate residuals. These residuals were composed of staristically independent components, one of which is the random disaggregate appraisal etror. By analysing the relationships between true volatility, appraisal smoothing, the magnitude of random appraisal error and heterogeneity, they found that the random disaggregate error in the Russell-NCRELF databank has been in the range of $6 \%$ to $13 \%$ of the underlying property value.

Fisher et al (1999) stated that in the USA, the return characteristics of the NCREIF Property Index (NPI) have been well researched, and it is generally accepted that the index lags and is less volatile than the underlying private transaction market. These characteristics make direct comparisons with public marker performance indices difficult. Much of the past work on the NPI lag is summarized by Gelmer (1998). Geltner uses repeat measures regressions as well as an unsmoothing technique to show that the NCREIF databank is quite informarive and, with appropriate statistical adjustments, the NPI proxies reasonably well as a measure of quarterly private marker changes. However, even with the adjustments suggested by Geltner, the NPI is based on appraisals and its accuracy is a function of the reliability of the individual appraisals.

Mallison and French (2000) addressed the issue of uncertainty in property valuarion. They describe the consequences of the conclusions from the Mallinson report (1994). The conclusions were that all valuations are uncertain and that the appraisers should, when necessary, expand not just on the details of the property but also on the valuation itself: its dynamics, irs irrelariveness and its uncertainties. If abnormal uncertainty exists, the appraisers should be able to report this uncertainty as part of their disclosure statement.

Regarding previous research on lagging of valuations, Clayton et al (2001) found an average of nine months lag. To put this in perspective, Fisher et al (1999) found at least wo quarters. Blundell and Ward (1997) found 4.5 months and the IPD/Drivers Jonas studies found more than nine months, using annual data. In the opinion of several major valuation firms in the Netherlands, interviews revealed that in general a nune-month lag is considered on the high side and may only be applicable during a market slowdown with little selling acrivity. 
In general, the research studies discussed mainly concentrated on valuation accuracy and the random appraisal error in the mature real estate indices and markers of the UK and USA. In appraisal accuracy literature, it has been pointed out dearly that appraisals may sometimes be a self-fulfiling prophecy, as market participants and intermediaries are influenced in price determination by historic appraisals. As discussed above, the random error is also strongly related to market efficiency in terms of the trading frequency and liquidity of certain markets. Therefore, this study will investigate the valuation accuracy and systematic and random appraisal error found in the real estate investment market of the Netherlands, which can be expected to have a lower market capitalization and less liquidity in comparison to the USA and UK real estate investment markets.

\subsection{Methodology}

The most obvious method of approaching the problem of valuation accuracy is to compare the actual appraised value and the subsequent achieved sale price, which is usually done by a total-variance and/or a partitioned variance test.

The total variance test involves computing the gap between each valuation and the achieved price, expressing this as a proportion of the valuation. The partitioned variance test takes the toral variance test one step further by attempting to split the difference into systematic and random components. The systematic components are mainly caused by the lagging effect in two ways: the valuation being based on historic market evidence (information lag), and the varying period between the dare of the latest valuation and the date of the sale transaction (rime lag). The analysis is carried out on a yearly basis, allowing international comparison with the UK and the USA.

In addition, the variation in the random error per month has been reviewed. When it is known that the length of time between appraisals and subsequent sales varies widely, the differences as such are acrually not comparable. Therefore this research suggests that deviations between valuations and transacrions should be incerpolated into a monthly figure, which is the smallest unit of time for making a correct analysis. The interpolation into monthly differences can be done using the following formula. The results are shown in the appendix.

$D i f f_{A p p_{0} \text { satis }}=\left[\left(1+\frac{S a l e_{m}-A p p_{0}}{A p p_{0}}\right)^{\frac{1}{m m}}\right]-1$

with

Appo Appraised market value at $\mathrm{t}=0$

Sale Achieved net sale price

$\mathrm{m} \quad$ Period between date of appraisal and date of sale in months

The research in this chapter will apply the partitioned variance test, in accordance wich Fisher, Miles and Webb (1999), Crosby (2002), Cullen (1994) and Mokrane 
investor wants to sell a very large building. Thirdly, real estate normally will have a long holding period in which no trading takes place. If one wants to measure the performance, it will be necessary to periodically value the property. However, valuations are not selling prices and will at most be the best estimates of the most probable prices. Valuations also generate specific problems such as smoothing (auto-correlation beween one valuation and the next) and lagging (valuations are being based upon transactions from the recent past and therefore will lag the current market situation).

Due to these uncertainties, there has always been a need for betrer real estate performance measurement, since pension funds and insurance companies are looking for stable and reliable returns. As far back as in 1975, the Frank Russell company started to measure real estate returns in the United States of America (USA), followed by the National Council of Real Estate Inwestments Fiduciaries (NCREIF) at the beginning of the 1980s. In the meantime, the NCREIF real estate index has become a wellestablished instrument for real estate investors in the USA. In 1985 this example was followed by the Investmenr Property Darabank (IPD) in the UK, which provides not only a real estate index but also a more extensive benchmarking service for each of the contributors to the service. Since 1995. IPD has expanded its operations in continental Europe by establishing services in Ireland and the Netherlands (1995), Sweden (1996), Germany (1997), France (1998), Spain and Portugal (2000), and outside Europe, in South Africa (1995). In the Netherlands the real estate index has been set up by the Real Estate Council of the Netherlands ( $R O Z$ ) in cooperation with IPD. Although the nine years of ROZ-IPD real estate indices is already significant, it needs more to convince institutional investors and their asset liability managers that real estate as an asser class is a stable and reliable investment.

The main purpose and motivation of this dissertation is to try to reduce the uncertainties in the performance of real estate investments for institutional investors in the Netherlands, addressing the various issues mentioned above.

\subsection{Background ROZ-IPD Netherlands Property Index}

Nearly all of the chapters in this dissertation are based on research carried out by the ROZ-IPD Netherlands Property Index. The background of the ROZ-IPD Netherlands Property Index is therefore briefly outlined below.

The ROZ-IPD Netherlands Property Index was founded with the intention of publishing an independent index of directly-held real estate investments with an institutional character. Alongside this publicly obtainable information, benchmark reports are drawn up for the members. These allow the members to compare their own results to the benchmark.

Methodologically, real estate indices are created based on confidential information about individual properties provided by the contributors, mostly institutional investors like pension funds and insurance companies as well as listed and unlisted property companies. Those indices are often used for performance measurement and benchmarking purposes. In this respect, the most imporant figures are the cash fow (net rental income) and the valuations reflecting capital growth or depreciation of each 
(2002), in order to quantify the random appraisal error by correcting for systemaric lagging elements as a result of market fuctuations between the acrual date of sale and date of appraisal. Since both dates (appraisal and sale) are known, the effect of market movements can easily be measured quite precisely by using the capiral movement from the ROZIPD Netherlands Property Index. When this adjustment, based on capital growth, has been performed, the analysis will finally determine the random appraisal erroe.

The random appraisal error can allso be divided into two components: a systematic lagging component and a random component. The systematic lagging component in the appraisal error exists as a result of the fact that appraisals are based on partially obsolete information and input, while marker circumstances have in the meantime evolved. Using the quarterly return figures from the NCREIF index, Clayton et al (2001) discovered that on average, appraisers base their opinion on nine-monthold information. From a more theoretical point of view, the effect of the systemaric lagging error due to market fluctuations on the interpolated monthly difference will be stable over time if it is accepted that annual capital movement in the ROZ-IPD Index shows a linear growth pattern over twelve months. Thus, to isolate the effect of the random appraisal error, the average monthly capital growth over the year is used to correct the total difference per month.

Within this framework, the research has also adjusted for this systematic component in the appraisal error, but the average period used to look back on this aged information and input therefore needs to be approached. The nine-month-old information lag was also found in the Netherlands by major valuation firms like DTZ, Troostwijk and Jones Lang LaSalle, although recent observations show an improvement towards a six-month lag at the date of the appraisal.

Another lagging element occurs because of the fact that the ROZ-IPD Index requires many end of year valuations. The last figures show that around 4,000 external valuations were produced at the end of 2002 . To schedule all this work, valuation firms will in practice start their work as early as October, which means another three months of information lag, if they don't make adjustments for this (which is generally not done).

In addition to this systematic component of the appraisal error, it has to be realized that the final result of an appraisal is also influenced by the individual behaviour and nature of the appraiser involved, which can be seen as a random residual. This residual is actually much harder to determine without information about the nature of the ransactions used in the valuation process.

Since this remaining difference is based on more behavioural elements of the appraiser, it is therefore also much more difficult to analyse. However, Cullen (1994) examined the random error between 1982 and 1993, in order to find out whether random errors vary over time depending on the state of the real estate market. But according to his findings, that did not appear to be the case. 
What needs to be contributed to the debate is whether or not the random error varies throughout the year. In the appendix, end of year valuations have been used and the random error has been examined when the propery is sold in January, February etc through December, to establish whether the random error is different depending upon the month of sale.

\subsection{Data}

From the beginning of the ROZ-IPD Index in 1995, most institutional real estare investors were represented (directly or indirectly). As a result of the investors' commitment, the overall marker coverage of the ROZ-IPD Netherlands Property Index was already extremely large, at $70 \%$ of institutional real estate investments undertaken by Durch institutional investors in the Netherlands, and the coverage has grown towards $85 \%$ nowadays. Within the perspective of investment markets' liquidity, the present coverage of the ROZ-IPD Index is compared with similar figures for the NCREIF and IPD UK Index, as stated in Table 5.1.

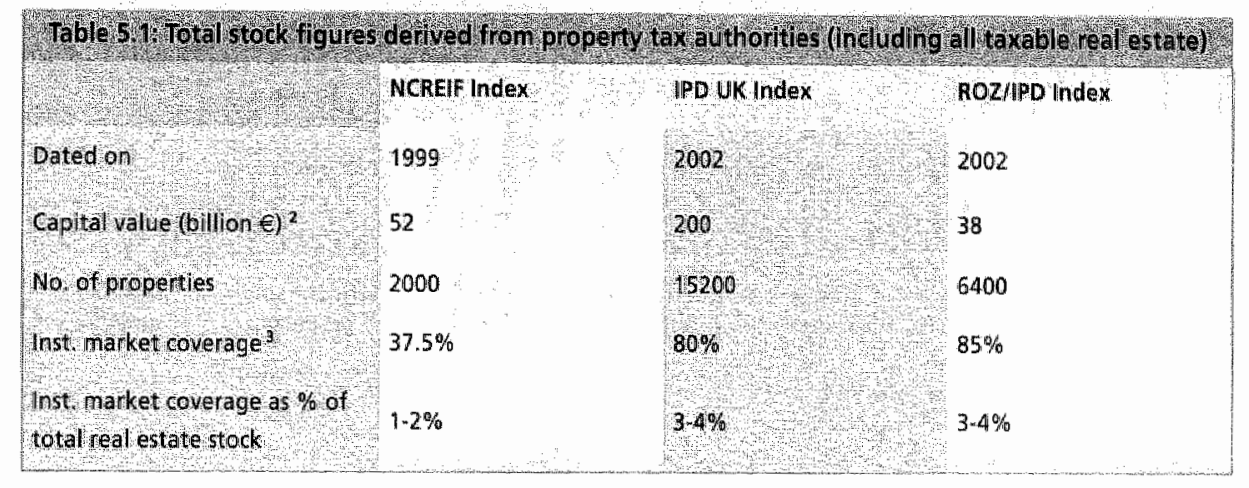

Regarding market coverage corrected for market share, the real estate investments of institutional investors in the three countries represent approximately the same percentage of the total national real estate stock. The coverage of these institutional real estate markets is between $3 \%$ and $4 \%$ of the cotal real estate stock in each of the countries. The capital value and number of properties covered by each of the indices indicate the average capical value per property. In the ROZ-IPD Netherlands Property Index, this is rather small compared with the average in the NCREIF Index and IPD UK Index. The index universe of the ROZ-IPD Netherlands Property Index has a significantly different market structure as a result of the large proportion of residential real estate investments, which generally have relatively smaller capital wallues compared with office investments. As far as retail investments are concerned, the average size per investment is also smaller in the Nerherlands than in the UK and the USA, since investments in single shop unit represent a large portion of the retail universe in the ROZ/IPD index.

The residential segment in the ROZ-IPD Netherlands Property Index has another particular feature: partial selling. During the last eight years in the Norherlands, part-

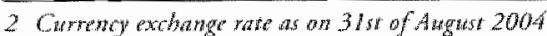

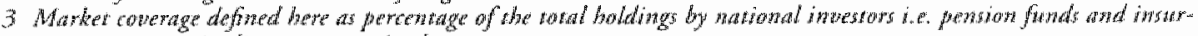
ance composties in dited propury in that costary 
selling of residential investments has been a widespread phenomenon and has turned out to be very beneficial for investors. Due to the popularity of part-selling in these years, it should be born in mind that the resulting reduction in the capital value of these properties could cause difficulties when the appraisals and subsequent sale prices are analysed. Therefore, as mentioned before, the main research will be restricted to the commercial segments. Furthermore, in cases where there was no difference between the sale price and the previous valuation, this data was excluded, on the assumprion that the sale price was already known at the date of valuation.

Due to the scale of the USA and UK real estate markets, one would expect higher liquidity than for the real estate market in the Netherlands, resulting in a more accurate price-fixing mechanism. With the release of more up-to-date and consistent transaction information, these Anglo-Saxon real estate investment markets should be considered more transparent and efficient than the comparable market in the Netherlands. As well as market capitalization, the counts of retail and office properties sold could be viewed as a proxy for the liquidity of a commercial market, as set out in Table 5.2.

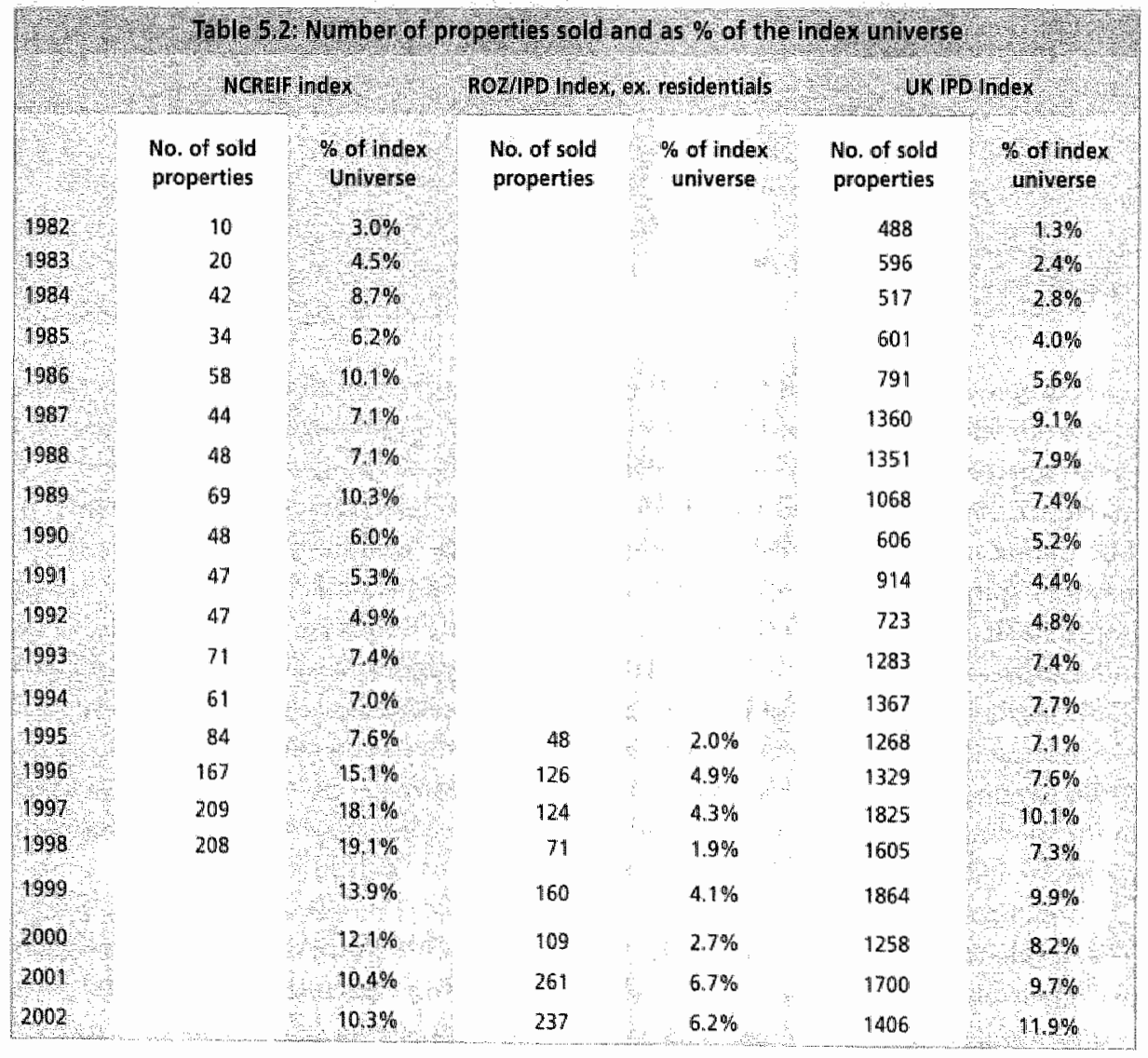

Note: NCREIF numbers of sold properties $1999-2003$ were not awailable at the time 
Alchough selling activity within the ROZ-IPD Index as a percentage of the total index universe is in the same order of magnicude as with the other indices, the numbers of properties sold for each index, related to market coverage and capitalization of each specific index, indicate roughly that a rarher small sample of properties has been traded in the institutional real estate investment market in the Netherlands over the period under consideration. Obwiously, the lack of a large number of transacrions in the Necherlands can be expected to have repercussions on the price-fixing mechanism for this particular investment market, resulting in continuous smoothing of appraisals on the one hand due to lagging the underlying market and on the other, relating to the ability of the appraiser to do an appropriate appraisal.

In accordance with Brown (1995), Lizieri and Venmore Rowland (1991), Cullen (1994) and McAllister ( 1995$)$, the application of the total variance test, which examines the difference between each valuation and the subsequent sale price, gives the following deviations per annum for each of the real estate markets studied, as shown in Table 5.3.

\begin{tabular}{|c|c|c|c|}
\hline & NCREIF index & hOZUIPD Index & IPD UK Index \\
\hline 17983 & & & $10.8 \%$ \\
\hline 1984 & & & $4.3 \%$ \\
\hline 1985 & $6.9 \%$ & & $8.3 \%$ \\
\hline 1986 & $0.1 \%$ & & $6.2 \%$ \\
\hline 1987 & $1.9 \%$ & & $14.7 \%$ \\
\hline 1988 & $-3.3 \%$ & & $15.9 \%$ \\
\hline 1989 & $-1.7 \%$ & & $20.6 \%$ \\
\hline 1990 & $-2.3 \%$ & s. & $-1.1 \%$ \\
\hline 1991 & $13.4 \%$ & 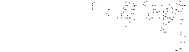 & $1.8 \%$ \\
\hline 1992 & $0.1 \%$ & & $1.2 \%$ \\
\hline 1993 & $3.3 \%$ & & $4.4 \%$ \\
\hline 1994 & $-1.4 \%$ & & $4.5 \%$ \\
\hline 1995 & $0.9 \%$ & $7.8 \%$ & $.3 .0 \%$ \\
\hline 1996 & $3.1 \%$ & $4.6 \%$ & $0.9 \%$ \\
\hline 1997 & $4.2 \%$ & $43 \%$ & $3.3 \%$ \\
\hline 1998 & $6.6 \%$ & $15.3 \%$ & $4.4 \%$ \\
\hline 1999 & $0.1 \%$ & $14.3 \%$ & $5.0 \%$ \\
\hline 2000 & $0.2 \%$ & $10.1 \%$ & $3.5 \%$ \\
\hline 2001 & $0.3 \%$ & $25 \%$ & $2.7 \%$ \\
\hline 2002 & $2.6 \%$ & $4.2 \%$ & \\
\hline Avg. & $-0.1 \%$ & $79 \%$ & $5.7 \%$ \\
\hline $\mathrm{SB}$ & $5.1 \%$ & $4.9 \%$ & $5.9 \%$ \\
\hline
\end{tabular}


Although these three indices cover different cycles in their respective real estare markets, it should be noted that the average percentage difference between sale price and appraisal in the Netherlands is higher than in the USA and UK. This could be explained by the fact that UK and USA real estate markets have greater market depth, higher liquidity and a longer performance history. However the standard deviations dont vary too much; they are between $4.9 \%$ ands $5.9 \%$.

\subsection{Results}

Many factors can be seen as causing the deviation between sale and appraisal found in inefficient real estate markets. However, if the results of the total variance test in the case of the ROZ-IPD Index are studied in more detail by analysing the distribution of the overall price/valuation match for all of the sold properties recorded from 1995 2002 , it becomes clear from the Table (5.4) that right skewness occurs. More than 75\% of the observed transactions have achieved a sale price higher than the appraisal.

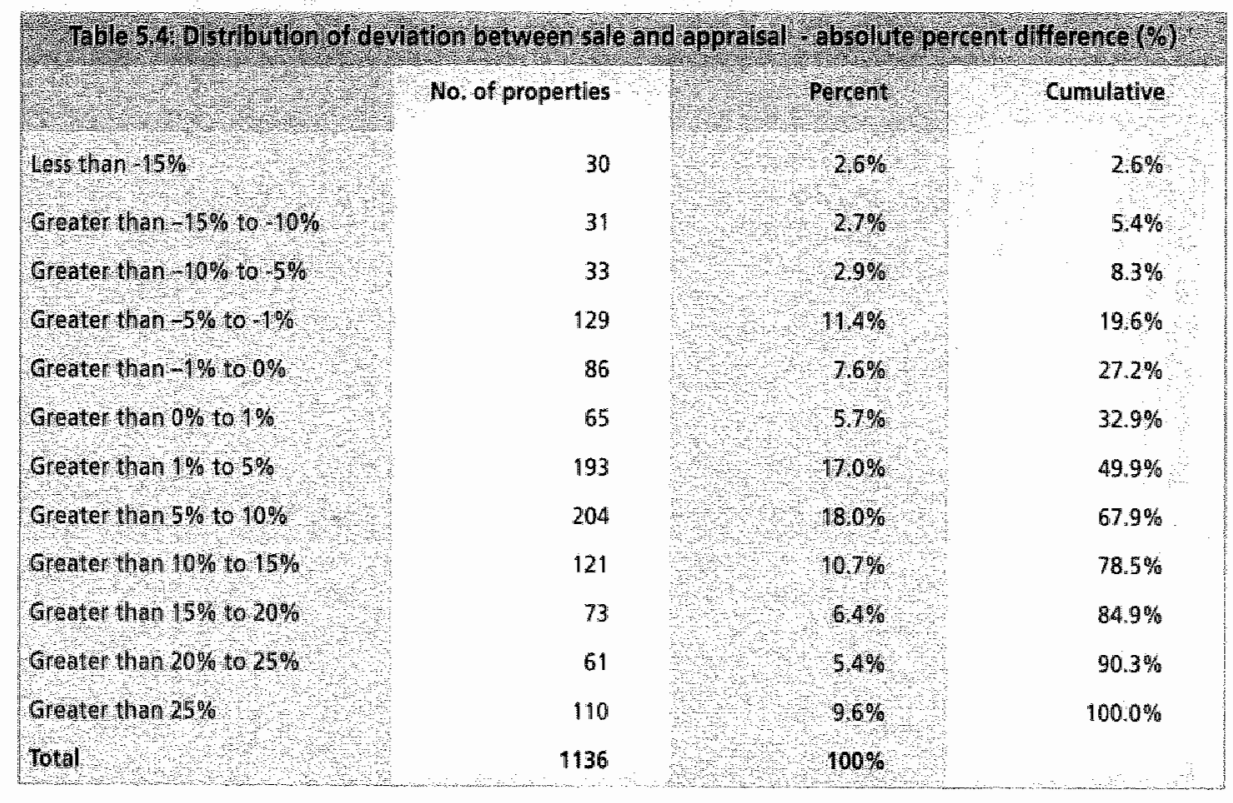

SOURE: ROZ-IPD DATAEANK

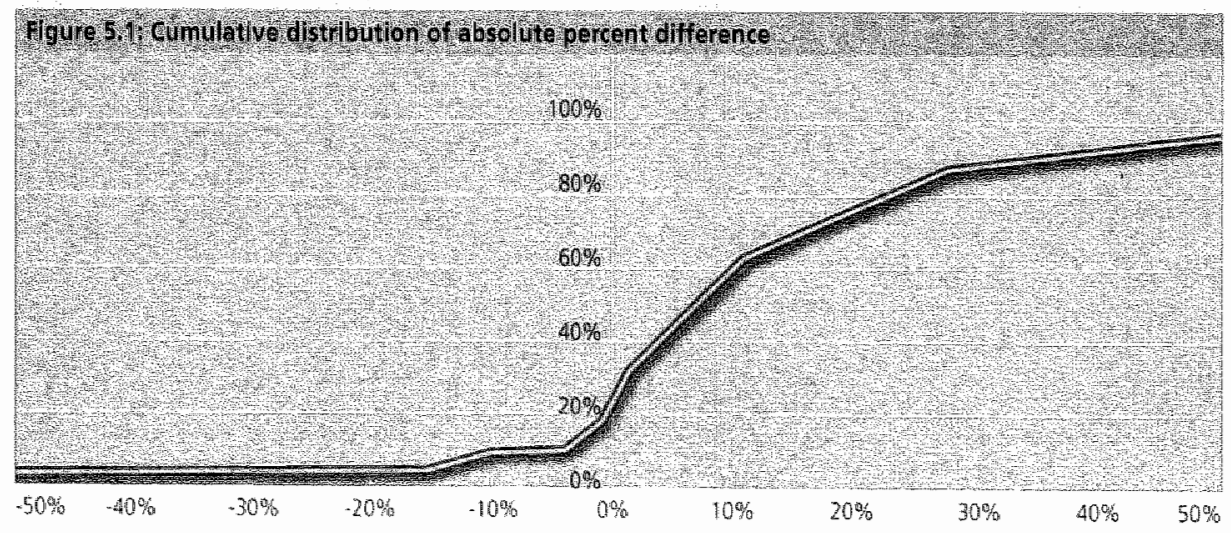


Since the eight-year period covered involves a rising market, the findings concerning the skewness have to be put into perspective. This can be done by determining the percentage of the sale prices counts per year. They have an appraisal within the range of the standard error of the absolute difference calculated to give an indication of the spread of the observations, as shown in Figure 5.2. This gives a dear picture of variations over the eight-year period. In the case of the ROZ-IPD Index the percentage varies between $75 \%$ and $85 \%$ of the observations each year; the average over the years was roughly $80 \%$. Compared with similar research performed by Cullen (1994) for rhe UK real estate investment market, the percentages of the ROZ-IPD Index are slightly higher. This observation is, however, not very surprising in view of the fact that some extreme deviations will have a more substantial impact on average and standard error in the researched sample of the ROZ-IPD Index, than in the IPD UK sample which is based on a much larger count of transaction obserwations. This Figure also indicates that evolving market circumstances can't be recognized in the pattern of the Figure as it seems that variations in the ratios are modest.

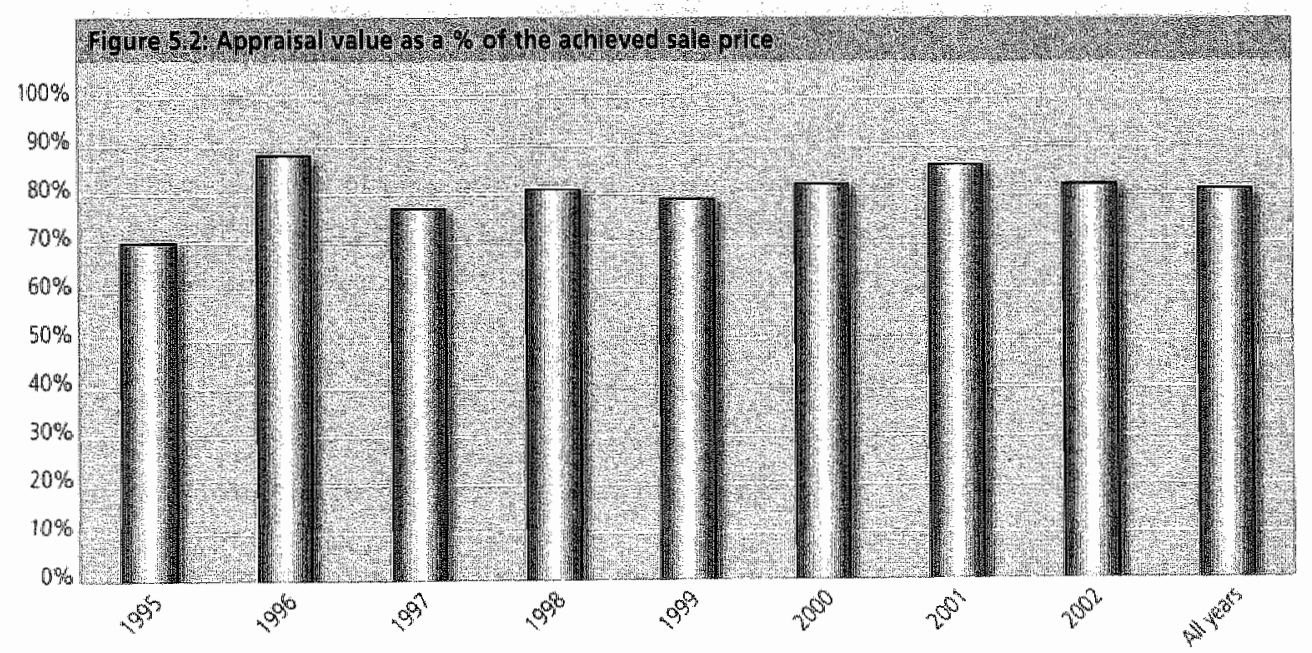

As it is highly likely that many of the sale decisions are based on a previous valuation. this confirms the hypothesis (Geltner and Fisher, 2000) that the distribution of sale prices would be partly rruncated. This reflects the fact that in the bottom half of the distribution, prospecrive sales might be withdrawn from the (falling) market, so the observed sales are not always a representative sample of the market. Baum (2002) already suggested that valuations immediately before a sale tend to be on the low side, to make the sale more probable. 'Therefore, it has to be considered that in particular, random issues like remuneration schemes (managers will always be rewarded for realised profits and not for capital losses), have had a relevant impact on appraisal accuracy over the years.

A partitioned variance test was carried out on the ROZ-IPD Index in order to focus on the determination of the random appraisal error and irs components. In relation to the previously discussed right skewed deviations and statements in the preceding 
paragraphs, the differences between appraisal and achieved sale price are explained by a systematic lagging error and a random appraisal error. It is known that market capital growth or decline occurs during the period berween the date of appraisal and the date of sale.

Table 5.5 shows the random appraisal error by correcting the total absolute difference compared with average growth rates for capital development in the observed years during the period between the appraisal and the actual sale, divided into a difference due to the time elapsing between the date of appraisal and date of sale as well as the so-called information lag, estimated at nine months for the Netherlands as previously argued.

\begin{tabular}{|c|c|c|c|c|c|}
\hline (1) & Number & Average deviation & $\begin{array}{l}\text { Market change } \\
\text { between }\end{array}$ & $\begin{array}{l}\text { Systematic info } \\
\text { lagging }\end{array}$ & $\begin{array}{l}\text { Random error } \\
\text { appraisal }\end{array}$ \\
\hline 1995 & 48 & $78 \%$ & $0.3 \%$ & $0.2 \%$ & $7.2 \%$ \\
\hline 1996 & 126 & $46 \%$ & $0.2 \%$ & $0.2 \%$ & $4.2 \%$ \\
\hline 1997 & 124 & $43 \%$ & $1.7 \%$ & $1.5 \%$ & $10 \%$ \\
\hline 1998 & 71 & $15.4 \%$ & $3.0 \%$ & $2.7 \%$ & $9.7 \%$ \\
\hline 1999 & 160 & $143 \%$ & $3.9 \%$ & $3.4 \%$ & $7.0 \%$ \\
\hline 2000 & 109 & $10.1 \%$ & $3.6 \%$ & $2.8 \%$ & $3.7 \%$ \\
\hline 2001 & 261 & $25 \%$ & $2.1 \%$ & $1.6 \%$ & $-1.1 \%$ \\
\hline 2002 & 237 & $4.2 \%$ & $1.0 \%$ & $10 \%$ & $2.2 \%$ \\
\hline Total & 1136 & 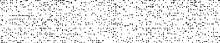 & & ?. & \\
\hline Avarage & & $7,9 \%$ & $2.0 \%$ & $17 \%$ & $4.2 \%$ \\
\hline 61 dey & & $4.9 \%$ & $1.5 \%$ & $1.0 \%$ & $3.6 \%$ \\
\hline
\end{tabular}

Table 5.5 gives a clear picture of the effects of behavioural issues in the appraisal process during different time spans. It clearly indicates that in the case of the ROZIPD Netherlands Property Index, the random appraisal error as a percentage of the appraised value has three components, the systematic information lag, the time lag and the remaining random behavioural residual. These results obviously confirm the hypothesis that behavioural effects in the appraisal process have also had a significant impact on the appraisal process. And secondly, it has to be acknowledged that timing eftects can be identified in the random behavioural residual, since its influence decreases as the respective time spans increase.

Is it fair to say that valuers are sufficiently accurate in estimating the achievable market price? To answer this question, one should look for a 'benchmark' from another similar asset class. An example of such a benchmark could be real estate shares and the way analysts try to forecast the value of the shares, followed by the achieved stock price. 
As early as 1932, in a speech at a joint meering of the Econometric Society and the American Statistical Association, Cowles (1933) discussed the issue 'Can stock market forecasters forecast?. He came to the conclusion that in all cases, the performance of the forecasters was worse than the market average, with their underperformance ranging from $1.2 \%$ to $4 \%$. In this case, one should bear in mind that the year 1929 was included in all his observations.

Elton et all (1986) examined the information content in analysts' recommendations, made on a five-point buy, hold or sell scale. The survey also included changes in analysts" recommendacions. Including changes, they found that approximately $4.5 \%$ extra returns can be earned by purchasing new buy recommendations rather than new sells.

Desai and Jain (1.995) examined the performance of common stock recommendations made by prominent money managers at Barron's Annual Roundtable from 1968 to 1991. They found that the buy recommendations earned significant extra returias of $1.9 \%$ from the recommendation day to the publication day, a period of about 14 days. However, the extra returns are essentially zero for a one to three year post-publication day holding period.

Womack (1996) found that following analysts' buy recommendations, the mean postevent drift is modest at $+2.4 \%$ and short-lived, but for sell recommendations, the drift is larger and extends for six monrhs.

In the more popular arena, the Dow Theory Forecasts newsletter was consulted. The March 2004 newsletter shows that if December 1994 forecasts had been followed, a return of $151 \%$ would have been achieved over the 10 -year period, against the S\&P index return of $126.7 \%$, which means an average yearly mismatch of around $2.5 \%$.

The problem with all those studies is that a fair comparison between analysts and valuers fail because unlike the Real Estate valuer, stock analysts only provide buy and sell recommendations but nor what the exact stock price should be at a particular time. Interviews with experts from the equity market show they are convinced that estimates of prices will never be given due to liability questions.

Maybe a better comparison might be the initial public offering, followed by the achieved stock price. Brounen and Eichboltz (2002) studied initial public offerings for Real Estate companies in the USA and several councries in Europe. They found a difference of $3.0 \%$ between the initial offering and the price on the first trading day. Is this far out of range compared with the appraisal error of between $5 \%$ to $7 \%$ in the Netherlands, the UK and the USA (even lower)? Based on research in the Netherlands, one might exclude the systematic information lag, because this exists to a much lesser extent in the stock market, but the difference will still be around $5 \%$.

If this is compared to initial public offerings for industrial companies, the difference between the initial offering and the stock price at the end of the first rading day is much higher. Ibbotson (1975) studied initial public offerings in the USA over a 
10-year period, and found a $11.4 \%$ difference between the initial stock price and the price at the end of the first trading day. Loughran and Ritter (2004) conducted a similat study over the years 1980 through to 2003 and found an average difference over that period of $6.3 \%$ between the initial stock price and the price at the end of the first trading day:

The feeling is that valuers and appraisers are doing a fine job, despite all the sceptical views of stock and bond analysts for instance, because despite the abundant flow of information which they have at their disposal, their estimates may not differ too much from the ones the valuers achieve. Unfortunately it has been not possible to prove this.

\subsection{Conclusions}

This chapter has analysed the difference between the sale price and the previous valuation over the years $1995-2002$, based on the ROZ-IPD Netherlands Property Index. During those years, an average of $7.9 \%$ was observed, based on the total variance test. The partitioned variance test was applied to correct for systematic errors, i.e. the time lag (the period between valuation date and sale date) as well as the information lag (the valuations are based on "old" data).

As far as the time lag is concerned, the correction leads to an average (random) appraisal error, which remains at $5.9 \%$. This compares with previous studies in the UK (Cullen 1994), showing an appraisal error of between $2 \%$ and $10 \%$, and the USA (Clayton, Geltner et al), showing an appraisal error of between $6 \%$ and $13 \%$, although these were based on different periods of time which also included a depressed market.

After this, a correction for the information lag at the date of the valuation was calculated and this reduced the average appraisal error to a behavioural residual of $4.2 \%$ on average. Previous literature doesn't distinguish between the different components of the appraisal error as is done in this chapter, so unfortunately no comparison could therefore be made. On the other hand, in determining the components, the input from other surveys has been utilised for each of the components.

In a few years' time, this analysis should be repeated, since it is highly likely that if results under clepressed market circumstances could be and were also included, the results would most probably be different. 


\section{APPENDIX}

As stated previously, this survey aimed to find out whether the random appraisal error would vary between the different months within the years. For this exercise; residential sales (excluding part- selling) were also included, since one can expecr to see a larger appraisal error as a result of this inclusion. The formula as explained in paragraph 5.3 has been applied to calculate the monthly corrected deviations for the different time spans, as shown in the Table 5.A.1 and Figure 5.A.1.

\begin{tabular}{|c|c|c|c|c|}
\hline Combined lindex type & Counts & Avabs difference & $\begin{array}{c}\text { Av monthly difference } \\
(\% \mathrm{mom})\end{array}$ & $\begin{array}{l}\text { Standard error } \\
(\% \text { mom })\end{array}$ \\
\hline Jan & 53 & $34 \%$ & $7.8 \%$ & $25.9 \%$ \\
\hline Feb: & 85 & $6.2 \%$ & $3.4 \%$ & $5.8 \%$ \\
\hline March & 46 & $11.6 \%$ & $3.6 \%$ & $4.6 \%$ \\
\hline Apr & 61 & $9.4 \%$ & $2.5 \%$ & $43 \%$ \\
\hline May & 64 & $64 \%$ & $2.8 \%$ & $38 \%$ \\
\hline Jun & 70 & $10.2 \%$ & $1.8 \%$ & $31 \%$ \\
\hline aul & 117 & $72 \%$ & $0.8 \%$ & $24 \%$ \\
\hline Aug: & 44 & $11,1 \%$ & $1.6 \%$ & $25 \%$ \\
\hline sep & 86 & $6.4 \%$ & $0.9 \%$ & $18 \%$ \\
\hline odt & 119 & $6.6 \%$ & $1.0 \%$ & $1.7 \%$ \\
\hline Nov & 93 & $8.6 \%$ & $0.8 \%$ & $1,8 \%$ \\
\hline Dec & 301 & $9.8 \%$ & $1.0 \%$ & $15 \%$ \\
\hline All months & 1136 & & $1.8 \%$ & $60 \%$ \\
\hline
\end{tabular}

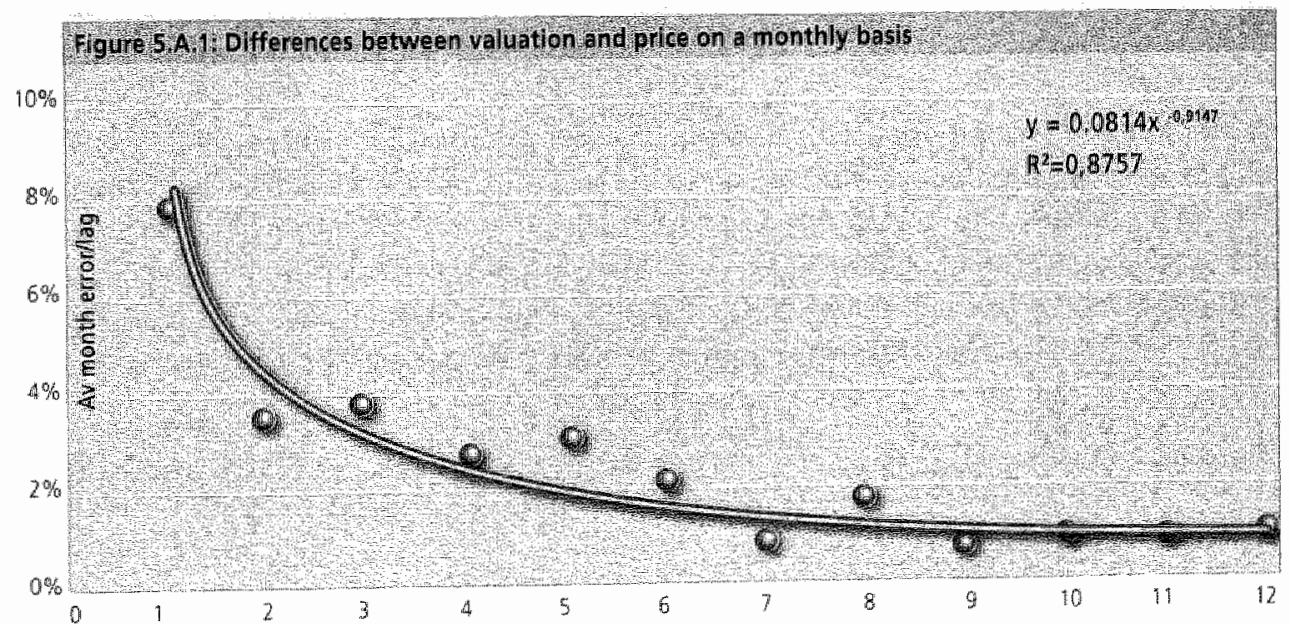


Using the formula described for a uniform comparison, it will not be hard to explain that the trend line, inserted in Figure 5.A.1, has a strong fit when it is reduced into a power-funcrion, so when the staristics in the Table and the graph are srudied, it has to be recognized that in general, periods shorter than a nine-month time span show a completelly different characteristic for the calculated average monthly deviation than periods longer than nine months. For periods longer than nine months, the average and standard deviation ate substantially decreased and become constant, which indicares that after eight months, the monthly deviarions are explained by the lagging of appraisals to the market because the effect of the random appraisal error levels out over time.

Confirmed by several appraisal accuracy studies, it has often been shown that lagging error is constant over time, justifying linear interpolation of annual figures for capital growth to quantify systematic lagging error elements. Assuming that capital growth is a linear trend during the respective years of the studied spans berween the appraisal and sale, this correction for lagging, calculated as a monthly deviation, will generare a horizontal asymprote. If monthly deviations are corrected for this assumption relating to lagging, the random appraisal error will be isolated. In Table 5.A.2, the lagging and appraisal errors are segregated.

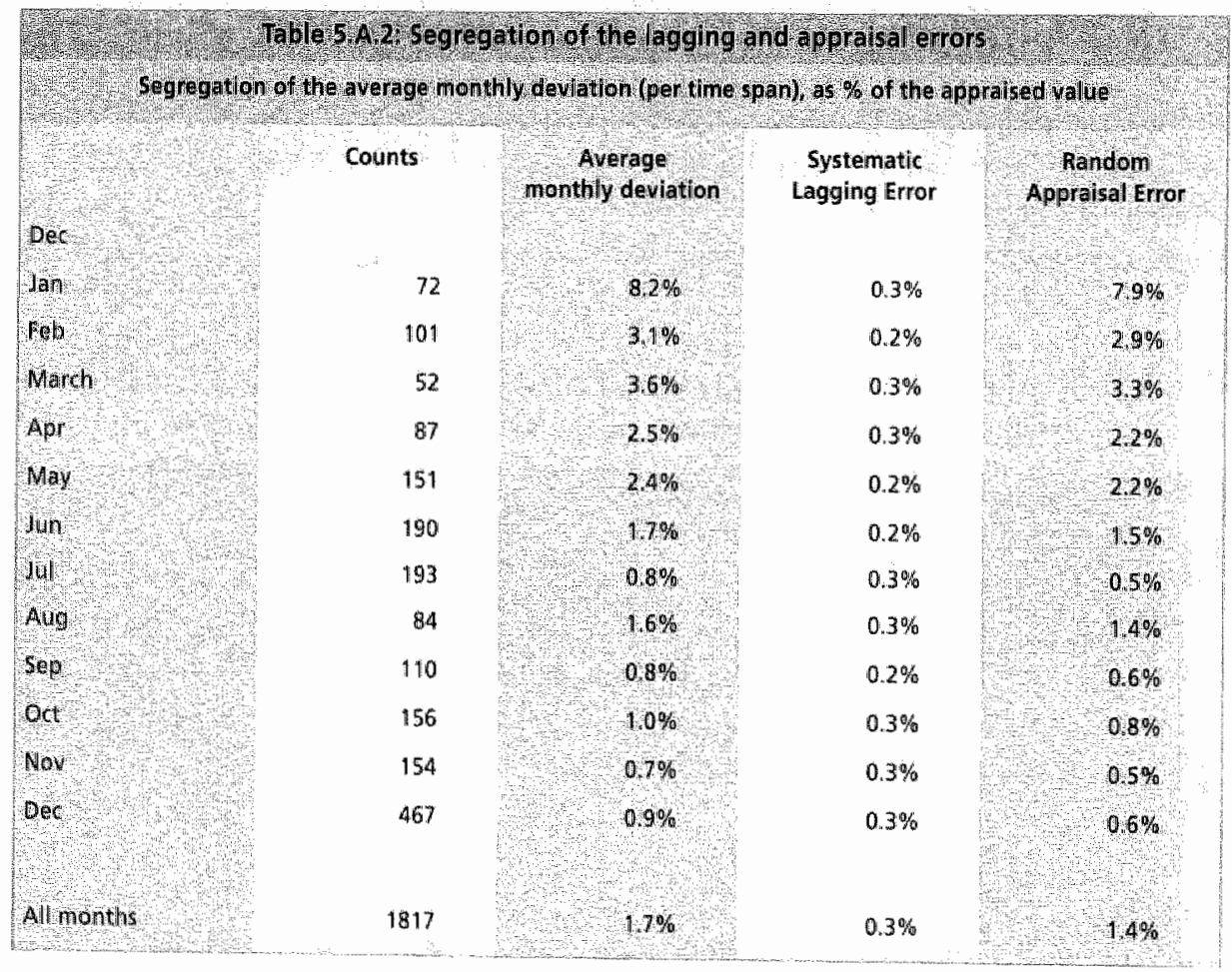




\begin{tabular}{|c|c|c|c|c|}
\hline & Counts & $\begin{array}{l}\text { Average } \\
\text { deviation }\end{array}$ & $\begin{array}{l}\text { Systernatic } \\
\text { Lagging Error }\end{array}$ & $\begin{array}{l}\text { Random } \\
\text { Appraisil Error }\end{array}$ \\
\hline Jan & 72 & $8.2 \%$ & $0.3 \%$ & $29 \%$ \\
\hline Fe $b$ & 101 & $6.5 \%$ & $0.4 \%$ & $62 \%$ \\
\hline March & 52 & $119 \%$ & $0.9 \%$ & $110 \%$ \\
\hline Apr & 87 & $118 \%$ & $1.2 \%$ & $10.5 \%$ \\
\hline May & 151 & $199 \%$ & $1.0 \%$ & $12.9 \%$ \\
\hline Jun & 190 & $121 \%$ & $1.2 \%$ & $10.9 \%$ \\
\hline Jat & 193 & $68 \%$ & $2.1 \%$ & $4.7 \%$ \\
\hline Aug & 84 & $160 \%$ & $2.4 \%$ & $13.6 \%$ \\
\hline Sep & 110 & $90 \%$ & $2.2 \%$ & $6.9 \%$ \\
\hline oct & 156 & $120 \%$ & $2.8 \%$ & $9.2 \%$ \\
\hline Nov & 15.4 & $98 \%$ & $2.9 \%$ & $6 \% 9 \%$ \\
\hline Dec & 467 & $13.6 \%$ & $4.2 \%$ & $9.4 \%$ \\
\hline All months & 1817 & $11,4 \%$ & $2.4 \%$ & 9 \\
\hline
\end{tabular}

Now that the appraisal error has been quantified in the case of the ROZ-IPD Index, it could be argued that the random appraisal error is a compilation of using systematically-aged information and more random behavioural issues in the appraisal process. As demonstrated, the average appraisal error decreases to a minimum for time spans longer than nine months, which is obviously an indication of the systematic information lag caused by the use of aged information in valuations. In general, it can be concluded that the average information lag approximates to the nine months found. Thus, the systematic information lag has to be isolated by another partitioned variance test to generate a random residual, which implies all the behavioural effects in the valuations.

The second partitioned variance test encompasses the same linear interpolation to correct the average monthly appraisal error, on the understanding that information lag is a result of the appraisal's preceding nine-month period and, therefore, annual capital growth of the respective preceding year will be needed in order to perform this partitioned variance analysis. The random residual can be derived by correcting the average monthly appraisal error for the nine-month information lag. 


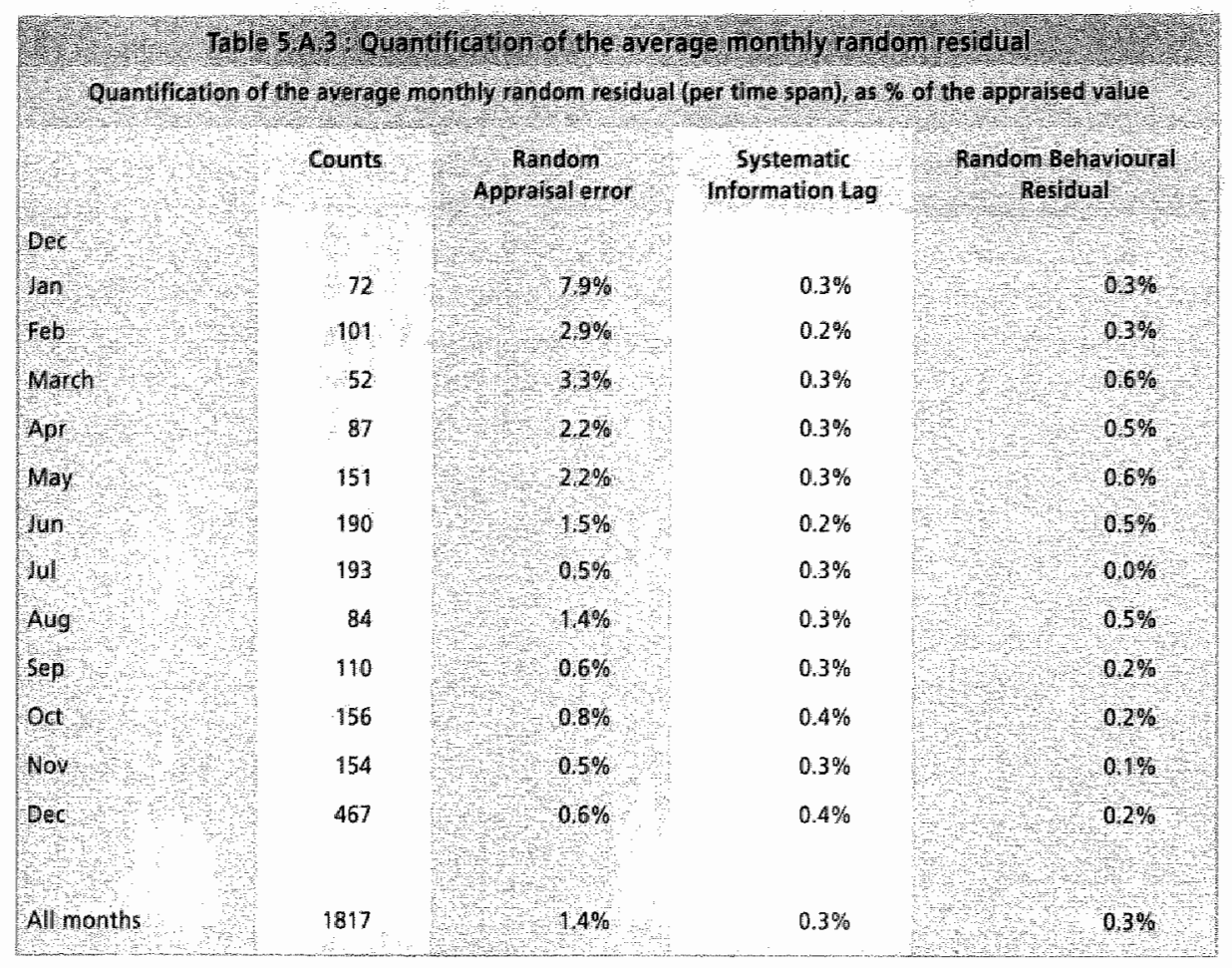

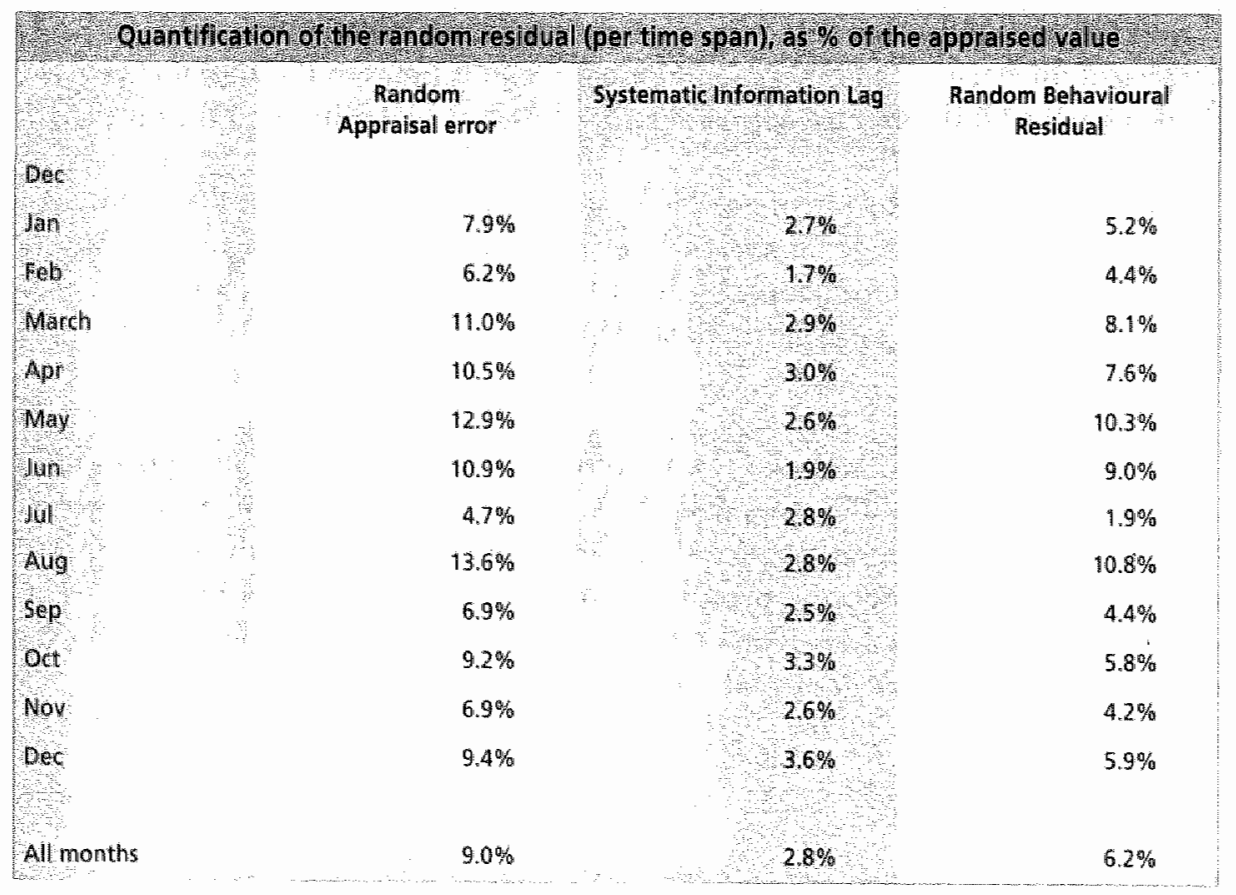


It has to be acknowledged that timing effects in the random behavioural residual are recognized, since its influence decreases as the respective time spans increase. The random error was also examined on a monthly basis and different random errors were found, depending upon the number of months berween the date of valuation and date of sale.

Comparison with the analysis, on a yearly basis, in the main part of this chapter is not possible since the monthly "sample" residentials have also been included. It is surprising to see that the random residual varies so much depending on the month in which the sale took place. The difference "cleared" for the systematic errors (time and information lag) ranges between $10.8 \%$ and $4.2 \%$. No explanation could be found, and more research is necessary. 


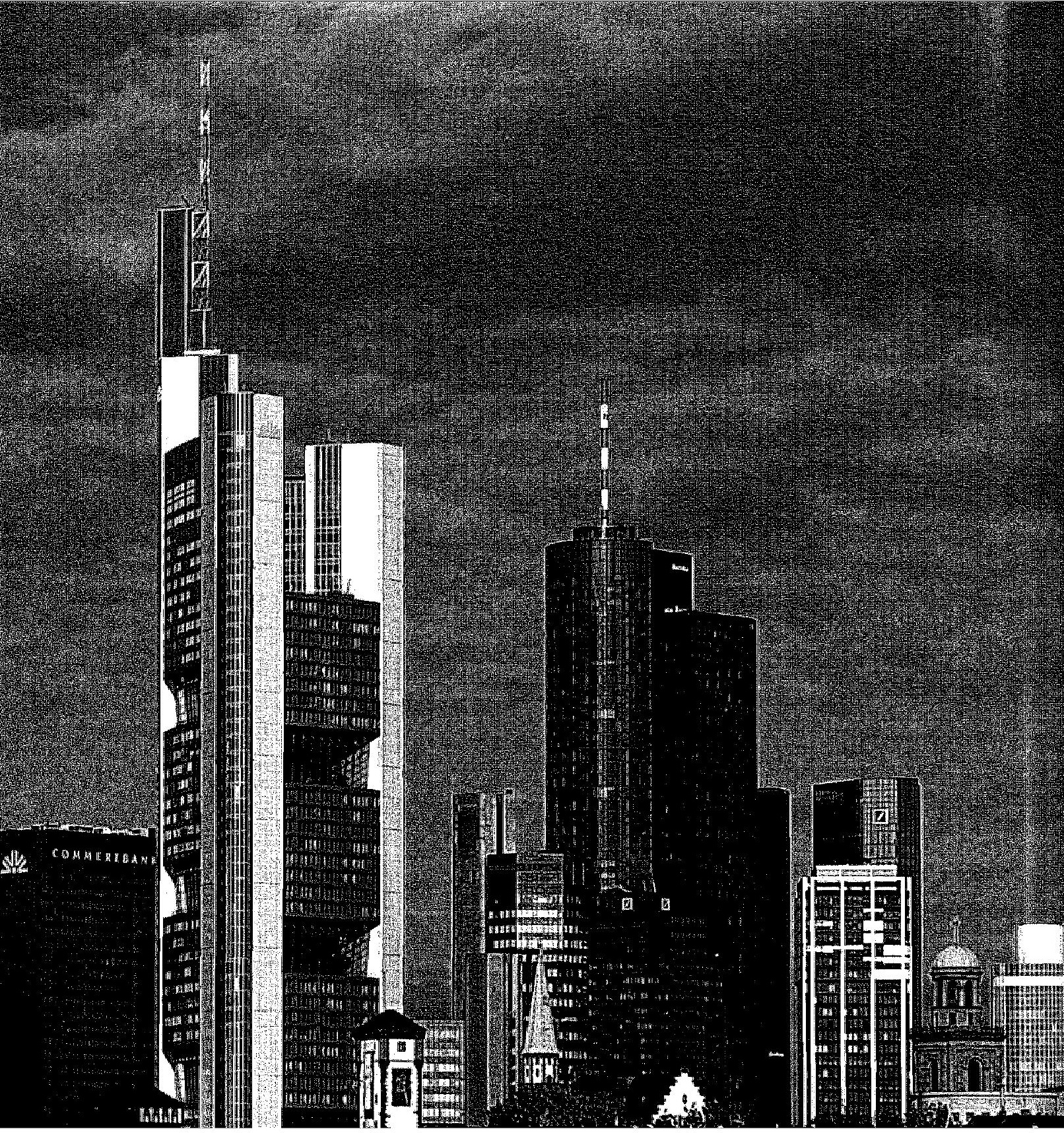




\section{CHAPTER 6}

\section{European market dimensions: an inventory of the potential investment market in 11 European countries'}

\subsection{Introduction}

Oince the introduction of real estate indices of directly held propercy, such as Frank Russell. NCREIF and IPD, knowledge of real estate performance has significantly increased. In countries with capitalised pension schemes (such as the USA, the UK and the Netherlands) there always has been capital allocated to invest in institution-grade real estate. Whereas in the past, institutional investors' preference for most real estate investment was domestic, the introduction of the Euro currency has enabled a number of investors to shift their allocation towards cross-border investments within the "Euro" area, without an exchange rate risk. As stated by the real estate investment research directors of several companies (ING Real Estate and AXA amongst others) this allows institutional investors to concentrate their investments in

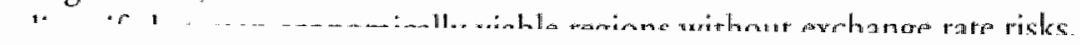


The purpose of this chapter is to create more reliable estimates of the total size of the potential real estate investment market in Western European countries in which IPD operates. To compile an accurate escimate of the value of investment property in each national market, the research on the investment markets is divided into two parts: France, Germany, Sweden, the Netherlands and the UK, in which reliable estimates could be expected, and Denmark, Ireland, Finland, Norway, Portugal, and Spain, in which countries it was expected that some data would be available. The results of the survey are only preliminary. They should be added to, updated and improved on over rime. The appendix of this chapter details the full results per counrry.

\subsection{Literature}

The size of the real estare market has been studied for some time in the USA. Estimates have been made of the total stock, and its relationship to GDP (Gross Domestic Product) has been investigated. Some academic articles are referred to in this chapter to give an impression of the different views on real estate market sizes in the USA. As far as Europe is concerned, academic studies in this field are very limited and have only been conducted in the last few years - however, research has mainly been carried out by investment bankers and professional research companies.

Miles (1992) estimated a value of $\$ 2.7$ trillion for commercial real estate and a value of $\$ 6.1$ trillion for residential. Miles and Tolleson (1997) updated and expanded Miles' 1992 survey, using new data, and also made estimates by property type. They used the 1991 data, calculated the value growth factor from the NCREIF index, added improvements and growth in stock and arrived at a new value estimate of $\$ 3.7$ trillion for commercial real estate including apartments and hotels. The traditional sectors of office, retail and industrial/manufacturing declined in value from $\$ 2.7$ trillion in 1990 to $\$ 2.6$ trillion in 1996 due to the dramatic drop in walues at the beginning of the $1990 \mathrm{~s}$, despite improvements and growth of stock of around 30\%. The respective shares of the real estate sectors they found were office $38 \%$, retail $42 \%$ and industrial/manufacturing 20\%. Miles and Tolleson also estimated the value of oil and gas reserves, agricultural land and timberland. Given the size of the investible universe and a required average of $10 \%$ in pension funds' real estate portfolios, they concluded that real estate was underweight by more than $50 \%$.

Hartzell et al (1994) used data on aggregate real estate values for a sample of countries to develop estimates of the total value of real estate by property type in the USA. They used property-specific data from local property tax records created by Real Estate Data Inc.. (REDI) in a 1989 survey. For the USA as a whole, the values were estimated to be $\$ 2.43$ trillion for commercial property and $\$ 8.7$ trillion for residential property.

Liang and Mclntosh (1999) also assumed that there should be a relationship berween a country's GDP and the real estate srock. They extended the research to other countries outside the USA and made estimates for 44 countries. They created a formula which will be explained in this chapter. 
Mahoney et al (2000) looked at the implications of property stock income data by real estate investment portfolio allocation. For the top 20 Metropolitan Statistical Areas (MSAs) they estimated $\$ 3.79$ trillion of property capital stock income in 1998. Their conclusion was that a broad-based index fund for real estate would have its largest concentration in California, followed by the Industrial Midwest and the Old South. They also concluded that no NCREIF institutional investors or Real Estate Investment Trusts (REITs) actually held a market-value weighted real estate portfolio, which might be partially due to asset selection being based on superior forecasting. They showed that both NCREIF institutional investors as well as REITs appeared to hold reall estate portfolios that were heavily concentrated in high-qualicy locations, and not evenly spread according to the property stock income. Malpezzi et al (2001) expanded the survey by estimating the stock of private real estate capital for each of the 242 MSAs in the USA.

Hu et al (2000) looked at the evolution of real estate in the economy. They focussed on several important aspects of the economy, including GDP, households and corporate asset allocation and the debt and equity markets. They developed indicators for each of the sectors and documented the evolution of real estate since the early 1980 s. They found that the contribution of real estate to GDP between 1980 and 2000 remained stable at $11 \%$.

Henderson Global Investors (2000) also made an estimare of the global institutional property market. They distinguished berween the invested institutional property market (that invested in by institutions), the potential investment in institutional property (that in which institutions could invest), and the whole commercial property market (total stock). The potential investment in the institutional property market is, according to their survey, around $\$ 4.3$ trillion. It could be as high as $\$ .6$ trillion and is unlikely to be any lower than $\$ 3.5$ trillion. The distribution of the potential investment in the instirutional property market is put at around $37 \%$ in the USA, around $8 \%$ in the UK, around $30 \%$ in Continental Europe and around $19 \%$ in Asia. Australia and South America represent about $3 \%$ each. Henderson used GDP figures to gross up the potential investment market in some countries.

AIG, American International Group (2001) calculated a total potential investment in the institurional property market of USA $\$ 5.1$ trillion, of which $39.9 \%$ is in the USA, $8.2 \%$ in the UK, $22.7 \%$ in Continental Europe, $25.8 \%$ in Asia and Australia and $3.3 \%$ in South America.

In the UK, Bootle (2002) estimated that in 2001, the total commercial property stock was worth $£ 630$ billion, including $\$ 127$ billion of property in the leisure sector, $\mathbb{1 4} 15$ billion in retail and office and $£ 88$ billion in inclustrial property. He also concluded that property and property related activities contributed around $15 \%$ to GDP each year.

A survey by the pension real estate association (PREA, 2003), concluded that real estate equiry accounted for $5.3 \%$ of the total assets $-67 \%$ of the properties were core, 
$16 \%$ value added and $17 \%$ opportumistic. According to the survey, 64\% of the PREA members reported that their target allocation in real estate equity would be $8 \%$.

From a review of the previous literature it becomes clear that it is very difficult to estimate the real estate investible universe or stock without a solid inventory bottom up). Furthermore, the relationship between real estate and other parts of the economy is not always clear. Therefore the Liang and McIntosh survey is followed. In this survey, they deweloped a formula which relates the GDP in a country to the investible universe and the total stock (cop down).

\subsection{Methodology}

In choosing the methodology there were two possibilities, top down or bottom up. The top down approach is relevant when a relationship might be found between macro-economic daca like GDP and the real estate data and/or investments. The bottom up approach might be applicable for those countries where it is possible to find reliable real estate stock data, as well as a count of all the real estate investments by different type of investors in each country, if and when available.

\section{Model. by Llang and McIntosh}

In order to obtain a benchmark ratio of invested to potential investment real estate, a model established by Liang and McIntosh was used. Liang and McIntosh were both working at Prudential Real Estate Investors at the time and they tried to find out what the potential real estate investment opportunities for American investors would be outside the USA. They distinguish between the total stock and higher-grade real estate, which they define as real estate atcractive to (institutional) real estate investors. The assumption they make is that American real estate investors who are willing to invest elsewhere, will most likely only invest in higher-grade real estate. Their model estimates the potencial investment market in other countries, using the ratio of the potential investment market to GDP found in the USA. "The starting point for this model is the relationship berween the potential real estate investment market, GDP and GDP per capita, and a country used as a base for the potential investment market to GDP ratio.

(1) REix

$$
=\mathrm{GDPX}^{*}\left(\mathrm{RE}_{U S A} / \mathrm{GDP}_{\text {USA }}\right) *\left(\mathrm{PCGX} / \mathrm{PCG}_{U S A}\right) 1 / 3 * \mathrm{~F}
$$

In which:

REx Investment-grade real estate in country $x$

GDP Gross domestic product in $€$

PCG Gross domestic product per capita in

USA Subscript for the USA

$x \quad$ Subscript for any other country

F Adjustment factor

Liang and Mclntosh make use of an adjustment factor, because real estate in some countries is concentrated in a very small area or location. Examples are Singapore, Hong Kong and to a lesser exrent, the UK because of the importance of London as 
a financial centre. In those countries, Liang and McIntosh assume that the real estate stock will be substantially higher because of the rolle they play in the World Economy. Another assumption they made is the effect of the exclange rate. When they carried out their survey in 1998, the exchange rates over the previous years had been very volatile. Therefore, Liang and Mcintosh decided to use the average exchange rate to the USA $\$$ between 1995 and 1998 as a proxy for the real exchange rate. They also assumed that the ratio between higher-grade real estate and the total stock was abour 1:3.

When the Liang and Melntosh model was applied to estimate the real estate investment universe for the different European countries, it was done in a slightly different way. The goal was to achieve estimates of what had been invested by institutional investors, what the potential investments for institutional investors would be, and where possible, make a reasonable estimate of the total real estate stock in a particular country. A similar ratio between higher-grade real estate and other real estate was assumed (1:3). It was not necessary to use the adjustment factor, since locations with exceptionally high concentrations of real estate like Singapore and Hong Kong were not part of the survey. Then the "base" country had to be decided on. A lot of information on the real estate market in the Netherlands and on the potential investment: market for real estate was generated, including the real estate stock. Since that was not so much the case at the beginning of the survey for other European countries, it was decided to use the Netherlands as the "base" country. When the Liang and Mclntosh formula is converted for the purposes of this survey, the formula changes as follows:

(2) REx

$$
=\operatorname{GDPx} *\left(\mathrm{RE}_{\mathrm{NL}} / \mathrm{GDP}_{\mathrm{NL}}\right) *\left(\mathrm{PCGx} / \mathrm{PCG}_{\mathrm{NL}}\right) 1 / 3
$$

In which:

Re Investment-grade real estate in $€$ in country $x$

GDP Gross domestic product in $€$

PCG Gross domestic product per capita in $€$

NL. Subscript for the Netherlands

x Subscript for any other country

The exchange rate consequences are limited in Europe: for the Euro countries, they are non-existent. If one looks at the Euro since its introduction, its exchange rate has weakened against the GBP and the Danish and Swedish Crown, but last year the Euro strengthened against those currencies. For this survey, the exchange rares as of March 2004 were used.

\subsection{Data}

In order to obtain relevant data from all the countries to be covered, a framework was ser up in which the data required for each country was specified. This data was retrieved from national databases for statistics and European databases (Eurostat) as well as market reports produced by national research institutes. The data needed was Gross Domestic Product (GDP) (real and per capita GDP), the rotal value of national real estate, investments in real estate by institutional investors, investments in real estate by privare investors and other investors, the total stock of space and ner rents for 
the different sectors; the market size of rental housing, and the value of the residential investment matket and the potential investment market (estimated using the model of Liang and Mclntosh).

The avaliability of the data varied from country to country as shown below. The UK, Germany, France, the Netherlands and Sweden were able to supply almost all the data needed.

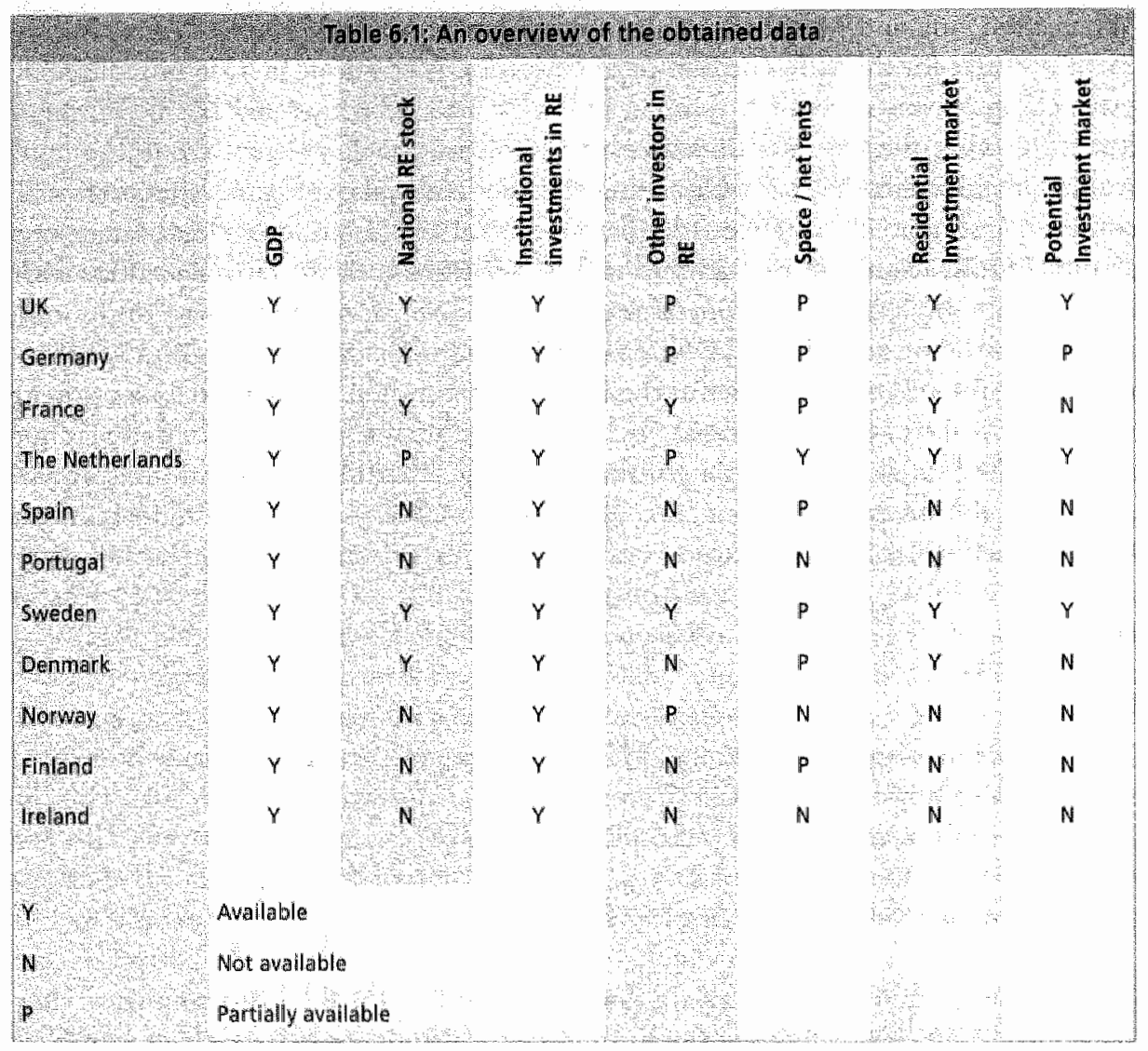

\section{THE REAL ESTATE INVESTMENT MARKET FOR INSTTTUTIONAL INVESTORS}

To estimate the total investment of institutional investors in the real estate market, various sources were used. For each country, an inventory of institutional investors was made, and aggregate numbers from national statistical bureaus and independent real estate research firms used, and for the UK, Ireland, Portugal and Spain data assembled by IPD was employed. This data was in turn based on a bortom up approach to real estate investments by institutions.

For data on the investment market in the Netherlands, the national real estate gazerte "VastGoedMarkt" was used as a source, as it has a very good overview of the institutional market, wich continuous coverage of market transactions since 1974. In order to obtain 
the total stock and the value of the retail market an in-depth inventory made by Bolt (2003) was used. For the industrial market, as well as for the transport and wholesale sectors, an extensive report by Rabobank (2002), analysing recurns from 75 different branches, was employed. For the Swedish market, the national statistical databank and data from the independent firm Byggstatistik provided in-depth evidence, with information on the total value of the national real estate stock, total market size, the potential investment market, the institurional market, the private market and the municipal market. A wery detailed botrom up approach was used. For the Finnish marker, research institute KTI supplied a detailed overview of the institutional owners and the ownership stakes in Finnish real estate. For the German market, the national statistical databank and Bulwien provided an extensive overview of all the institutional investors and their ownership of real estate in Germany and abroad. 'They also supplied data on the size and value of the total real estate market in Germany. For the French institutional real estate market, data on the institutional ownership of real estate was obtained from the National Instirute for Statistics and Economic Studies (INSEE). For the other countries the sources were limited or could not be found, even by the IPD country managers. For these, the average ratio of GDP to national real estate for Germany, France, Sweden, Denmark, the Netherlands and the UK was used to provide estimates.

\subsection{Results}

\section{INSTITUTIONAL INVESTMENTS IN REAL ESTATE}

Institutional investments in real estate in the 11 countries examined have a total estimated value of $€ 983$ billion, as can be seen in "Table 6.2. The UK has the largest real estate investment market, followed by Germany, France and the Netherlands. Sweden is the fifth largest market, and in total the five largest market represent a value of $€ 878$ billion. The 6 smaller markets have a total value of $€ 105$ billion. Private investors competing in the same segment as institutional investors are not taken into account. This is due to lack of information for this sector, as reliable sources on private ownership are only available for the UK and for Sweden, and these are nor detailed.

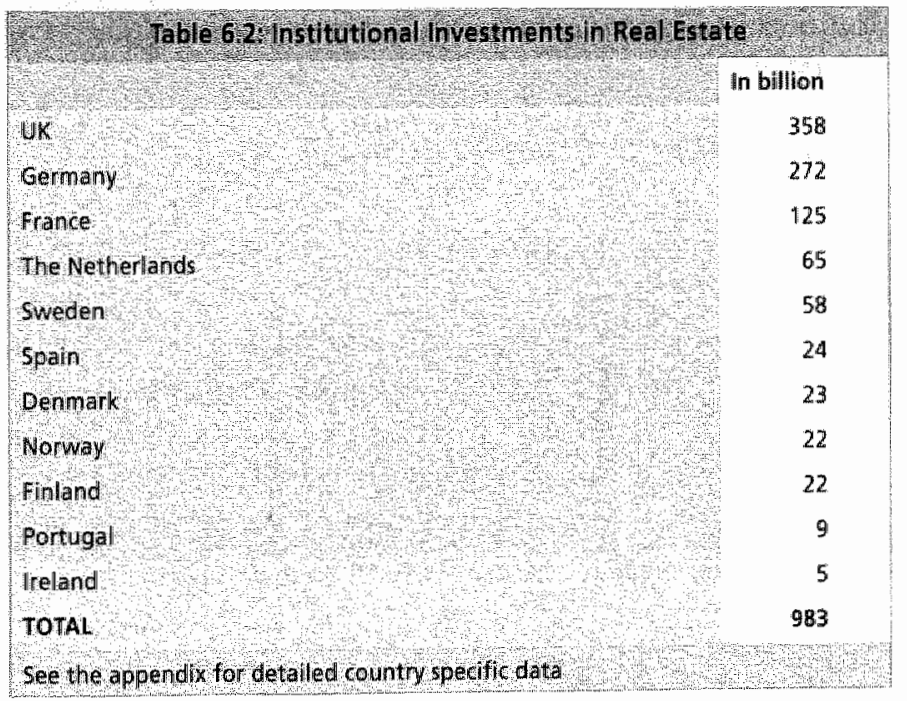




\section{TOTAL REAL ESTATE ASSETS / GDP RATIO}

Reliable figures on the total size of the real estate stock could only be found for six countries (Germany, the UK, France, Denmark; Sweden and the Netherlands). The figures per country are shown in the appendices at the end of this chapter. From these figures; the ratio to GDP was calculated for these countries. After that, a value weighted average ratio of 3.22 for the six countries was calculated. It was assumed that this ratio could be used to estimate the size of the real estate markets in the other 5 countries, based on their GDP. GDP data was taken from the Eurostat databank, in order to obtain relliable and comparable data from the same source. The GDP per capita used was defined at Purchasing Power Standards, the definition used by Eurostat: The results are shown in Table 6.3.

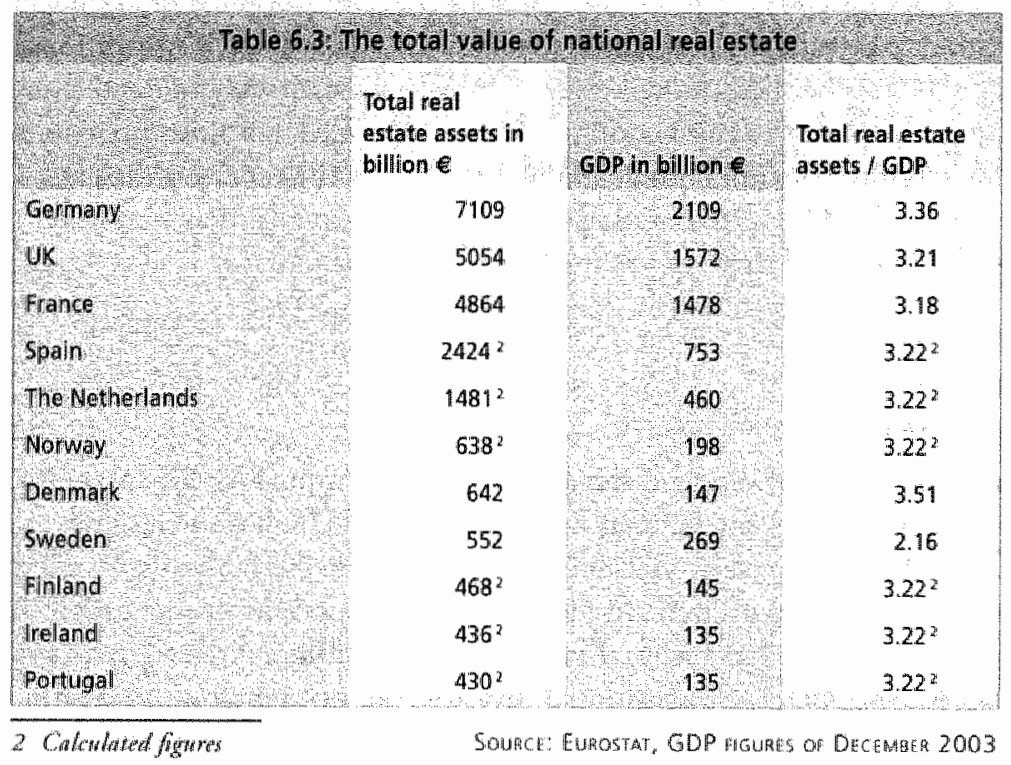

\section{CHecks AND balances OF THE Results}

In order to compare institutional investment in real estate across countries, ratios were calculated to provide an overview.

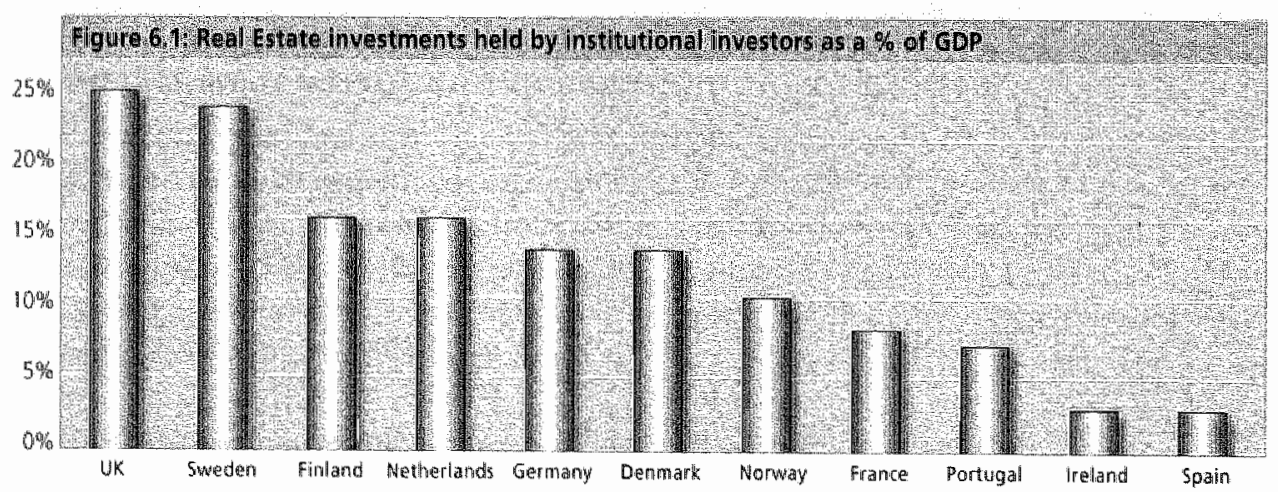


The ratio of institutional investment in reall estate to GDP averages $12 \%$ in the 11 countries examined. The high rate in the UK can be explained by high real estate prices, especially for financial sector properties in London. Sweden's high ratio is partly explained by the large property holdings of pension funds, life insurance companies and listed real estate companies. The low ratio for Spain can be partly explained by the high level of private ownership of dwellings, as well as by the extent of owner-occupation in the corporate sector.

\section{THE POTENTIAL INVESTMENT MARKET FOR REAL ESTATE PER COUNTRY}

The potential investment market is the part of the market in which institutions can invest, i.e. the value of all real estate suitable for investment by institutions. There are different models that can be used to obrain an estimate of the porential investment market. In the Netherlands and in Sweden and the UK, a bortom up approach has been taken. The Swedish potential investment market was estimated by taking the invested market and adding the private investment market and the municipal real estate companies which are acrive in the market. The ratio of potential real estate investment to GDP turns out to be $42 \%$ in Sweden, as can be seen in Table 6.4.

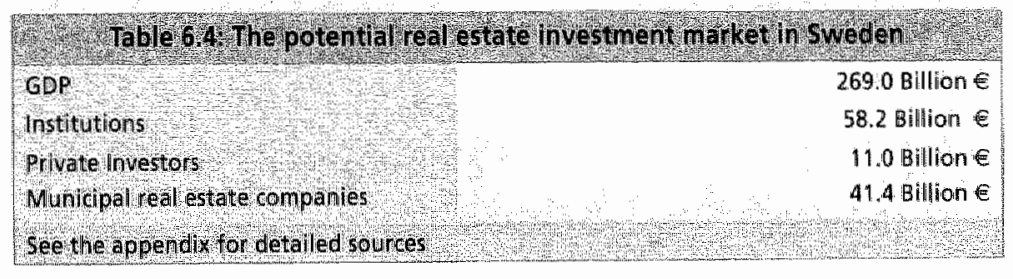

The approach in the Netherlands differed as there are no statistics for private investors and company real estate holdings. Here a bottom up approach was taken, based on the stock of space and net rents. IPD's income return statistics were then used to estimate values for the different sectors (income capitalisation method). Once the values had been obtained, the potential investment part was determined using ratios of the market structure of corporate real estate, the market size for rental housing, and the potential investment part of the retail market.

The ratio of potential real estate investment to GDP is $40 \%$ in the Netherlands, as can be seen in Table 6.5.

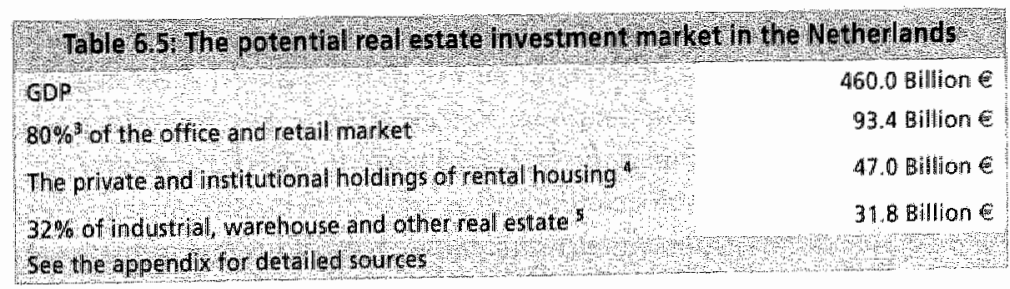

Assumed percemsage based on UK estinates

Anstumed percentage based on UK estowates

5 Fon model 
For the UK, the same ratios were applied as for the Netherlands. The ratios for the potential investment market were estimated as follows: the value of institutional and private investment in residentials calculated using an income capitalisarion model.

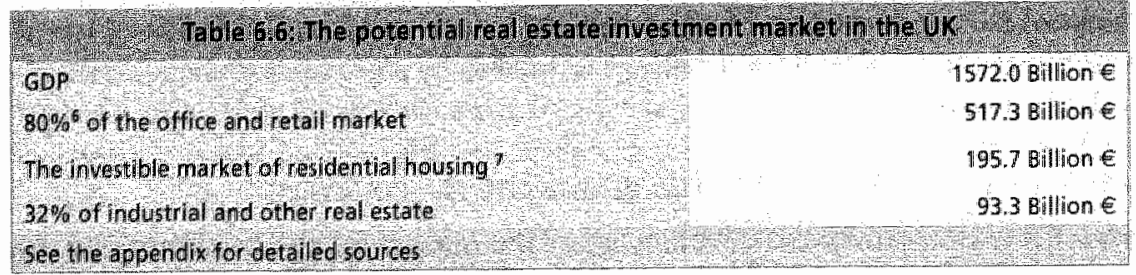

The ratio of invested real estate to GDP is $49 \%$ in the UK, based upon the figures in Table 6.6. The higher ratio of porential real estate investment to GDP compared with the Netherlands and Sweden can be attributed to the effect of the relatively larger commercial (office and retail) real estate marker in the UK compared with the Netherlands and Sweden.

By using the ratio of the Dutch potential investment real estate market to GDP for the Nerherlands in the above Liang and Mclntosh model, the following porential investment market sizes for real estate can be estimated:

\begin{tabular}{|c|c|}
\hline Wrty & (in Billione) \\
\hline Germany & 819 \\
\hline ux & 625 \\
\hline France & 604 \\
\hline Spain & 273 \\
\hline The Netherlands & 180 \\
\hline Sweden & 104 \\
\hline Norway & 83 \\
\hline Denmerk & 76 \\
\hline Finland & 55 \\
\hline Areland & 55 \\
\hline Pritugal & 45 \\
\hline Total & 2921 \\
\hline
\end{tabular}

This model does not take into account differences between the markets, such as home ownership ratios, social housing policies, tax policies, corporate real estate ownership, office employment levels, and country-specific laws and regulations. 'Checks and balances" were then applied, where available, to determine whether the outcome in each country seemed reasonable. The results were discussed with IPD offices and specialists in each country; based on their first impressions, they agreed that the results were reasonable, and sometimes even reliable.

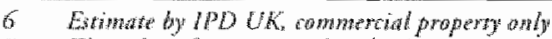

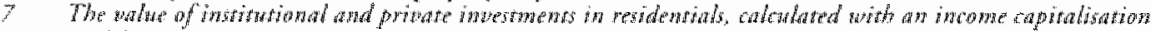
model 


\subsection{Summary and conclusions}

Although restricted by the lack of data, the data which was found has resulted in some encouraging findings. First, the total invested real estate assets of institurional investors has been calculated at $€ 983$ billion (Table 6.2). The potential investment matrkt was estimated at $€ 2921$ billion (Table 6.7), resulting in an average percentage of $34 \%$ invested compared with the potential investment possibilities, for the 11 countries analysed.

An interesting outcome of the calculations is also the remarkably similar ratio between the potential investment stock and the total real estate stock of $11 \%-13 \%$, with the exception of Sweden, as can be seen in Table 2.8. It seems that the model used by Liang and McIntosh, whereby the differences of GDP berween the countries has been. neutralised, leads to similar real estate potential investment markets as a percentage of the cotal real estate stock. Of course, this will need further research, but if this conclusion stands up, reliable estimates of the real estate stock in other countries should be possible.

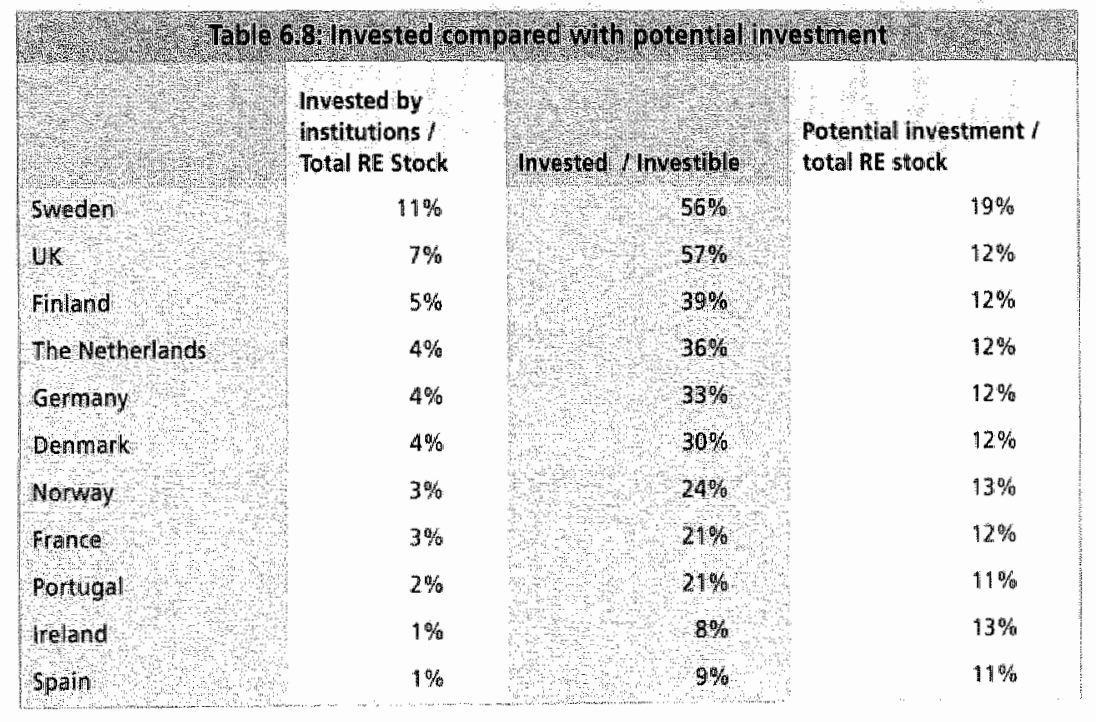

The main conclusions drawn are that in the 11 countries examined, real estate investments held by insticutional investors compared with GDP ranged from $23 \%$ for the UK to $3 \%$ for Spain. Furthermore, institutional real estate investments as a percentage of total real estate stock range from $11 \%$ for Sweden, to $1 \%$ for Spain. And finally, the estimate of the potential investment real estare market as a percentage of the total srock ranges berween $11 \%$ and $13 \%$ for all countries, with the exception for Sweden where ir is $19 \%$. This is the first time such calculations have been made and therefore no comparison can be made with existing literature. 
Although this survey doesn't have higher ambitions than achieving an inventory, a couple of practical implications can already be seen, for instance the liquidity issue. Most real estate analyses and asset liability managers consider direct real estate and to a lesser extent non listed real estate companies as being illiquid compared with stocks and bonds. If the assumption from this survey is that the potential investment market for real estate is on average three times higher than the actual real estate investments by (institutional) investors it might lead to a somewhat different view of the liquidity of direct real estate as such. More extensive research about potential buyers and sellers on the real estate market would lead to a clearer view of the element of real estate liquidity. 


\section{APPENDIX}

As referred to in this chapter, country overviews have been made reflecting the data which could be found for each of the examined countries. All data sources have been described to allow for better judgement and future improvements by local experts. Gross Domestic product and size of the real estate investment market are included for all countries. For certain countries a breakdown into commercial (retail, office and industrial) and residential could be found or calculated. This results in some countries have significantly more data than orhers, where the data availability was limited. 


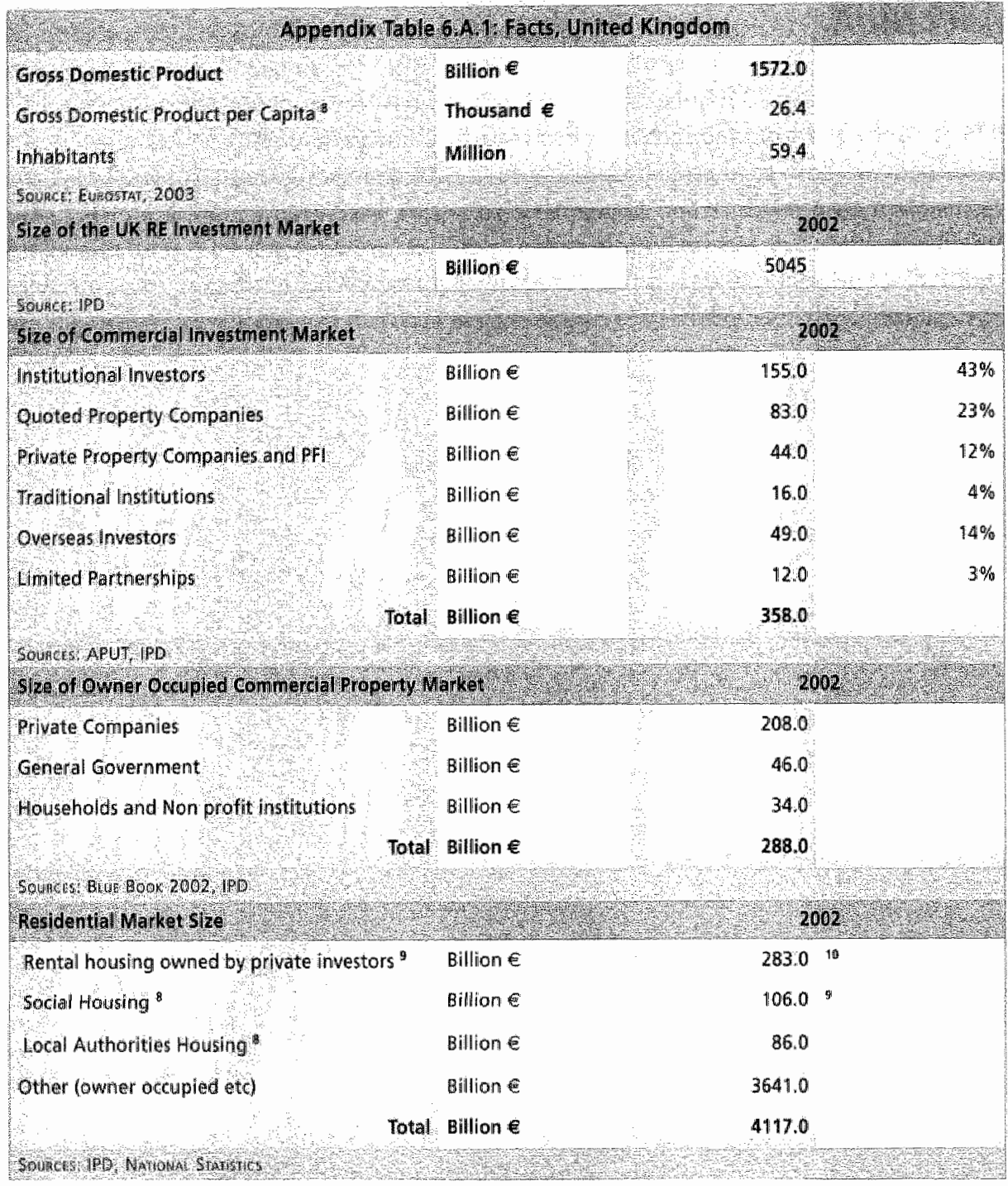

\begin{tabular}{|c|c|c|c|c|}
\hline & 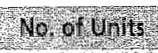 & prenunnit & Costinit & Howne ret \\
\hline Priwate Investors & 2181000 & 8746.4 & $20 \%$ & $5.40 \%$ \\
\hline of which are furmished & 586,000 & & & 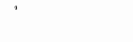 \\
\hline Value & Bllione & 282.6 & & \\
\hline
\end{tabular}

If Af pumbixsing pouter standands

9 Nombers for lengland and Woles only (2002)

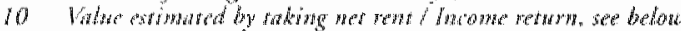




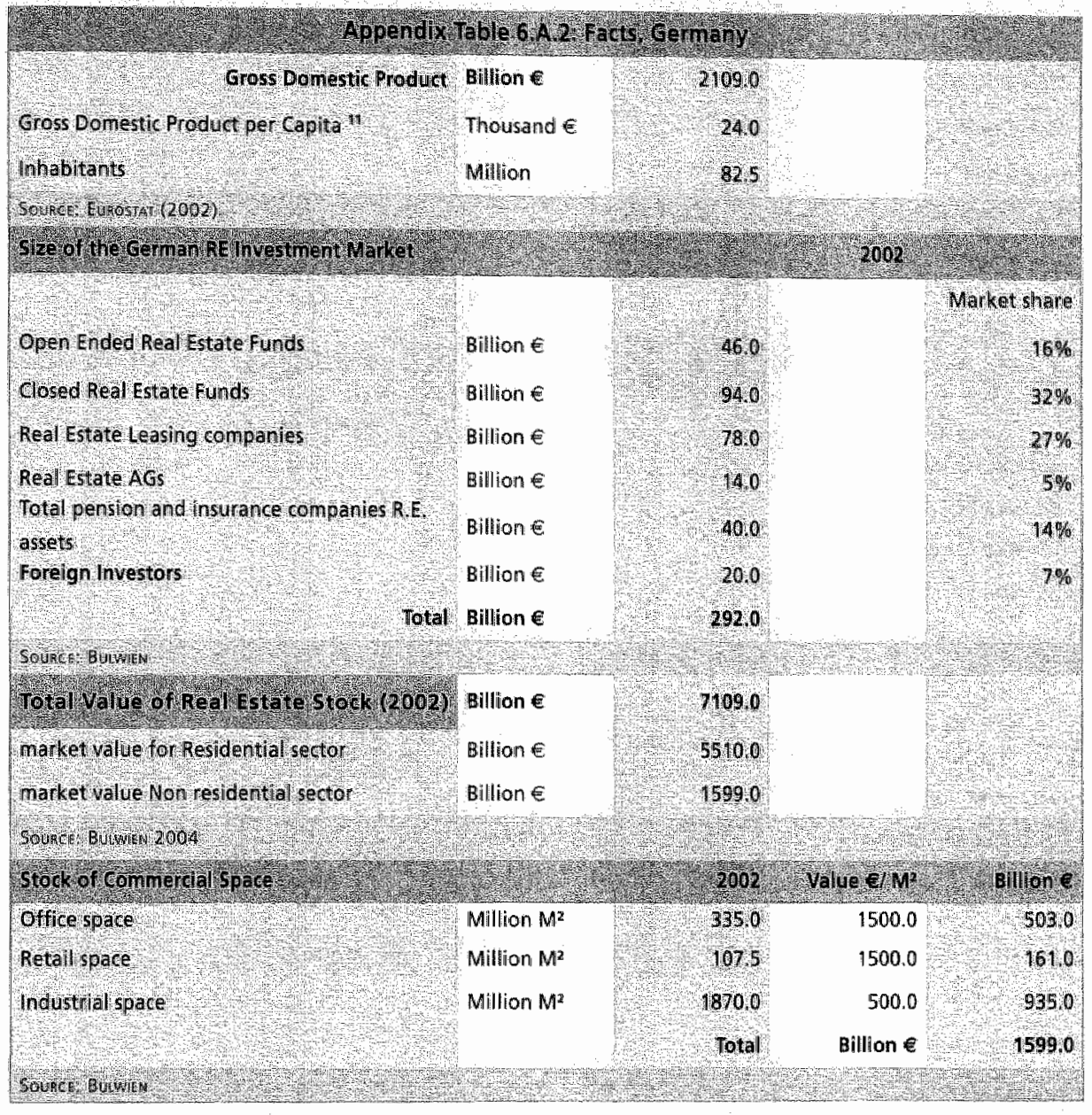

II At pnothasing power standiad's 


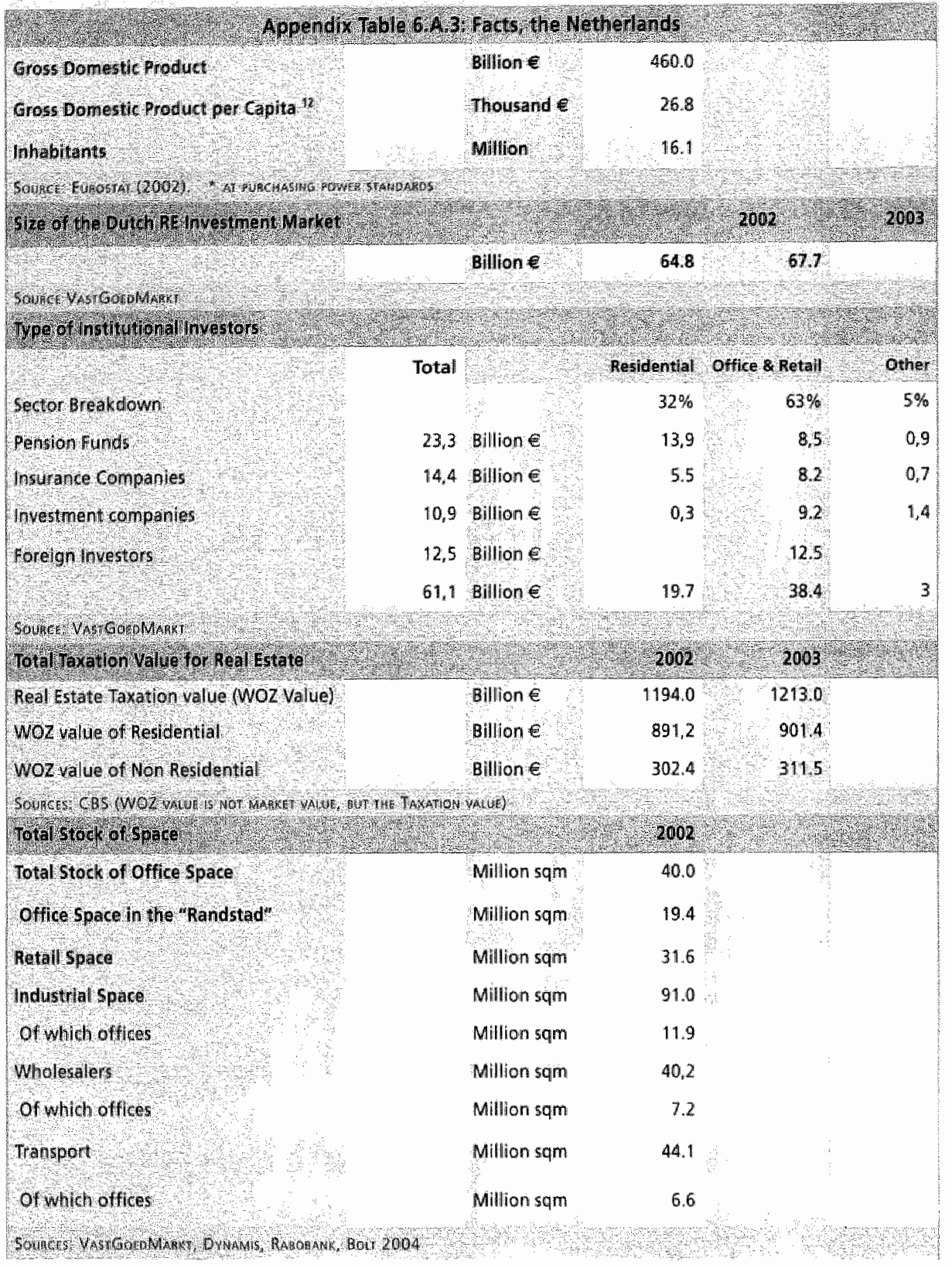

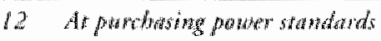




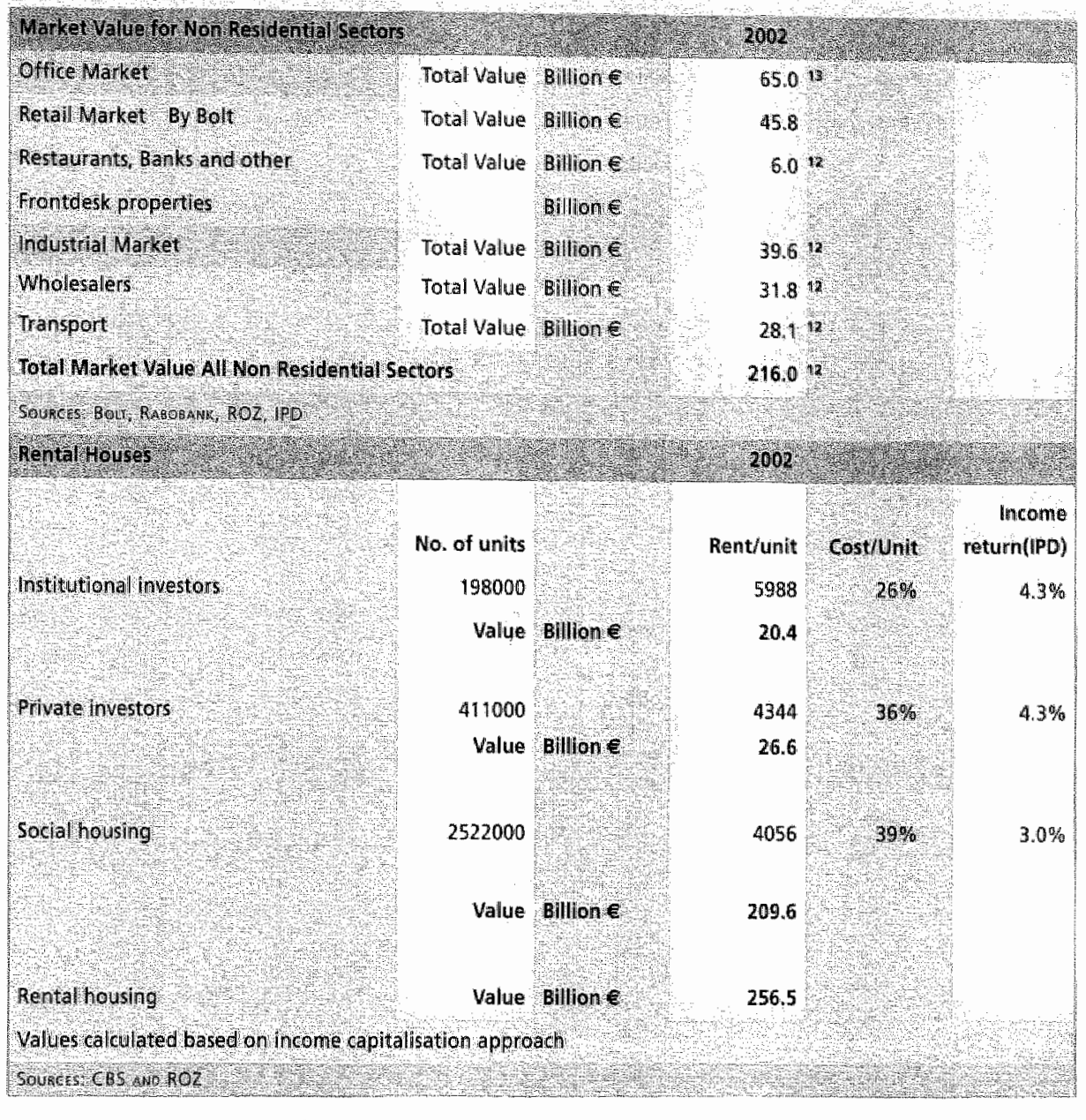

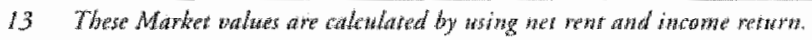




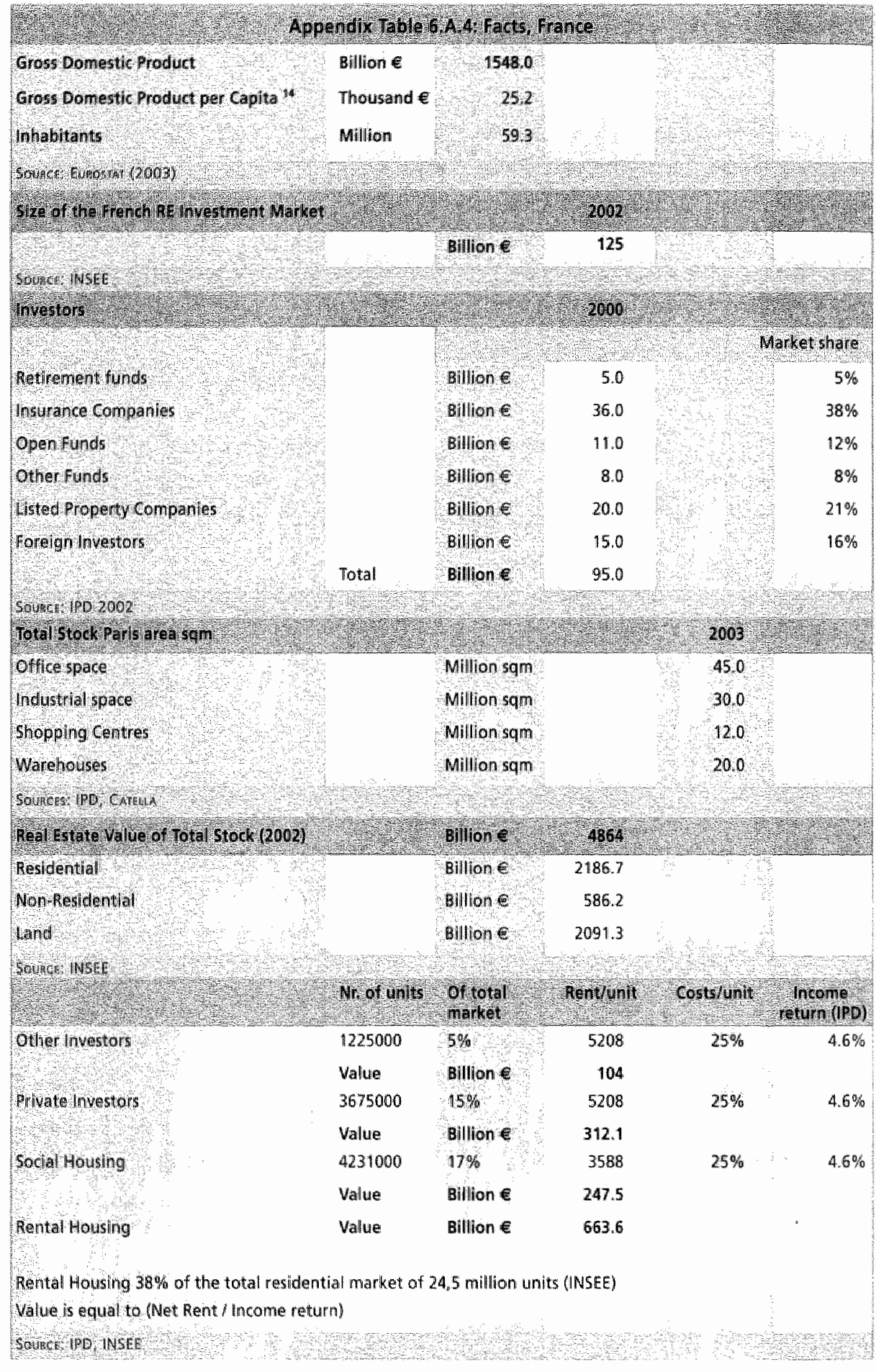

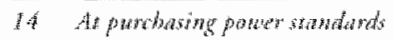




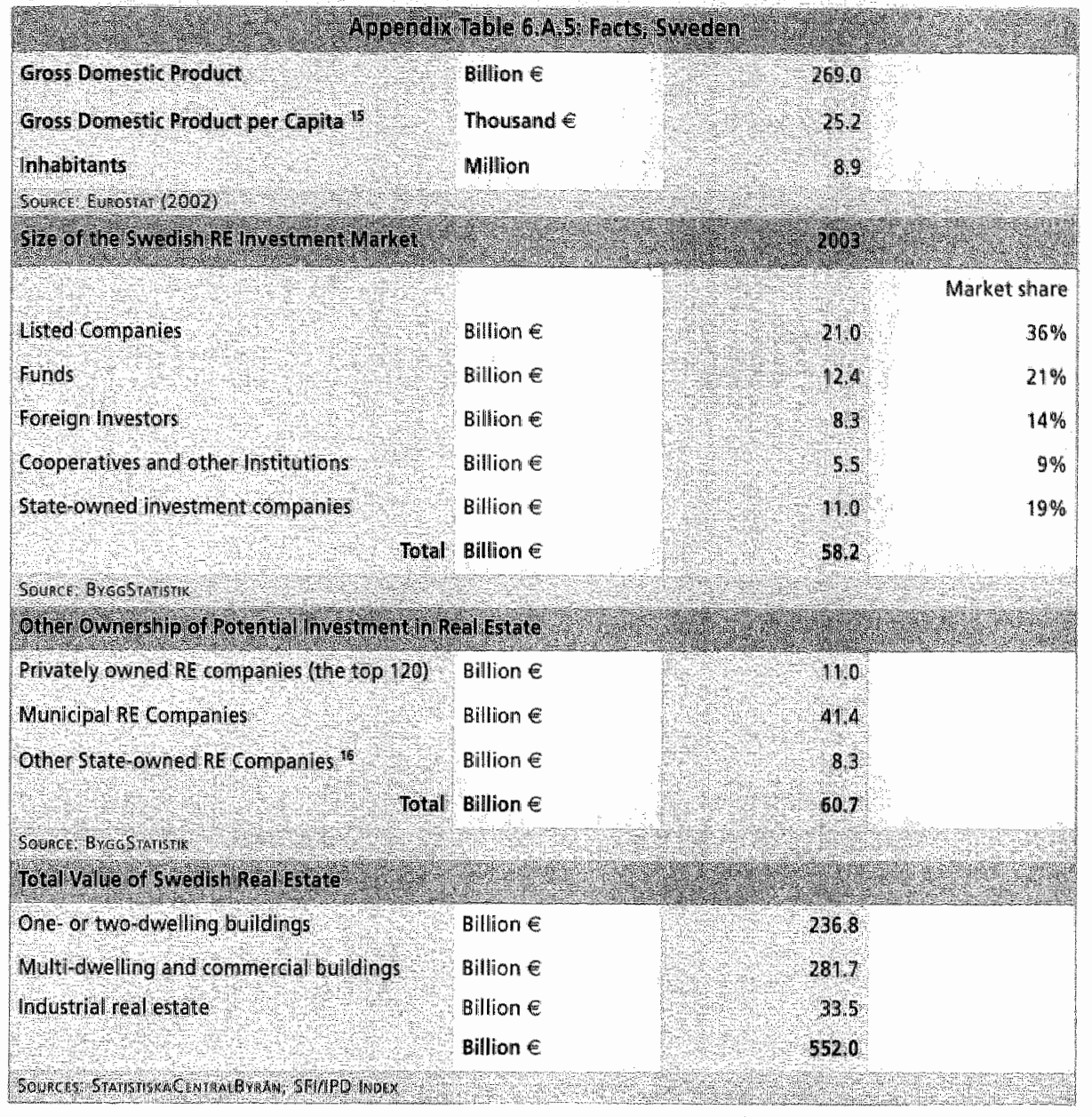

15 At parchasing powere statudards

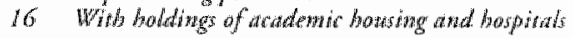




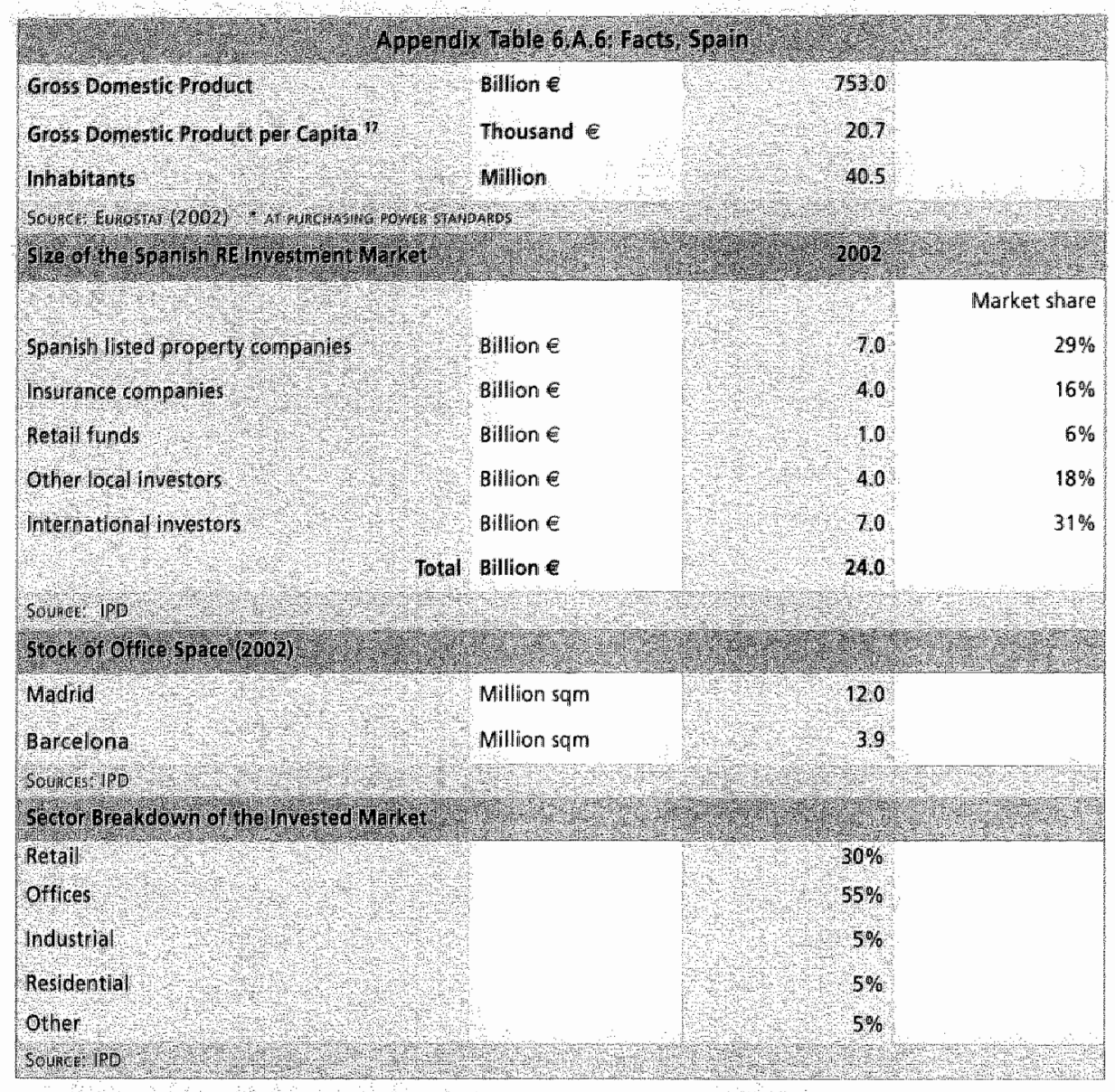

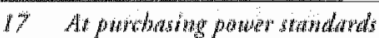




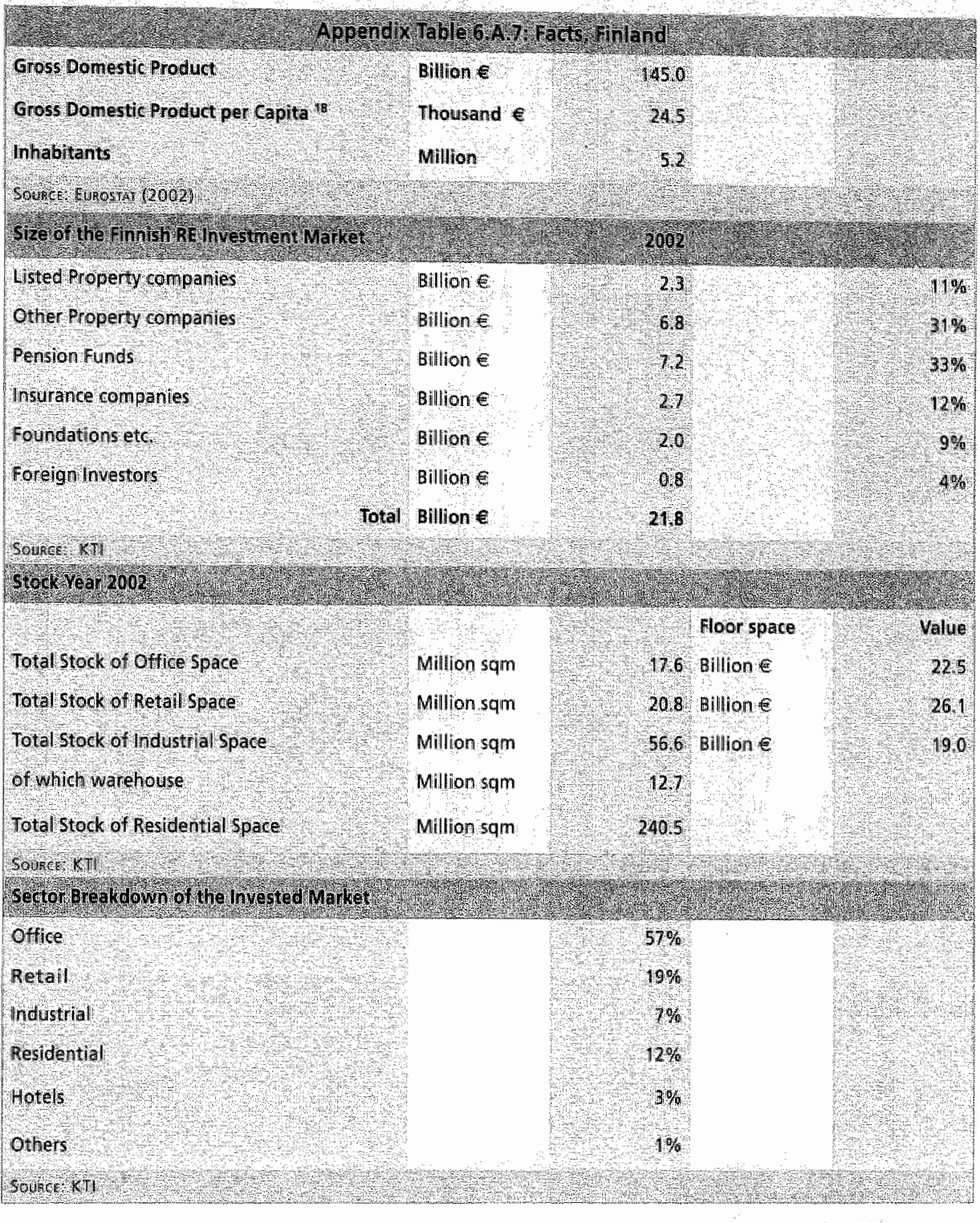

18 At purchasing power standards 


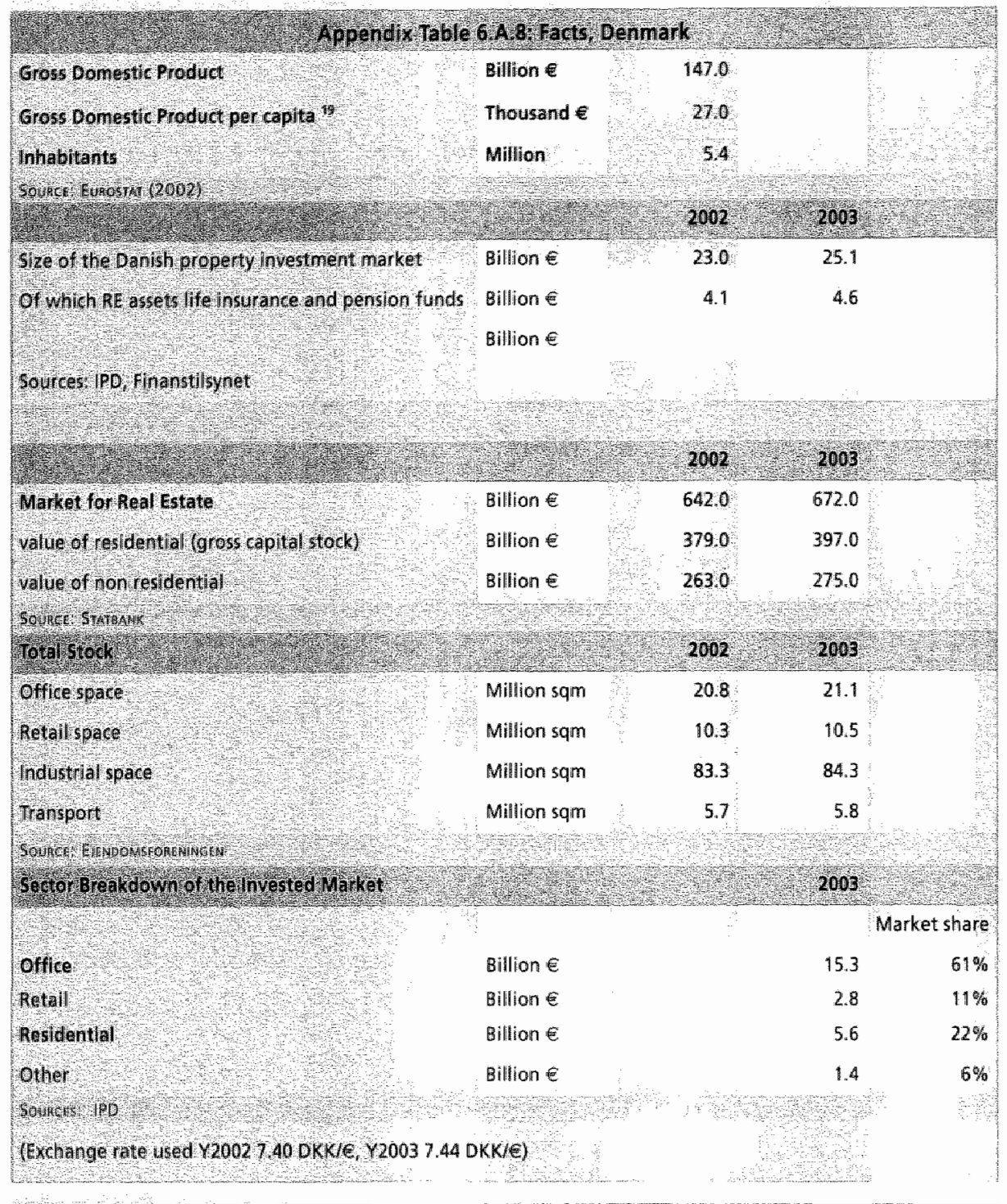

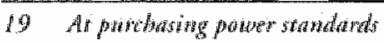




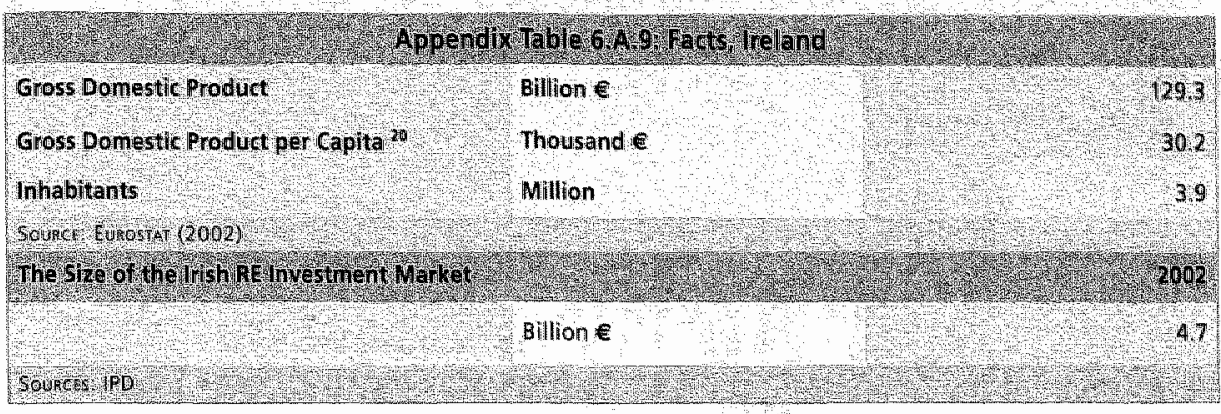

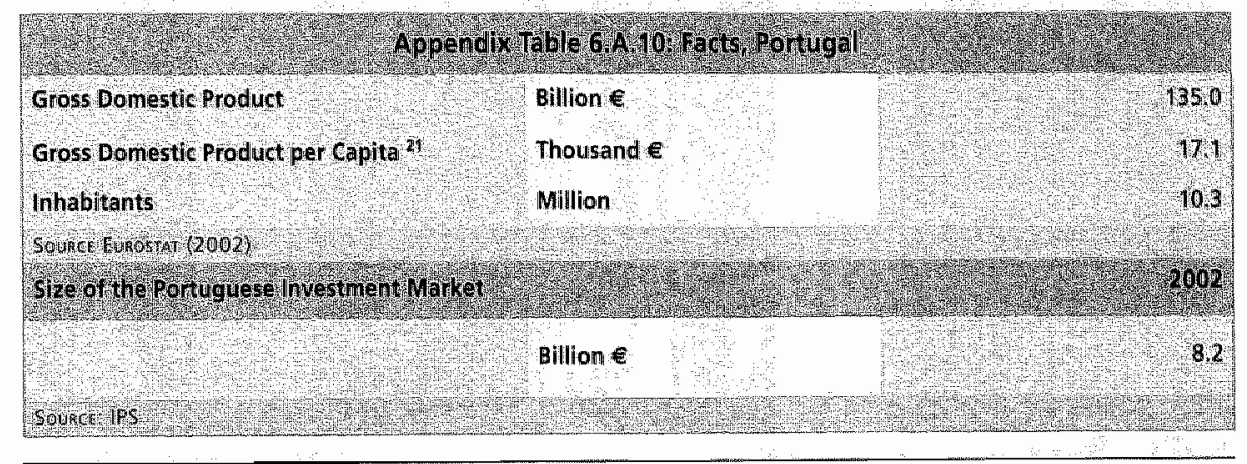

20 At purcharing pouer stamdards

21 At purchasing power standats 


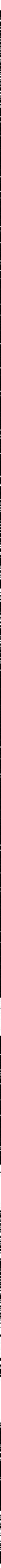




\section{CHAPTER 7}

\section{Conclusions and Further Research}

I

n the Netherlands, scientific studies on direct real estate are rare, especially regarding direct real estate performance. Experiences with the ROZ-IPD Netherlands Property Index for direct holdings in real estate by institutional investors have been a considerable inspiration for this study. The need was felt for longer return time series and particularly for higher quality of valuations, leading to the other two chapters of the dissertation. Because of the longer time series, asset liability managers of pension funds and insurance companies already feel more comfortable about investing in direct real estate as an asser class. Based on those series, other diversification studies have been carricd out, showing that direct real estate over time is negatively correlated with most of the other major asset classes, which again makes direce real estate an attractive asset class to invest in. It has also led to consideration of higher proportions (between $10 \%$ and $15 \%$ ) in the asset mix, instead of $7 \%$ to $9 \%$, where the asset mix of most institutional investors currently stands. This was the precise purpose of this study: to make institutional investors and others aware of the performance of direct real estate as an asset class, and what they might realistically expect from returns on investments in direct real estate. The valuations used to determine the capital increase or decrease are the Achilles heel of all property indices. Established Valuation Guidelines and a constant monitoring of the main valuation assumptions and parameters should reduce the risk somewhat. Valuation consistency as well as valuation accuracy are therefore two other important issues in this study.

\subsection{Conclusions}


studies. To fill this gap in data availability, 25-year return time series for offices, retail and residential real estate were constructed for the Netherlands. As many as 30,000 observations were recorded or generated. Repeated-measures regression calculations provided indices exhibiting fait to very acceptable parterns, as graphical comparisons with major economic indicators rewealed. Annual returns should still be taken with some caution, since regression noise might still exist for years due to a low number of obserwations. However, the results so far will hopefully encourage Dutch investors to contribute their archives as well, to enhance the reliability of the series. Researchers in other countries are encouraged to emulate initiatives like this, to meet the urgent need for historic real estate data.

The third chapter describes the creation of the historic time series for office rents. The time series is composed of historic information between 1977 and 1989 , which has been assembled in a unique databank consisting of more than 3,500 office transactions over that period. This databank was then combined with the aggregate data from the DTZ office transaction databank through to 2003 . The results were put into an international context with similar time series from the USA and the UK. The cycle was also reviewed, comparing it with the economic growth figures over those years. The conclusion was that the time series reflected the economic circumstances quite well - although smoothed, much more than total returns. It is believed that most of the smoothing is caused by the fact that incentives like rent free periods and tenant improvements in a market downturn are not sufficiently reflected in the market rent.

The main purpose of chapter 4 was to determine whether or not external as well internal valuers apply consistent and uniform valuation models. Therefore the more qualitative elements in valuations, such as general principles and the use of the ROZ valuation regulations provided were examined. Also, statistical analysis has been carried out on several property segments of the index databank, to determine differences in assumptions on the input variables net yield, discount rate and exit gross yield, in order to find out whether uniformity has improved over time. As far as the qualitarive analysis is concerned, the main conclusion is that valuations should be checked by the owner for compliance of the valuation regulations to a much greater extent than is the case at present. The impression is that a lot of improvement might be achieved if owners took more notice of the correct way of applying market evidence, the "solid" basis of yield and discount rate, inflation rate (especially fexible inflarion scenarios) and more uniformity in timing of the cash inflow and outflow (per year in arrears, quarterly in advance etc.). The answer to the question of whether uniformity of assumptions on the input variables has improved is "no". The standard deviation of the variables in most sub segments of the three property categories did not decrease. This could be caused by the increased uncertainty in the property market, but this was not investigated further. "The residentials display the largest differences in all analyses and the exit gross yield has by fat the highest standard deviation. In comparing external versus internal assumptions, it appears that differences in net yields are small, except for residentials. However, some sub segments show smaller differences in the last few years, compared with the beginning of the index, which is positive. Among the external waluers, the differences in net yield for offices and retail are small. However; 
the discount rate and the exit gross yield are rather uniform in the office segments - though for residentials, differences of more than $2 \%$ in one year are not unusual.

Chapter 5 analyses the difference between the sale price and the previous valuation over the years 1995 - 2002, based on the ROZ-IPD Netherlands Property Index. During those years, observations were based on the total variance rest, showing an average of $7.9 \%$. The partitioned variance test was applied to correct for systematic errors, i.e. the time lag (period between valuation date and sale date) as well as the information lag (valuation based on 'old' data).

As far as the time lag is concerned, the correction leads to an average (randomy) appraisal error, which comes out at $6.2 \%$. This compares with previous studies in the UK, showing an appraisal error between $2 \%$ and $10 \%$, and in the USA, showing an appraisal error between $6 \%$ and $13 \%$, although these were based on different periods of time which included a depressed market.

A correction for the information lag at the date of the valuation was then made, reducing the average appraisal error to a behavioural residual of $4.2 \%$ on average. Previous literature doesn't cover similar surveys, therefore comparison was not possible.

This analysis should be repeared in a few years time, since it is very likely that if results under depressed market circumstances can be and are also included, the results will be different.

Chapter 6 employs a fundamental approach to the estimation of the size of the invested volume in real estate, the porential investment market and the total stock of real estate in 11 European countries. The available data varies from country to country, being strongest in Sweden and the Netherlands, followed by the UK and Germany. The survey was limited by the fact that real estate stock data and estimates of the investment marker were not always readily awailable. The main conclusions drawn are that in the 11 countries examined, real estate inwestments held by institutional investors compared with GDP ranged from $23 \%$ for the UK to $3 \%$ for Spain. Anorher conclusion is that institutional real estate investments as a percentage of total real estate stock range from $11 \%$ for Sweden to $1 \%$ for Spain. The last main finding is that the estimate of the potential investment real estate market as a percentage of the total stock ranges from $11 \%$ to $13 \%$ for all countries, with the exception of Sweden where it is $19 \%$.

\subsection{Relevance}

The ROZ-IPD Netherlands Property Index is an initiative of the ROZ in cooperamtion with the Investment Property Databank (IPD) in London. The ROZ-IPD Index measures the performance of direct real estate in the Netherlands owned by 28 participating institutional investors. It comprises both internal and external valuation data on 6,250 individual properties which together represent a value of 38.4 billion euros at the end of 2003. 
Right from the start of the ROZ-IPD Necherlands Property Index there has been a demand for longer time series. Early attempts failed due to lack of reliability in the data supplied or insufficiently reliable data. The development of the time series as described in this dissertation became more urgent when the Pensions and Insurance Supervisory Authority of the Netherlands, the Dutch National Bank (DNB) introduced a requirement in its 2002 report for financial buffers for the downside risk in the different asset classes, due to the dramatic stock market drops in the years 2000 through 2002. For the alsset class stocks the DNB required a financial buffer of $40 \%$ and due to the lack of historic data they required the same $40 \%$ for real estate. The general feeling of the pension funds and insurance companies was that the buffer size for real estate was too high, but that had to be proven. Therefore, a 25 -year time series was developed together with the Dutch Asset Liability Management (ALM) consultants Ortec and the University of Cincinnati. The results for real estate were promising: over the 25 year period between 1977 and 2002, real escate showed a higher average total return compared with stocks (10.9\% versus $10.5 \%$ ), as well as a much lower risk (standard deviation $5.5 \%$ versus $21 \%$ ). Based on these results, discussions began with DNB about a much lower financial buffer for real estate investments compared with stocks. DNB was interested, but wanted further research on the time series, requesting un-smoothing of the capital growth figures of the time series. This resulted in a slightly higher standard deviation of $7.5 \%$.

In May 2004, DNB recommended a reduction in the financial buffer both for investments in stocks and real estate to $25 \%$, sacrificing the theoretically much lower financial buffer required for real estate in favour of a bigger reduction of the financial buffer for stocks. "That was the only possibility at that time, because DNB viewed real estate and stocks (and the risks of those investments) as a single asset class. Later on, a DNB internall research study proposed separate financial buffers for real estate and stocks. In October 2004, DNB published a consultation paper on its governance of institutional investors. Among many items in that study, a paragraph was devoted to the financial buffers to cover the downside risk of the investment. Indeed, the financial buffers for real estate and stocks had been separated. As far as the financial buffers for real estate are concerned, DNB now suggests a buffer of $15 \%$ in the case of real estate investments by pension funds and $20 \%$ for insurance companies.

Another issue has been to achieve an initial reliable estimate of the real estate stock and real estate investment universe in the European countries. To begin with, a study of the potential investment universe in 11 European countries was conducted. The outcome was presented at the IPD/Inrev conference in May 2004 and is in the process of being checked by the 11 countries involved. The study has also been taken up by the Union Bank of Switzerland (UBS), in order to carry our a similar one in Asia. Furthermore, the study prompred the designers of the Liang and McIntosh model to

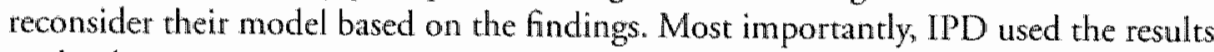
to develop a pan-European real estate index, based on the weightings of the investment universe in each of the countries as described in this research. 
The results of the study on valuation accuracy and consistency have been communicated to the majority of the valuation furms in the Netherlands which value the properties included in the ROZ-IPD Netherlands Property Index. Also an extended version of the study won the IVBN (association of Dutch institutional investors in real estate) thesis prize in 2004. Many of the findings and recommendations have been used to improve the ROZ Valuation Guidelines. In DNB's consultation paper on solvency of October 2004, it recommended the adoprion of the ROZ Valuation Guidelines as the standard for all pension funds and insurance companies in the Netherlands.

Because real estate transparency and the industry itself is still developing and will most likely continue to do so for many more years, it can be expected that the findings of this dissertation could also contribute positively to further research.

\subsection{Further research}

Writing a dissertation like this makes you aware of the fact that many areas still need to be explored in the field of institutional direct real estare investments in the Netherlands. Just a selection of further research suggestions is described below, resulting from the different subjects covered.

As far as the historic returns are concerned, several improvements could be looked at, especially the cash flow estimations. These have been estimated, using the $1995 \mathrm{cash}$ flow and adjusting this by annual inflacion back to 1976. In the case of residential investments, this should not be too far out of range because of the cash peturn guaranteed by the government, based on ten-year government bond returns. As far as commercial real estate is concerned, cyclical patterns should be investigated to generate more realistic cash flow patterns. Other countries should also be encouraged to generate similar time series based upon the RMR method as introduced by David Geltner.

The crearion of historic office rents turned out to be an embarrassment. The expected cyclical pattern was much more mild than one would expect. The main reason is that office market rents don't reflect the effect of incentives in depressed office markets. Previous research from the UK also suggests this. However, if more information about cyclical parterns in office rents could be developed and some sensible escimate of furure cycles created, further projection of cyclical patterns in office market rents could then be included in office market rental growth estimates in the DCF valuation models. Until that time, the DCF model could be useful for scenario analysis

The difference berween market rent and effective (net of incentives) rent could be as high as $30 \%$. In a few years time, the ROZ-IPD Index will permit analysis of this effect in the office market in the Netherlands.

Valuation consistency and accuracy are continuous processes and embedded in the quallity control process and analysis of the ROZ-IPD Index procedures. It is wery likely that future research will improve valuation consistency further, while valuation accuracy will also be improved by more observations of sales as well as greater transparency and increased knowledge of the real estate market in the Necherlands. 
Suggestions for further research on the real estate market dimension in Europe include the urgent need to obtain the rotal stock for the countries where this information does not exist. What could also contribute would be a uniform international comparison of the main statistical data on the total value of national real estate assets, and the definitions of these statistics. Other suggestions for further research concern the size of the potential investment market, and in what way national market characteristics affect this; for example, the incidence of owner-occupied residential and owner-occupied corporate real estate. It would also be of interest to investigate whether there are any country-specific laws or regulations which may have an impact on the size of the potential investment market. Suggestions for further research also include an urgent need for obtatning the total stock for the countries where this information does not exist. Furthermore, an international comparison of the main statistical data on the total value of national real estate assets and the definitions of these statistics would be of value. 


\section{REFERENCES}

AIG Global Real Estate Research (2001), Why should Investors Consider International Real Estate Investment. Global Real Estate Perspective.

ARES conference (1996) Orlando. Panel Discussion on European Real Estate Indices, I. W. Goslings and A.C. Hordijk.

ARES conference (2004) Captain Island Florida. Development of historic time series for office rents. A. Hordijk, and C. Schekkerman.

Bailey, M.J., R.F. Murh and H.O. Nourse (1963) A Regression Method for Real Estate Price Index Construction. Journal of the American Statistical Association, Vol. 58, page 933-942.

Barber, B., R. Lehavy and B. Trueman (2000), Brokerage Houses and their Stock Recommendations: Does Superior Performance Persist?, working paper, California, Haas School of Business.

Baum, A., N. Crosby, P. Gallimore, P. McAllister and A. Gray (2001) The influence of valuers and valuations on the workings of the commercial property investment market. Research paper funded by IPF, JLL and RICS

Baum, A. (2002) Commercial Real Estate Investments. Oxford, Chandos Publishing.

Bjorring, J., J. Lakonishok and T. Vermaelen (1983) Stock Prices and Financial Analysts' recommendations. Journal of Finance, Vol. 38, page 187-204.

Blundell, G.F. and C.R.W. Ward (1997) The Accuracy of Valuations- Expectation and Reality. The University of Reading.

Bollinger, C. R., K.R. Ihlanfeldt and D.R. Bowes (1998) Spatial Variation in Office Rents within the Adanta Region. Urban Studies, Vol. 35(7), page 1097-1118.

Bolt, E.J. (2003) Winkelvoorzieningen op waarde geschat, theorie en praktijk. Page 136-138.

Boyd, T. (2002) Property cash flow studies: focusing on model consistency and data accuracy. Queensland University of Technology.

Brounen, D. and PM.A. Eichholtz (2002) Initial Public Offerings. Journal of Real Estate Finance and Economics, Vol. 24 (1).

Brown, G.R. (1995) Estimating Effective Rents. Journal of Property Finance, No. 2, page 33-42. 
Brown, G.R. and G. Mtysiak (2000) Sticky Valuations, Aggregation Effects and Property Indices. Journal of Real Estate Finance and Economics, No. 1; page 49 66.

Brown, S.J., C.H. Liu, W.N. Goetzmann, S.M. Wachter, B. Renaud, M. Zhang, 5. Koeberle, Y. Doon, R.E. Edelstein, A.L. Lacayo, D.C. Lee and P.M.A. Eichholtz (2001) A Global Perspective on Real Estate Cycles.

Case, K.E and R. Shiller (1987) Prices of Single-Family Homes since 1970: New Indexes for Four Cities. New England Economic Review, September/October, page 46-56.

Case, K.E. and R.J. Schiller (1989) The Efficiency of the Market for Single-Family Homes: American Economic Review, Vol. 79(1), page 125-137.

Catella (2004) Property Market Trends, Catella l'roperty Group.

Catella (2004) European Office Markets, Catella Property Group.

Chinloy, P, M. Cho and I.F. Megbolugbe (1997) Appraisals, Transacrion Incentives and Smoothing. Journal of Real Estate Finance and Economics, No. 1/2, page 89-110.

Chinloy, P. and E. Maribojoc (1998) Expense and rent Strategies in Real Estate Managenent. Journal of real Estate Research, No. 3, page 267-282.

Cho, H., Y. Kawaguchi and J.D. Shilling (2003) Unsmoothing Commercial Property Returns: a Revision to Fusher-Gelner-Webb's unsmoothing methodology. Journal of Real Estate Finance and Economics, No. 2, page 393-405.

Clayton J., D. Geltner and S. W. Hamilton (2001) Smoothing in Commercial Property Valuations: Evidence from individual Appraisals. Real Estate Economics, Vol. 29:3. page $337-360$.

Court, A. (1939) Hedonic Price Indexes with Automobile Examples, General Motors Corp. The Dynamics of Automobile Demand. New York, General Motors Corp. page 99.117.

Cowles, A. (1933) Can stock market forecasters forecast?. Econometrica, Vol. 1, page $309-324$

Crosby, N. (2000) Valuation accuracy: variation and bias in the context of standards and expectations. Journal of Property Investment and Finance, Vol. 18: 2, page 130-161.

Crosby, N.. A. Lavers and J. Murdoch (1998) Property valuation and the margin of error in the UK. Journal of Property Research, Vol. 15:4, page 305-330. 
Cullen, I. (1994) The accuracy of valuations revisited, evidence from IPD UK of properties sold (1988-1993).

Dale-Johnson, D. (2001) Long-term Ground Leases, the Redevelopment Option and: Contract Incentives. Real Estate Economics, No. 3, page 451-484.

D'Arcy, E., T. McGough, and S. Tsolacos (1997) National Economic Trends, Marker Size and City Growth Effects on European Office Rents. Journal of Property Research, 16(4), page 297-308.

Davidson, A. and C. Darlow (1993) The Boston Gilmore Rental Equivalent Tables and Lease Incentives. London, The Estates Gazerte Limited.

DB Real Estate Research, march 2004.

Drivers Jonas / IPD (1988) The Variance in Valuations. Drivers Jonas / IPD, London.

Desai, H. and P. Jain (1995) An analysis of the Recommendations of the 'Superstar' Money Managers at Barron's Annual Roundtable. Journal of Finance, Vol. 50 , page $1257-1273$.

DTZ, Jones Lang LaSalle, Cushman Wakefield Healy Baker, CB Richard EAlis \& Dynamis (2002) Recommendations to improve the ROZ Valuation Guide Lines.

Dynamis (2004) Sprekende Cijfers, kantorenmarkt 2004

Elton, E., M. Gruber and S. Grossman (1986) Discrete Expectational Date and Portfolio Performance. Journal of Finance, Voll. 41, page 699-713.

ERES Conference (1998) Maastricht, the Netherlands. Analysis of Valuation Yields, Hordijk, A.C.

ERES Conference (2001a), Allicanre. The impact of valuation rules on the quality of valuations in the ROZ-IPD Property index in the Netherlands. Hordijk, A.C. and A.P. van kiel.

ERES Conference (2001b), Singapore. Valuation Accuracy in Real Estate Indices: the Case of the Netherlands, Hordijk, A.C. and A.P. wan Riel.

ERES 2002. Valuation accuracy: addressing the Carsberg recommendations. Crosby, N. and G. Matysiak.

European Property Straregies Conference (1999) Wiesbaden. Valuation Standards for Performance Measurement, Lundström, $S$. 
Fisher, J. D, ME. Miles and RB. Webb (1999) How reliable are commercial appraisals? Another look. Real Estate Finance, Fall, page 9-15.

Francis, J.M. (1995) Deniving IRR Sets from Market Transactions. Appraisall Journal, No. 2, page 195-201.

Gallimore, P. (2002) The Components of Appraisal Accuracy, Real Estate Valuation Theory, Research Issues. Real Estate, Appraisal Institute and ARES.

Gatzlaff D., and D. Geltner (1998) A Transacrion-Based Index of Commercial Property and its Comparison to the NCREIF Index. Real Estate Finance, Vol. 15(1), page $7-22$.

Geltner, D. and W.N. Goetzmann (2000) Two Decades of Commercial Property Returns: A Repeated-Measures Regression-Based Version of the NCREIF Index. Journal of Real Estate Finance and Economics, Vol. 21(1), page 5-21.

Geltner, D. and J.D. Fisher (2000) De-Lagging the NCREIF Index: Transaction Prices and Reverse-Engineering. Real Estate Finance, Vol. 17(1), 7-22.

Geltner, D. (2003) IRR-based Property-level Performance Attribution. Journal of Portfolio Management, September, page 138-151.

Gelmer, D. (1993) Estimating Market Values from Appraised Values Without Assuming an Efficient Market. Journal of Real Estate Research, Vol. 8(3), page $325-346$.

Geltner, D. (1997) How accurate is the NCREIF Index as a benchmark and who cares? Real Estate Finance, Vol. 4, page 25-38.

Geltner; D. (1996) The Repeated Measures Regression-Based Index: A Berter Way to Construct Appraisal-Based Indexes of Commercial Property Value. Real Estate Finance, Vol. 12(4), page 29-35.

Goetzmann, W.N. (1992) The Accuracy of Real Estate lndices: Repeat Sale Estimators. Journal of Real Estate Finance and Economics, Vol. 5, page 5-54.

Goetzmann, W.N. and L Peng (2002) The Bias of the RSR Estimator and Accuracy of Some Alternatives. Real Estate Economics, No. 1, page 13-39.

Gool, P. wan, P. Jager and R.M. Weisz (2001) Onroerend Goed als Belegging. Culemborg, Srenfert Kroese.

Gool, P. van (2003) Presentation at ROZ/IPD launch. 
Graff, A. G., MS. Young and D. Geltner (1994)Random Disaggregate Appraisal Error in Commercial Property. Journal of Real Estate Research, No: 4, page 403-413.

Graff, R.A and M.S. Young (1998) The Magnitude of Random Appraisal Error in Commercial Real Estate Valuation. Journal of Real Estate Research, Vol. 12 , page $33-54$.

Grossman, S. and J. Stiglizz (1980) On the Impossibility of Informationally Efficient Markets. American Economic Review, Vol. 70, page 393-408.

Gunnelin, A., P.H. Hendershott, M. Hoesli and B. Söderberg (2002) Determinants of Cross-Sectional Variation in Discount Rates; Growth Rares and Exit Gap Rates: Real Estate Economics, Vol. 32, No. 2.

Hakfoort, J.R. (1994) Property Cycles; a Review of the Literature and some Preliminary Results from the Dutch Office Market. City University Business School.

Hartzell, D., R. Pittman, D. Downs (1994) An Updated Look at the Size of the U.S. Real Estate Market Portfolio. The Journal of Real Estate Research, Spring Vol. 9 No. 2.

Have, G.G.M. ten (1997) Taxatieleer onroerende zaken. Houten, Stenfert Kroese, EPN.

Have, G.G.M. ten (1998) Taxatie en Controle moet gescheiden blijven. VastGoedMarkt, No. 5, page 26.

Hayes, F.H. (1945) The Use of Knowledge in Society. American Economic Review, Vol. 35, page 519-530.

Hendershott, P.H. and E.J. Kane (1995) U.S. Office Market Values during the Past Decade: How Distorted have Appraisals Been. Real Estate Economics, No. 2, page $101-116$.

Hendershort, P.H. (2001) Properry Asset Bubbles: Evidence form the Sidney Office Market. Journal of Real Estate Finance and Economics, No. 1, page 67-81.

Hendershott, P.H., B.D. MacGregor and R.Y.C Tse (2002) Estimation of the rental Adjustment Process. Real Estate Economics, No.2, page 165-183.

Henderson Global Investors (2000) The Case for Global Property Investment.

Hoesli, M., J. Lekander and W. Witkiewicz (2004) International Evidence on Real Estate as a Portfolio Divider. Journal of Real Estate Research, No. 2, page 161. 206. 
Hordijh, A.C. and A.P. van Riel (2001c) Construction of a Historic Netherlands Property Index using Repeated Measures Regression Techniques. ROZ-IPD Netherlands Property Index.

Hordijk, A.C. and J. Voorhorst (1999) Developing Historical Time Series in a Market Without External Valuations. ROZ-IPD Netherlands Property Index.

Hordijk, A.C and H.M. de Kroon (2002) Valwation Accuracy in Real Estate, the Case of the Netherlands. ROZ-IPD Netherlands Property Index.

Hordijk, A and C. Alhqvist (2004) European market dimensions: An inventory of the investible market in 11 European countries. The Compendium of Real Estate Papers Volume 2, IPD London.

Hordijk, A. and W. wan de Ridder (2004) Valuation model uniformity and consistency in real estate indices, the case of the Netherlands. Journal of Property Investment and Finance, Vol. 23 No. 2.

Hordijk, A. and M.A.J. Theebe (2004) Long-run Return Series for the European Continent: 25 Years of Dutch Commercial Real Estate. Journal of Real Estate Portfolio Management, Vol. 10 No. 3, page 217-230.

Hu, D. and A. Pennington-Cross (2001) The Evolution of Real. Estate in the Economy. Journal of Real Estate Portfolio Management, Vol. 2, page 169-176.

Huele, A. , A. Hordijk, F. Seyffert and F. Dijkstra (1997) The experience of Establishing the Dutch Property Index. Amsterdam, Stichting Fundatie Bachiene.

Hutchison, N. and N. Nanthakumaran (1996) Estimation of the Invested Worth of Commercial Property. Bristol, The Cutting Edge.

Ibbotson, R. (1975) Price Performance of Common Stock New Issues. Journal of Financial Economics, Vol. 2, page 235-272.

INSEE (2003) Patrimoine des ménages dynamique d'allocation et comportement de consommation. Institut National de la Statistique et des. Etudes Economiques.

International Monetary Fund (2003) World Economic Outlook; Chapter 2: When Bubbles Burst. Washington D.C.

IPD (1999) Internal Analysis on Swedish Results, Key T. , J. Franson.

IPD/IPF Property Investment Conference (2002) Brighton, UK. Property and Prosperity, Bootle, R. 
IPD European Property Strategies Conference (2002) Whesbaden "Germany. Valuations - standards, accuracy, consistency, iWokrane, $M$.

IPD European Property Strategies Conference (2002) Wiesbaden, Germany. Bechade, A.

IVSC Conference (2004) Vancouver. Valuations accuracy in real estate indices, the case of the Netherlands. Hordijk, A.

Jeffries, R.L. (1994) Lease Incentives and Effecrive rents. Journal of Property Valuation and Investment, No, 2, page 21-42.

Kaiser, R.W. (1997) The Long Cycle of Real Estate. Journal of Real Estate Research, Vol. 14(3), page 233-258.

Keeris, W.G. (2000) Beheer van gebouwen, Technische Universiteit Eindhoven, Eindhoven.

Kramer, B. (2003) Presentation at ROZ/IPD launch.

Krische, S.D. and C. Lee (2000) The information content of analyst Stock Recommendations. Working paper, Parker Center for Investment Research.

Lakonishok, J., A. Shleifer and R. Vishny (1992) The impact of Institutional Trading on Stock Prices. Journal of Financial Economics, Vol. 32, page 23-43.

Liang, Y. and W. McIntosh (1998) Sharpe's Alpha: a New Performance Measure. Real Estate Finance, the Quarterly Review of Commercial Finance Techniques, Vol. 25, No. 3, page 13-17.

Liang, $Y_{n}$, R.C. Hess, D. Bradford and W. Mclntosh (1999) Return atrribution for commercial real estate investment management, Journal of Real Estate Portfolio Management, Vol. 5, No. 1, page 23-30.

Liang, Y., W. Mclntosh (1999) Global Commercial Real Estate. Prudential Research report, April.

Lizieri, C.M. and P. Vermone-Rowland (1991) Valuation Accuracy: a Contribution to the Debate. Journal of Property research. No. 2, page 115-122.

Loughran, T. and J.R. Ritrer (2004) Why has IPO Lnderpricing Changed Over Time: Financial Management, Vol. 33, No. 3, page 5-37.

Lusht, K.M. (2001) Real Estate Valuation: principles and applications. KML, State College. 
Mahoney; J, J. Murphy and S. Keogh (1998) The Internal Rate of Return and Institutional Performance Measurement for real Estate Portfolios. Real Estate Finance: The Quarterly Review of Commercial Real Estate Techniques, Vol. 15, No. 2, page $63-72$

Mahoney, J., S. Malpezzi and J. D. Shilling (2000) Implications of Income Property Stock Data for Real Estate Investment Portfolio Location. Real Estate Finance; Winter, page $1-14$.

Mallinson Report (1994) Commercial Property Valuations. Royal Institution of Chartered Surveyors.

Mallinson, M. and N. French (2000) Uncertainty in property valuation. Journal of Property Investment \& Finance, Vol. 18:1, page 13-32.

Malpezzi, S., J. Shilling and Y. Yang (2001) The Stock of Priwate Real Estate Capital in U.S. Metropolitan areas. Journal of Real Estate Research, Voll. 22, No. 3.

Matysiak, G. and P. Wang (1995) Commercial property market prices and valuations: analysing the correspondence. Journal of Property Research, Vol. 12, page $181-202$.

McAllister, P. (1995) Valuation accuracy: a contribution to the debate. Journal of Property Research, Vol. 12, page 203-216.

McAllister, P. and H. Tarbert (1999) Bargaining, Utility and Rents: Analysing the Effect of Potential Lease termination on Rent Negotiation Outcomes. Journal of Property Investment and Finance, Vol 17, No. 4, page 353-364.

Michaely, R. (1999) Conflict of Interest and the Credibility of Underwriter Analyst Recommendations. The Review of Financial Studies, Vol. 12:4, page 653-683.

Miles, M. (1992) What is the Value of all U.S. Real Estate. Real Estate Review, Vol. 20, No. 2, page 69-75

Miles. M. and ]. Mahoney (1997) Is Commercial real Estate an Inflation Hedge. Real Estate Finance: the Quarterly Review of Commercial Real Estate Techniques, No. 4 , page $31-45$.

Miles, M. and N. Tolleson (1997) A revised look at how reall estate compares with other major components of domestic investment universe. Real Estate Finance, spring:

Munneke, H.J. and B.A. Slade (2000) An Empirical Study of Sample Selection Bias in Indices of Commercial Real Estate. Journal of Real Estate finance and Economics, Vol. 21, page 45-64 
Newell, G. and J. MacFarlane (1995) Improves Risk Estimation using Appraisallsmoothed real Estate Returns. Journal of Real Estate Portfolio Management, No. 1 , page $51-57$.

Newell, G. and J. MacFarlane (1996) Risk Estimation and Appraisal-smoothing in UK Property returns. Journal of Property Research, No. 1, page 1-12.

Newell, G. (1997) The Qualiry of appraisal reports in Australia. The Appraisal Journal, January.

Pacific Rim Real Estate Society Conference (1998) Perth. The Accuracy of Commercial Property Valuations. G. Newell and R. Kishore.

Pagliari Jr. J.L. (1991) Inside the Real Estate Yield. Real Estate Review, Fall.

Parker, D. (1999) A note on valuation accuracy: an Australian case study. Journal of Property Investment \& Finance, Vol. 17:4, page 401-411.

Pellicer, J-L. and N. Tyrrell (2004) Investing in Residential Real Estate. DB Real Estate Research, March.

PREA (2003) PREA research report. J. Nowakowski, March.

PropertyNL (2003) Quarterly Research, June.

Pugh, C. and A. Dehesh (2001) Theory and Explanation in Intermational Property Cycles since 1980. Property Management, No. 4, page 265-297.

Rabobank (2002) Trends en Cijfers, november.

Rodney, W. and A. Axcell (2000) The Valuation of Real Estate where no Market Evidence Exists or only Limited Market Data is Available. City University Business School.

Rosen, S. (1974) Hedonic Prices and Hedonic Markets: Product Differentiation in Pure Comparison. Journal of Political Economy, Vol. 82, page 34-55.

ROZ Valuers Meering (2000) The Hague. Valuation Analysis by IPD, Horsey, T.

ROZ-IPD (2001) ROZ-IPD Netherlands Property Index Participants ${ }^{*}$ Valuation Reports.

Rust, W. (2004) Restwaarde berekening van commercieel vastgoed. Property NL, Vol. 4, No. 9, page 80-89.

Scarett, D. (1996) Property Valuation: the 5 methods. London, E \& FN Spon. 
Shiller, R. (1991) Arithmetic Repeat Sales Price Estimators Journal of Housing Economics, Vol. 1, No. 1, page 110-26.

Sivitanides, P. and R. Siwitanidou (1996) Office Capitalization Rates: Why Do They Vary Across Metropolitan Markets? Real Estate Issues.

Smit, W.N.M. (2002) Uniformering ROZ IPD taxaties, thesis SBV MRE.

Smith, T.R (1995) Statistical Implications of the most probable prices. The Appraisal Journal, Vol. 1, page 81-86.

Steele, M. and R. Goy (1997) Short Holds, the Distribution of First and Second Sales and Bias in the Repeat-salles Price Index. Journal of Real Estate Finance and Economics, No. 1/2, page 133-154

Stickel, S. (1995) The anatomy of the Performance of Buy and Sell Recommendations. Financial Analysts Journal, Vol. 51, page 25-39.

Talmage, P. (1995) What's the JRR for an REO? Appraisal journal, No. 2, page 202203.

Theebe, M.A.J. Presentation at ROZ / IPD launch.

Tinbergen, J. (1959) On the Theory of income Distribution. Selected Papers / Jan Tïnbergen, page 243-263.

Tsolacos, S. (1995) Industrial Property Development in the UK: a Regional Analysis of New Orders. Journal of Property Research, Vol. 12, No. 2, page 95-125.

Tsolacos, S. and T. McGough (1995) Property Cycles in the UK: an Empirical Investigation of the Stylized Facts. Joumal of Property Finance, No. 4, page 45-62.

Tsolacos, S. and T. MoGough (1999) An Economic and forecasts of the Office Rental Cycle in the Dublin Area. Journal of Property Research, No. 4, page 309-32:

Vastgoedmarkt (1994) Overview of Construction Costs and CPI 1992 - 1994, March.

Wang, K., T.V. Grïssomand and S.H. Chan (1990) The functional relationship and use of going-in and going-out capitalization races. Journal of Real Estate Research, Summer.

Webb, R.B.(1994) An analysis of properties sold from the Russell - NCRELF Index (1978-1992). Real Estate Finance, Vol. 11:1, page 62-65.

Wheaton, W. C. and R. G. Torto [1994\}, Office Rent Indices and their Behaviour over Time, Journal of Urban Economics, No. 35, page 121-134. 
Wiltshaw, D.G. (1996) Spatial autocorrelation an valuation accuracy: a negllected. methodological problem. Journal of Property Research, Vol. 13, page 275-286.

Wiley. R.J. (1993) Real Estate Accounting and Mathematics Handbook. New York, John Wiley \& Sons.

Wincott, R.D. and G.R. Mueller. (1995) Market analysis in the appraisal process. The Appraisall Journal, January, page 27-32.

Womack, K. (1996) Do Brokerage Analysts" Recommendations Have Investment Value? Journal of Finance, Vol. 51, page \$37-167.

\section{WEBSITES}

The association of Property Unit Trusts

www.aput.co.uk

Axa

www.axa.com

\section{Bulwien Gesa AG}

www.bulwien.de

\section{Byggstatistilk}

www.byggstatistik.se

\section{Catella Property Group}

www.catella.com

\section{Conseil National des Centres Commerciaux}

www.cncc.com

April 2004

\section{Ejendomsforeningen Danmark}

www.ejendomsforeningen.dk

Europe Real Estate Publishers

www.curope-re.com

\section{Eurostat}

epp.eurostat.cec.eu.int

\section{Swedish Property Index}

www.fasrighetsindex.se 
Danish Financial Supervisory Authority www.finanstilsynet.dk

Institute for Real Estate Economics

www.kti.fi

March 2004

Nederlandse Vereniging van Makelaars

wwwnvm.n!

Organisation for Economic Co-operation and Development www.oecd.org

Office of Federal Housing Enterprise Oversight www.ofheo.gov

Statistics Sweden

Www.scb.se

Statbank Denmark

www.statbank.dk

March 2004

National Statistics UK

www.statistics.gov.uk

Vastgoedmarkt

www.vastgoedmarkt..nl

Contributors OF DATA

Paulus van Wetten - head of Real Estate Research Forris Bank, the Netherlands

Dirk Rompelman - adviser and former editor in chief of VastGoedMarkt

ROZ-IPD Databank 1995- 2003

ROZ Historical "Time Series Databank 25-year

ROZ-IPD Index Participants Valuation Reports

NCREIF Databank, USA

Jones Lang LaSalle Research 


\section{NEDERLANDSE SAMENVATTING}

Werenschappelijke studies over direct onroerend goed zijn betrekkalijk zeldzaam in Nederland, zeker wanneer het rendementen van direct onroerend goed betreft. Ervaringen van de ROZ/IPD Vastgoedindex met betrekking tot direct aangehouden onroerend goed zijn een grote inspirarie voor dir onderzoek geweest. Her doel van dit proefschrift is er toe bij te dragen dat institutionele beleggers en anderen zich bewrust zijn wan het rendement van direct onroerend goed als beleggingscategorie en wat zij realiter kunnen verwachten van de rendementen van investeringen in direct onroerend goed.

Er was vraag naar meerjarige rendement tijdreeksen zowed als naar langjarige reeksen voor markthuren, die geleid hebben tot twee hoofdstukken in dit proefschrift. Door de langere historische tijdsreeksen voelen Asset Liability Managers van pensioenfondsen en verzekeraars, die de afstemming tussen opgebouwd en op te bouwen vermogen en de (toekomstige) pensioenverplichtingen beoordelen, zich zekerder bij het investeren in direct onroerend goed als beleggingscategorie. Mede gebaseerd op de historische tijdsreeksen zijn ook andere daaraan gerelareerde onderzoeken uitgevoerd die aantonen dat direct onroerend goed over langere termijn negatief correleert met de meeste andere vermogens categorieën, wat aantoont dat direct onroerend goed een aantrekkeiijke vermogens categorie is om in te investeren. Het heeft inmiddels geleid rot breed gesteunde aanbevelingen om een aanzienlijk hoger aandeel direct onroerend goed in de vermogens allocatie te nemen, tussen $10 \%$ en $15 \%$ in plaats van tussen $7 \%$ en $9 \%$, die gebruikelijk was bij de beleggingen in direct vastgoed van de meeste institutionele beleggers.

Een belangrijk ander thema in dit proefschrift zijn de taxaties van vastgoed die de jaarlijkse waarde toename of afname bepalen. Taxaties worden over het algemeen als de Achilleshiel van alle onroerend goed indices gezien. Vastgestelde taxarie richtlijnen en een constante controle van de voornaamste taxatie aannames en parameters moeten de risico's op verkeerde taxaties volgens dit onderzoek duidelijk kunnen verminderen.

Hoofdstuk 2 suggereert dat bijna alle studies over de rendementen van onroerend goed of de rol van onroerend goed in een gemengde portfolio zijn gebaseerd op Angelsaksische rendement indices. Voor investeerders op het Europese continent moesten deze conclusies tot nu toe als representarief gezien worden voor hun thuismarkten, orndat er geen historische tijdreeksen zijn voor hun eigen landen die lang genoeg terug gaan om dergelijke studies uit te kunnen voeren. Om in dit gebrek aan informarie te voorzien zijn er 25 jarige historische tijdreeksen voor kantoren, winkels en woningen in Nederland geconstrueerd. De totale databank beslaat meer dan 30.000 waarnemingen over die 25 jaar. Op basis van berekeningen aan de hand wan meerdere waardebepalingen per object in de tijd zijn indices gecreëerd, die redelijke tot zeer redelijke overeenkomsrige patronen laten zien in vergelijking tot van belang zijnde economische indicatoren, zoals de ontwikkeling van her bruro national product en de consumenten besredingen in diezelfde periode. De jaarlijkse rendementen moeten met enige woorzichtigheid worden bekeken, omdat verstoring van de regressie nog enkele jaren kan voorkomen als gevolg van het lage aantal observaties in de beginjaren van de reeks. Echter, de resultaten tot zover zullen hopelijk Nederlandse investeer- 
ders aanmoedigen om hun archieven open te stellen, om zo de betrouwbaarheid van deze historische tijdreeksen nog verder te vergroten. Onderzoekers in andere landen worden bij deze van harte aangemoedigd om soortgelijke onderzoeken ook te verrichten om zo te voorzien in de vraag naar historische data over onroerend goed.

Her derde hoofdstuk beschrijft de creatie wan historische tijdreeksen voor kantoorhuren. De tijdreeksen bestaan uit historische informatie russen 1977 en 1989, die verkregen is uit een unieke databank met daarin ruim 3500 kantoor transacties over de betreffende periode. Deze databank is vanaf 1990 gecombineerd met de geaggregeerde data van de DTZ kantoren transacties tot en met 2003. De resultaten zijn in een internationale context geplaatst met gelijksoortige tijdreeksen uit de Verenigde Staten en het Verenigd Koninkrijk. Er is onderzocht of deze huren een cyclisch patroon volgen. Vervolgens zijn de reeksen vergeleken met onder andere de economische groei cijfers over de berreffende jaren. De conclusie was dat de huurontwikkeling in de tijd, hoewel gedempt en vertraagd, de economische omstandigheden vrij goed weergeven, in sommige opzichten zelfs beter dan de totale rendementen voor kantoorbeleggingen, zoals berekend in hoofdstuk 2 . Aangenomen wordt dat het merendeel van de demping veroorzaakt wordt door het feit dat tegemoetkomingen, zoals huurvrije perioden en investeringen voor de huurders in een neergaande markt niet voldoende in de markthuur worden meegenomen.

Het hoofddoel van hoofdstuk 4 was om te bepalen of externe en interne taxateurs consistent en uniform taxatie modellen hanteren. Om die reden zijn de meer kwalitatieve elementen in taxaties, zoals algemene principes en het gebruik van de gegeven $\mathrm{ROZ}$ taxatie richtlijnen, onderzocht. Daarnaast is ook statistische analyse uitgevoerd op verschillende onroerend goed segmenten van de ROZ Vastgoedindex databank om zo de verschillen in aannames mer berrekking tot de netto aanvangsrendementen, de disconteringsvoet en de eindwaarde bepaling vast te stellen om daarmee te bepalen of de uniformiteir door de jaren heen is verbeterd. War betreft de kwalitatieve analyse is de hoofdconclusie dat taxaties veel frequenter en meer inhoudelijk moeten worden gecontroleerd door de eigenaar en steekproefsgewijs door de ROZ op naleving van taxatie richtlijnen en het gebruik van realistische aannames dan nu het geval is. De indruk bestaat dar veel verbetering kan worden bereikt wanneer eigenaren meer aandacht besteden aan de wijze waarop marktgegevens, de basisrente, de disconteringsvoet, het inflatie percentage (in het bijzonder flexibele inflatie scenario's) en grotere uniformiteit met berrekking tor het juiste tijdstip van de huurinkomsten en de exploitatie uitgaven, per jaar achteraf, per kwartaal vooruit of andere varianten, worden toegepast. Het antwoord op de vraag of uniformireit van aannames ten aanzien van de input variabelen tussen 1994 en 2002 van de tijd is verbeterd, is "nee". De standaarddeviatie van de variabelen in de meeste subsegmenten van de drie onroerend goed categorieèn is namelijk niet afgenomen. Dir kan echter mede veroorzaakt worden door de groeiende onzekerheid in de onroerend goed markt over de toekomstige ontwikkelingen. Dit is echter hier niet nader onderzocht. De woningen geven de grootste varieteit weer in alle analyses en de eindwaarde berekening voor woningen kent verreweg de grootste verschillen in benadering. Wanneer externe met interne taxaties worden vergeleken lijkt her erop dat de verschillen in netto aanvangs- 
rendementen kleiner zijn geworden in vergelijking tor het begin van de index. Tussen de externe taxateurs onderling zijn de verschillen in netto aanvangsrendement woor kantoren en winkels in de loop van de rijd kleiner geworden. De disconteringsvoer en de eindwaardes zijn redelijk uniform woor kantoor segmenten. Voor woningen zujn verschillem in eindwaardes van $10-15 \%$ niet ongebruikelijk.

Hoofdstuk 5 analyseert de verschillen tussen de verkoopprijs en de latatste taxatie over de jaren 1995 - 2002, gebaseerd op gegevens uit de ROZ/IPD Vastgoedindex. Observaties in die jaren zijn gebaseend op het ongewogen verschil, met een gemiddelde van $7.9 \%$. De zogenaamde partitioned variance test; waarbij her gemiddelde verschil wordt opgeknipt in systemacische en niet systematische verschillen is vervolgens toegepast om het effect van systemarische oorzaken te elimineren, bijvoorbeeld de marktbeweging gedurende de periode tussen de taxatie datum en de verkoop datum. Na correctie hiervoor resteert een gemiddelde verschil van 5,9\%. Dit komt overeen met vergelijkbaar onderzoek in het Verenigd Koninkrijk, waarbij het verschill russen taxatie- en verkoopprijs $2 \%$ tot $10 \%$ is. Een zelfde onderzoek uir de Verenigde Staren komt op een verschil van $6 \%$ tot $13 \%$, hoewel deze onderzoeken gebaseerd zijn op andere en langere perioden en daarom ook een neergaande markt onvatten. Vervolgens is een correctie aangebracht voor het feit dat de taxarie gebaseerd is op informatie uit het verleden, waardoor een inschattingsverschil overblijft wan $4.2 \%$ gemiddeld. Eerdere literatuur beschrijft een dergelijk onderzoek niet zo in detail en gekwantificeerd, waardoor een vergelijking maar gedectrelijk mogelijk is. Deze analyse moet over enkele jaren herhaald worden, angezien het zeer aannemelijk is, dat wanneer gegevens onder neergaande marktomstandigheden worden toegevoegd, de resultaten duidelijk anders zullen zijn.

Hoofdstuk 6 gebruikt een fundamentele aanpak om de omvang van het geinvesteerde vermogen in onroerend goed, de potentiële beleggingsmarkt voor onroerend goed en de totale woorraad van onroerend goed in 11 . Europese landen vast te stellen. De beschikbare data varieert per land, met de grootste hoevee heid informatie uit Nederland en Zweden, gevolgd door het Verenigd Koninkrijk en Duitsiand. Het onderzoek werd gelimiteerd door het feit dat informatie ten anzien van de woorraad van het onroerend goed en de schatting van de beleggingsmarkt niet al rijd voor handen was. De hoofdconclusie is dar in de 11 landen die onderzocht zijn, de verhouding van onroerend goed in handen van institurionele beleggers en het bruto national product varieert van $23 \%$ in her Verenigd Koninkrijk to $3 \%$ in Spanje. Een andere conclusie is dat institutionele vasrgoed investeringen als een percentage van de totale on roerend. goed voorraad variëren van $11 \%$ voor Zweden tor $1 \%$ voor Spanje. De opmerkelijke conclusie is dat de schatring van de potentiële onroerend goed beleggingsmarkt als een percentage van de totale onroerend goed voorraad varieert van $11 \%$ tot $13 \%$ voor alle landen, met uitzondering wan Zweden, waar dit $19 \%$ is.

\section{Relevantie:}

De ROZ/IPD vastgoedindex, waarvan de gegevens essentieel waren voor dit proefschrift, is een initiatief van de Raad voor Onroerende Zaken (ROZ) en de Investment Properry Darabank (IPD) in Londen. Deze index is in her leven geroepen om de 
rendementen van direct aangehouden vastgoed door de instirutionele beleggers, zoals pensioenfondsen en verzekeraars te meten. Sinds de start van de index in 1995 is de marktdekking gestaag gegroeid naar ongeveer $85 \%$ in 2004 , overeenkomend met bijna 40 miljard van het in Nederlands vastgoed belegd vermogen door institurionele beleggers.

Al vanaf het ontstaan van de ROZ-IPD vastgoedindex is er gevraagd naar langere renclement reeksen voor vastgoed. Aan die vraag kon lange tijd niet worden voldaan omdat de gegevens van de beleggers maar moeilijk konden worden verzameld en gegevens uit andere bronnen niet altijd even nauwkeurig waren vastgelegd. Daarin kwam verandering toen de voormalige pensioen- en verzekeringskamer, tegenwoordig ondergebracht bij $\mathrm{DNB}$, vanwege de sterke achtereenvolgende dalingen op de aandelen markten, in 2002 risico buffers voor een eventuele toekomstige waardedaling ging eisen per vermogens categorie. Daarbij werden aandelen en vastgoed samen ondergebracht in zakelijke waarden en werd de daarbij behorende buffereis op $40 \%$ gesteld. De Stichring ROZ vastgoedindex was inmiddels met hulp van de pensioenfondsen, verzekeraars en externe partijen zoals taxatie bureaus al behoorlijk gevorderd met het verzamelen van historische rendement reeksen vanaf 1983. Dit gebeurde volgens de methode die door professor David Geltner (Massachusetts Institute of Technology) ontwikkeld was en die gebaseerd was op de analyse van de waarde ontwikkeling van vastgoedobjecten in de tijd aan de hand van externe taxaries en aan- en verkopen. In overleg met ORTEC, een organisatie die voor de meerderheid van de pensioenfondsen en verzekeraars de toereikendheid van de bezittingen berekent ten opzichte van de toekomstige verplichtingen (ALM) zijn de criteria vastgesteld waaraan de verder te ontwikkelen reeksen moesten voldoen. Volgens die criteria zijn de reeksen verzameld (zie hoofdstuk 2 ) en de resultaten waren veelbelovend : de gemiddelde rendementen voor vastgoed over 25 jaar waren beter dan die van de aandelen met een lagere standaarddeviatie ( een veelgebruikte maatstaf voor her risico). De aandelen hadden tussen 1977 en 2002 een gemiddeld rendement gehaald van 10,5\% met een standaarddeviatic van $21 \%$, terwijl die cijfers voor vastgoed $10,9 \%$ respectievelijk $5,5 \%$ waten. Gebaseerd op deze uitkomsten zijn met de DNB gesprekken gewoerd over een lagere buffereis voor vastgoed. In het najaar van 2004 heeft dit er mede toe geleid dat de DNB in een consultatie document heeft voorgesteld om de zakelijke waarden te splitsen in aandelen en vastgoed en de buffereis voor aandelen te stellen op $25 \%$ en die voor vastgoed op $15 \%$ voor pensioenfondsen en $20 \%$ voor verzekeraars.

De uitkomsten wan her onderzoek naar consistentie en nauwkeurigheid wan taxaties ( hoofdstuk 4) zijn gecommuniceerd met de pensioenfondsen, verzekeraars en de taxateurs. Het heeft ertoe geleid dat de $\mathrm{ROZ}$ taxatieregels zijn verbeterd, uitgebreid en waar nodig aangescherpt. Deze taxatieregels, die vrij te verkrijgen zijn via de website, zijn in het eerder genoemde consultatie document van DNB aanbevolen als de marktstandaard woor institutionele beleggers. Een uitgebreide versie van het onderzoek naar taxatie consistentie heeft in 2004 de scriptie prijs gewonnen van de Vereniging van Institutionele Vastgoed Beleggers IVBN. 
Het onderzoek naar de accuraatheid van taxaties ( hoofdstuk 5) waarbij her verschil wordt geanalyseerd tussen de verkoopprijs en de laarste taxatie waarde, heeft geleid tot een verkorte versie van het onderzoek welke is geplaatst op de website van de International Valuation Standards Committee IVSC.

Het onderzoek om te komen tot een eerste schatting van de omvang van het vastgoed in 11 Europese landen ( hoofdstuk 11 ), alsmede het belegd vermogen in vastgoed door institutionele beleggers en de beleggingsmogelijkheden in vastgoed per land zijn in 2004 gepresenteerd op de jaarlijkse IPD conferentie over Europese wastgoed beleggingsstrategieën. De uitkomsten zijn door IPD gebruikt om een pan Europese vastgoedindex te ontwikkelen, waarbij door dit onderzoek de weging per land kon worden vastgesteld. Verder gebruikt de Union Bank of Switserland UBS dezelfde methodiek om schattingen te maken van de omvang van de vastgoed beleggingsmarkt in Azië en heeft Hongarije onlangs besloten om dezelfde door Liang en Macintosh ontwikkelde en in dit onderzoek nader uitgewerkte merhodiek te gebruiken voor een eerste schatting van de omvang van de voorraad vastgoed en de vastgoed beleggingsmarkt in hun land.

Het is buitengewoon bemoedigend en stimulerend dat de uitkomsten van zoveel onderzoeken uit dit proefschrift hun weg al gevonden hebben naar de praktijk. Omdat de transparantie van vastgoed nog volop in ontwikkeling is en dat waarschijnlijk ook nog vele jaren zal zijn, is de verwachting dat dic proefschrift ook zal kunnen bijdragen aan verder onderzoek. 


\section{CURRICULUM VITAE}

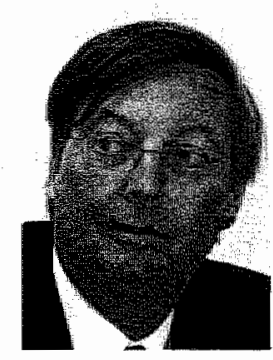

\section{Nederlands}

Aart Hordijk studeerde de kwantitatieve variant wan de bedrijfseconomie aan de Vrije Universiteit van Amsterdam. Daarna vervulde hij zijn militaire dienstplicht waar hij afzwaaide als officier. Zijn maatschappelijke carrière startte hij in de software industrie, eerst bij NCR en vervolgens bij Shell. Na 7 jaar stapte hij over naar her vastgoed. Het wak leerde hij bij een particuliere belegger. Vervolgens zette hij zijn carrière voort bij DTZ Zadelhoff waar hij de research afdeling opzette en vorm gaf. Daarna stapte hij over naar her ABP, waar hij betrokken was bij taxaties, portefeuille management en vastgoed indices. Sinds 1.995 is hij de directeur van de ROZ en de Stichring ROZ Vastgoedindex, die in samenwerking met IPD in London de ROZ-IPD Vastgoedindex in Nederland titbrengt. Al sinds 1991 is hij berrokken bij vastgoedonderwijs aan de ASRE in Amsterdam, daarna ook aan de Universiteit van Amsterdam en als gastdo. cent aan de Universiteit van Antwerpen en de Universiteit van Ulster. Internationaal is hij de Nederlandse vertegenwoordiger in de IVSC, International Valuation Standards Commitree en maakt hij deel uit van de editorial board van de Journal of Real Estate Portfolio Management.

\section{English}

Aart Hordijk, a citizen of the Netherlands, studied economics at the Free University of Amsterdam. After he was graduared he fulfilled his military service where he ended as lieutenant. He started his career in sofware development, first at NCR followed by Shell. After seven years he decided to move away from software development and started to work in real estate investments. First he worked for a private real estate investor, thereafter he joined DTZ, where he has set up the Research Department in whe Netherlands. Then he joined ABP; the Dutch Government Pension fund, where he was involved in valuations, portfolio management and real estate indices. In 1995 he became the director of ROZ Real Estate Council of the Netherlands as well as the director of the Dutch real estate index organisation, which cooperates with the IPD Investment Property Databank in London to produce the ROZ-IPD Real, Estate Index. Already since 1991 he is involved in Real Estate education with the Amsterdam School of Real Estate in the Master of Real Estate Program. Later on he became also a visiting lecturer at the University of Amsterdam, the University of Antwerp and the University of Ulster. Internationally, Aart is the representative for the Netherlands in the IVSC, the International Valuation Standards Committee, and he is a member of the editorial board of the Journal of Real Estate Portfolio Management. Hordijk also publishes regularly, nationally as well as internationally and organises yearly real estate research seminar in the Netherlands. 
Notes 
Notes 
Notes 


\author{
VALUATION AND CONSTRUCTION ISSUES \\ IN REAL ESTATE INDICES \\ By: Aart Hordijk. \\ ISBN 90-77997016, 164 pages, full colour. \\ www.europe-re.com/bookstore
}

\title{
Colofon
}

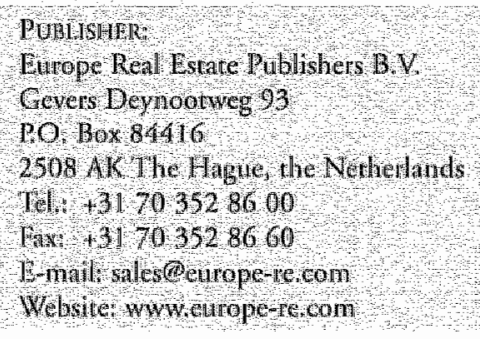

\section{PUHISWIR:}

Lurope Real Estare Mublishers B.V

2508 AK The Hague the Nerhedlands

$116+31703528600$

* 3770,3286

Weasite wwwetrepe-re,on
AUThor:

Aant Hordink

Propuclator

Allen Bekket Herd of prodnction

Ingrid Hoevenagel (oordnator $/ \mathrm{h} / \mathrm{p}$.

Brll Goosen, An-direchon

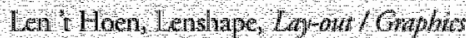

nowolknowpenl

\section{Photography}

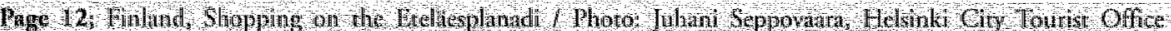

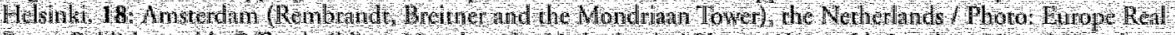

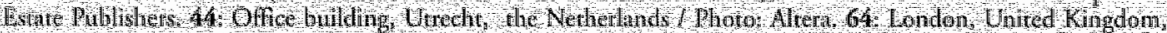

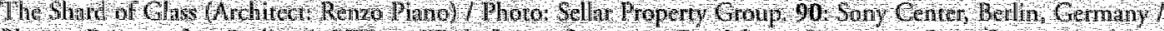

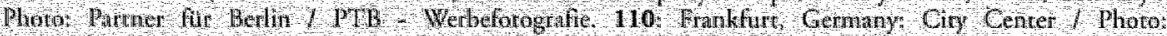

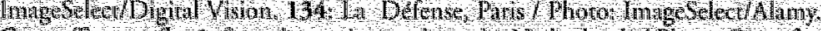

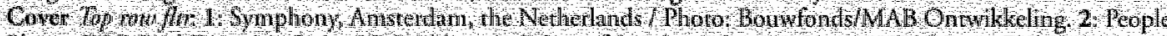

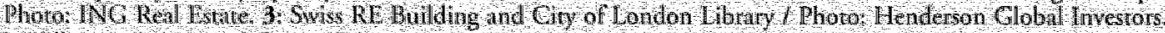

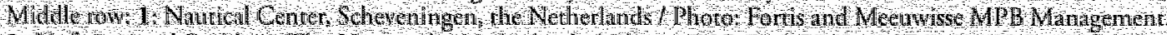

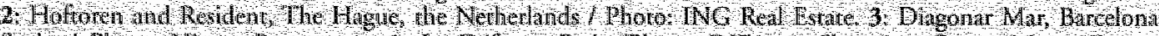

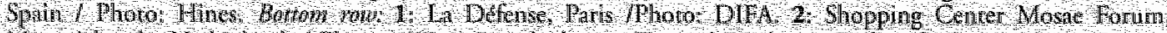

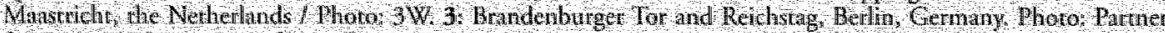

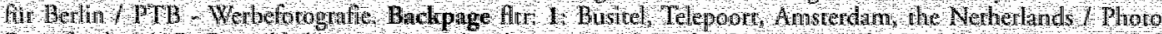
Bonw fonds MAB Ontwilkeling, 2 Armida Shopping and Trade Cencer Knikan, Jurkey 1 Photo Armada

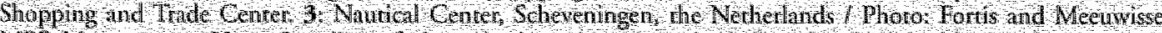
MPB Mtaighenzent Note: Suppliets of photos and graphic naterial not nentoned in the list above are credied

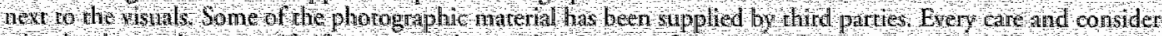
anon has been taken to verify tf any copyrghe was duc In case of om issions please contact rhe publsher. 


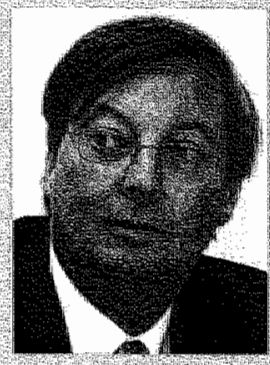

\section{ABOUT TWE AUTKOR}

Aart Hordijk, a cirizen of the Netherlands, studied economics at the Free University of Amsterdam. After lie was graduated he fulfilled his military service where he ended as lieutersant.

He started his carreer in software development, first at NCR followed by Shell. After seven years he decided to move away from software development and started to work in real estate investments. First he woilked for a privare red estate investor, thereafter he joived DTZ, where he has set up the Research Deparment in the Netherlands. Then he joined ABP the Dutch Governnent Pension lund, where the was involved in valuations, portfolio management and real estate indices.

II 1995 he became the director of $\mathrm{ROZ}$ Real Estate Council of the Netherlands as well as the director of the Durch real estate index organisation, which cooperates with the IPD Investment Property Databank in London to produce the ROZ-IPD Real Estate lindex Already since 1991 he is insolved in Real Estare education with the Amsterdam Sehoul of Real Estate in the Master of Real Estate program. Later on he became also a visiting lecturer at the University of Ansterdam, the University of Antwerp and the University of Ulster:

Internationally Aart is the representative for the Netherlands in the IVSC, the International Valuation standards Commitree and he is a merriber of the editorial board of the Journal of Real Estate Porfoljo Management. Hordijk also publishes regularly, nationally as well as internationally and he organises yearly a real estate tesearch seminar in the Netherlands. 